ST (3)

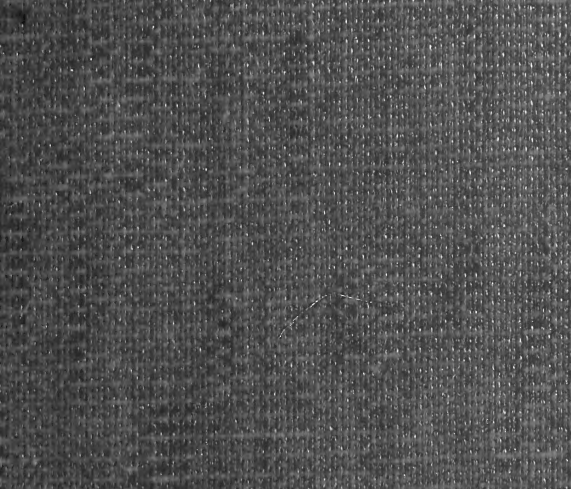

4.

W.

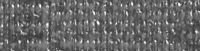

(3)

A.

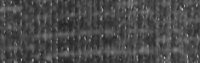

Whathes

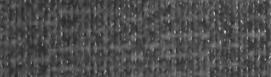

(4)

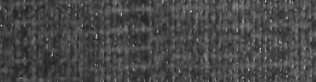

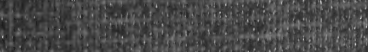

7.

Phat

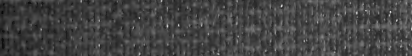

6.5.

2.

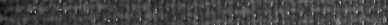

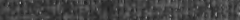

sis

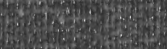

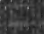

Whis

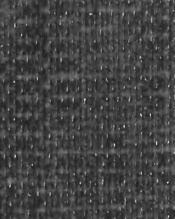

(2):

th.

378

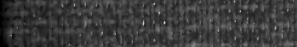

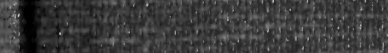

(x)

19.

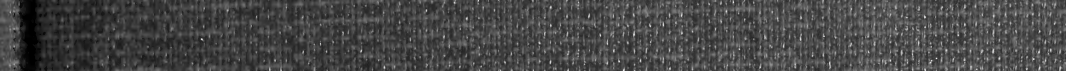

49.5. 


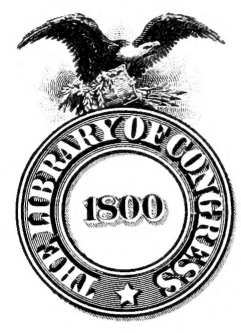






\title{
AGRICULTURAL
}

\section{QUALITATIVE AND QUANTITATIVE}

\section{CHEMICAL ANALYSIS.}

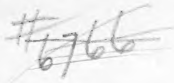

AFTER

E. WOLFF, FRESENIUS, KROCKER, AND OTHERS.

\author{
EDITED BY

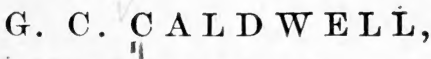

PROFESSOR OF AGRICULTURAL CHEMTSTRY IN THE CORNELL UNIVERSITY.

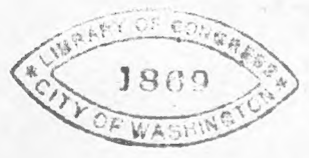

\author{
NEW YORK: \\ ORANGE JUDD AND COMPANY, \\ 245 B ROA D WA Y.
}


Entered according to Act of Congress, in the year 1869, by ORANGE JUDD \& CO.,

In the Clerk's Office of the District Court of the United States for the Southern District of New York. 


\section{P R E F A C E.}

The purpose of this work is to supply a complete manual of chemical analysis, for the use, especially, of agricultural students.

The qualitative and quantitative processes that are described refer only to such substances as are found in soils, plants, animals, fertilizers, or other materials or products of agriculture; and, moreover, in order to reduce the size, and consequently the cost of the book as much as possible, except in two or three instances, only those methods of analysis are introduced which are most commonly used by good chemists, and have been tried and found reliable, with such improvements as have been made in more recent practice.

The chapters on Special Analyses consist, in the main, of a translation of the "Anleitung zur Chemischen Untersuchung landwirthschaftlich-wichtiger Stoffe, von Dr. Emil Wolff, 2te Auflage, 1867," a work of the first authority in Germany; two or three unimportant matters have been omitted, the arrangement has been somewhat altered, and some additions have been made to the original. The other chapters, on reagents, manipulation, etc., are 
made up largely from the "Anleitung zur Quantitativen Chemischen Analyse, von Dr. C. R. Fresenius, 5te Auflage, 1866."

Concerning late improvements in methods of analysis, the Zeitschrift für Analytische Chemie, by the same authority, has been frequently consulted.

The scheme of qualitative analysis has worked well in my own hands, and with my own students, but, nevertheless, I would have preferred to give it a more careful trial before publishing it.

Valuable assistance in testing this and other methods of analysis has been received from Mr. T. B. Comstock, while a student in my laboratory.

The use of the old system of atomic weights, and of the old nomenclature, would doubtless have made the book more simple to the majority of students at first, but, nevertheless, it seemed more expedient to follow the common usage in the best recent works on chemistry. The same may be said in regard to the use of the centigrade thermometer and the metric system of weights and measures.

Although the work has been somewhat hastily prepared to meet a pressing want in my own laboratory, I trust it may yet be found to answer a good purpose in other laboratories where agricultural chemistry is made a specialty.

Cornell University, College of $\}$ G. C. C. Agriculture, August, 1869. $\}$ 


\section{TABLE OF CONTENTS.}

\section{CHAPTER I.-The Reagents.}

List of the reagents needed, with directions for preparing them, when not more readily obtained otherwise, and for testing their purity. 7

\section{CHAPTER II.-Analytical Manipulation.}

Determination of specific gravity, solution, craporation, precipitation, filtration (including Bunsen's new method), weighing of residues and precipitates, measuring and dividing solutions, and

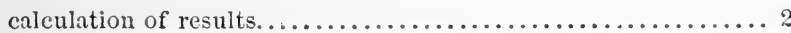

\section{CHAPTER III.-DEeactions and Dlethods of Quantita- tive Estimation.}

Potassium, sodium, ammonium, barium, calcium, magnesium, aluminium, iron, manganese, zinc, lead, copper, and arsenic; silicic, sulphuric, carbonic, phosphoric, nitric, hydrochloric, hydrocyanic, hydroferrocyanic, hydrosulphuric, hydriodic, hydrofluoric; oxalic, acetic, tartaric, citric, malic, lactic, uric, hippuric, and tannic acids; cellulose, starch, gum, the sugars, albuminoids, urea, fat,

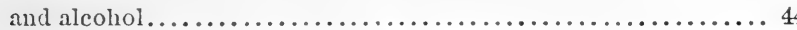

\section{CIIAPTER IV.-Gpecial Drethods of malysis.}

Course of qualitative analysis, estimation of water, of organic matter, of sulphur and chlorine in organic compounds, special methods of separation of bases and acids, schemes of analysis...128

\section{CHAPTER V.-Analysis of Goils and Hecks.}

Mechanical and chemical analysis, and examination of physical propcrties, of soils, and examination of marl, limestone, and clay.....165 


\section{CHAPTER VI.-Fertilizers.}

Farm-yard manure, urine, solid excrements, bone-meal, bone black, bone-ash, phosphorite, guano, superphosphate, gypsum, salt, potash compounds, and Chili saltpetre...................213

\section{CHAPTER VII.-Ashes.}

Ashes of plants, of animal substances, and of fuel..............241

\section{CHAPTER VIII.-Fodder and Food.}

Fodder plants, beets, turnips, potatoes, seeds, meal, flour, milk, butter, cheese, and vinegar..........................251

\section{CHAPTER IX.-WVool and Bark.}

Examination of wool and tanners' bark.....................269

\section{CHAPTER X.-BEeverages.}

Water and wine.

\section{CHAPTER XI.-Tables.}

Metric system of weights and measures, atomic weights of elements, factors for calculating analyses, estimation of tannin in bark, etc.284 


\section{A G R I C U L T U R A L}

\section{QUALITATIVE AND QUANTITATIVE \\ CHEMICAL ANALYSIS.}

CHAPTER I.

REAGENTS.

The following list contains all the reagents used in the various courses of analysis described in this book, arranged in alphabetical order. Most of them can be procured of the druggists, or the dealers in apparatus and chemicals.

Directions are given here for the preparation of such reagents only as cannot be thus obtained conveniently. The chemical tests to which each reagent should be subjected, in order that the analyst may be assured of its purity, and the strength of the solutions to be made, are also given, when it is necessary. Most of this information is taken from the works of Fresenius.

The new system of nomenclature and the new formulas being adopted in this work, the new name and formula of each reagent are given first, and, for the benefit of those who are less familiar with these, the old name and formula are afterwards enclosed in parentheses, whenever there is any essential difference between the new and the old. 


\section{1. a.-Acid, acetic. $-\mathrm{HC}_{2} \mathrm{H}_{3} \mathrm{O}_{2} \cdot\left(\mathrm{HO}, \mathrm{C}_{4} \mathrm{H}_{3} \mathrm{O}_{3} \cdot \mathrm{HO}, \overline{\mathrm{A}}\right.$. $)$}

-This should leave no residue on evaporation, and should emit no empyreumatic odor when evaporated after saturation with sodic carbonate; neither hydrosulphuric acid, argentic nitrate, nor baric chloride should produce any change in it, nor ammonic sulphide, after neutralization with ammonia.

b. Acid, citric. $-\mathrm{H}_{3} \mathrm{C}_{6} \mathrm{II}_{5} \mathrm{O}_{7} \cdot\left(3 \mathrm{HO}, \mathrm{C}_{12} \mathrm{H}_{5} \mathrm{O}_{11}\right.$. $)$-Recrystallize it, unless clean and colorless.

c. Acid, hydrochloric.-HCl. (Chlorhydric acid. Mu riatic acid.) - This must be colorless, and it should leave no residue when evaporated on platinum foil, nor should it attack the foil; it should give no blue color to starchpaper, nor should it bleach starch that has been faintly colored blue with iodine; it should give no turbidity with baric chloride, after having been considerably diluted, nor should it be colored by hydrosulphuric acid or potassic sulphocyanate.

For the dilute acid, add the concentrated acid to 4 parts of water.

d. Acid, hydrosulphuric. $-\mathrm{H}_{2} \mathrm{~S}$. (HS.) - Pour dilute sulphuric acid through a funnel tube over fused ferrous sulphide, in a common bottle, and conduct the gas that is evolved, first through water in a small wash-bottle, and then into distilled water. The solution should emit a strong odor of sulphuretted hydrogen, and should be freshly made.

e. Acid, nitric. $-\mathrm{HNO}_{3}$. $\left(\mathrm{HO}, \mathrm{NO}_{5^{\circ}}\right)$ - This should be colorless, and should leave no residue when evaporated on platinum foil; after having been considerably diluted, it should not be made turbid by argentic nitrate or baric chloride. For the dilute acid, add the concentrated acid to 4 parts of water.

f. Acid, nitro-hydrochloric. Aqua regia.-Mix together 1 part of pure nitric acid, and 3 or 4 parts of pure hydrochloric acid. 


\section{g. Acid, oxalic, $-\mathrm{H}_{2} \mathrm{C}_{2} \mathrm{O}_{4^{*}} \cdot\left(2 \mathrm{HO}, \mathrm{C}_{4} \mathrm{O}_{6^{\circ}}\right)$ This should} not present the least appearance of eftlorescence; it should give a perfectly clear solution with water, and should leave no residue when ignited in a platinum dish. If theacid does not meet these requirements, it should be purified by repeated recrystallization.

Stolba (Fresenius, Zeitschrift 8, 63) recommends sublimation as a convenient method of purifying oxalic acid.

Dry the acid thoroughly by keeping it in a warm place for a considerable time, with occasional stirring; when a small portion of it, gently heated in a test tube, gives off but little water before subliming, it is sufficiently dry. Put it, then, in a large beaker to the depth of $15-20 \mathrm{~mm}$., cover the beaker with a hollow cone of paper, and imbed it in iron turnings in an iron dish, to the same depth as that of the acid inside, and heat it cautiously, raising the temperature very gradually. Scrape off the outside of the cone of sublimed acid, separate the more solid yellowish outer part from the white inner portion, and purify each by itself by crystallization from solution as usual.

h. Icid, sulphuric. - $\mathrm{H}_{2} \mathrm{SO}_{4} \cdot\left(\mathrm{HO}, \mathrm{SO}_{3}\right)$. - Common sulphuric acid usually contains lead, which is precipitated as a fine white powder, when the acid is diluted with considerable water, or when mixed with 4 or 5 parts of a!cohol ; it sometimes gives a red color with a solution of feirous sulphate, where the two liquids come in contact $(\S$ $62)$, and, when diluted, gives the reaction for chlorine with argentic nitrate ( $\$ 63)$, and for arsenic by Marsh's test $(\$ 5 \%)$. The pure acid should give none of these reactions, nor any blue color after dilution with 20 parts of water, when a little starch paste and potassic iodide are added to the cooled liquid; it should be volatilized completely when heated.

The dilute acid is prepared by adding the concentrated acid to 5 parts of water, slowly, and with constant stirring, letting the mixture stand a long time if any plumbic 
sulphate is precipitated, and then decanting the clear supernatant liquid for use.

\section{i. Acid, silicic.-See Quartz.}

k. Acid, tannic, needs no testing.

2. Alcohol. $-\mathrm{C}_{2} \mathrm{H}_{6} \mathrm{O}$. $\left(\mathrm{C}_{4} \mathrm{H}_{6} \mathrm{O}_{2} \cdot\right)$-This is used both in its pure state (absolute alcohol), and mixed with water until its specific gravity is 0.83 or 0.84 , corresponding to about $\left.90^{\circ}\right|_{0}$ of pure alcohol, by volume.

It should be volatilized completely, and leave no odor of fusel oil when rubbed between the hands; it should burn with a pale blue, barely visible flame, and should not redden blue litmus-paper.

3. a.-Ammonic acetate. $-\mathrm{NH}_{4} \mathrm{C}_{2} \mathrm{H}_{3} \mathrm{O}_{2}$. (Acetate of ammonia. $\mathrm{NH}_{4} \mathrm{O}, \mathrm{C}_{4} \mathrm{H}_{3} \mathrm{O}_{3} \cdot \mathrm{NH}_{4} \mathrm{O}, \overline{\mathrm{A}}$.) - This should be colorless, free from empyreumatic odor, and inorganic acids, and should be completely volatilized when heated.

b. Ammonic carbonate $-\left(\mathrm{NH}_{4}\right)_{2} \mathrm{CO}_{3}$. (Carbonate of ammonia. $\mathrm{NH}_{4} \mathrm{O}, \mathrm{CO}_{2}$. - This should be completely volatilized when heated, and, after supersaturation with nitric acid and heating, should give no reaction with solutions of silver, barium, or ammonic sulphide. Dissolve it in 4 parts of water, and add 1 part of ammonia. Keep some of the salt also in the dry form.

c. Ammonic chioride. $-\mathrm{NH}_{4} \mathrm{Cl}$. (Chlorice of ammonium.)-This should be completely volatilized when heated on platinum foil, and should give no reaction with ammonic sulphide, baric chloride, or litmus. Dissolve in 8 parts of water. Keep some of the salt also in the form of a dry powder.

d. Ammonic fluoride. $-\mathrm{NH}_{4} \mathrm{~F}$. (Fluoride of ammonium.) -This, when heated in a platinum dish, should leave no residue; if impure, it may be purified by sublimation between two platinum dishes. It should be kept in gutta percha bottles. 
e. Ammonic hydrate. $-\mathrm{NH}_{4} \mathrm{HO}$. Ammonic $\mathrm{NH}_{3}$. This should be colorless, and leave no residue when evaporated in a watch-glass: after dilution with its volume of water, it should give no very marked turbidity with limewater, and, after supersaturation with nitric acid in slight excess, it should give no precipitate or color with argentic nitrate, baric chloride, or ammonic sulphide.

f. Ammonic molybdate. - $\left(\mathrm{NH}_{4}\right)_{2} \mathrm{MoO}_{4}$. (Molybdate of ammonia. $\mathrm{NH}_{4} \mathrm{O}, \mathrm{MoO}_{3}$. -Dissolve 1 part of molybdic acid in 8 parts of ammonia-water, pour the solution into 20 parts by weight of nitric acid (Sp. Gr.=1.2), let the mixture stand several days in a warm place, and decant the clear liquid for use. When moderately heated with excess of nitric acid, it should give no yellow precipitate.

g. Ammonic nitrate. $-\mathrm{NH}_{4} \mathrm{NO}_{3}$. (Nitrate of ammonia. $\mathrm{NH}_{4} \mathrm{O}, \mathrm{NO}_{5}{ }^{\circ}$ ) - This shonld give no reaction with baric chloride or argentic nitrate, and should be completely volatilized when heated.

h. Ammonic oxalate. $-\left(\mathrm{NHI}_{4}\right)_{2} \mathrm{C}_{2} \mathrm{O}_{4}$. (Oxalato of ammonia. $2 \mathrm{NH}_{4} \mathrm{O}_{2} \mathrm{C}_{4} \mathrm{O}_{6}$ ) - This should be completely rolatilized by heat, and should give no reaction with hydrosulphuric acid, or ammonic sulphide, or with baric chloride in a solution acidified with hydrochloric acid. Dissolve in 24 parts of water.

i. Ammonic sulphate.- $\left(\mathrm{NHI}_{4}\right)_{2}, \mathrm{SO}_{4}$. (Sulphate of ammonia. $\mathrm{NH}_{4} \mathrm{O}, \mathrm{SO}_{3^{\circ}}$ ) - This may be readily prepared by neutralizing ammonic hydrate with dilute sulphuric acid.

7. Ammonic Sulphide.- $\left(\mathrm{NH}_{4}\right)_{2} \mathrm{~S}$. (Sulphide of ammonium. $\mathrm{NH}_{4} \mathrm{~S}$.) -Conduct sulphuretted hydrogen $(\S 1$, d) into 3 parts of ammonic hydrate as long as the gas is absorbed, and add 2 parts of fresh ammonic hydrate. The reagent should cvolve sulphuretted hydrogen freely when mixed with strong acids, and should give at least only a white precipitate with them; it should give no re- 
action at all with solutions of lime or magnesia; when evaporated in a platinum dish, the residue should be volatilized completely on ignition.

Dissolve some flowers of sulphur in a small portion of the reagent, and label this solution, ammonic sulphide with excess of sulphur.

l. Ammonic tartrate.- $\left(\mathrm{NII}_{4}\right)_{2} \mathrm{C}_{4} \mathrm{H}_{4} \mathrm{O}_{6}$. (Tartratc of ammonia. $\left.2 \mathrm{NH}_{4} \mathrm{O}, \mathrm{C}_{8} \mathrm{H}_{4} \mathrm{O}_{10^{\circ}}\right)-$ Neutralize tartaric acid with ammonic hydrate, and then add more ammonic hydrate, so that it shall be in excess over the acid.

\section{m. Ammonic-ferrous sulphate. $-\left(\mathrm{NII}_{4}\right)_{2} \mathrm{Fe}\left(\mathrm{SO}_{4}\right)_{2}$.} (Sulphate of protoxide of iron and ammonia. $\mathrm{NH}_{4} \mathrm{O}$, $\left.\mathrm{FeO},\left(\mathrm{SO}_{3}\right)_{2} \cdot\right)$-Divide a quantity of sulphuric acid into two equal parts; heat onc of them with an excess of small clean iron nails free from rust, as long as the evolu. tion of hydrogen continues. Neutralize the other portion of the acid accurately with ammonic carbonate, and then add a few drops of sulphuric acid. Filter the solution of ferrous sulphate, obtained by the action of the acid on the nails, into the ammonic sulphate, evaporate the mixture a little if necessary, and let it crystallizc. Let the crystals drain in a funnel, dry them by exposure to the air on filter-paper, and keep them in a well stoppered bottlc. The solution of the salt in water acidified with sulphuric acid should give no red color with potassic sulphocyanate.

4. Argentic nitrate. - $\mathrm{AgNO}_{3^{\circ}}$ (Nitrate of silver. $\mathrm{AgO}, \mathrm{NO}_{5}$.) - After the solution of this reagent has been completely precipitated with hydrochloric acid, the filtrate from the precipitate should leave no residue when evaporated, and the same filtrate should give no color with ammonic sulphide. Dissolve in 20 parts of water.

All the silver refuse, consisting of precipitates containing silver, and solutions to which argentic nitrate has been added, should be thrown into a bottle containing dilute hvdrochloric acid. When a sufficient quantity of the 
precipitated chloride has accumulated, separate it from the liquid by decantation of the latter, wash it well with water, pour dilute sulphuric acid over it, and put some pieces of zinc in contact with it.

When the whole is changed to a gray metallic powder, and the zine is all dissolved, filter out and wash the powder well, dry, and ignite it. Dissolve the silver thus obtained in nitric acid, add water, filter if necessary, evaporate the filtrate to dryness on the water-bath, and dissolve the residue in 20 parts of water, and subject the solution to the tests above described.

5. (1.-Baric acetate. - $\mathrm{Ba}\left(\mathrm{C}_{2} \mathrm{H}_{3} \mathrm{O}_{2}\right)_{2}$. Acctate of baryta. $\mathrm{BaO}, \mathrm{C}_{4} \mathrm{H}_{3} \mathrm{O}_{3}$. $\mathrm{BaO}, \overline{\mathrm{A}}$.) - This should be colorless and should have no cmpyreumatic odor, and it should give no reaction with ammonic sulphide or argentic nitrate; after complete precipitation with sulphuric acid, the filtrate should leave no residue on evaporation. Dissolve in 10 parts of water.

\section{b. Baric chloride.- $\mathrm{BaCl}_{2}$ ( (Chloride of barium. $\mathrm{BaCl}$.)} - This should not affect litmus-paper, nor give any reaction with ammonic sulphide; after complete precipitation with sulphuric acid, the filtrate from the precipitate should leave no residue when eraporated. Dissolve in 10 parts of water.

c. Baric hydrate- $\mathrm{Ba}(\mathrm{HO})_{2}$. (Hydrate of baryta. Baryta water. $\mathrm{BaO}, \mathrm{HO}$.) - After precipitation of the barium from the solution by sulphuric acid, the filtrate should remain clear when mixed with alcohol, and should leave no residue when evaporated. Dissolve in 20 parts of water. In determinations of urea in urine, a mixture of one volume of a cold saturated solution of baric nitrate and two volumes of a cold saturated solution of baric hydrate is used.

c. Baric nitrate.- $\mathrm{Ba}\left(\mathrm{NO}_{3}\right)_{2}$. (Nitrate of baryta. $\mathrm{BaO}$, $\mathrm{NO}_{5^{\circ}}$ ) - This should be completely precipitated by sul- 
phuric acid so that the filtrate from the precipitate leaves no residue when evaporated, and it should give no reaction with argentic nitrate.

e. Calcic chloride.- $\mathrm{CaCl}_{2}$. (Chloride of calcium. $\mathrm{CaCl}$.) -This should not affect litmus-paper, should give no. reaction with ammonic sulphide, nor any ammonia when heated with sodic hydrate. Dissolve the crystals in 5 parts of water.

The crude, impure, fused chloride answers for desiccating purposes.

$f$. Calcic fluoride.- $\mathrm{CaF}_{2}$. Fluor spar.-To save trouble, buy the powdered fluor spar.

g. Calcic hydrate.- $\mathrm{Ca}(\mathrm{HO})_{2}$. Time-water. (CaO, IIO.) - Digest slaked lime with cold water with occasional stirring, let the mixture stand quietly for a time, and decant the clear liquid for use. It should give a dark color to turmeric-paper, and a considerable precipitate with ammonic oxalate.

For many purposes milk of lime is used in preference to lime-water ; this reagent is simply lime-water mixed with an excess of undissolved calcic hydrate. It should be made with lime from white marble, and should be kept in well stoppered bottles, and shaken up when used.

h. Calcic sulphate.-CaSO ${ }^{*}$ (Sulphate of lime. $\mathrm{CaO}$, $\mathrm{SO}_{3}$.) -Digest powdered, crystallized gypsum a long time with cold water, with frequent agitation, let the mixture stand quietly at last, and decant the clear liquid for use.

6. Chlorine.-Cl.-Nearly fill a flask with manganic binoxide in pieces about as big as peas, and then add so much common, concentrated hydrochloric acid, that about half the oxide will be immersed in it. Conduct the gas, by a glass tube passing through the cork with which the mouth of the flask is closed, through a cylinder or washbottle containing concentrated sulphuric acid. The ero- 
lution of the chlorine begins at common temperatures, but a little heat must be applied after a time.

7. Cobaltic nitrate. $-\mathrm{Co}\left(\mathrm{NO}_{3}\right)_{2^{2}}$-Dissolve the salt in 10 parts of water.

8. Cochineal solution.-Boil cochineal with water. The solution will keep better if about half its volume of alcohol is added to it.

9. a.-Cupric acetate. $-\mathrm{Cu}\left(\mathrm{C}_{2} \mathrm{H}_{3} \mathrm{O}_{2}\right) \mathrm{CuO}$. (Acetate of copper. Verdigris. $2 \mathrm{CuO}, \mathrm{C}_{4} \mathrm{H}_{3} \mathrm{O}_{3}$.) -To prepare the solution of this salt for washing the precipitate of baric sulphate, dissolve the commercial salt in water containing a little acetic acid, add 2 drops of sulphuric acid, if this acid is not already present, then a few drops of baric chloride until the liquid gives a faint reaction for barium, boil a short time, and filter. The solution should be sufficiently concentrated to deposit crystals on cooling. Use the supernatant saturated solution.

b. Cupric sulphate. $-\mathrm{CuSO}_{4}$. (Sulphate of copper. $\mathrm{CuO}, \mathrm{SO}_{3}$.) - This should be recrystallized once or twice.

10. Curcuma-paper. - Turmeric-paper. - Digest pulverized curcuma root with 6 parts of weak alcohol, color slips of unsized paper with the yellow extract, and dry them.

11. Ether. $-\mathrm{C}_{4} \mathrm{H}_{10} \mathrm{O} . \quad\left(\mathrm{C}_{4} \mathrm{H}_{5} \mathrm{O}\right.$. $)$-This is sufficiently pure as obtained of the druggist.

12. a.-Ferric chloride.- $\mathrm{Fe}_{2} \mathrm{Cl}_{6}$ (Perchloride of iron. $\mathrm{Fe}_{2} \mathrm{Cl}_{3^{\circ}}$ ) - Its solution should give a permanent precipitate with a drop or two of ammonic hydrate; it should give no blue color with potassic ferricyanide. Dissolve in 20 parts of water.

b. Ferric oxide. $-\mathrm{Fe}_{2} \mathrm{O}_{3}$. (Sesquioxide of iron.)-This is also known as colcothar.

c. Ferric nitrate. $-\mathrm{Fe}\left(\mathrm{NO}_{3}\right)_{3^{\circ}}$ (Nitrate of sesquioxide of iron. $\mathrm{Fe}_{2} \mathrm{O}_{3}, 3 \mathrm{NO}_{5}$.) -Dissolve iron in nitric acid, 
evaporate the solution to expel excess of acid, and dissolve the residue in 10 parts of water.

d. Ferrous chloride. $-\mathrm{FeCl}_{2}$. (Protochloride of iron. FeCl.) -Dissolve pianoforte wire in concentrated hydrochloric acid; the solution should be made as it is wanted.

e. Ferrous sulphide.-FeS. (Sulphide of iron.)-Get the fused sulphide of the druggists.

13. Hydrogen.-H.-This is made by the action of dilute sulphuric acid on granulated zinc. To purify the gas conduct it through a U tube, or a calcic-chloride cylinder, containing freshly ignited charcoal, and in order to dry it, through another cylinder containing calcic chloride.

14. Indigo solution.-This may be prepared by treating 1 part of finely powdered indigo with 5 parts of fuming sulphuric acid 48 hours in the cold, and pouring the mixture into 20 parts of cold water.

15. Iodine.-I.-This needs no testing.

16. a.-Iron Turnings.-These should be clean and free fiom grease.

b. Iron wire.-Get the finest pianoforte wire, frce from rust.

17. a.-Lead-paper.-Soak slips of unsized paper in a solution of plumbic acetate, dry, and keep in a well stoppered bottle.

b. Litmus-paper (blue).-Digest litmus with 6 parts of water, filter, divide half of the filtrate into two equal parts and carefully saturate the free alkali in one of these parts with sulphuric acid, until the liquid has taken a red color that does not disappear after standing a few minutes; add the other part to this, color strips of unsized paper in the blue liquid, dry them, and keep in a dark place. The strips should have a blue color.

c. Litmus-paper (red).-Add sulphuric acid to the other half of the extract of the litmus until a permanent 
red color is just obtained; color slips of unsized paper in this solution, dry them, and keep in a dark place. The strips should have a distinct red color.

18. a.-Magnesia (calcined).-MgO.-This should be freshly ignited before being used.

b. Magnesia mixture.-Mix together 1 part of magnesic sulphate, $\mathrm{MgSO}_{4}, 1$ of ammonic chloride, 4 of ammonic hydrate, and 8 of water; let the mixture stand several days in a moderately warm place, and decant the clear solution for use.

19. Malt.-Get good brewer's malt.

20. Manganic binoxide.- $\mathrm{MnO}_{2}$. - The commercial, native, crystallized binoxide of manganese is generally sufficiently purc.

21. a.-Hercuric nitrate.- $\mathrm{Hg}\left(\mathrm{NO}_{3}\right)_{2}$. (Nitrate of mercury. $\mathrm{HgO}_{\mathrm{g}} \mathrm{NO}_{5}$.) - Dissolve mercury in its own weight of nitric acid (Sp. Gr.=1.4), heat the mixture towards the close of the cperation, and, finally, add to it twice its bulk of water.

b. Mercurous nitrate. $-\mathrm{Hg}_{2}\left(\mathrm{NO}_{3}\right)_{2}$.- (Subnitratc of mercury. $\left.\mathrm{IIg}_{2} \mathrm{O}, \mathrm{NO}_{5}{ }^{\circ}\right)$-Pour 1 part of pure nitric acid (Sp. Gr.=1.2) over 1 part of mercury, let stand 24 hours in a cool place, separate the crystals from the undissolved mercury and the mother-liquor, dissolve them in water mixed with $\left.{ }^{1}\right|_{16}$ of nitric acid, by trituration in a mortar, filter, and keep the solution in a bottle with metallic mercury covering the bottom.

Microcosmic salt.-See sodic ammonic phosphate.

Milk of lime.-See calcic hydrate.

22. 0xygen.-O.-Mix'together in a mortar $100 \mathrm{grms}$. of potassic chlorate and 0.1 grm. of ferric oxide, half fill a retort with the mixture, and heat over a coal fire, at first gently. As soon as the contents of the retort are partly fused, mix them together by gentle agitation. Collect 
the gas in the gasometer; for use, conduct it from the gasometer through a solution of caustic potash (Sp. Gr. $=$ 1.27) in a Liebig's potassa-bulb, then through a $U$ tube containing pumice-stone soaked in sulphuric acid, and finally through a tube containing calcic chloride.

Phosphorus salt.-See sodic ammonic phosphate.

23. Platinic chloride $-\mathrm{PtCl}_{4}$ : (Bichloride of platinum. $\mathrm{PtCl}_{2}$.)-Its solution, evaporated to dryness on the water-bath, should leave a residue entirely soluble in alcohol.

Precipitates and solutions containing platinum should be thrown into a bottle containing a solution of ammonic chloride. When a sufficient quantity of the precipitate has accumulated, separate it from the liquid by filtration, wash, dry, and ignite it strongly. Exhaust the residue thoroughly with hot nitric acid, wash the insoluble part in water, dissolve in aqua regia with the aid of a gentle heat, adding fresh portions of nitric acid until the platinum is completely dissolved, evaporate the solution on the water-bath, with the addition of hydrochloric acid, and dissolve the semi-fluid residue in 10 parts of water.

24. a.-Plumbic acetate.- $-\mathrm{Pb}\left(\mathrm{C}_{2} \mathrm{II}_{3} \mathrm{O}_{2}\right)_{2}$. (Acetate of lead. $\mathrm{PbO}, \mathrm{C}_{4} \mathrm{H}_{3} \mathrm{O}_{3}$. $\mathrm{PbOA}$.) -The basic acetate, $\mathrm{Pb}\left(\mathrm{C}_{2} \mathrm{H}_{3} \mathrm{O}_{2}\right)_{2} 2 \mathrm{PbO}$, is prepared by treating $120 \mathrm{grms}$. of crystallized common acetate (sugar of lead) with 60 grms. of gently ignited, and then finely pulverized plumbic oxide (litharge), and 400 c.c. of water' let the mixture stand some time in a warm place with frequent agitation, and finally filter the liquid for use.

b. Plumbic binoxide, $-\mathrm{PbO}_{2}$.

c. Plumbic oxide.-PbO. Litharge.

25. a. -Potassic acetate. $-\mathrm{KC}_{2} \mathrm{H}_{3} \mathrm{O}_{2}$. (Acetate of potassa. $\mathrm{KO}, \mathrm{C}_{4} \mathrm{H}_{3} \mathrm{O}_{3}$.) - This should be white and free from empyreumatic odor. Dissolve in 5 parts of water. 
b. Potassic bisulphate.-KHSO ${ }_{4}$ (Bisulphate of potassa. $\mathrm{KO}, \mathrm{HO}_{2} \mathrm{SO}_{3^{\circ}}$ )

c. Potassic chromate. $-\mathrm{K}_{2} \mathrm{CrO}_{4}$ (Chromate of potassa. $\mathrm{KO}, \mathrm{CrO}_{3^{\circ}}$ )-This should give no turbidity with argentic nitrate, after acidification with nitric acid. Make a cold saturated solution.

d. Potassic chlorate. $-\mathrm{KClO}_{3}$. (Chlorate of potassa. $\mathrm{KO}, \mathrm{ClO}_{5^{\circ}}$ )

e. Potassic dichromate. $-\mathrm{K}_{2} \mathrm{Cr}_{2} \mathrm{O}_{2}$. (Bichromate of potassa. $\mathrm{KO}, 2 \mathrm{CrO}_{3}$.) - This should be recrystallized. Dissolve it in 12 parts of water.

f. Potassic ferricyanide. $-\mathrm{K}_{3} \mathrm{Cy}_{6} \mathrm{Fe} . \mathrm{K}_{3} \mathrm{Cfdy}$. (Ferricyanide of potassium. $\left.\mathrm{K}_{3} \mathrm{Cy}_{5} \mathrm{Fe}_{2^{\circ}}\right)$-This should give no blue color with ferric chloride.

g. Potassic ferrocyanide. $-\mathrm{K}_{4} \mathrm{C}_{6} \mathrm{Fe}$. $\mathrm{K}_{4} \mathrm{Cfy}$. (Ferrocyanide of potassium. $\mathrm{K}_{2} \mathrm{Cy}_{3} \mathrm{Fe}$.)-Dissolve in 12 parts of water.

h. Potassic hydrate.-KHO. (Potassa KO,HO.)This should not be changed by ammonic sulphydrate, and should effervesce but slightly if at all with hydrochloric acid; the solution obtained with hydrochloric acid in excess, when evaporated to dryness should give a residue that is at least almost completely dissolved by water; the same solution should give, at the most, but a very slight reaction for phosphoric acid with ammonic molybdate, and should give but a slight flocculent precipitate with ammonia in excess, after long standing in a warm place. Pure potassa prepared from an alchoholic solution of the hydrate should give none of these reactions. Dissolve in 10 parts of water.

i. Potassic iodide.-KI. (Iodide of potassium.)-This is sufficiently pure as obtained from the druggists.

$k$. Potassic permanganate. $-\mathrm{K}_{2} \mathrm{Mn}_{2} \mathrm{O}_{8}$. (Permanganate of potassa. $\mathrm{KO}, \mathrm{Mn}_{2} \mathrm{O}_{r}$.) 
l. Potassic sodic carbonate. $-\mathrm{KNaCO}_{3}$. (Carbonate of potassa and soda. $\mathrm{KO}, \mathrm{NaO}, 2 \mathrm{CO}_{2}$.)-Recrystallize some potassic sodic tartrate, ignite the salt in a silver dish until completely charred, exhaust the black residue with water, filter, evaporate the filtrate to dryness in the silver dish, and keep the salt in a well stoppered bottle; when it is fused with a little pure sodic nitrate, and the residue is dissolved in water and nitric acid, and then ammonia added, each in slight excess, no flocculent precipitate should appear after long standing in a warm place.

m. Potassic sodic tartrate. $-\mathrm{KNaC}_{4} \mathrm{II}_{4} \mathrm{O}_{6}$. (Seignette salt. Tartrate of potassa and soda. $\mathrm{KO}, \mathrm{NaO}$, $\mathrm{C}_{8} \mathrm{H}_{4} \mathrm{O}_{30}{ }^{\circ}$ )-This should be recrystallized once or twice. It should give a colorless solution with water.

n. Potassic sulphocyanate.--KCyS. (Sulphocyanide of potassium. $\mathrm{KCy} \mathrm{S}_{2}$.)-Dissolve in 20 parts of water.

26. Quartz, powdered.-- $\mathrm{SiO}_{2}$.-Drench red-hot quartz with cold water, and reduce the friable mass to a very fine powder.

2\%. a.-Soda lime. $-\mathrm{Na}_{2} \mathrm{CaO}_{2}$. - This should not effervesce much with acid, and, when mixed with pure sugar and heated to redness, it should evolve no ammonia.

In order to have the reagent perfectly free from nitrogen, Lawes and Gilbert found it necessary to mix it intimately with $1-2{ }^{\circ}$ of sugar or some other nonnitrogenous substance, and ignite the mixture in a muffle, then to moisten it, and heat it again gently.

b. Sodic acctate. $-\mathrm{NaC}_{2} \mathrm{H}_{3} \mathrm{O}_{2}$. (Acetate of soda. $\mathrm{NaO}, \mathrm{C}_{4} \mathrm{H}_{3} \mathrm{O}_{3}$ ) - - This should be colorless and have no empyreumatic odor, and should give no reaction with ammonic molybdate or baric chloride. Dissolve in 10 parts of water.

c. Sodic ammonic phosphate.- $\mathrm{NaNH}_{4} \mathrm{HPO}_{4}$ Phosphorus salt. (Phosphate of soda and ammonia. $\mathrm{NaO}$, 
$\mathrm{NH}_{4} \mathrm{O}, \mathrm{HO}, \mathrm{PO}_{5}$.) - This should give a colorless bead when fused on platinum wire.

d. Sodic bisulphite.- $\mathrm{HNaSO}_{3}$. (Bisulphite of sorla. $\mathrm{NaO}, \mathrm{HO}, \mathrm{SO}_{2}$.) - This should give a residue when heated with sulphuric acid, whose solution is not changed by hydrosulphuric acid or ammonic molybdate. Dissolve in 10 parts of water.

e. Sodic carbonate. $-\mathrm{Na}_{2} \mathrm{CO}_{3}$. (Carbonate of soda. $\mathrm{NaO}, \mathrm{CO}_{2^{\circ}}$ ) - This should be perfectly white, and the solution obtained after supersaturation with nitric acid should give no precipitate nor color with baric chloride, argentic nitrate, or potassic sulphocyanate, nor any reaction with ammonic molybdate, nor any insoluble residue of silicic acid when evaporated to dryness. Dissolve the crystallized salt in 3 parts of water, or the anhydrous salt in 5 parts. Keep some of the ignited salt in the dry form.

$f$. Sodic hyposulphite. $-\mathrm{Na}_{2} \mathrm{~S}_{2} \mathrm{H}_{2} \mathrm{O}_{4}$. (Hyposulphite of soda. $\mathrm{NaO}, \mathrm{HO}, \mathrm{S}_{2} \mathrm{O}_{2}$.)

g. Hydric di sodic phosphate. $-\mathrm{Na}_{2} \mathrm{HPO}_{4}$. (Phosphate of soda. $2 \mathrm{NaO}, \mathrm{HO}, \mathrm{PO}_{5^{\circ}}$ ) - This should not be made turbid when heated with ammonia, and the precipitate produced by argentic nitrate, or baric chloride, should be dissolved completely and without effervescence by dilute nitric acid. Dissolve in 10 parts of water.

h. Sodic nitrate. $-\mathrm{NaNO}_{3}$. (Nitrate of soda. $\mathrm{NaO}$, $\mathrm{NO}_{5}$.) - This should give no reaction with argentic nitrate or baric chloride, nor with sodic carbonate.

28. Starch-paper.-Boil starch with 25 parts of water, saturate strips of paper with the liquid, and dry them.

Tamnin.-See acid, tannic.

29. Tin.-Sn.-Get the best tinfoil of the druggists, or pure tin in small sticks.

Turmeric-paper.-See curcuma-paper:

30. Uranic acetate. $-\left(\mathrm{U}_{2} \mathrm{O}\right) \mathrm{C}_{2} \mathrm{H}_{3} \mathrm{O}_{2}$. (Acetate of 
uranium. $\left(\mathrm{U}_{2} \mathrm{O}_{2}, \mathrm{C}_{4} \mathrm{H}_{3} \mathrm{O}_{4}.\right)$-Heat uranic nitrate until a small part of the uranic oxide is reduced, digest the yellowish-red residue with acetic acid, filter the liquid and set the filtrate aside to crystallize; the crystals are composed of uranic acetate, while uranic nitrate remains in solution.

The solution of the acetate should not be changed by sulphuretted hydrogen after acidification with hydrochloric acid, and should give a precipitate with ammonic carbonate that is entirely soluble in an excess of the reagent.

31. Urea.-Recrystallize it from its solution in alcohol.

32. Water, distilled. $-\mathrm{H}_{2} \mathrm{O}$. - This can be prepared by the analyst himself, if necessary. Dealers in apparatus can supply small stills of copper and worms of block-tin, put together and ready for use. The water must be colorless and tasteless, and it should leave no residue when evaporated in a platinum dish. Ammonic sulphide should give no color to it, nor should basic plumbic acetate make it turbid, nor should ammonic oxalate or argentic nitrate make it turbid after long standing.

33. Zinc.-Zn.-This should give no reaction for arsenic with Marsh's test, and, when dissolved in nitric acid with the aid of heat, it should give no red color with potassic sulphocyanate. Fresenius recommends that before using zinc for reducing ferric to ferrous oxide in the estimation of iron by the permanganate process, it should be tested by the same process. Dissolve a piece of the zinc in dilute sulphuric acid in the small, long-necked flask, as described in $\S 52, b$, and, after the flask is filled with water and its contents are cold, add a drop of a very dilute solution of potassic permanganate, and at the same time add another drop to the same volume of pure water, and stir both mixtures well. The depth of color communicated to both liquids should be precisely the same. 


\section{CHAPTER II.}

ANALYTICAL MANIPULATION.

Determination of Specific Gravity.

34. By the specific gravity of a solid or liquid is understood its weight as compared with the weight of an equal volume of water.

a. The most obvious method of determining it is to weigh equal volumes of the substance and of water. This is easily accomplished in the case of liquids, with the aid of the so-called specific-gravity bottle or piknometer, an instrument made of thin glass and provided with an accurately ground stopper; the stopper is sometimes perforated. The weight of the empty bottle is ascertained, then its weight when completely filled with water, or filled to a mark on the neck, and finally when filled to the same extent with the liquid under examination; before weighing, in each case, all adhering particles of liquid should be carefully wiped off with blotting paper; both weighings should be made at as nearly the same temperature as possible, or at about $15^{\circ} \mathrm{C}$., the usual temperature of the working room. Divide the weight of the liquid by that of the water, for the specific gravity of the former.

$b$. The specific gravity of liquids is also determined with great facility, though with less accuracy, by means of the areometer or hydrometer; this is a glass tube closed at both ends, considerably enlarged towards one end, and loaded with mercury to make it take a vertical position in the liquid, but not with enough to cause it to sink under the surface. The use of the areometer depends upon the principle, that the less the specific gravity of a liquid is, the less its buoyant power. The specific gravi- 
ties corresponding to the different depths to which the instrument will sink in liquids of different densities, are marked on a scale in the upper, slender part of the tube. The temperature of the liquid whose specific gravity is to be determined with the hydrometer should be as nearly $15^{\circ}$ C. as possible.

c. As there is a fixed relation between the degree of concentration and the specific gravity of a solution of any given substance, areometers are constructed, upon whose seales the amount of the substance in 100 parts of its solution is given, instead of the specific gravity of a solution of that particular degree of concentration. Thus, we have alcoholometers for mixtures of alcohol and water, saccharometers for solutions of sugar, acetometers for solutions of acetic acid, lactometers for milk.

35. a.-To determine the specific gravity of a solid, we may weigh it first in the air, and then while immersed in water, and suspended from the arm of the balance by a fine thread or hair. The difference between these two weights, divided into the weight of the body in the air, will give its specific gravity.

b. Or, if the substance is in the form of a powder that is insoluble in water, we may weigh it first by itself in the specific-gravity bottle, then fill the bottle with water, as in $\S 34, a$, and weigh again. The difference between the weights of water that the bottle will hold, with and without the substance in it, which is the weight of a rolume of water equal to that of the solid substance, divided into the weight of the substance itself, will give its specific gravity.

$c$. Or, taking advantage of the fact that a cubic centimetre of water weighs very nearly one gramme at common temperatures, we may make a rough determination of the specific gravity by filling a 500 c.c. graduated cylinder exactly up to the 250 c.c. mark, then putting a 
weighed quantity of the substance (100 or 200 grms.) in the cylinder, shaking the mixture well so as to disengage bubbles of air, and observing the volume oceupied by both the substance and the water; the increased volume, which represents that of the substance added, expressed in cubic centimetres, divided into the weight of the substance taken, expressed in grammes, will nearly equal the specific gravity.

d. If the substance is soluble in water, some other liquid, like alcohol or naptha, must be used. Determine the specific gravity of the substance with reference to this liquid, by the same rules as above, and then multiply the result by the specific gravity of the liquid used, with refcrence to the common standard, water; the product will be the specific gravity of the substance with reference to the same standard.

e. The specific gravity of a substance may be determined roughly, but very expeditiously, as, for example, of potatoes, by putting several samples in a shallow dish containing a saturated solution of common salt, and adding water with constant stirring, until the buoyant power of the liquid is diminished to such a degree that half the samples swim at the surface, and half sink to the bottom; it can then be assumed, with sufficient accuracy for some purposes, that the average specific gravity of the article under examination is the same as that of the solution, and this can be determined with the aid of the hydrometer $(\S 34, b)$.

\section{SOLUTION.}

36. In order that a substance may be analyzed according to the methods described in the following pages, it must be brought into solution if not already dissolved. The solvents most commonly used are water, hydrochloric acid, and nitric acid, for inorganic substances, and water, 
alcohol, and ether, for organic matters. As the manner of making the solution is described in each case, when special directions are necessary, but little need be said on the subject here. As a general rule, heat increases the solvent power of the dissolving agents to a considerable extent, and hence it should always be applied, unless the solution is very easily accomplished without, or unless directions are given to the contrary. Time is often an important element in effecting solution, and hence long continued digestion at a moderately high temperature may be useful, or even necessary. A great excess of strong acid in a solution to be analyzed often causes much trouble; hence, as little acid as possible should be used, and in case a large quantity has been added to the substance, it should, in most cases, be removed subsequently by evaporation almost to dryness.

Unless a substance is readily and completely soluble, it is essential that it should be as finely divided as possible, and, to this end, it should be ground to a fine powder in a porcelain mortar, or, better still, an agate one.

In order to reduce a substance to a sufficiently fine powder, it is sometimes necessary to levigate it, which means simply to grind it in the agate mortar with the addition of water enough to make a thin paste, until no grittiness can be felt under the pestle, nor any grating sound heard. Then rinse the contents of the mortal into an evaporating dish, dry the substance thoroughly over the water-bath, and mix the dry residue together carefully by further grinding in the mortar.

In making a solution for quantitative purposes, when the loss of even a minute part of the substance would impair the accuracy of the results obtained, if the mixture of substance and solvent is to be boiled, or if the substance is a carbonate, and is to be treated with an acid, it is best to operate in a flask placed on its side, or with its mouth loosely stoppered by a small funnel, or in a beaker 
covered with one of the large watch-glasses now so much used for this purpose. The flask with the funnel in its mouth is better for the solution of carbonates, since fresh quantities of acid can be conveniently added from time to time. When the solution is finished, carefully rinse the funnel or watch-glass into the flask or beaker.

Heat is most conveniently applied to a mixture of substance and solvent with the aid of the water-bath, or sandbath, in making solutions for quantitative purposes, and often in qualitative analysis also. When it is necessary to boil the mixture of substance and solvent for a considerable time, and the solvent is more or less volatile, it is best to connect the flask with the lower end of a Liebig's condenser ; the rapor of the liquid as it is condensed flows back into the flask, and it is unnecessary to renew the solvent until it is quite saturated. See $\S 39, c$.

\section{EVAPORATION.}

3\%. A liquir may be evaporated either to get rid of a superabundance of water, that makes the solution too dilute, or to expel an excess of acid, or for the purpose of weighing what it has in solution. In the first and second cases, the operation may be performed in porcelain dishes, unless the solution is strongly alkaline.

a. In the third case, if the quantity of the liquid is large, it may be evaporated to a small bulk in a porcelain dish, and then carefully transferred to a platinum dish or crucible. Or the original solution may be put into the platinum dish in small quantities at a time; if, however, the solution contains free chlorine, or nitric and hydrochloric acids together, it must be evaporated in a porcelain dish until no more fumes of chlorine are evolved; the residue may then be transferred to the platinum vessel, and the evaporation continued.

When a considerable quantity of a liquid is to be evap- 
orated, the operation may be periormed at first directly over the lamp; but in quantitative work the evaporation should be completed on the water-bath in all cases; if the original quantity of the solution is small, it is better to conduct the whole evaporation on the water-bath.

If the evaporation is connected with quantitative work, the dish should never be more than three-fourths filled, and the solution should not be allowed to boil at any time in an open ressel; evaporation will, however, proceed quite rapidly in a flask placed partly on its side, and in this case gentle boiling may be allowed.

Unless the eraporation is performed in a room set apart for the work, and entirely free from dust, solutions should be kept covered with filter-paper during the operation; the paper should be supported by glass rods, or a glass triangle, laid over the dish in such a manner that it cannot cons in contact with the liquid; if the solution is strongly acid, the paper should have been well washed with acid, as directed for washing filters $\$ 39, a$; otherwise, drops of acid, that have condensed on the glass rods and come in contact with the paper, may fill back into the liquid and carry with them inorganic substances that were dissolved out of the paper.

To prevent the salts in solution from being deposited on the sides of the dish above the liquid, and even over the edge, smear the rim of the dish, just below the edge on the inside, with the thinnest possible coat of tallow. Or, fit the dish in a little jacket of firc-clay, in such a manner that the part of it above the liquid shall be kept very hot. Or, turn the crucible on its side, and apply the flame of the lamp just above the surface of the liquid.

b. When, as is often the case in agricultural analysis, potassa or soda is to be estimated in a solution containing a large quantity of ammoniacal salts, and from which these salts are to be removed by evaporation to dryness and ignition, Fresenius recommends to evaporate the so- 
lution to dryness in a porcelain dish on the water-bath, dry the residue thoroughly at a temperature a little above $100^{\circ} \mathrm{C}$., transfer it to another dish with the aid of a spatula, rinse the porcelain dish with a little water into the crucible in which the residue is to be finally ignited, eraporate these washings to dryness, then ignite the dry residue, obtained above, in small portions at a time, and finally rinse the dish that contained it into the crucible, with the aid of a little finely powdered ammonic chloride, and ignite again. The dish with the residue should be kept in the desiccator while waiting for the ignition.

\section{PRECIPITATION.}

38. Precipitation is usually resorted to in order to separate certain substances from other's in the same solution, or simply from the solution itself; it consists in adding some reagent to the solution, which causes the substance or substances in question to enter into an insoluble form. The operation is usually performed in beakers, because, from these, the precipitate is more easily transferred to the filter.

Care must be taken not to use too large an excess of the precipitant, and yet there must be no doubt at all that enough has been added; if the precipitate does not settle speedily, so that the effect of the addition of a few more drops of the reagent can be observed, a small portion of the mixture should be thrown on the same filter that is finally to receive the whole of the precipitate, and the necessary test can be applied to the filtrate; this small portion that has been separated from the main part of the liquid should then be mixed with it again, before more of the precipitant is added.

The solution and the reagent should always be well mixed by stirring, and, in most cases, the solution should be so dilute that, when the precipitate settles, it will not, 
occupy more than one-third or one-fourth the space taken up by the liquid above it; and, moreover, for convenience in filtration, the beaker should not be more than twothirds or three-fourths filled by the mixture.

$\Lambda$ few precipitates may be filtered out at once, in quantitative analysis, but in most cases digestion in a warm place for a longer or shorter time, is required. The beaker should be carefully covered during the digestion, so that no particle of dust can get in, and the operation is most conveniently performed on the sand-bath.

When about to transfer the contents of the beaker to the filter, smear a very little tallow under the lip of the former, wet a glass rod in the liquid, and hold this wet rod against the lip of the beaker in such a manner that the liquid will run down the rod and against one side of the filter.

Of course every particle of the precipitate must be transferred to the filter if the two are to be weighed together, with or without ignition. Most of the precipitate can be rinsed out of the beaker by means of the jet from the washing-bottle; if any particles remain adhering to the glass, they may be loosened with a stiff feather; or, when the precipitate is to be ignited before being weighed, a quarter or a half of a filter, of the same size and kind as that in the funnel, may be moistened slightly and rubbed over the sides and bottom of the beaker with the aid of the glass rod, or of glass-pointed pincettes, and then transferred to the filter, with most of the remainder of the precipitate adhering to it; a little subsequent rinsing with the wash-bottle will leave the beaker thoroughly cleansed; or the precipitate that adheres obstinately to the sides of the beaker may be dissolved in very dilute acid, and re-precipitated on neutralization of the acid with ammonia or soda, and the addition of a little more of the precipitant. If the second method of cleaning the beaker is followed, remem- 
ber to subtract the weight of $\left.1^{\prime}\right|_{4}$ or $\left.1^{\prime}\right|_{2}$ filter-ash from the weight of the ignited residue instead of 1 as usual.

\section{FILTRATION.}

39. a.-Solid particles are separated from the liquids with which they may be mixed by the process of filtration, referred to in the preceding paragraph, which consists simply in passing the liquid through porous unsized paper, that intercepts the solid.

Paper, already cut in convenient sizes, can be had of apparatus dealers. For quantitative purposes, filters of Swedish paper should be used, or common white filters that have been washed in dilute acid; to wash filters, pour over them, in layers of moderate thickness in a large evaporating dish, a mixture of one part of hydrochloric acid and nine parts of water; digest for several hours at a moderate temperature, wash with distilled water by decantation until the washings no longer redden litmus, transfer the bunches of paper to blotting paper, and leave them undisturbed until the filters can be separated from each other without being torm. These washed filters are more suitable for filtration by Bunsen's process than those of Swedish paper, as they are stronger and less liable to be torn.

To make the filter, fold the circular piece of paper twice in directions at right angles to each other, and through the centre; open the quadrant thus formed in such a manner as to make a conical cavity, put it in a glass funnel, which should be at least $3-5$ millimetres larger than the filter, wet the latter with a little water from the washingbottle, and press it closely against the glass throughout with the finger.

The filter should never be filled with the liquid to within less than $6 \mathrm{~mm}$. of the top, and should not ordinarily be much more than half filled with the precipitate when the liquid has drained off. 
Most liquids may be filtered much more rapidly when hot, and many precipitates are much less liable to pass through the filter, or to choke it up, when formed in nearly boiling hot solutions by hot reagents.

When possible, it is best to let the solid matter settlo to the bottom of the ressel containing the mixture of liquid and precipitate, then to decant as much as possible of the clear, supernatant liquid on the filter, pour fresh distilled water over the contents of the beaker, stir well, and perhaps heat almost to boiling, let the precipitate settle, and decant the liquid again; this may be repeated a number of times before putting the solid substance on the filter.

If the precipitate is to be dissolved without weighing or ignition, it is generally best to wash it altogether by decantation, and then to pour the solvent over the filter through which the decanted liquid was passed, and collect it in the beaker containing the main portion of the washed precipitate; the precipitate may then be digested with the reagent if necessary, and, afterwards, the filter well washed out with water, that is added to the solution just made; in this way we may avoid any considerable dilution of the solvent before it has had time to act on the substance to be dissolved. If the solvent is one that, in its concentrated state, would attack the paper, it may be poured at once over the precipitate in the beaker, while another portion may be diluted somewhat, and passed repeatedly through the filter, to take up the small quantity of the substance on that.

The thorough washing of precipitates and residues, that is so essential in quantitative analysis, and is often not unimportant in qualitative work, may sometimes be greatly facilitated by this process of decantation, particularly if the solid is one that settles readily; but if Bunsen's process of filtration is followed, decantation may be dispensed with. 
In washing precipitates on the filter, the washing-bottle is an indispensable aid. This consists simply of a flask of a capacity of 150-1000 c.c., according to the purpose for which it is to be used, clesed by a good cork that is piereed with two holes; through one of these holes pasies a glass tube, 8 or $10 \mathrm{~cm}$. long, that extends just beyond the cork on the inside, and, outside, is bent at an angle of about $110^{\circ}$; the tube that passes through the other hole extends nearly to the bottom of the flask, and, outside, is bent at an angle of about $70^{\circ}$, and drawn out to a small jet at the end; water in the flask is forced out at this jet on blowing air in at the mouth of the shorter tube.

Each portion of water with which a precipitate on the filter is washed should be allowed to pass through completely before another is added, and the precipitate should be stirred up as much as possible by the jet from the wash-bottle with each fresh addition.

Insoluble residues and precipitates must be washed, particularly in quantitative operations, as long as the washwater carries off any notable quantity of matters in solution; the washings are tested by evaporating a drop to dryness on platinum foil, to see if any residue is left, or by a chemical test, as, for example, when washing a precipitate of baric sulphate that was formed by adding baric chloride to a solution of a sulphate; as long as any of the soluble chloride remains in the pores of the filter, or adheres to the precipitate, and is taken up by the water, the washings will givo the usual reaction for chlorine with argentic nitrate (\$63).

When the contents of the filter are to be weighed or ignited, dry the whole together in the drying-chamber or air-bath, with the funnel well covered with filter paper.

b. A method lately devised by Bunsen (Annalen der Chemie, 148, 270. American Joumal of Science and Art, 21 Series, $4 \%$, 321) for increasing the rapidity of fil- 
tration, and of the washing of precipitates, promises to be very useful.

He supports the filter by a hollow cone of thin platinum foil in the throat of the funnel, and then rarefies the air in the funnel-tube; the excess of pressure on the liquid in the filter canses it to flow ihrough rery rapidly, while there is no danger of tearing the paper.

To make the platinum funnel, a cast of the glass funnel must first be taken. Select a funnel with perfectly smooth and straight sides, and opening at an angle of $60^{\circ}$, fit in it a piece of oiled writing paper in such a manner that it shall touch the glass everywhere, like an ordinary wellfitted filter, and fasten the paper in place with two or three drops of sealing-wax around the rim. Half fill the funnel then with gypsum paste, into which, before it hardens, a plug of wood is inserted, to serve as a handle. When the gypsum cone has hardened, remore it from the funnel, oil the paper again, and plunge it, with the paper still adhering, into a large porcelain crucible filled with another portion of gypsum paste; when this mould has hardened, take the cone out and rub off the paper with the fingers.

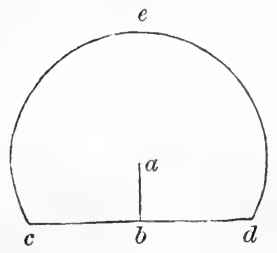

Fig. 1.

Now, cut out a piece of thin platinum foil weighing about $0.154 \mathrm{grm}$., of the precise shape and size represented in the adjoining figure, with a slit running from $b$ to $a$, the centre of the circle of which the arc, $c e d$, forms a part; ignite it in the flame of the lamp to make it perfectly flexible, lay the gypsum cone on it so that the apex of the cone shall coincide with $a$, bring up the edge, $a b d$, and press it well against the cone, and then do the same with the edge, $a b c$; after fitting the foil to the cone as perfectly as nossible with the fingers, put the whole in the mould in the crucible, and revolve the cone back and forth until the platinum has taken the exact shape of the 
plaster casts, and retains its form when removed from the mould; if found necessary, it may be ignited once more and shaped in the mould with the cone. It may be soldered at its upper edge by a grain of gold and borax, so that it will be less liable to get out of shape, but this is not necessary. If properly made, the light should not be visible through the point of this platinum funnel when it is held before the window.

With the platinum funnel in the throat of the glass. funnel, adjust the paper filter, which may be much smaller than would be used in the ordinary way of filtering, in the usual manner, with special care to secure perfect contact between the filter and the funnel at all points. Connect the tube of the funnel with a large, strong glass flask, by means of a rubber cork pierced with two holes, so that the tube extends about $6 \mathrm{~cm}$. beyond the cork; through the other hole pass a short glass tube so that it extends just to the lower surface of the cork; this tube should be bent once at a right angle outside of the flask; it may be connected with a small brass stop-cock by means of a short rubber tube with a small bore and very thick walls; all the rubber tubing used in the apparatus should be of this kind.

Now, pour the liquid to be filtered on the filter, rarefy the air in the flask, and keep the former full as long as any of the liquid remains. The precipitate may be allowed to come within $1 \mathrm{~mm}$. of the edge of the filter.

In washing the precipitate, pour the water from a flask, fill up to about a centimetre above the rim of the filter, with care not to disturb the precipitate, and let each portion of water drain off completely before adding a fresh quantity; thus the washing may be thoroughly effected in a wonderfully short time; if the vacuum in the flask is nearly perfect, or the pressure on the filter is nearly an atmosphere, three or four washings suffice, even in the case of precipitates that are the most difficult to wasb. 
Moreover, the precipitate is so completely deprived of its water, that it may be easily removed from the filter, or can be ignited at once without further drying.

To ignite the precipitate at once, Bunsen directs to wrap the filter around it, put the whole in the crucible, set the latter on its side as usual, apply the heat at the top of the crucible first, and gradually carry it towards the bottom as the filter is burned.

The rarefaction of the air may be produced in various ways. The flask may be connected with the upper end of a water-pipe 30 feet high in such a manner as to make a Sprengel's air-pump. Desaga, of Heidelberg, furnishes a complete apparatus for this purpose.

Or, an air-tight connection may be made between two large glass bottles, or demijohns, by means of a long piece of thick walled rubber tubing; then put one bottle filled with water on a high shelf, while the other is put on the floor, connect the filtering-flask with a tube leading just through the cork of the upper bottle, allow the water to flow from the upper bottle to the lower one, while provision is made for the escape of the air from this lower bottle; the rarefaction of the air in the filtering-flask will follow. When all the water has flowed from the upper to the lower bottle, their relative positions may be reversed, the proper connection made between the filteringflask and the upper bottle, and the filtration continued.

Or, a small demijohn may be closed by a rubber cork through which passes a glass tube, connected with a small brass stop-cock; connect the demijohn with an airpump, exhaust the air, close the stop-cock, connect the demijohn with the filtering-flask, and open the stop-cock when all is ready for the filtration. In order to prevent acid fumes or ammonia coming from the filtered liquid from injuring the stop-cock, a wash-bottle, containing sodic hydrate or sulphuric acid, may be interposed. (J. M. Crafts.) 
For fuller details in regard to this mode of filtration we refer to the original articles.

$c$. When several portions of a solvent, such as water, alcohol, or ether, are to be made to act on a substance, each portion can be readily separated from the substance by the following contrivance.

Close the flask with a rubber cork pierced with two holes; through one of these pass a short bent tube, like the shorter tube of the common washing-bottle, and in the other hole fit a tube which is widened out, fumnel-like, at one end, but not so much as to prevent its being put into the flask easily; near the other end, this tube is bent at an acute angle, and the end is drawn out to a point and left with a pretty large opening, after the fashion of the other tube of the washing-bottle; the long arm of the tube should reach nearly to the bottom of the flask, and have a piece of fine linen firmly bound over its mouth.

The substance and the solvent having been digested in the flask, when the solvent is supposed to be saturated, and it is desired to replace it by a fresh quantity, force air into the flask by the shorter tube and the solution will be expelled, and at least partially filtered on its way through the muslin; then, if the end of the longer tube is immersed in a fresh quantity of the solvent, this may be drawn into the flask by suction at the mouth of the short tube.

If heat is used, the mouth of the short tube may be connected with the lower end of a Liebig's condenser; then the vapors of the solvent are condensed, and the liquid flows back into the flask, and the ebullition can be maintained as long as is desired without the necessity of adding fresh quantities of the solvent to replace what is lost by evaporation; when it does become necessary to replace this portion of the solvent by a fresh one, the rubber tube that connects the flask with the condenser may be closed with a clamp, and, the application of heat being 
continued, the liquid will be forced out through the muslin filter; on immersing the open end of the longer tube in a fresh quantity of the solvent, and removing the lamp, this liquid will flow in.

The solution may not be perfectly clarified in passing through the linen filter, in which ease it will have to be filtered again through paper.

To effect more perfect filtration, a thick mat of guncotton may be bound over the linen; this layer of cotton should not be anywhere less than $14 \mathrm{~mm}$. thick.

\section{WEIGHING OF RESIDUES AND PRECIPITATES.}

40. When it is possible, residues or precipitates are ig. nited before being weighed.

This ignition may be performed in two ways.

a. If the substance is not altered in its chemical composition by contact with burning organic matter, or at the somewhat high temperature that is sometimes necessary to effect the complete incineration of the filter, roll the well-dried filter together around the precipitate, put the whole in the previously ignited and weighed crucible, cover and heat, at first very gently; when the filter is completely charred and no more smoke is given off, turn the crucible on its side, lay the cover partly on the edge of the crucible and partly on the triangle, and heat the contents of the crucible until the ash is quite white.

$b$. If the filter may not be burned in direct contact with the precipitate, crush and work it gently between the fingers over a sheet of glazed paper, to loosen the precipitate as much as possible, place the crucible on the glazed paper, and empty the contents of the filter into it. Put the crucible on the porcelain plate belonging to the Bunsen's burner, open the filter on another piece of glazed paper, fold its eiges up so as to make a little tray, with a soft feather carefully brush into this tray any 
particles of the precipitate that may have fallen on the first piece of paper, roll the filter up, enclose it in a short spiral on one end of a platinum wire that was weighed with the crucible, hold it over the crucible, and set fire to it; by applying the charred filter to the flame of the lamp two or three times it may be almost completely incinerated; finally, either let the ash and the wire drop into the crucible and ignite the whole four or five minutes, or until the ash is white, or, in case the filter-ash must be kept entirely separate from the precipitate, let the two drop into the hollow lid of the crucible, and ignite the precipitate and ash separately.

The glazed paper used above should be of a light color if the precipitate is dark-colored, and vice versa, and the whole operation should be performed in a place free from currents of air.

$c$. If the quantity of the precipitate is rery small, and yet is of such a nature as to be partly reduced to a lower degree of oxidation if ignited with the filter, the ignition may be performed as in $\alpha$; when it is completed, put a piece of dry ammonic nitrate in the crucible, cover well, and ignite again, but very gently at first.

Ferric oxide or baric sulphate may be ignited in this way when nothing better can be done.

Sometimes, when a portion of the filter is very difficult to incinerate completely, the combustion may be facilitated by adding a little ammonic nitrate as above.

After weighing, subtract the weight of the filter-ash, which has been determined once for all for the particular kind and lot of paper and size of filter used, by the incineration of half a dozen or a dozen together, and dividing the total weight of the ash thus obtained by the number of filters burned.

d. If the substance to be weighed cannot be ignited, a filter should be previously thoroughly dried in the steam or air-bath at the same temperature to which it is after- 
wards to be exposed with the precipitate, and weighed, either between two watch-glasses with ground edges and fitting well together, or in a stoppered glass tube; after careful drying with the precipitate, it is again weighed in the same manner. It should then be dried an hour longer and weighed again, and this should be repeated until a constant weight is obtained. Swedish filter-paper or washed filters should always be used in this operation.

$e$. The substance that has been dried or ignited, and is to be weighed, should always be allowed to cool under a bell-glass over concentrated sulphuric acid, or in the desiccator more commonly used for this purpose; this desiccator consists simply of a short and wide glass cylinder, with a ground edge upon which a ground glass plate will fit closely, particularly if the edge is smeared with a lit:'? tallow.

The pair of watch-glasses containing the dried filter, or the crucible with the ignited precipitate, rests on a triangle in the cylinder over fused calcic chloride, with which the bottom is covered.

No object should be weighed until it is entirely cold.

f. Platinum vessels, after having been heated by gas, should be rubbed with a little sand on the moistened finger. The sand should be fine, and all its grains should be rounded. The crucible should also be cleaned from time to time by fusing a little potassic bisulphate in it. The crucible should be supported over the lamp on stout platinum wire, which is stretched from side to side of a larger iron-wire triangle, in such a manner as to make a second triangle inside of, and about $6 \mathrm{~mm}$. smaller than, the iron triangle.

\section{MEASURING AND DIVIDING SOLUTIONS.}

41. For these purposes graduated pipettes and cylinders, and $\left.{ }^{1}\right|_{4},{ }^{1}{ }_{2}$, and 1 litre flasks are used. 
The analyst should test the correctness of the graduation of his instruments before using them, by comparing them with each other; the ${ }^{2}{ }_{t}$ litre flask should require just as much water to fill it twice up to the mark on the neck as is required to fill the $\left.{ }^{1}\right|_{2}$ litre flask once up to the mark on its neck. In the same way the $\left.{ }^{1}\right|_{2}$ litre flask should be compared with the 1 litre flask, and these with the graduated cylinders, and the pipettes with each other and the graduated cylinders.

When a certain quantity of any standard or titrated solution is to be measured out with a pipette or flask, the instrument should either be dry on the inside, or it should be rinsed ont with a little of the solution to be measured, and the last drop of the solution that remains in the point of the pipette should either always be allowed to remain there, or it should always be blown out into the ressel containing the measured solution; the same course should be followed in testing the graduation of the pipettes.

To read off the height of a solution in a burette or other graduated instrument, be sure, first, that it is in a vertical position, so that the surface of the liquid in it will be horizontal; then place the cylinder between the eye and a brightly illuminated white wall, and real the height of the lower surface of the dark zone that is readily seen under these circumstances just beneath the surface, while the eye is in the same horizontal plane.

In filling a Mohr's burette, fill up to above the zero mark with the solution, and quickly open wide the clamp for a moment so that the rubber tube and the glass tube below the clamp will be completely filled; then open the clamp a little and allow the liquid to flow out, drop by drop, until the dark zone, mentioned above, reaches the zero mark.

The temperature of all measured liquids should be as nearly $15^{\circ} \mathrm{C}$. as possible.

When the quantity of a solution to be divided is not 
too large, the division may be more accurately made by weighing than by measuring. Get the weight first of the whole amount of the liquil, in a small flask, pour out about the quantity desired for a particular analysis, and weigh the flask again with the remainder of the liquid; pour out another quantity and weigh again, and so on until the division is completed.

For this purpose, a flask with a little spout, attached just below where the neck widens out into the body, will be found very convenient.

\section{CALCULATION OF RESULTS.}

42. The results of an analysis are usually calculated so as to give the per cent composition of the compound analyzed.

If the substance determined is weigher or estimated in the form in which it existed in the compound, and it was determined in the undivided solution of the same, nothing remains to be done but to estimate the percentage by a simple rule-of-three calculation, in which the amount taken for analysis is the first term, the amount of the substance found the second, and 100 the third.

If the substance was determined in a fractional part of the solution, the same fractional part of the weight of the compound taken for analysis must be made the first term of the proportion; or the amount of the substance found may be estimated for the whole amount of the original solution by multiplication by the proper number, and this product is then made the second term of the proportion, the first term being the weight of the whole amo:mt taken for analysis.

In gravimetrical analysis the substance is usually weighed in the form of some insoluble compound that did not exist at all in the compound analyzed, and the amount of the substance in the weight that was found of this insoluble compound must first be calculated. 
This may be effected by a rule-of-three calculation also, in which the molecular weight of the insoluble substance is made the first term, the weight of the substance sought in a molecule of the insoluble substance the second, and the weight of the insoluble compound found the third.

For example, in a determination of sulphuric acid, $\mathrm{SO}_{3}$, $1.13 \mathrm{grm}$. of baric sulphate was found; then we have

$$
\begin{aligned}
& \mathrm{BaSO}_{4}: \mathrm{SO}_{3}=\mathrm{BaSO}_{4}: \mathrm{SO}_{3} \\
& 233: 80=1.13 \quad: 0.3879 \text { grm. }
\end{aligned}
$$

The same result can be more expeditiously obtained, however, with the aid of Table III, where for each special case a part of this calculation has already been performed, namely, the division of the second term by the first; nothing is left to be done, therefore, but to multiply the weight of the insoluble compound found, whose name is given in the first column, by the decimal in the second column against the name of the substance sought in the third column. In the above-mentioned case we find, on consulting the table, the proper decimal against the names sulphuric acid and baric sulphate is 0.3433 , which multiplied into $1.13 \mathrm{grm} .=0.3879$. 


\section{CHAPTER III.}

BEHAVIOR OF THE MORE COMION BASES $\triangle$ ND $\Lambda$ CIDS WITH REAGENTS, AND THEIR QUANTITATIVE ESTIMATION.

43. The substances for whose qualitative detection or quantitative estimation directions are given in the following pages, are as follows.

1. Inorganic, basic elements.-Potassium, sodium, barium, calcium, magnesium, aluminium, iron, manganese, zinc, lead, and copper.

2. Volatile, basic radical.-Ammonium.

3. Acid elements and inoryanic acids.-Arsenic, chlorine, iodine, fluorine, sulphur, and sulphuric, phosphoric, carbonic, silicic, and nitric acids.

4. Compound, acid radiculs.-Cyanogen and ferrocyanogen.

5. Organic arids.-Oxalic, acetic, tartaric, citric, malic, uric, hippuric, lactic, and tannic acids.

6. Indifferent organic substances.-Cellulose, starch, sugar, gum, albuminoids, urea, fat, and alcohol.

\section{POTASSIUN. K. 39.1}

44. - Salts of potassium, with all the acids mentioned in $\$ 43$, except tartaric, are casily soluble in water. The tartrate is soluble in free alkali or mineral acid, or in considerable water.

Reactions. - In tolerably concentrated, neutral or slightly acid solutions of potassic salts, containing hydrochloric acid or a soluble chloride, platinic chloride, $\mathrm{PtCl}_{4}$, gives a yellow, granular, crystalline precipitate, $\mathrm{K}_{2} \mathrm{PtCl}_{6}$, which is sparingly soluble in water, and nearly insoluble in alcohol. Its solubility is slightly increased by the 
presence of free hydrochloric acid. No precipitate will be given by the reagent in a very dilute solution of the potassic salt, but if such a solution is evaporated nearly to dryness with a little platinic chloride, and alcohol is added to the residue, the yellow double salt remains undissolved.

If a drop of a solution of a potassic salt is evaporated to dryness in the platinum-wire loop, and the loop with the residue on it is held at the end of the inner blowpipe flame, or in the corresponding part of the flame of the Bunsen gas-burner, a violet color is communicated to the flame beyond the wire. Viewed through thick blue glass, this color has a more reddish appearance, but the light is not entirely absorbed; the presence of sodium, barium, calcium, and copper, may interfere with this reaction.

In a silicate, this reaction for potassinm may be obtained by fusing it, in a fine powder, with pure gypsum, treating the fused mass with water, filtering, and testing the filtrate.

Quantitative estimation.-Potassium may be determined as potassic chloride, $\mathrm{KCl}$, potassic sulphate, $\mathrm{K}_{2} \mathrm{SO}_{4}$, or potassic platinic chloride, $\mathrm{K}_{2} \mathrm{PtCl}_{6}$.

The first two salts are soluble in water, and therefore cannot be obtained by precipitation; other metals and acids being removed from the solution by methods hereinafter described, the pure salt is then left as a residue on evaporation to dryness.

a. Determination as potassic chloride.-The solution being freed from other metals and acids, evaporate it to dryness over the water-bath, and ignite the residue in a well covered platinum crucible, very gently for a considerable time at first, to avoid the decrepitation and consequent loss that might result from too rapid heating; finally, heat the crucible to a dull red for a short time. The residue contains $52.41^{\circ} \%_{0}$ of potassium. 
b. Determination as potassic sulphate.-The solution being freed from other metals and from non-volatile acids, as directed in each special case, evaporate it to dryness and ignite the residue in a platinum crucible, as directed for the ignition of potassic chloride, except that it may be more strongly heated at the close of the operation.

If volatile acids, such as hydrochloric, nitric, or acetic, are present in the solution containing the potassium to be determined, sufficient sulphuric acid must be added before evaporation to expel them; in order, however, to avoid the disagreeable operation of expelling a large excess of sulphuric acid also, it is well to add but little at first; the evidence that enough has been used will be found in the evolution of abundant white acid fumes towards the close of the evaporation; if these fumes do not appear, of course a little more acid must be added, and the evaporation continued.

After igniting the residue in the platinum crucible gently for a little while, put in a small fragment of well dried ammonic carbonate, and ignite again while the crucible is loosely covered, very gently at first, and then gradually raise the heat to a full red; repeat this addition of ammonic carbonate and the subsequent ignition as long as there is any change in weight.

The ignition with ammonic carbonate facilitates the expulsion of the second equivalent of sulphuric acid from the potassic bisulphate, and it should be used in the manner indicated whenever free sulphuric acid was present in the solution that was evaporated. The residue of potassic sulphate contains $44.89^{\circ} \%_{0}$ of potassium, or $\left.54.08^{\circ}\right|_{0}$ of potassa.

c. The determination of potassium as potassic platinic chloride depends upon the insolubility of this compound in alcohol.

The solution being freed from all except potassic and sodic chlorides, and, according to Stohmann, calcic and 
magnesic chlorides also, and highly concentrated, add platinic chloride in excess, until the liquid has a bright yellow color, and evaporate the mixture nearly to dryness over the water-bath, with care not to heat the water quite to boiling:

Pour alcohol of $\left.84^{\circ}\right|_{0}$, mixed with $\left.{ }^{1}\right|_{6}$ its volume of ether, over the residue, let stand several hours in a well covered vessel, with occasional stirring, transfer the insoluble double chloride to a dried and weighed filter, wash it with alcohol and ether mixed as above directed, dry at $100^{\circ} \mathrm{C}$, and weigh.

If great accuracy is required, eraporate the filtrate from this first portion of the chloride nearly to dryness, at a temperature not above $75^{\circ} \mathrm{C}$, after addition of some water and more platinic chloride, and some sodic chloride if but little of this is supposed to be present, and treat this almost dry residue with the mixture of alcohol and ether as above; if a second quantity of insoluble chloride is thus obtained, collect it on a filter, wash, dry, and weigh it, and add the amount so found to the first quantity.

The salt contains $\left.16^{\circ}\right|_{0}$ of potassium.

If the quantity of the precipitate is quite small, less than $0.03 \mathrm{grm}$. or thereabouts, it is better to collect it on a small filter, incinerate the filter, add a little pure oxalic acid to the cooled resiclue, cover the crucible, and ignite again gently at first, and more strongly afterwards; after this ignition nothing but platinum and potassic chloride remains; dissolve out the salt by washing the residue with water until the washings give no turbidity with argentic nitrate, and dry, ignite, and weigh the platinum.

d. In some cases, as in the analysis of rood-ashes, potassium or potassa may be determined by a volumetric process, which consists in ascertaining the amount of a solution of sulphuric acid of known strength, that is re- 
quired to combine with it and form a salt which is neutral to test-papers $(\S 45)$.

PREPARATION OF TIE STANDARD ACID AND ALKALINE SOLUTIONS.

45. a.-Sulphuric acid.-To about 1100 c.c. of water add nearly 68 grms. of concentrated sulphuric acid, mix the whole well together, let the mixture cool to the temperature of the working room, and then estimate sulphuric acid with baric chloride $(\$ 59)$ in two or three portions of 20 c.c. each, with the utmost care; having in this way determined the strength of the solution; dilute it so that one litre shall contain exactly one equivalent of the acid expressed in grammes, or 40 grms. Supposing that the mean of three satisfactory determinations, as above, gives $0.84 \mathrm{grm}$. of sulphuric acid in 20 c.c. : then we learn from the proportions, $20: 0.84=1000: 42$, and $40: 42=$ 1000 : 1050 , that 50 c.c. of water must be added to one litre of the acid that we have made, in order that it shall be of the proper strength; to effect this further dilution, measure out 1000 c.c. of the acid in the litre flask, pour it withont any loss into the bottle in which it is to be kept, rinse the walls of the flask with exactly 50 c.c. of distilled water, pour this water likewise into the same bottle without loss, and mix the acid and rinsings together well; finally pour about half the contents of the bottle into the flask, rinse off the walls of the flask with the liquid, and pour it back into the bottle.

The bottle containing this standard acid should be kept well stoppered; each time that a portion is to be taken out, the contents of the bottle should be shaken up in such a manner as to rinse down the water that may have evaporated in the space above the liquid and condensed on the glass. (Fiesenius. Quantitative Chemische Analyse.) Since 40 is the equivalent of sulphuric anbydride, $\mathrm{SO}_{3}$, 
and this standard or normal solution contains an equiralent of the anhydride expressed in grammes, in a litre, ( = 1000 cubic centimetres) it contains, then, an equivalent, expressed in milligrammes, in one cubic centimetre $=40$ mgr. or 0.04 grm. The quantity of acid in one eubic centimetre will combine with exactly one equivalent of potassic oxide or potassa, $\mathrm{K}_{2} \mathrm{O}$, expressed in milligrammes, $=4 \% .1$ $\mathrm{mgr}$. or $0.04 \% 1 \mathrm{grm}$., and form a salt whose solution is neutral to test-papers; in a like manner, the acid in one cubic centimetre of the standard solution will combine with or neutralize one equivalent of sodic oxide or soda, $\mathrm{Na}_{2} \mathrm{O}$, expressed in milligrammes $=31 \mathrm{mgr}$. or $0.031 \mathrm{grm}$., or with one equivalent of ammonic oxide, $\left(\mathrm{NH}_{4}\right)_{2} \mathrm{O},=26$ mgr. or $0.026 \mathrm{grm}$.

The neutrality of the solution may be determined by its effect on paper that has been colored by litmus, or by adding a small quantity of a solution of litmus, or of cochineal or curcuma root. Litmus is colored blue by free alkali, and red by free acid; cochineal under the same circumstances is colored purple and light reddish-yellow, while curcuma or turmeric is colored brown by free alkali, and yellow by acids.

If, then, to a solution containing any one of the alkalies just mentioned, either in a free state or combined with the weak carbonic acid, we add a little cochineal solution, and then the standard acid from a burette or a graduated pipette, with constant stirring, until the purple color suddenly disappears, and a reddish-yellow one takes its place, that remains permanent throughout the whole liquid, we may know that, for each cubic centimetre of acid added, there were $0.0471 \mathrm{grm}$. of $\mathrm{K}_{2} \mathrm{O}$, or 0.031 of $\mathrm{Na}_{2} \mathrm{O}$, or 0.026 of $\left(\mathrm{NH}_{4}\right)_{2} \mathrm{O}$ in the solution; the whole amount of the alkali in the quantity of its solution taken for analysis will be given by the product of the number of cubic centimetres of acid required, into the corresponding equivalent 
of the alkali, expressed in milligrammes or fractions of a gramme as above.

b. Standard oxalic acid.-Put 63 grms. of pure crystallized oxalic acid in a litre flask, fill the flask up to about two-thirds with water, and, after the acid is entirely dissolved, add more water until it rises nearly to the mark on the neck of the flask; bring the water to a temperature of $15^{\circ} \mathrm{C}$, and then, holding the flask by the rim, so that it will take a vertical position, carefully add water up to the mark on the neck. Mix the whole well together by shaking, transfer the liquid to a well stoppered bottle, and keep it in a dark place. As 63 is the equivalent of crystallized oxalic acid, expressed in grammes, this normal solution contains, like the standard sulphuric acid, one equivalent of the acid expressed in milligrammes, $=63 \mathrm{mgr}$. or $0.063 \mathrm{grm}$, in one cubic centimetre.

c. A standard soda solution is often wanted in connection with the use of the standard acid, and for other purposes, and its preparation may be described here.

It is made of such a strength that one cubic centimetre of it will be exactly neutralized by one cubic centimetre of the standard acid, or will contain $0.031 \mathrm{grm}$. of sodic oxide, $\mathrm{Na}_{2} \mathrm{O}$.

To prepare it, put 5 c.c. of the standard acid in a small flask with a very little cochineal solution, and then add a diluted solution of sodic hydrate, of which a considerable quantity has been previously made, from a 5 c.c. pipette graduated into twentieths of a cubic centimetre, very slowly and with constant shaking of the flask, until the reddish-yellow color is just changed to purple; suppose that 2 c.c. have to be added; then evidently 3 c.c. of water must be added to 2 c.c. of the soda solution, in order to make 5 c.c. of the latter that shall exactly neutralize 5 c.c. of the standard acid; or $\frac{3 \times 1000}{2}=$ the amount of water to be added to one litre of the sodic solution, to 
make it of the normal strength. When the solution has been prepared according to these directions, and the water and alkali are well mixed, it should be tested, to be sure that the equality between the acid and the alkaline solution is perfect. Keep the solution in a bottle closed with a cork, through which passes a calcic-chloride tube that is stopped at its lower end with a plug of cotton and then filled with soda-lime; by this arrangement the free expansion of the air in the upper part of the bottle with changes of temperature is permitted, while no carbonic acid can enter; it is well to bend the slender part of the calcic-chloride tube at a right angle just above the cork, so that no soda-lime can possibly fall into the bottle, and to fill the burette by means of a small siphon passing through the cork to the bottom of the bottle, the longer arm of which may be closed at the end by a clamp on a rubber tube.

To 100 c.c. of this solution add 900 c.c. of water, making both measurements with the utmost care, mix well, and test this solution with the standard acid; 1 c.c. of the latter should require exactly 10 c.c. of the former to neutralize it ; keep this solution in the same manner as described for the other standard soda solution, and labeled, $\left.{ }^{1}\right|_{10}$ standard soda solution.

\section{SODIUM. Na. 23.}

46. Salts of sodium, with all the acids named in $\S 43$, are soluble in water. The double chloride of sodium and platinum is also soluble in both water and alcohol.

When this solution is very slowly evaporated to dryness, slender, rosy, prismatic crystals are formed, while the crystals of the corresponding potassium salt are octahedral and granular.

Reactions.-When a drop of a solution of a salt of sodium is evaporated to dryness in the platinum-wire loop, 
and the loop is then held at the end of the inner blowpipe flame, or in the corresponding part of the flame of a Bunsen's gas-burner, a yellow color is communicated to the flame beyond the wire.

These yellow rays are completely absorbed by blue glass of sufficient thickness. This test for sodium is very delicate, and is not masked by even a considerable proportion of any other metal, except copper and calcium. The presence of a very large proportion of potassium may conceal the sodium reaction. In that case, green glass will absorb the violet rays of the potassium flame, but will not affect the colored rays produced by the sodium.

Quantitative estimation. - $a$. Sodium, like potassium, may be weighed as chloride or as sulphate, on evaporating the solution to dryness, from which all other acids execpt hydrochloric or sulphuric have been removed by the methods described in each special case.

The operations of evaporation and ignition may be conducted precisely as directed for the treatment of the corresponding potassium compounds (\$ 44), except that no provision need be made to guard against loss by the decrepitation of the sodic sulphate.

Sodic sulphate, $\mathrm{Na}_{2} \mathrm{SO}_{4}$, contains $\left.32.39^{\circ}\right|_{0}$ of sodium or $\left.43.66^{\circ}\right|_{0}$ of soda, $\mathrm{Na}_{2} \mathrm{O}$. Sodic chloride contains $\left.39.32^{\circ}\right|_{0}$ of sodium.

b. If potassium is present, the two metals being converted into chlorides, ascertain the amount of the same by evaporation to dryness and weighing the residue after gentle ignition, as directed for the treatment of potassic chloride $(\$ 44, a)$, and then determine the amount of potassic chloride in this mixture, with the aid of platinic chloride, as directed under potassium $(\S 44, c)$. The difference between the sum of the two chlorides and the amount of potassic chloride will give the sodic chloride.

In this separation, enough platinic chloride must be 
added to convert both the potassium and the sodium into the platinic compounds, and the evaporation with platinic chloride should not be carried to complete dryness, so as to avoid expelling the water of crystallization of the sodic salt. The filtrate from the potassic salt should have a deep yellow color, and the salt, when examined with the magnifier, should be seen to consist only of yellow octahedral crystals or a yellow granular powder.

$c$. If sulphuric acid is present in the solution containing sodium and potassium, the conversion of these metals into chlorides may be effected by gentle ignition with powdered ammonic chloride. Evaporate the solution of the sulphates to dryness, mix the residue with a little more than its weight of pure ammonic chloride, heat the mixture gently as long as fumes are evolved, and weigh; add more ammonic chloride to the contents of the crucible, ignite, and weigh again, and repeat this operation as long as there is any change in weight.

d. In case the quantity of one metal in the mixture of the chlorides is not very much larger than that of the other, they may be estimated with accuracy by the indirect process. Determine the chlorine in the known weight of the mixture by the volumetric process $(\S 63, b)$, and then calculate the amount of potassium and sodium in it by the following formulas, in which $\mathrm{S}=$ the weight of the mixture of the chlorides, and $A=$ the amount of chlorine contained therein.

$$
\begin{aligned}
\text { Potassium } & =\frac{[(\mathrm{S}-\mathrm{A}) \times 1.54]-\mathrm{A} .}{0.63} \\
\text { Sodium } & =\frac{\mathrm{A}-[(\mathrm{S}-\mathrm{A}) \times 0.91]}{0.63}
\end{aligned}
$$

$e$. If it is more convenient to weigh the metals as sulphates, the sulphuric acid may be determined in the usual 
manncr $(\$ 59)$, and the respective amounts of sodic and potassic sulphate estimated by the following formulas, in which $\mathrm{X}=$ the amount of the sodic sulphate, $\mathrm{Y}$ that of the potassic sulphate, A the weight of the mixed sulphates, and $S$ that of the sulphuric acid contained therein.

$$
\mathrm{X}=\frac{\mathrm{S}-(\mathrm{A} \times 0.45919)}{0.10419} \cdot \mathrm{Y}=\mathrm{A}-\mathrm{X}
$$

In determining potassium and sodium by either of these indirect methods, it is absolutely essential that all other metals be carefully removed.

\section{AMMONIUM. $\mathrm{NH}_{4}$ 18. AMMONIA. $\mathrm{NH}_{3}$.}

47. All the salts of ammonium are either volatilized by heat or decomposed with expulsion of the ammonia, and their solubility is the same as that of the potassium salts, except that the tartrate is more soluble.

Reactions.- Salts of ammonium behave like salts of potassium, with platinic chloride, except that when ammonic platinic chloride is ignited, nothing but metallic platinum is left behind.

When salts of ammonium are gently heated with baric or sodic hydrate, ammonia is expelled and gives a blue color to a pice of moistened red litmus-paper held in the tube above the liquid, or a brown color to a piece of turmeric-paper. To make this reaction as delicate as possible, put the substance to be tested in a small beaker, with baric or calcic hydrate $i_{i}$ a dry form, moisten the mixture with water, cover the beaker with a watch-glass on the under side of which is a slip of the moistened test-paper, and heat the whole gently. Sooner or later, the presence of ammonium will be manifested by a change in the color of the paper, if any is present in the substance.

The test is a delicate one, as thus performed, and none of the metals interfere with it, if present. 
A still more sensitive test is that known as Nessler's. When a mixture of solution of mercuric iodide in potassic iodide, and potassic hydrate, is added to a solution containing ammonium, a light or reddish-brown precipitate is obtained, $\mathrm{NH}_{4} \mathrm{I}$. To make this test still more delicate, as in the case of an exceedingly dilute solution of the ammoniacal salt, add 25 c.c. of karic hydrate to a litre of the water to be examined, distil off $\left.{ }^{1}\right|_{4}$ of the mixture, and test the distillate with the Nessler solution.

If the solution is not too dilute, a good reaction is obtained on holding a drop of the Nessler solution, suspended on the end of a glass rod, in the test-tube just above a mixture of the substance tested and baric hydrate; if ammonium is present, the drop is colored reddish-brown.

To make a litre of the solution for this test, and a solution that can also be used for quantitative purposes, dissolve 62.5 grms. of potassic iodide in 250 c.c. of water, and add to this a concentrated solution of mercuric chloride, until the precipitated mercuric iodide ceases to be dissolved on agitation; then dissolve 150 grammes of caustic potassa in its own weight of water, and add it gradually to the iodized mercurial solution, and finally the necessary amount of water to make one litre; let the mixture stand 8-10 days, decant the clear and nearly colorless liquid, and keep it in well stoppered bottles in a dark place.

Quantitative estimation.- $\alpha$. Ammonium may be determined in the form of the ammonic platinic chloride, $\left(\mathrm{NH}_{4}\right)_{2} \mathrm{PtCl}_{6}$, when all metals except sodium (and calcium and magnesium, Stohmann,) are absent. The course to be followed is precisely the same as that described for the determination of potassium in the corresponding manner $(\$ 44, c)$. The double chloride contains $\left..7 .64^{\circ}\right|_{0}$ of ammonia $\left(\mathrm{NH}_{3}\right)$, or $\left.8.07^{\circ}\right|_{0}$ of ammonium. 
b. Ammonia may also be determined by expulsion from the mixture containing it by a strong base, and collecting the product in a known quantity of standard acid. (Schlössing's process.) The solution to be examined, which should not be more than 35 c.c. in bulk, nor contain more than $0.3 \mathrm{grm}$. of ammonia, is put in a shallow vessel, A, about $5 \mathrm{~cm}$. in diameter, which, in its turn, is put on a plate about $10 \mathrm{~cm}$. in diameter, the bottom of which is covered with mercury. Put 10 c.c. of the normal sulphuric acid in another, and rather smaller, shallow vessel, B, that is supported over A by a glass triangle; then put about 10 c.c. of milk of lime or sodic hydrate in A with the ammoniacal solution, by means of a pipette, and finally invert a bell-jar or a weighted beaker over the whole, and be sure that its rim is completely immersed in the mercury.

After 48 hours, the ammonia will usually be entirely expelled from the substance, and absorbed by the acid; in the analysis of animal and vegetable liquids, Schulze found that three or four lays were required, but that after the expiration of that time the ammonia was completely liberated. To test the matter, lift the edge of the belljar or beaker, or take out the stopper of the tubulure, if the bell-jar has such an appendage, and introduce a piece of moistened red litmus-paper; this should retain its red color even if left for a considerable time in the jar.

If the operation is finished, titrate the acid in the vessel $\mathrm{B}$, with the standard solution of soda; the difference between the number of cubic centimetres of acid put into $\mathrm{B}$ in the beginning, and the number of cubic centimetres of soda solution required to neutralize what acid remains free, multiplied into $0.017 \mathrm{grm}$. will give the amount of ammonia $\left(\mathrm{NH}_{3}\right)$ in the substance analyzed-or, multiplied into $0.026 \mathrm{grm}$. will give the amount of ammonic oxide $\left(\mathrm{NH}_{4}\right)_{2} \mathrm{O}$.

If albuminoids are present in the substance examined, 
it is better to use freshly ignited magnesia, instead of milk of lime, to set free the ammonia, so as to avoid the formation of the compound out of a portion of the albuminous matters (Vogel).

$c$. When the substance does not contain, besides ammonia, nitrogenous organic matter that would yield more ammonia on being heated with an alkali, the determination may be more expeditiously performed as follows.

Weigh the substance out in a small tube about $10 \mathrm{~mm}$. in diameter and $5 \mathrm{~cm}$. long, put it in a small flask, $A$, containing a moderately concentrated solution of sodic hydrate which has been previously boiled for a considerable time to expel all traces of ammonia, and allowed to cool again. Freshly ignited magnesia is sometimes used in the place of the alkali. Put the flask in an inclined position on the wire gauze over the lamp, and connect it quickly with the tube of a small cooling apparatus; connect the other end of this tube by a good cork with a tubulated receiver, $B$, through the tubulure of which passes another small tube that is bent twice and carried to the bottom of a small flask, $C$. Put into the receiver, $B$, the larger portion of 50 c.c. of standard sulphuric acid and the remainder in the flask $C$, and color the acid in both vessels with a little cochineal; neither tube that passes into $B$ should dip into the liquid contained in it. Be sure, now, that the apparatus is tight throughout, boil the contents of the flask $A$ gently, and continue the boiling for a little while after the drops of condensed liquid as they fall into the receiver have ceased to change the color of the acid as they come in contact with it. Then remove the lamp, and allow the contents of the flask $C$ to flow back into $B$; rinse $C$ several times with cold water, and allow these rinsings to flow into $B$ also; finally disconnect the receiver $B$ from the rest of the apparatus, transfer its contents to a beaker without any $3^{*}$ 
loss, titrate the acid remaining free with the standard sodic solution, and estimate the amount of ammonia in the substance analyzed, as directed in b. (Fiesenius.)

d. If the standard acid in either of these processes, $b$ or $c$, should contain but a very small amount of ammonia, instead of titrating with soda, the determination may be completed more satisfactorily with the aid of the Nessler solution, by preparing a solution containing an accurately known quantity of ammonia, of such a strength, that about equal volumes of it and of the solution containing the unknown amount of ammonia, will give the same shade of color with equal small quantities of this reagent.

The color observations in this process are best made in narrow glass cylinders of such a diameter that 100 c.c. of the water to be tested form a stratum about $18 \mathrm{~cm}$. deep, and by placing these cylinders upon a sheet of white paper near a window and looking at the surface of the liquid obliquely.

The amount of ammonia present in the solution to be examined should not be great enough to give a precipitate with the reagent, but only a coloration; the best results are obtained when there is not more than one milligramme of $\mathrm{NH}_{3}$ in 100 c.c. of the solution, but even if the solution is ten times stronger than this, the results are more accurate than those obtained by titration; it is important that the temperature of the solution tested should be nearly the same as that of the other solution containing a known quantity of ammonia, which is made the standard of comparison, and that neither free potassa or soda, nor calcic or magnesic carbonate should be present.

To estimate the ammonia in a solution by this method, first make a standard solution of ammonic chloride containing 0.3147 grm. in one litre, which is equal to 0.1 grm. of ammonia $\left(\mathrm{NH}_{3}\right)$ in the litre; add 1 c.c. of the 
standard iodized mercurial solution to 100 or 150 c.c. of the distillate, obtained in $b$ or $c$, or to any clear and colorless solution containing ammonia; put in another testtube, containing about 100 c.c. of water, as much of the standard solution of ammonic chloride as is thought necessary to give the same shade of color with the testliquid, make the volume of this mixture the same as of the other, by addition of water, add 1 c.c. of the iodized mercurial solution, let stand ten minutes, and then compare shades of color; if not alike, make another more or less diluted portion of the standard ammonic solution, according as the shade of color of the first was too dark or too light, and repeat the test..

(W. A. Miller:)

BARIUN. Ba. 187.

48. Compounds o. barium with sulphuric, oxalic, carbonic, phosphoric, tartarie, and silicic acids, and with fluorine, are insoluble or sparingly soluble in water. The sulphate and silicate are insoluble in acids.

Reactions.-Sulphuric acid and all soluble sulphates produce, even in very dilute solutions of barium salts, a finely pulverulent precipitate of baric sulphate, $\mathrm{BaSO}_{4}$, insoluble in acids, except when hot and concentrated, and even then but very sparingly soluble. This sulphate is slightly decomposed when boiled with a solution of sodic carbonate, but is not changed at all if a soluble sulphate is mixed with the carbonate.

\section{CALCIUM. Ca. 40.}

49. Compounds of calcium with oxalic, carbonic, phosphoric, tartaric, and silicic acids, and with fluorine, are insoluble or sparingly soluble in water. The tartrate dissolves in 352 parts of boiling water. The silicate and fluoride are insoluble in acids. Both water and acids dissolve the sulphate in small quantity. 
Reactions.-If dilnte sulphuric acid or ammonic sulphate is added to a not too dilute solution of a calcic salt, free from a large excess of strong acids, a white precipitate of calcic sulphate, $\mathrm{CaSO}_{4}, 2 \mathrm{H}_{2} \mathrm{O}$, is formed immediately or after standing some time, which is soluble in an excess of mineral acid, and slightly soluble in acetic acid and water.

This sulphate being much less soluble in alcoho than in water, the addition of a quantity of this reagent about equal to the volume of the solution, will often cause the formation of a precipitate, at least after standing some time, that would otherwise not appear.

This precipitate is readily decomposed when boiled with a solution of sodic carbonate, calcic carbonate and sodic sulphate being formed.

Ammonic oxalate gives, even in very dilute solutions of calcic salts, if they contain no free mineral acid, a white crystalline precipitate of calcic oxalate, $\mathrm{CaC}_{2} \mathrm{O}_{4}$, soluble in hydrochloric or nitric acid, and insoluble in acetic acid or a solution of ammonic chloride. If the solution of the calcic salt is very dilute, a precipitate may not appear until after the mixture has stood some time.

Quantitative Estimation.-Calcium is usually determined as carbonate, $\mathrm{CaCO}_{3}$, by precipitation with ammonic oxalate and conversion of the oxalate into carbonate by ignition.

a. 1. - If the salt is soluble in water or the acid is one that, like carbonic acid, may be expelled by hydrochloric acid, or can be removed by evaporation to dryness, like silicic acid, or the solution gives no precipitate with ammonia, add ammonic oxalate to the hot solution free from any great excess of acid, and then ammonic hydrate until the liquid, after being well stirred, gives off an ammoniacal odor, let the mixture stand in a warm place 12 hours, decant the clear liquid into a filter, wash the precipitate 
several times by decantation, and finally rinse it into the filter with hot water. Ignite the precipitate and filter separately $(\S 40, b)$, keeping the filter-ash on the crucible cover. Keep the crucible at a faint red heat 5 or 10 minutes at the close of the ignition; at no time should it be heated to a higher temperature than this; during this short ignition lift the cover of the crucible a few times.

After weighing, moisten the contents of the crucible with a little water and apply a piece of turmeric-paper to the moist mass; if the paper is turned brown, rinse it off with a very small quantity of water, put a small lump of ammonic carbonate into the crucible, heat the crucible over the water-bath until its contents are dry again, ignite gently, and weigh again; repeat this operation with fresh portions of ammonic carbonate, and ignition, as long as there is any change in weight. The change of color in the turmeric-paper showed that the first ignition was carried too far, so as to expel some of the carbonic acid, and leave calcic oxide. (Fresenius.)

The residue of calcic carbonate contains $40{ }^{\circ} \%$ of calcium or $56{ }^{\circ} \%$ of calcic oxide or lime.

2. If a blast-lamp is at hand, or a gas blowpipe, it is best to ignite the precipitate of calcic oxalate 10 minutes to an incipient white heat, after the usual ignition to a red heat over the common lamp; in this way all the calcic carbonate will be converted into calcic oxide, which may be weighed as such; no testing of the ignited residue is necessary, and moreover the filter may be burned with the precipitate.

3. Instead of igniting the precipitate of ammonic oxalate, after it has been well washed in the usual manner, dissolve it in dilute hydrochloric acid while yet moist, add water in such a quantity that the ratio between the oxalic acid and the water will be about $1: 400$ or 500 , add to this $6-8$ c.c. of concentrated sulphuric acid, and then estimate the oxalic acid in this solution with the aid 
of the standard permanganate solution, as directed in $\S 69, a$. This method yields results that are hardly less accurate, if any at all, than the other two already described. For each equivalent of oxalie acid found, expressed in milligrammes, reckon one equiralent of lime, similarly expressed, or $0.028 \mathrm{grm}$.

If the amount of calcic oxalate in the filter is very small, it may be converted into sulphate by ignition with pure ammonic sulphate, and the lime weighed as sulphate, containing $41.18^{\circ} \%$ of lime.

b. If the acid in combination with the lime is one that, like phosphoric acid, cannot be readily removed, add ammoria until a permanent precipitate just begins to appear, dissolve this by adding a few drops of hydrochloric acid, add ammonic oxalate in excess, then sodic acetate, and proceed as in $a$ with the precipitated calcic oxalate.

\section{MAGNESIUU. Mg. 24.}

50. Compounds of magnesium with phosphoric, carbonic, oxalic, and silicie acids, and with fluorine, are insoluble or sparingly soluble in water. The silicate and fluoride are insoluble in acids.

Reactions.-The carbonate is not precipitated from solutions of magnesic salts containing much ammonic chloride, on addition of an alkaline carbonate.

Hydric disodic phosphate produces a white precipitate of ammonio-magnesic phosphate, $\mathrm{Ng}_{\mathrm{N}} \mathrm{NH}_{4} \mathrm{PO}_{4}$, in solutions of magnesic salts containing ammonic salts. The precipitate, at first flocculent, if at all abundant, becomes more granular and erystalline after standing some time, or after violent agitation of the liquid containing it. If the solution of the magnesic salt is very dilute, the precipitate may not appear for some hours, and then it is crystalline and adheres to the sides of the tube; if, before the solution was set aside, it was stirred with a glass rod, and the 
walls of the tube rubbed here and there with the rod, the precipitate is deposited along these lines, producing the appearance of white streaks on the glass.

Even in concentrated solutions containing magnesium and ammonic chloride and sodic phosphate, the whole of the ammonio-magnesic phosphate is not deposited until after long standing; hence, if the first precipitate produced on adding the reagent is filtered out, and the clear filtrate stirred and set aside, a fresh precipitation will take place, and partly on the walls of the tube in the manner described above.

Quantitative estimation.-Magnesium is usually deter. mined as pyrophosphate, $\mathrm{Mg}_{2} \mathrm{P}_{2} \mathrm{O}_{7}$. .

a. To the solution of the magnesic salt add a considerable quantity of ammonic chloride, and then ammonia in slight excess; if this ammonia causes the formation of a precipitate, add enough more ammonic chloride to dissolve it; then add hydric disodic phosphate, as long as a precipitate is formed, stir the mixture well, with care not to touch the sides of the beaker with the rod, cover the beaker carefully, and let it stand with its contents 12 hours without applying heat; decant the clear liquid through the filter, rinse the contents of the beaker into the filter with portions of the first filtrate, and wash the contents of the filter with a diluted ammonia water containing one part of ammonia water of $0.96 \mathrm{Sp}$. Gr. and three of water, until the last fire drops of the washings give no opalescence with very dilute nitric acid containing argentic nitrate.

Ignite the precipitate and filter separately. Rose recommends to ignite the precipitate for a short time in a porcelain crucible over the blast-lamp; in this way it is obtained quite white.

Add $0.002 \mathrm{grm}$. to the residue of magnesic phosphate for every 110 c.c. of the filtrate from the precipitate (but 
not the washings), to compensate for the solubility of the salt in the ammoniacal solution in which it was precipitated. (Fresenius.)

The residue contains $36.04^{\circ} \%_{0}$ of magnessic oxide or magnesia, $\mathrm{MgO}$.

If the solution containing the magnesium is strongly acid, Rose recommends that the sodic phosphate be added first, and then a sufficient -quantity of ammonia to supersaturate the acid; thus he prevents the formation of any hydrated magnesic oxide that is liable to be precipitated with the phosphate and make it impure.

b. Separation of Calcium and Hagnesium.-This is effected with ammonic oxalate in the presence of ammonic chloride, and ammonia in slight excess. Add the ammonic chloride and ammonia as directed above in ", and then ammonic oxalate; this last reagent must be added in slight excess, after it has ceased to give any further precipitate of calcic oxalate, in order to convert all the magnesium into oxalate. Let the mixture stand 12 hours in a moderately warm place, decant the clear liquid into the filter, wash the precipitate in the beaker once with water, decant the washings, dissolve the precipitate in a little dilute hydrochloric acid, add ammonia in slight excess, and ammonic oxalate; let the mixture stand until the precipitate has completely subsided, then filter through the same filter as before, and wash. The first filtrate has the larger portion of the magnesium in it; the second, the rest.

Acidify the second filtrate, and concentrate that and the washings by evaporation, add the residue to the first filtrate, and precipitate magnesium in this solution as phos ate. Treat the precipitate of calcic oxalate on the filter as directed in $\S 49$.

If, in the filtrate from the calcic oxalate, there is a great excess of ammonic salts, it will be safer to evaporate the solution to dryness and expel them by ignition, 
dissolve the residue in water acidified with hydrochloric acid, filter if necessary, and then to precipitate the magnesium in the usual manner with hydric disodic phosphate.

c. If but little calcium is mixed with considerable magnesium in the substance to be analyzed, evaporate the solution to dryness, and ignite the residue gently to expel ammoniacal salts completely, dissolve this residue in a very little water mixed with a few drops of hydrochloric acid, add strong alcohol and a slight excess of pure concentrated sulphuric acid, and digest the mixture in the cold several hours. Collect the precipitated calcic sulphate on the filter, wash it first with almost absolute alcohol and finally with alcohol of about $40{ }^{\circ}$, dry, ignite and weigh.

Expel the alcohol from the filtrate and washings by heat, and determine magnesium in the usual manner with sodic phosphate.

\section{ALUMINIUM. Al. 27.5.}

51. Compounds of aluminium with phosphoric and silicic acids, and fluorine, are insoluble in water. The silicate is insoluble in acids.

Reactions.-Solutions containing aluminium give a precipitate, $\mathrm{Al}_{2} \mathrm{O}_{3}, 3 \mathrm{H}_{2} \mathrm{O}$, or $\mathrm{Al}_{2} \mathrm{H}_{6} \mathrm{O}_{6}$, with ammonic or sodic hydrate; the precipitate is dissolved in an excess of the latter reagent, but not in the former.

When a compound of aluminium is fused on platinum foil with four or five times its bulk of sodic and potassic carbonate, the fused mass dissolved in a very little water, and the solution filtered if necessary, nitric acid added to the filtrate carefully until effervescence ceases, and then a few drops of ammonia until the solution emits a faint odor of the reagent, a white flocculent precipitate appears, at once, or after standing some time; it will appear sooner, or be more readily perceived, on heating the liquid gently for a time. 
Quantitative estimation,-Aluminium is al ways weighed as sesquioxide, $\mathrm{Al}_{2} \mathrm{O}_{3}$.

To the not too dilute hot solution add a fourth or a third of its volume of ammonic chloride, if not already present, and then ammonic hydrate until a faint odor of ammonia is perceptible after vigorous stirring; heat the mixture almost to boiling until no more ammonia is given off, let it stand a few hours in a moderately warm place, decant the clear liquid through the filter, wash the precipitate two or three times with hot water, by decantation, transfer the whole to the filter, and wash it until the washings leave no fixed residue on platinum foil ; if the solution contained sulphuric acid in notable quantity, it will be best to dissolve this first precipitate in dilute hydrochloric acid, and re-precipitate the aluminic hydrate with ammonia, as abore. Dry the precipitate very thoronghly, and ignite it gently at first, and carry the heat to a full red, finally.

The residue is pure alumina.

IRON. Fe. 56 .

52. Compounds of iron with carbonic, phosphoric, oxalic, and silicic acids, and sulphur, are insoluble in water; the silicate is insoluble in acids.

Ferric salts give a yellowish-red color to solutions containing them in notable quantity.

Reactions.-Solutions of ferrous and ferric salts give precipitates, $\mathrm{FeO}, \mathrm{H}_{2} \mathrm{O}$, or $\mathrm{FeH}_{2} \mathrm{O}_{2}$ and $2 \mathrm{Fe}_{2} \mathrm{O}_{3}, 3 \mathrm{H}_{2} \mathrm{O}$ or $\mathrm{Fe}_{4} \mathrm{H}_{6} \mathrm{O}_{9}$, with ammonic or sodic hydrate; the ferrous salts, however, give no precipitate with ammonia in the presence of ammonic salts. These precipitates are insoluble in excess of the precipitant. The precipitate produced in solutions of pure ferrous salts is white; in solutions of ferric salts, reddish-brown.

Solutions of ferrous salts give a blue precipitate with 
potassic ferricyanide; ferric salts give no precipitate with this reagent.

Ferric salts give a deep red color with potassic sulphocyanate; this reaction is exceedingly delicate. Nitric acid causes the color to disappear after a while, and ammonic hydrate destroys it immediately. Ferrous salts give no color with this reagent.

Ferrous salts are converted into ferric compounds when heated with nitric acid.

Quantitative estimation.-Iron may be determined by a gravimetric or a volumetric process. In the former case it is weighed as sesquioxide, $\mathrm{Fe}_{2} \mathrm{O}_{3}$.

a. Add ammonic hydrate in excess to the hot solution, in which the iron has been completely oxidized by heating with nitric acid, if any ferrous oxide was present, heat the mixture almost to boiling, and then let it stand until the larger lart of the liquid can be decanted into the filter; wash the precipitate several times by decantation, and afterwards on the filter, until a drop of the washings leaves no residue on evaporation on platinum foil, and ignite the precipitate and filter separately. The residue is pure ferric oxide, and contains $70^{\circ} \omega_{0}$ of iron.

If the substance analyzed contained silica, this precipitate is liable to be contaminated with it, and should be digested with concentrated hydrochloric acid, after having been gently ignited; if silica is present, it will remain undissolved, and may be filtered out and weighed.

b. The volumetric process, with potassic permanganate, is particularly convenient for the determination of iron in the presence of aluminium. The iron is converted into a ferrous salt, and then it is ascertained how much of a solution of permanganate of known strength is required, to oxidize the ferrous to a ferric salt.

To make the solution of permanganate, dissolve about $8 \mathrm{grms}$. of the crystallized potassic permanganate of the 
druggists in one litre of water; as this solution is changed by exposure to the air, its strength must be determined from time to time, and the oftener, the more imperfectly it is protected from such exposure.

To determine its strength, weigh out accurately about 1.4 grms. of ammonio-ferrous sulphate, dissolve the salt in about 200 c.c. of distilled water, to which about 20 c.c. of dilute sulphuric acid have been added. To protect the salt more completely from oxidation while the solution is taking place, heat it with a part of the water in a small flask closed by a cork through which two short glass tubes pass; fasten the flask in an inclined position in a retort-holder, and heat its contents while a slow current of carbonic acid is conducted through the upper part of it. When the solution is completed, let the liquid cool in the current of carbonic acid, transfer it quickly to a beaker or a larger flask, rinse the flask out with the rest of the water, set the vessel over white paper, and immediately begin to add the solution of permanganate from a burette, with constant stirring of the liquid. At first, the red drops disappear the instant that they come in contact with the solution, and the latter gradually takes a yellowish tint; add the permanganate more and more carefully as the drops begin to disappear less readily, and stop when the last drop gives an unmistakable reddish color to the whole liquid.

Ammonio-ferrous sulphate contains just one-seventh of its weight of iron, and hence the amount of permanganic solution used in this trial will convert a weight of iron from ferrous to ferric oxide, equal to one-seventh of the weight of the salt taken.

The concentration of the solution of permanganate should be such, that from 20 to 30 c.c. is required for 1.4 grms. of ammonio-ferrous sulphate, or $0.2 \mathrm{grm}$. of metallic iron.

Now, to determine iron by this process the ferric salt 
must be in the form of a sulphate or a chloride, and the solution should contain about $0.5 \mathrm{grm}$. of iron and an excess of free sulphuric or hydrochloric acid and as little nitric acid as possible; heat the solution in a small, longnecked flask placed in an inclined position, drop in a few pieces of pure zinc, and conduct carbonic acid through the flask in the same manner as described above, for dissolving the ferrous salt; the ferric compound is reduced to a ferrous salt by the zine, with the evolution of hydrogen. When the solution is decolorized, and all the zinc is dissolved, cool the liquid as quickly as possible by immersing the flask in cold water, while carbonic acid is still passing through, transfer the solution to a beaker, rinse the flask into the beaker with a considerable quantity of water, and dilute the solution until it contains about 200 c.c. for every $0.2 \mathrm{grm}$. of iron supposed to be present; the solution must be more largely diluted if the salt was a chloride, or was dissolved in hydrochloric acid, instead of sulphuric.

To this solution add the solution of permanganate in the same manner as directed above, for the treatment of the ferrous salt.

The amount of iron in the quantity of solution taken will be given by the proportion

$$
\mathrm{C}: \frac{\mathrm{F}}{\bar{\gamma}}=\mathrm{C}^{\prime}: \mathrm{X}
$$

in which $\mathrm{C}=$ the number of cubic centimetres of permanganic solution used in the trial with the known quantity of ferrous salt, $\mathrm{F}=$ the weight of the ferrous salt taken, $\mathbf{C}^{\prime}=$ the number of cubic centimetres of permanganic solution used in the trial with the substance examined, and $\mathrm{X}=$ the amount of iron therein.

The solution of potassic permanganate is most conveniently kept in a bottle provided with an ordinary washing-bottle arrangement for filling the burette from it - then the bottle need not be opened until empty, no 
dust can get into it, particularly if the open end of the shorter tribe is closed with a plug of cotton, and its strength will not change perceptibly in two or three months.

c. The following rolumetric method of estimating ferric oxide has given satisfactory results (Oudemans, Fresenius's Zeitschrift, 6, 129), and is very easily executed.

Prepare a standard solution of sodic hyposulphite, by dissolving 24.8 grms. of the pure crystallized salt in one litre of water; this gives a $\left.{ }^{1}\right|_{10}$ normal solution, since 248 is the equivalent of the crystallized salt. Determine the strength of a solution of ferric chloride containing no traces of free chlorine, as carefully as possible, by precipitation with ammonia $(a)$.

To a quantity of this solution, accurately measured, containing about $0.2 \mathrm{grm}$. of iron, add a little hydrochloric acid, one or two drops of a concentrated solution of cupric sulphate, and the same quantity of potassic sulphocyanate; heat this blood-red liquid to about $40^{\circ} \mathrm{C}$, and allow the standard solution of hyposulphite to flow from a burette into it with constant stirring, until the red color disappears, leaving a clear, colorless liquid; towards the end of the operation, when the color of the solution has become quite pale, wait a few seconds between each addition of a few drops of the hyposulphite. Divide the quantity of ferric oxide corresponding to the amount of ferric chloride taken, by the number of cubic centimetres of the solution of hyposulphite required in this trial, and the quotient will give the amount of ferric oxide which the sodic hyposulphite in one cubic centimetre of the standard solution is able to reduce to protoxide.

Having in this way determined the value of the solution of hyposulphite with reference to ferric oxide, this oxide may be determined in any solution containing it or the corresponding chloride, in the manner described 
above; the solution should contain no free chlorine or nitric acid.

The standard solution of hyposulphite should be carefully protected from the light, and the determination of its strength should be repeated from time to time by comparison with a portion of the solution of ferric chloride of known strengith, as above.

\section{MANGANESE. Mn. 55.}

53. Compounds of manganese with phosphoric, carbonic, oxalic, and silicic acids, and sulphur, fluorine, and cyanogen, are insoluble or sparingly soluble in water. The silicate is insoluble in acids.

Reactions. - A solution containing manganese gives a precipitate, $\mathrm{MnO}, \mathrm{H}_{2} \mathrm{O}$, or $\mathrm{MnH}_{2} \mathrm{O}_{2}$, with sodic or ammonic hydrate; the presence of ammonic chloride prevents the formation of the precipitate by ammonic hydrate; in this way manganese may be partially separated from iron for qualitative purposes.

When a compound of manganese is fused with potassic and sodic carbonate and sodic nitrate, the fused mass takes a bluish-green color, which can be masked only by the presence of a very considerable quantity of iron. In case this large proportion of iron is present, it may be precipitated by ammonia after adding considerable ammonic chloride, filtering it out quickly, and evaporating the filtrate; then test a few drops of the concentrated liquid by fusion, as above.

Quantitative estimation.-The manganese is usually precipitated as carbonate; when ignited, this carbonate is converted into manganous manganic oxide, $\mathrm{Mn}_{3} \mathrm{O}_{4}$, which is weighed. Heat the solution, free from any great excess of mineral acid, nearly to boiling in a capacious flask, add sodic carbonate very slowly until it is in excess, boil a few minutes, and wash the precipitate by decantation and on 
the filter; ignite the filter and its contents separately. The ignition should be carried to a full red heat. The residue contains ${ }^{2} 2.05^{\circ} \%_{0}$ of manganese.

\section{ZINC. Zn. 65 .}

54. Compounds of zine with phosphoric, carbonic, oxalic, and silicic acids, and sulphur and cyanogen, are insoluble or sparingly soluble in water. The silicate is insoluble in acids.

Reactions.-Solutions of zincic salts give a white precipitate, $\mathrm{ZnO}, \mathrm{H}_{2} \mathrm{O}$ or $\mathrm{ZnII}_{2} \mathrm{O}_{2}$, with sodic or ammonic hydrate, soluble in excess of the precipitant, and re-precipitated from this solution on dilution with considerable water and boiling.

Solutions of zincic salts give a white floceulent precipitate, $\mathrm{Zn}_{4} \mathrm{Fe}_{2} \mathrm{Cy}_{6}$, with potassic ferrocyanide, that is difficultly soluble in acids.

LEAD. Pb. 207.

55. Compounds of lead with sulphuric, phosphoric, carbonic, oxalic, and tartaric acids, and sulphur and fluorine, are insoluble, or sparingly soluble in water. The sulphate and sulphide are insoluble in dilute acids.

Reactions.-Solutions of salts of lead give a white precipitate, $2 \mathrm{PbO}, \mathrm{H}_{2} \mathrm{O}$ or $\mathrm{Pb}_{2} \mathrm{H}_{2} \mathrm{O}_{3}$, with sodic or ammonic hydrate, insoluble in excess of the precipitant.

If free from a very large excess of strong acid, they give a white precipitate, $\mathrm{PbSO}_{4}$, with dilute sulphuric acid, which appears at once, or after some time if the solution is very dilute; this precipitate is insoluble in dilute acids, and is more insoluble in dilute sulphuric acid than in pure water; it is soluble in a solution of ammonic tartrate containing an excess of ammonia; if this solution is acidified with acetic acid and potassic dichromate add- 
ed, a yellow precipitate of plumbic chromate, $\mathrm{PbCrO}_{4}$, is formed.

Lead is precipitated from its solutions by metallic zinc in the presence of free acid.

\section{COPPER. Cu. 63.5.}

56. Compounds of copper with phosphoric, oxalic, carbonic, tartaric, and silicic acids, and sulphur and cyanogen, are insoluble, or sparingly solub?e in water. The sulphide and silicate are insoluble in dilute acids.

Cupric salts give a blue or a greenish-blue color to solutions containing them.

Reactions.- Solutions containing copper give a greenish precipitate, $\mathrm{CuO}, \mathrm{H}_{2} \mathrm{O}$ or $\mathrm{CuH}_{2} \mathrm{O}_{2}$, with sodic or ammonic hydrate. This precipitate is dissolved by an excess of ammonic hydrate, giving a deep blue solution; the reaction is very delicate.

Solutions of copper give a red precipitate with potassic ferrocyanide, $\mathrm{Cu}_{4} \mathrm{Fe}_{2} \mathrm{Cy}_{6}$.

Copper is precipitated from its solutions by zine in the presence of free sulphuric or hydrochloric acid; free nitric acid hinders the reduction, but does not prevent it.

ARSENIC. As. $\%$.

5\%. When a solution containing arsenic is treated with dilute sulphuric acid and metallic zinc, in a small flask closed with a cork through which passes a glass tube drawn out to a small jet at the end, and the escaping gas is lighted, after it has been evolved long enough to expel the oxygen from the flask, a bluish flame is produced, which deposits black, shiny spots on a cold porcelain surface. The arsenic was evolved as arseniuretted hydrogen, $\mathrm{AsH}_{3}$. This reaction is very delicate, and is known as Marsh's test. 


\section{ACIDS.}

SILICIC ACID. $\mathrm{H}_{2} \mathrm{SiO}_{3}$.

58. All silicates are insoluble in water and dilute acids, except those of potassium and sodium.

Silicates may be decomposed, and the metals contained in them brought into a soluble form, by means of concentrated hydrochloric or sulphuric acid, by hydrofluoric acid or ammonic fluoride, or by fusion with an alkaline carbonate, and subsequent treatment with dilute hydrochloric acid.

Reactions.-If a solution of a soluble silicate is evaporated to dryness, after addition of hydrochloric acid, the residue gently ignited and treated with dilute acid, the silica remains undissolved in the form of a white, gritty powder.

When a silicate in powder is fused in a bead of sodic carbonate, on platinum wire, the carbonic acid is cxpelled by the silicic, and its evolution causes the bead to froth.

If a very small fragment of an insoluble silicate is fused in a bead of phosphorus-salt, on platinum wire, the bases are dissolved out, and the silica remains floating about in the bead, retaining the form of the original fragment.

Quantitative estimation.-Silicic acid is always weighed as such.

a. 1. - If the acid is to be determined in a solution or a soluble silicate, add an excess of hydrochloric acid to the solution, or the very finely powdered solid, and evaporate the mixture to dryness on the water-bath with frequent stirring to break up the lumps.

If, as is sometimes the case, the solution analyzed contains organic matter, or ferrous oxide, add a few drops of nitric acid towards the close of the evaporation. If a solid is being treated, the digestion should be continued, with 
the addition of fresh quantities of acid if necessary, until no gritty particles can be felt under the end of the stirring rod. Heat the residue to a temperature somewhat above $100^{\circ}$, in an air-bath, made by suspending the dish on wires inside of an iron dish, so that there shall be a space of about $12 \mathrm{~mm}$. between the two at all points; when the whole is completely dry and no more acid fumes escape, moisten the residue with concentrated hydrochloric acid, let it stand half an hour, add water, and digest the mixture awhile, wash the insoluble residue two or three times by decantation, wash well on the filter, dry, and ignite. The residue is generally pure silicic acid.

All the bases with which the silica was combined can be determined in the filtrate from it.

2. Sometimes this residve is mixed with sand which it may be desired to estimate.

In this case collect the mixture on a dried and weighed filter, dry it at $100^{\circ} \mathrm{C}$., and weigh it; then separate it from the filter as completely as possible without tearing the latter, and boil it with several portions of a concentrated solution of sodic carbonate, or with sodic carbonate to which about $\left.{ }^{1}\right|_{4}$ of sodic hydrate has been added, or with sodic hydrate alone; dilute each portion of the liquid if it contained much free alkali, let it cool, and throw it on the same filter from which the mixture of silica and sand was taken; finally, transfer the insoluble sand to the same filter, wash it well, dry, and ignite. If the extraction of the silica was performed in a silver dish, the amount taken into solution by the alkaline liquids may be estimated also; for this purpose, evaporate all the filtrates and washings to dryness, after having added an excess of hydrochloric acid, and determine the silica as in $a$.

3. Sometimes, in agricultural analyses, this residue contains, besides silica and sand, free carbon, or coal. In this case, dry the whole at $100^{\circ}$ and weigh it, separate it 
from the filter as above, treat it with the alkaline solutions also in the same manner, cullect the residue that is insoluble in the alkali on a dried and weighed filter, dry and weigh it, and finally ignite and weigh again. The first of the three weighings gives the total amount of silica, sand, and coal, the second the sand and coal, and the third the sand alone.

$b$. If the silicate is insoluble in water or acids, pulverize it until an impalpable powder is obtained, mix a weighed quantity of it, in a platinum crucible, with four parts of finely powdered potassic sodic carbonate, as intimately as possible by stirring with a glass rod; wipe the glass rod with a little more of the carbonate on a slip of glazed paper, and transfer this from the paper to the crucible; the latter should not, with all its contents, be more than two-thirds filled. Cover it well and heat at first moderately over a blast-lamp, or, after imbedding it in calcined magnesia in a Hessian crucible, in a furnace; carry the heat gradually to an intense red; after about 20 minutes the mass will have ceased to boil and bubble, and the operation is finished. Put the crucible, when cold, into a beaker with considerable water, and add hydrochloric acid gradually, as directed for the solution of carbonates, $\S 36$; when the mass is entirely loosened from the crucible, take the latter out, rinse it carefully into the beaker, transfer the contents of the beaker to a platinum or a porcelain dish, evaporate to dryness, and eliminate silicic acid, as in $a$.

$c$. Of course potassium and sodium cannot be determined in the filtrate from the silica in $b$, since both metals have been added to the substance in a large and undetermined quantity.

For the determination of these elements the silicate must be decomposed with the aid of hydrofluoric acid or a fluoride. 
1. Decomposition with hydrofluoric acid.-Provide a leaden cup about $16 \mathrm{~cm}$. in diameter and $16 \mathrm{~cm}$. deep with a close-fitting cover, with projections on the sides about $8 \mathrm{~cm}$. from the bottom, supporting a perforated shelf, and with a shallow tray in the bottom about $12 \mathrm{~cm}$. in diameter and $3 \mathrm{~cm}$. deep, all made of lead; spread a layer of finely powdered fluor spar about $12 \mathrm{~mm}$. deep, over the bottom of the tray in the cup, and mix it with enough concentrated sulphuric acid to make a thin paste; put the shelf in its place and on the shelf a shallow platinum dish, such as a crucible cover, containing 1-2 grms. of the very finely pulverized and carefully weighed substance, spread over the surface of the dish in as thin a layer as possible and moistened with sulphuric acid; put the cover on the cup, and set it in a warm place where the temperature is about $60^{\circ}$ or $\gamma 0^{\circ} \mathrm{C}$, and lift the cover a few times in the course of the digestion; the evolution of the hydrofluoric acid should be maintained all the time. After 48 hours take the substance out, expel most of the sulphuric acid by heat, boil the residue with dilute hydrochloric acid, and, if anything remains undissolved, treat this residue with hydrofluoric acid in the same manner as above described. The alkaline metals can be determined in this solution by hydrochloric acid.

2. Decomposition by ammonic fuoride.-This method is considered by many to be easier of execution and more certain in its results than the other. Mix the very finely pulverized silicate with 4-5 times its weight of ammonic fluoride in a platinum dish, moisten the mixture thoroughly with concentrated sulphuric acid, and heat the whole on the water-bath in a place where the fumes of hydrofluoric acid will be carried off speedily; after a time, when the evolution of acid fumes has ceased, moisten the residue again with sulphuric acid, and heat it, directly over the lamp at last, until it is completely dry and all 
the sulphuric acid is expelled; digest the residue with hydrochloric acid; it should be dissolved completely, although, if calcium is present, considerable time may be required. If the solution is not complete, the insoluble part should be treated again with ammonic fluoride.

\section{SULPIIURIC ACID. $\mathrm{H}_{2} \mathrm{SO}_{4}$.}

50. The sulphates of lead, barium, and calcium, are insoluble, or difficultly soluble, in water and dilute acids; the last of the three is much the most soluble.

Peactions.-Sulphuric acid and solutions of sulphates give a finely pulverulent precipitate, $\mathrm{BaSO}_{4}$, with baric chloride, insoluble in water or dilute acids; the reaction is very delicate.

Quantitative estimation.-This acid is always determined as baric sulphate, $\mathrm{BaSO}_{4}$. Heat the slightly acid solution nearly to boiling, and add a hot solution of baric chloride as long as a precipitate is formed; let the nixture stand until the precipitate settles, and wash the latter by decantation, until the washings give no reaction for barium with sulphuric acid; then pour 40 or 50 c.c. of the solution of cupric acetate (§9) over the precipitate in the beaker, add some water and so much acetic acid that, after digestion for 10 or 15 minutes at a temperature very near to boiling, no basic cupric salt separates from the solution; if any does appear, dissolve it by adding more acetic acid; stir the mixture constantly during the digestion. Filter, wash the precipitate with hot water, and, if the filter is still colored blue, moisten it with a little dilute hydrochloric acid and wash with more water, until the washings give no reaction for copper with potassic ferrocyanide. Ignite the precipitate and filter separately. The residue contains $\left.34.31^{\circ}\right|_{0}$ of sulphuric anhydride, $\mathrm{SO}_{3}$, or $\left.13.73^{\circ}\right|_{0}$ of sulphur. 
Unless the precipitated baric sulphate is washed, as above directed, with a solution of cupric acetate, the result of the analysis may be very unreliable, particularly if notable quantities of nitrates or alkaline salts were present.

CARBONIC ACID OR ANHYDRIDE. $\mathrm{CO}_{2}, 44$.

60. Carbonates of all except the alkaline metals are insoluble, or sparingly soluble in water; all carbonates, without exception, are dissolved by dilute acids, with the expulsion of carbonic anhydride, $\mathrm{CO}_{2}$.

Reaction.-When dilute nitric or hydrochloric acid is added to a carbonate, whether a solid or in solution, the anhydride is expelled with effervescence, and if a drop of lime-water, suspended on the end of a glass rod, is held in the tube just above the liquid, it is made turbid by the formation of insoluble calcic carbonate.

Quantitative estimation.-Carbonic acid is usually estimated by the loss of weight suffered by the carbonate on treating it with a stronger acid, or by collecting and weighing the expelled anhydride itself.

$a$. For the first method a convenient form of an apparatus is represented in the adjoining figure.

The carbonate is weighed in the flask $A$ and water is added. $B$ is nearly filled with nitric acid; $C$ contains fused calcic chloride to absorb the moisture from the carbonic acid as it passes out, and so retain it in the apparatus. The apparatus being put together, with water enough in the flask $A$ to cover the mouth of the tube leading from $B$, close the

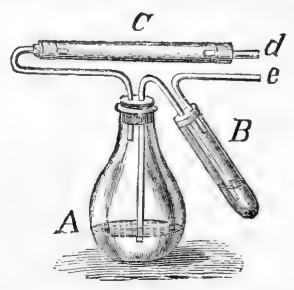

Fig. 2. mouth of the tube at $e$ with the finger, and suck a very small quantity of air out at $d$; on letting air in 
again at $d$, the water will rise in the tube leading from $A$ to $B$, and, if the apparatus is tight, will remain at a stationary level above that of the water outside of the tube. Now, weigh the whole apparatus, apply suction at $d$ to cause a little nitric acid to flow over into $A$ from time to time, and in this manner keep up a slow evolution of carbonic acid; when all the carbonate is decomposed, and all the nitric acid transferred to the flask, apply a little heat to the latter; then, by suction at $d$, draw air through the apparatus as long as any acid taste is perceived in the gas, let the apparatus cool, and weigh it. The air should be caused to pass through a calcic chloride tube before it goes into the apparatus, in order to dry it thoroughly.

The loss of weight suffered by the whole apparatus equals the carbonic anhydride, $\mathrm{CO}_{2}$.

This method, otherwise very convenient, is, according to Prof. S. W. Johnson, (American Journal of Science and Arts, Second Series, 48, 111) liable to the objection, that in freeing the apparatus completely from carbonic acid, some vapor of water escapes the desiccating material. He therefore proposes to fill the apparatus with carbonic acid gas before weighing it, and then to weigh it again as soon as the decomposition of the carbonate is completed; it is essential only, that the substance under examination dissolve freely in cold acid, and that the analysis and weighings be conducted in an apartment not liable to changes of temperature.

His apparatus may be closely imitated by substituting for the acid reservoir in the above figure, another one consisting of a bulb of sufficient size blown on a tube of which one end, that passes just through the cork in the flask, has an internal diameter of $7 \mathrm{~mm}$., is cut off obliquely, and bent so that, on inclining the whole apparatus when put together, the acid can be made to flow from the bulb into the flask; the other end of this tube is turned 
upwards. Short pieces of thick-walled rubber tubing that will fit snugly on the outer termination of the calcic chloride tube and the acid reservoir, at $d$ and $e$, are slipped over them, and these rubber tubes are then provided with well-fitting stoppers of glass rol; all these joints must be air-tight.

The carbonate is weighed as usual in the flask, A, better in the form of smali fragments than of a powder, the acid reservoir is nearly filled with hydrochloric acid (Sp. Gr. = 1.1), the apparatus is put together, and, after the glass-rod stoppers are removed, it is connected with a generator of carbonic acid, and a rather rapid current of washed gas is passed through for about 15 minutes, or until the acid in the reservoir is saturated, and the air displaced in the flask; then stop the opening at $d$, disconnect the apparatus from the generator, and close the opening at $e$, with care in this and all subsequent operations to handle the apparatus so as not to change its temperature.

Weigh it immediately, loosen the stopper at $d$, and incline the whole so that the acid will flow over, little by little, and produce a slow decomposition of the carbonate. Close $d$ again when the decomposition is ended, let the apparatus stand about 15 minutes, to be sure that it is cool, pass well-dried carbonic acid gas in again for about a minute, in the same manner as at first, and finally weigh it after closing $d$ and $e$.

b. For the second method the following form of apparatus is highly recommended by Fresenius.

In the apparatus represented by this figure $e$ contains soda lime or caustic potash in pieces, $a$ is a flask of about 300 c.c. capacity, the arm $f$ of the first $U$ tube is filled with fused calcic chloride, and the arm $f^{\prime}$ with pumice-stone that has been soaked in a concentraied solution of cupric sulphate, dried, and gently ignited so as to drive out the water of crystallization of the salt; $g$ contains pieces of glass, 6 to 10 drops of concentrated sulphuric acid in the 4 \% 
bottom and plugs of asbestos in the upper parts of both arms; $h$ is $\left.{ }^{7}\right|_{8}$ filled with about 20 grms. of coarse grained soda lime, and the remaining $\left.{ }^{1}\right|_{8}$ at $h^{\prime}$ is filled with coarse-

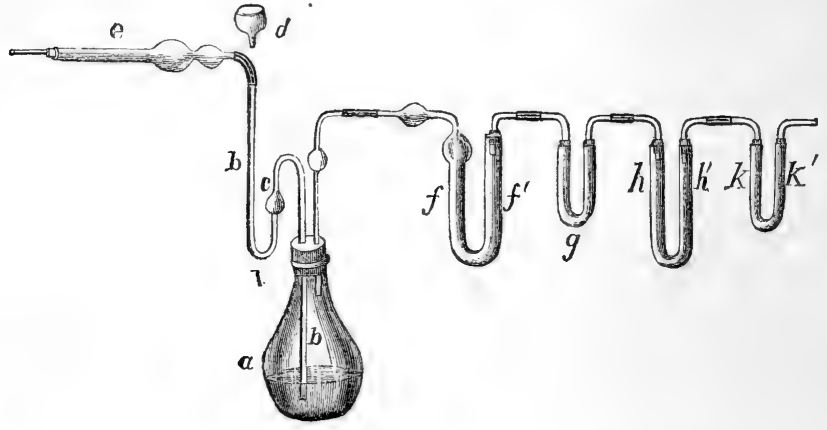

Fig. 8.

ly pulverized calcic chloride; the arm $k$ of the last $U$ tube contains calcic chloride, and the arm $k^{\prime}$ soda lime.

The carbonic acid evolved in $a$ is deprived of its water and hydrochloric acid in $\mathscr{f f}^{\prime \prime} ; g$ enables the operator to observe the rapidity of the flow of the gas, while the acid is absorbed and weighed in $g$ and $h h^{\prime}$; the contents of $7 k^{\prime}$ prevent carbonic acid and water from reaching the $U$ tube, $h h^{\prime}$, from the atmospherc.

Weigh out the substance in $\alpha$, add water, weigh $g$ and $h h^{\prime}$ together, connect the various parts of the apparatus with each other, and the little funnel $d$ with $b$, and put a few drops of mercury in at $d$ so as to close the tube at $i$.

Pour the usual quantity of dilute nitric or hydrochloric acid in at $d$, and, by suction at $l$, cause a little of the acid to flow over into the flask; regulate the flow of the gas by slowly transferring fresh quantities of acid from $b$ to $a$, and applying a gentle heat to the contents of the flask.

When the carbonate is completely decomposed, fill $d$ several times with hot water and transfer the same to $a$; then, substitute the calcic chloride tube $e$ for the funnel $d$, 
bring the contents of the flask to a gentle boiling, and continue the application of the heat until the bulb on $f$ becomes hot; draw about 1800 c.c. of air through the apparatus, by means of an aspirator connected with $l$, then immediately separate $a$ from $f$, and weigh $g$ and $h h^{\prime}$ again when they have become cold. The increase in weight gives the carbonic anhydride.

The tube $g$ can be used several times if it is carefully closed when not in use. If the tube $h h^{\prime}$ is used a second time, it will be safer to connect another with it on the outside, filled in the same way; if this second tube does not gain in weight, the first one may be used a third time, with the same precaution; if it does gain notably, use it alone in the third analysis, and re-fill $h h^{\prime}$.

c. It often happens that carbonic acid and chlorine are to be estimated in the same substance; in this case, after making the determination of the acid by either of the above methods, using, of course, pure nitric acid to set it free, filter the contents of the flask if not perfectly clear, and precipitate the chlorine in the filtrate and washings with argentic nitrate.

\section{PHOSPHORIC ACID. $\mathrm{H}_{3} \mathrm{PO}_{4} .98$.}

61. All phosphates except those of the alkaline metals are insoluble in water, but all are soluble in acids.

Reactions.-When a solution of a phosphate is added to one of magnesia containing an ammoniacal salt and an excess of ammonia, a white flocculent precipitate, $\mathrm{MgNH}_{4} \mathrm{PO}_{4}$, is produced, which, after standing for a time in a warm place, becomes more granular and crystalline; in very dilute solutions the precipitate does not appear until after long standing, and is then crystalline, and adheres to the sides of the tube in the same manner as described under magnesium. 
When a very small quantity of a solution of a phosphate is added to a considerable quantity of a solution of ammonic molybdate, containing an excess of nitric acid, a lemon-yellow, pulverulent precipitate is formed, at once or after long standing; a portion of the precipitate adheres strongly to the sides of the tube. This precipitate is soluble in a solution of a phosphate and in ammonia, but is insoluble in dilute nitric acid in the presence of excess of the molybdate. The reaction is exceedingly delicate.

Quantitative estimation.- $\because$. In cases where the acid is free or combined with an alkaline metal only, the determination of it may be made as magnesic phosphate, $\mathrm{Mg}_{2} \mathrm{P}_{2} \mathrm{O}_{7}$.

Neutralize a quantity of the solution of the substance containing not more than $0.2 \mathrm{grm}$. of the acid with ammonia, if it is acid, and add magnesia mixture $(\S 18, \zeta)$ as long as a precipitate is formed; $12-15$ c.c. of the reagent will be required for $0.2 \mathrm{grm}$. of $\mathrm{P}_{2} \mathrm{O}_{5}$; then add diluted ammonic hydrate containing one part of ammoniawater of $0.96 \mathrm{Sp}$. Gr. and three of water, until the volume of the mixture is about 110 c.c., and proceed further as directed for the treatment of the same precipitate under magnesium $(\S 50, a)$. It contains $\left.63.96^{\circ}\right|_{0}$ of phosphoric anhydride, $\mathrm{P}_{2} \mathrm{O}_{5}$.

If in any case the precipitate has a somewhat suspicious flocculent appearance, and does not become crystalline after long digestion, it had better be dissolved in dilute hydrochloric acid on the filter; evaporate the solution to dryness on the water-bath, treat the residue with dilute hydrochloric acid, and precipitate the phosphoric acid again with magnesia mixture as before. Nevertheless it is best to avoid the necessity of this re-solution and re-precipitation if possible, by careful attention to the directions for removing silicic acid and other substances from the solution at the proper time and in the proper 
place; according to Kubel (Versuchs Stationen, 10, 123) there is a loss of magnesia when the precipitated phosphate is dissolved and re-precipitated.

$b$. In the presence of alkaline earths, alumina, ferric oxide, and manganous oxide, phosphoric acid is best determined indirectly, by precipitation as ammonic phosphomolybdate. If silica is present, it must first be removed by evaporation to dryness in the usual manner $(\S 58, a, 1)$.

To the solution, free from silicic acid, add the solution of ammonic molybdate containing an excess of nitric acid, whose preparation is described in $\S 3, f$, and which, if made as there directed, contains $\left.5^{\circ}\right|_{0}$ of molybdic acid, in such a quantity that the amount of molybdic acid added shall be from 40 to 60 times as great as that of the phosphoric acid supposed to be in the solution; since the molybdic acid must be so largely in excess, it is well to take a quantity of the solution of phosphate that contains not over $0.1 \mathrm{grm}$. of the acid, and the solution should be tolerably concentrated. Digest the mixture from 12 to 24 hours at a temperature of abont $40^{\circ} \mathrm{C}$.; then take out a small sample of the clear liquid with a pipette, mix it in a test-tube with its volume of ammonic molybdate, and heat the mixture gently for an hour or more. If more of the precipitate appears, rinse the test-tube into the beaker again, add more ammonic molybdate, digest 12 hours longer, and repeat the test. Not until the mixture remains perfectly clear in this test may the precipitation be considered as finished.

Collect the precipitate on a small filter, rinse the beaker out with portions of the filtrate, and wash the contents of the filter with a mixture of 100 parts of the solution of ammonic molybdate, 20 parts of nitric acid (Sp. Gr. = 1.2), and 80 parts of water (Fies. Zeitschrift 6,405 ), until, in case lime was present, the filtrate gives no turbidity in strong alcohol to which sulphuric acid has been added. Dissolve the precipitate in the smallest quantity of am- 
monia (Sp. Gr. = 0.96), wash out the filter with a mixture of 3 parts of water and 1 of ammonia, and wash off what remains adhering to the walls of the beaker, in which the phospho-molybuate was precipitated, with a little of the same ammonia water, or clse collect this solution of the whole precipitate in that beaker; add dilute hydrochloric acid to the strong ammoniacal solution, until the yellow precipitate, that appears with each drop of the acid added, begins to dissolve again with some di:ficulty, showing that the ammonia is nearly neutralized, then add the magnesia mixture as long as a precipitate is produced, and the proper amount of the diluted ammonia, and proceed as in $a$.

Latschinow (Fies. Zeitschrift \%, 215) asserts that this precipitate of ammonio-magnesic phosphate must be fused with potassic sodic carbonate, the fused mass extracted with water, and this solution precipitated again with the magnesia mixture in the usual manner, after addition of a little citric acid.

c. In the absence of at least all but small quantities of iron and aluminium, phosphoric acid may be determined with sufficient accuracy for industrial purposes by a volumetric method that depends upon the following reactions. First, when a solution of uranic salt is added to one of a phosphate containing no other free acid than acetic, the uranic oxide is immediately precipitated in combination with phosphoric acid. Second, a solution containing the least traces of uranic oxide gives a brown precipitate with potassic ferrocyanide.

\section{Preparation of the standard solutions.}

1. Dissolve 12.6056 grms. of pure crystallized hydric disodic phosphate, that does not show the least signs of efflorescence, and has been thoroughly dried in powder by pressure between folds of bibulous paper, in about 300 c.c. of water, and, when the temperature of the solution is $15^{\circ} \mathrm{C}$., make the volume up to exactly 500 c.c. with dis- 
tilled water. One cubic centimetre of such a solution contains $0.005 \mathrm{grm}$. of phosphoric anhydride, $\mathrm{P}_{2} \mathrm{O}_{5}$.

2. Dissolve 100 grms. of sodic acetate in 900 c.c. of water, and add 100 c.c. of concentrated acetic acid.

3. Dissolve about 33 grms. of uranic acetate in about 1 litre of water, and proceed to titrate this solution with reference to the standard solution of phosphate so that 1 cubic centimetre of it shall exactly precipitate $0.005 \mathrm{grm}$. of phosphoric anhydride, as follows.

Put 25 c.c. of the standard phosphatic solution in a small flask, add 5 c.c. of the solution of sodic acetate, heat to about $50^{\circ} \mathrm{C}$., add 5 or 10 c.c. of the uranic solution from a burette or graduated pipette, heat to boiling, anc let the mixture stand a few minutes; the precipitate will settle quickly, and a drop of the clear supernatant liquicl can be taken out on the end of a small glass rod, and tested with the solution of potassic ferrocyanide for excess of uranic oxide; this test is best made by letting the drop fall gently in the middle of a small shallow pool of the solution of ferrocyanide, on a white porcelain plate, when the slightest excess of the uranic oxide in the solution will be manifested by the formation of a brown zone where the two liquids come in contact; the color soon spreads throughout the entire liquid. If no color appears, add 5 c.c. more of the uranic solution, boil again, let settle, and test a drop of the supernatant liquid in another little pool of the ferrocyanide, and so proceed until a brown color is produced in the test drop. Suppose that this brown color was obtained after adding 20 c.c. of the uranic solution, but not after adding 15 ; repeat the trial now with a fresh quantity of the standard phosphatic solution, adding 16 c.c. of the uranic solution at once, before making the test, and repeating the test after each addition of a cubic centimetre at a time. If, in this trial, we find that a brown color is obtained with $1 \%$ c.c. but not with 16 , we may make a third trial with another por- 
tion of the standard phosphatic solution, and locate the point of saturation more accurately between 16 and 17 cubic centimetres, beginning with 16.1 c.c. and so on.

If we find, finally, that 25 c.c. of the standard phosphatic solution requires 16.5 c.c. of the uranic solution for the complete precipitation of the phosphoric acid, then, evidently, to every 16.5 c.c. of the former, 8.5 c.c. of pure water must be added, in order to make a standard uranic solution, each cubic centimetre of which shall be exactly equivalent to $0.005 \mathrm{grm}$. of phosphoric anhydride.

The respective quantities of uranic solution and water being carefully measured out and mixed, for making half a litre or a litre of the standard solution, this solution should be tested, in order to be sure of its value with respect to phosphoric acid. Dilute 5 c.c. of the standa: 1 phosphatic solution, add 1-2 c.c. of sodic acetate, and then add the uranic solution from a burette graduated into $\left.{ }^{1}\right|_{10}$ cubic centimetres; exactly 5 c.c., not a tenth more or less, should be required before the reaction with the ferrocyanide is given.

The method of determining phosphoric acid volumetrically, with the aid of this standard uranic solution, is the same as that just described for the determination of the strength of this solution as originally prepared. The amount of phosphoric anhydride in the quantity of the solution taken is then given, by the product of 0.005 into the number of cubic centimetres of standard uranic solution required to precipitate the acid.

NITRIC ACID. $\mathrm{HNO}_{3}$ * 63.

62. All nitrates are soluble in water.

Reactions. - If a nitrate is heated with concentrated sulphuric acid and copper turnings, red fumes of nitric peroxide, $\mathrm{NO}_{2}$, become visible in the upper part of the 
tube, particularly if it is held over white paper and looked through lengthwise.

If a nitrate is mixed in a test-tube with strong sulphuric acid and the mixture is allowed to cool, and a concentrated solution of ammonio-ferrous sulphate is then poured slowly down the sides of the tube so as to float on the surface of the liquid in it, a colored ring is formed, the tint of which may range from a rose color to a dark brown, according as little or much nitric acid is present.

If a solution of a nitrate is poured into a test-tube containing 2-3 grms. of a mixture of clean iron filings and granulated zinc, or of sodium amalgam, and 5-6 c.c. of a strong solution of potash or soda are added, and the mixture is heated to boiling, ammonia is set free; its presence in the tube may be detected by moistened turmeric-paper, or by holding in the tube a drop of Nessler's solution, suspended on the end of a glass rod; this solution will be colored reddish-brown.

A delicate test for nitric acid in rain-water consists in acidifying 100 c.c. of the water with 2 or 3 drops of concentrated sulphuric acid, adding 2 or 3 pieces of pure zinc, and, immediately, a freshly prepared mixture of potassic iodide with a little boiled starch paste; the presence of nitric acid is indicated by a blue color. The reagents used should be tested by mixing them together without the water.

If the water contained nitrous acid, it will give a blue color with potassic iodide and starch paste alone.

Quantitative estimation.- $a$. Of the numerous methods of determining nitric acid, that of Schlössing has proved the most satisfactory in all cases. Frühling and Grouven have simplified Schlössing's apparatus somewhat. (Die landwirthschaftlichen Versuchs-Stationen, 9, 13.)

The dissolved nitrate is introduced into the flask $A$, of about 400 c.c. capacity, whose mouth can be perfectly closed by a rubber cork, through which passes a glass 
tube, $a$; the rubber tube $b c$ should be about $8 \mathrm{~cm}$. long, and have a clamp on it; $d$ is another narrow caoutchouc tube, $15 \mathrm{~cm}$. long. The neck of the jar B is ground on the outside so that a rubber tube slipped over it will more readily make a tight joint; a small glass tube, $g$, is connected with the jar by the stop-cock $k$ and rubber tubing; another glass tube, $l$, bent at an obtuse angle, and reaching above the level of the stop-cock $k$, is fastened in the tubulure $m$ of the jar by a good cork. This lastmentioned tube being in place, open the stop-cock $k$, pour

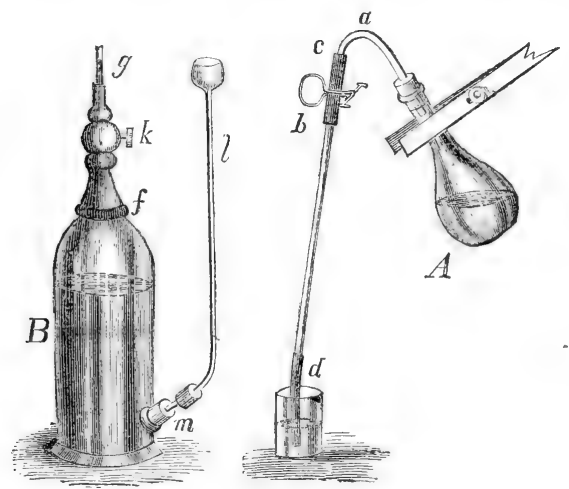

Fig. 4. a little boiled water into the jar through the tube $l$, and then pour in mercury until it rises to the lower rim of the rubber tube $f$ on the neck of the jar; close the stop-cock, put the jar in the mercury trough so that the mercury rises above the tubulure, and remore the glass tube $l$ and the cork; now, by means of a pipette, the lower end of which is bent so that it can be inserted in the tubulure, introduce 50 c.c. of well-boiled milk of lime, and then cover the mercury in the trough with water to the depth of about $3 \mathrm{~cm}$.

The solution of the nitrate in $A$, which must be neutral or alkaline, is boiled down to a small volume, while the open end of $d$ is immersed in water; when the bubbles of gas escaping from $A$ are completely condensed in passing through the water, showing that all the air has been expelled from the liquid in $\mathrm{A}$, close the clamp on $b c$, and 
dip $d$ in a glass containing a solution of ferrous chloride in hydrochiori: acid, remove the lamp from $\Lambda$, and open the clamp just enough to allow this solution to flow into the flask rather rapidly; when about 200 c.c. of the ferrous solution have passed in, replace this solution by dilute hydrochloric acid, and allow three or four portions of this to flow in also, and thus wash all the ferrous salt out of the tube; finally rinse the tube into the flask with a little distilled water. Now, close the clamp on $b c$, and, without allowing any air to enter the tube, insert $d$ in the tubulure of the jar B, replace the lamp under A, immediately open the clamp on $b c$, while holding the rubber tube tightly compressed between the fingers until a pressure is felt from within; then remove the fingers and allow the nitric oxide gas that is generated in the flask to pass into the receiver $B$. The reaction is generally terminated in about 8 minutes; so long as nitric oxide is escaping it bubbles up through the milk of lime in B, but as soon as nothing but water and hydrochloric acid pass over, both are absorbed by the milk of lime, and the bubbling of the gas through it ceases.

If the receiver $B$ is filled with gas before all the nitric acid in $\mathbf{A}$ is decomposed, close the clamp on $b c$, remove the lamp immediately from under $\mathrm{A}$, take the rubber tube $d$ out of the tubulure and let it lie in the water over the mercury, while the receiver is emptied in the manner described below; then fill the receiver again with mercury and milk of lime as directed above, insert $d$ in the tubulure again, apply heat to $\mathrm{A}$ while the tube $b c$ is closed with the fingers only, and proceed as before, until the dccomposition of the nitric acid is finished.

When the evolution of gas finally ceases, close $b c$, remove $d$ from the tubulure, and proceed to empty the gas from B. To this end, mount another flask, $\mathrm{C}$, in the same manner as $\mathrm{A}$ was arranged, put about 100 c.c. of distilled water in it, attach a rubber tube about $12 \mathrm{~cm}$. long to the 
glass tube that passes through the well-fitting rubber cork in the mouth of the flask, and put a clamp, $y$, on the end of the tube. Fasten this clamp open and boil the water in $\mathrm{C}$ until the air is completely expelled from the flask, and, while steam is still escaping from the end of the rubber tube, slip it over the glass tube $g$ on the receiver, and at the same moment open the stop-cock $k$; the aqueous vapor, from the water that continues to boil in the flask, condenses at first in the neck of the receiver and washes the milk of lime out of the upper part of it and out of the glass tube; if any milk of lime is carried into $\mathrm{C}$ in the operation that follows, the analysis is worthless.

Now, remove the lamp from $\mathrm{C}$, and a current starts in the opposite direction, which carries the nitric oxide into $\mathrm{C}$; the rapidity of the flow can be regulated by compressing the rubber tube between the fingers; as soon as the milk of lime in the receiver has reached the rim of the rubber tube $f$, close the stop-cock $k$ and conduct 20 or 30 c.c. of pure hydrogen into the receiver, open the stop-cock and allow this gas to flow into $\mathrm{C}$; repeat this two or three times, thus carrying the last traces of nitric oxide from $\mathrm{B}$ to C. Now, close $z$ again and also the clamp $y$ near this end of the tube, connect the rubber tube with a small gasometer containing oxygen, open the cock of the gasometer and the clamp $y$ again, and oxygen will pass into $\mathrm{C}$ and convert the nitric oxide into nitric acid; when all the oxygen has passed into the flask that will, close the gasometer cock, disconnect the rubber tube from it, and, after about 15 minutes, determine the nitric acid in the liquid in $\mathrm{C}$ by means of the $\left.{ }^{1}\right|_{10}$ standard solution of soda; each cubic centimetre of the sodic solution, containing $\left.{ }^{1}\right|_{10}$ of an equivalent of sodic oxide $\left(\mathrm{Na}_{2} \mathrm{O}\right)$, will combine with $\left.{ }^{1}\right|_{10}$ of an equivalent of nitric anhydride $\mathrm{N}_{2} \mathrm{O}_{5}$, expressed in milligrammes $=5.4 \mathrm{mgr}$. or $0.0054 \mathrm{grm}$.

$b$. Nitric acid may be very conveniently estimated in nitrates, as, for example, when it is desired to test the 
purity of nitre or of Chili saltpetre, by its expulsion at a high temperature by another acid, as silicic or chromic, that is not volatile at such a temperature.

Fuse a quantity of the salt, free from carbonic acid, ammonic salts, or organic matter, at the lowest possible temperature, pour it on a warm porcelain plate, pulverize the cake, and dry the powder thoroughly; then put 2-3 grms. of fincly powdered quartz in a platinum crucible, and ignite it strongly; add to this about 0.5 grm., carefully weighed, of the nitrate prepared as above directed, mix the two substances carefully with a dry glass rod, wipe off the rod with a little more of the quartz powder, and weigh the whole; ignite the well-covered crucible with its contents, for half an hour, at a barely visible red heat, weigh, and count the loss as nitric anhydride. Sulphates or chlorides are not decomposed under these circumstances, but, if carbonates are present, they must be removed by previous treatment of the salt with hydrochloric acid in slightest possible excess, and evaporation to dryness on the water-bath.

c. A very convenient method for determining nitric acid in nitrates is given by C. Noellner. (Fres. Zeitschrift $6,375)$. It depends upon the solubility of ammonic nitrate in absolute alcohol, and the insolubility of other salts of the alkalies and alkaline earths.

Heat a quantity of the salt containing not more than $0.2 \mathrm{grm}$. of the nitre with a small quantity of a solution of ammonic sulphate; ammonic nitrate is formed, and this remains in solution while all other salts are precipitated, when absolute alcohol is added to the liquid; let the mixture stand a few minutes, filter it, wash the precipitate, add an alcoholic solution of potassa to the filtrate, collect the precipitated potassic nitrate on a dried and weighed filter, wash it with alcohol, dry it at $100^{\circ}$, and weigh it. 
HYDROCHLORIC ACID. HCl. 36.5.

63. Chlorides of all the metals in the list in $\S 43$ are soluble in water. Plumbic chloride is sparingly soluble in cold water but readily soluble in hot.

Reaction.-When argentic nitrate is added to a solution containing a chloride or hydrochloric acid, a white precipitate is produced, $\mathrm{AgCl}$, which, if at all abundant, is collected together in curdy flakes on violently agitating the mixture. This precipitate is blackened on exposure to the light, is insoluble in dilute nitric acid, but is soluble in ammonia; from this solution it is re-precipitated unchanged, on addition of nitric acid in excess. It can be fused without decomposition. In contact with metallic zinc in the presence of sulphuric acid, it is decomposed, metallic silver being set free.

Quantitative estimation.-Hydrochloric acid or chlorine is most easily and accurately determined by precipitation as argentic chloride, and the estimation may be made either by a gravimetric or a volumetric process.

a. Gravimetric Process.-Add the solution of argentic nitrate, containing a slight excess of nitric acid, to the solution of the chloride, heat the mixture and stir or shake it vigorously to cause the precipitate to settle more readily, let it stand until the supernatant liquid is quite clear, decant the liquid through a small filter, agitate the precipitate with hot water, transfer it to the filter with the aid of a little water acidulated with nitric acid, wash it at first with the same acidulated water and afterwards with pure water, until the washings give no turbidity with ammonic chloride.

Dry the filter and its contents, separate the latter from the filter as completely as possible, burn the filter on the crucible cover, add the ash to the precipitate in the crucible, heat the whole some time with a little nitric acid, add a little liydrochloric, evaporate carefully to dryness on the 
water-bath, ignite the residue until it begins to fuse, and weigh it.

When this precipitate of argentic chloride is produced in the presence of much organic matter, it, together with the ash of the filter, must be fused with 3 or 4 parts of pure sodic carbonate, and the fused mass exhausted with water, the insoluble residue well washed, and the solutions and washings re-precipitated with argentic nitrate, and the precipitate treated as directed above for washing and ignition.

The precipitate contains $\left.24.74^{\circ}\right|_{0}$ of chlorine.

b. Tolumetric Process.-To prepare the standard solution of argentic nitrate, dissolve 18.\%5-18.8 grms. of the pure fused salt in 1100 c.c. of distilled water, filter the solution if necessary, and mix all parts of it well together.

Weigh out accurately four portions of pure sodic chloride of 0.1-0.18 grms. each; the salt should have been previously gently ignited, pulverized while warm, and kept in a well stoppered bottle until wanted for use.

Dissolve each portion of the salt in 20-30 c.c. of water, and add 2 or 3 drops of a cold saturated solution of potassic chromate. Now, allow the solution of argentic nitrate to flow from a burette, graduated into $\left.{ }^{1}\right|_{10}$ c.c., into one of these solutions, slowly and with constant stirring; each drop as it comes in contact with the liquid produces a red precipitate, which, at first, disappears when mixed with the rest of the solution, but finally the addition of a single drop causes the red color to remain permanent; all the chlorine has united with the silver.

A solution of argentic nitrate is to be made, one litre of which will exactly precipitate the chlorine in $\left.{ }^{1}\right|_{10}$ of an equivalent of sodic chloride expressed in grammes, or 5.85 grms. If the amount of sodic chloride in the solution tested in this first experiment was 0.11 grm., and 
18.\% c.c. of argentic nitrate were required, we learn by the proportion,

$$
0.11: 18.7=5.85: 994.5
$$

how much of the argentic solution that we have made would be required for the desired purpose; we must therefore add 5.5 c.c. of distilled water to 994.5 c.c. of the argentic solution, to make a litre of a solution that shall be exactly equivalent to $5.85 \mathrm{grms}$. of sodic chloride, or 3.55 grms. of chlorine; or, since it is more convenient to measure out one litre of the solution, and add a small quantity of water accurately measured with the pipette, we may learn from the proportion,

$$
994.5: 4.5=1000: x \text {, }
$$

how much water will be required for one litre.

Repeat the test made with one portion of the salt with two of the remaining three portions, keeping the first at hand as a standard of comparison, substitute the mean of the quantities of salt taken and of the three corresponding results in the place of the first and second terms in the first proportion given above, and make the standard silver solution accordingly; then, in order to be sure that the work has been correctly done, rinse the burette out with a little of the solution last prepared, fill up to the zero mark with this solution, and make a fourth trial with the last weighed portion of the sodic chloride. The number of cubic centimetres of the standard solution required, multiplied by 0.00585 , should give a product exactly equal to the amount of salt taken.

One cubic centimetre of this solution corresponds to $0.00355 \mathrm{grm}$. of chlorine.

The solution in which chlorine is to be determined with the aid of this standard solution must not be acid in the slightest degree, but should be neutral, or at the most very slightly alkaline. If strongly alkaline, it should first be neutralized with nitric acid; if acid, with sodic 
carbonate. Of course, neither of these reagents should contain any chlorine. Greater accuracy is secured, moreover, by using the same volume of a solution containing about the same amount of chlorine as in determining the standard of the argentic solution in the beginning-that is, about 25 c.c. containing about $0.15 \mathrm{grm}$. of chlorine.

It is well, also, to have on hand an accurately titrated solution of sodic chloride, containing exactly 5.85 grms. of solic chloride in the litre, and which, therefore, is exactly equivalent, cubic centimetre for cubic centimetre, to the argentic solution. Then, if it is feared in any case that too much argentic nitrate has been added, a cubic centimetre of this solution can be put in, when the red coloration will disappear, and argentic nitrate can be added again more cautiously; finally, when the desired result is obtained, subtract one from the number of cubic centimetres of argentic solution used.

\section{HYDROCYANIC ACID HCY.}

64. Cyantes of manganese, zinc, and copper, are insoluble in water.

Reactions.-Cyanides give a white precipitate, $\mathrm{AgCy}$, with argentic nitrate, insoluble in dilute nitric acid, and somewhat difficultly soluble in ammonia; when heated, it is decomposed, metallic silver being left behind.

If a cyanide is treated with dilute sulphuric acid in a watch-glass, and another watch-glass, with a drop of ammonic sulphide charged with excess of sulphur in its 'centre, is quickly inverted over the first glass, the hydrocyanic acid evolved from the cyanide is absorbed by the ammonic sulphide, and on evaporating the drop in the upper glass to dryness at a very gentle heat, ammonic sulphocyanate is left, which, if moistened with a drop of ferric chloride, gives a deep red color. 
HYDROFERROCYANIC ACID. HCfy.

65. Ferrocyanides of iron, zinc, manganese, lead, and copper, are insoluble in water; ferrocyanides of iron and copper are insoluble in dilute acids.

Reactions. - Ferrocyanides give a deep blue precipitate of Prussian blue, $\mathrm{Fe}_{3} \mathrm{Fe}_{4} \mathrm{Cy}_{18}$, with ferric chloride, which is not soluble in dilute hydrochloric acid, but is decomposed by sodic hydrate, the blue color being changed to red.

\section{HYDROSULPHURIC ACID. $\mathrm{H}_{2} \mathrm{~S}$.}

66. Sulphurets of arsenic, lead, copper, iron, manganese, and zinc, are insoluble in water; the first three are insoluble in dilute acids.

Reactions.-Sulphurets give with argentic nitrate a black precipitate, $\mathrm{Ag}_{2} \mathrm{~S}$, insoluble in dilute nitric acid and in ammonia.

When sulphurets are treated with hydrochloric or sulphuric acid, sulphuretted hydrogen, $\mathrm{H}_{2} \mathrm{~S}$, is evolved with effervescence ; the gas may be recognized by its disagreeable odor, and the property of blackening lead-paper.

\section{HYDRIODIC ACID. HI.}

67. Plumbic iodide is sparingly soluble in cold water, but readily soluble in hot; other iodides are soluble.

Reactions.-Iodides give a yellow precipitate, AgI, with argentic nitrate, which is very sparingly soluble in ammonia and in dilute nitric acid.

If enough potassic dichromate is added to a solution of an iodide to give it a pale yellow color, and then a little hydrochloric acid, iodine is set free, which, if it is present in notable quantity, gives the solution a darker 
§ 68. HYDROFLUORIC ACID. $§ 69 . \quad$ OXALIC ACID. 99

color; a drop of this solution on starch paper colors it blue; the latter reaction is very delicate.

HYDROFLUORIC ACID. HF.

68. Calcic and magnesic fluorides are difficulty soluble in water and acids.

Reactions.-When a fluoride in powder is moistened with concentrated sulphuric acid, in a leaden or platinum cup, and gently heated, hydrofluoric acid is evolved; if the cup is covered with a piece of Bohemian glass that is protected with a coating of wax, except along a few lines where the wax has been removed with a sharp point, the glass will be corroded on these lines, in a few hours at the most. If but a small quantity of hydrofluoric acid is present, the marks may not be seen until all the wax is carefully cleaned off and the glass is breathed upon.

To be sure that these faint marks are produced by traces of hydrofluoric acid in the substance, wipe the glass off carefully with water, and see that they can be developed again by the breath-and be sure, also, that the sulphuric acid used does not contain traces of hydrofluoric acid, as it sometimes does.

If a silicate is present, this reaction may not take place; in this case mix the substance with strong sulphuric acid in a watch-glass, heat until the mass is dry, and wash the residue off with water. If fluorine was present, the glass will be found to be corroded where it came in contact with the substance.

OXALIC ACID. $\mathrm{H}_{2} \mathrm{C}_{2} \mathrm{O}_{4}$. 90 .

69. Oxalates of barium, calcium, magnesium, iron, manganese, zinc, lead, and copper, are sparingly soluble, or insoluble, in water, but soluble in dilute acid.

Reactions.-Oxalates are decomposed, but not black. ened when heated. 
When an oxalate is heated with plumbic binoxide and concentrated sulphuric acid, a brisk effervescence ensues, carbonic acid being set free; if a drop of lime-water, on the end of a glass rod, is held in the tube above the liquid, it is made turbid by precipitation of calcic carbonate.

A solution of an oxalate in which no free acid except acetic is present, gives a fine white precipitate, $\mathrm{CaC}_{2} \mathrm{O}_{4}$, with calcic sulphate, insoluble in acetic acid.

Quantitative estimation.- a. Oxalic acid may be accurately determined by a volumetric process with potassic permanganate.

First make a $\left.{ }^{1}\right|_{10}$ standard solution of oxalic acid, by mixing together 10 c.c. of the standard acid already made and 90 c.c. of distilled water. Put 50 c.c. of this new standard solution, containing $0.315 \mathrm{grm}$. of the acid, in a beaker, add abont 100 c.c. of water and 6 to 8 c.c. of concentrated sulphuric acid, and heat to about $60^{\circ} \mathrm{C}$.; put the beaker on a sheet of white paper and add the standard solution of permanganate with constant stirring, in the same manner as directed for the determination of iron ( $\$ 52)$. When the reaction is completed, make another trial with the other 50 c.c. of the $\left.{ }^{1}\right|_{10}$ standard acid.

The standard of the permanganic solution with reference to oxalic acid being determined, to estimate the acid in any substance, whether free or combined, the substance must be freed from all other compounds that act in the same manner on the permanganate, such as ferrous oxide, or organic matter; dissolve it in water or hydrochloric or sulphuric acid, add 400 to 500 c.c. of water for every gramme of oxalic acid supposed to be present, and 6 to 8 c.c. of concentrated sulphuric acid, and proceed to titrate with the permanganic solution in the usual way. Let $m=$ the amount of permanganate used to oxidize 0.315 grm. of crystallized oxalic acid, or 0.18 grm. of oxalic anhydride, and $m^{\prime}$ the amount required to oxidize the acid 
in the quantity of substance taken. Then from the proportion,

$$
m: 0.18=m^{\prime}: \mathrm{x},
$$

we may learn how much oxalic anhydride, $\mathrm{C}_{2} \mathrm{O}_{3}$, was contained in the substance analyzed.

$b$. Oxalic acid may be estimated in any substance containing it and free from carbonic acid, by converting it into carbonic acid with the aid of manganic oxide and concentrated sulphuric acid, and determining this carbonic acid. Weigh the substance in the flask A, Fig. 1, $\S 60$, add about the same weight of manganic oxide free from carbonic acid, fill B with concentrated sulphuric acid, weigh the whole apparatus, and proceed further as in the estimation of carbonic acid with this form of apparatus $(\S 60, a)$. Each equivalent of oxalic anhydride, $\mathrm{C}_{2} \mathrm{O}_{3}$, yields two equivalents of carbonic anhydride, $\mathrm{CO}_{2}$.

ACETIC ACID. $\mathrm{HC}_{2} \mathrm{H}_{3} \mathrm{O}_{2} .60$.

70. All acetates are soluble in water.

Reactions. - Acetates are blackened when quickly heated to a high temperature, carbon being set free.

If a neutral acetate is mixed with a solution of ferric chloride, a deep red liquid is produced; on boiling the mixture a red precipitate is formed.

If an acetate is heated with concentrated sulphuric acid and alcohol in about equal volumes, acetic ether is disengaged, the pleasant aromatic odor of which is best distinguished from that of common ether, which may be formed from sulphuric acid and alcohol alone, after the liquid has become quite cold.

Quantitative estimation.-Free acetic acid may be estimated by a volumetric process; with the aid of the standard sodic solution.

Since neutral sodic acetate has a slightly alkaline reaction, it is best to ascertain first, the relation between 
this standard solution and one of acetic acid of known strength. For this purpose add a measured quantity of the standard sulphuric acid to a solution of sodic acetate, but not enough to decompose the whole of the acetate. Each cubic centimetre of the sulphuric acid, containing 0.04 grm., will set free an equivalent quantity of acetic anhydride, $=0.051 \mathrm{grm}$., or of the hydrated acid, $0.06 \mathrm{grm}$. Knowing, then, how much acid has been set free, we can titrate the mixture with the standard sodic solution, and learn how much acetic acid each cubic centimetre of the sodic solution will neutralize.

Merz recommends the use of a tincture of turmeric as a coloring matter that is not affected by neutral sodic acetate; the addition of a single drop of the soda solution to a solution of sodic acetate colored yellow by this tincture produces a brown color, while a drop of acetic acid restores the yellow color. (Wagner's Jahresbericht, 13, 498.)

TARTARIC ACID. $\mathrm{H}_{2} \mathrm{C}_{4} \mathrm{H}_{4} \mathrm{O}_{6} .150$.

71. Tartrates of barium, calcium, zinc, and copper, are difficultly soluble in water.

Reactions. - When tartrates are heated, they are blackened, and an odor of burnt sugar is given off.

If a solution of free tartaric acid, that is not too dilute, is mixed with a solution of potassic acetate, a crystalline precipitate, $\mathrm{KHC}_{4} \mathrm{H}_{4} \mathrm{O}_{6}$, is formed at once, or after some time, or after violent agitation, or addition of an equal volume of alcohol. If the two solutions are very concentrated, and are stirred in a watch-glass, a deposition of crystals marks the track of the rod over the glass.

Calcic chloride gives a white precipitate, $\mathrm{CaC}_{4} \mathrm{H}_{4} \mathrm{O}_{6}$, in solutions of a neutral tartrate, the formation of which is hastened by violent agitation; the presence of ammonic chloride only retards the appearance of the precipitate, 
but does not prevent it. The precipitate is soluble in boiling sodic hydrate, but re-precipitation follows on cooling.

With lime-water in large excess, so as to turn red litmus-paper blue, tartaric acid gives the same white precipitate.

With calcic sulphate, tartaric acid in tartrates gives no precipitate, thus distinguishing it from oxalic acid.

With argentic nitrate, neutral tartrates give a precipitate that is turned black when the mixture is boiled.

Quantitative estimation.-An approximate determination of tartaric acid may be made by adding potassic acetate to its moderately concentrated solution, and considerable alcohol, collecting the precipitate on a weighed filter, washing it with alcohol, and drying it at $100^{\circ} \mathrm{C}$, and weighing.

The residue of potassic tartrate, $\mathrm{KHC}_{4} \mathrm{H}_{4} \mathrm{O}_{6}$, contains $70: 18^{\circ} \%_{0}$ of tartaric anhydride, $\mathrm{C}_{4} \mathrm{H}_{4} \mathrm{O}_{5}$.

\section{CITRIC ACID. $\mathrm{H}_{3} \mathrm{C}_{6} \mathrm{H}_{5} \mathrm{O}_{7}$.}

72. Citrates of barium, calcium, and aluminium, are sparingly soluble in water.

Reactions. - When citric acid is heated, it fuses at first, and then carbon is separated with the evolution of pungent acid fumes. Citrates are blackened when heated.

Citrates give no precipitate with potassic salts.

With lime-water in excess, at ordinary temperatures, they give a very slight precipitate, which, on boiling, becomes quite abundant, but is mostly dissolved when the mixture is cooled.

Calcic chloride gives a precipitate $\mathrm{Ca}_{3}\left(\mathrm{C}_{6} \mathrm{H}_{5} \mathrm{O}_{7}\right)_{2}$, in solutions of neutral citrates, which, if obtained without heat, is soluble in ammonic chloride; it is re-precipitated from this solution on boiling, and is not then soluble in ammonic chloride; it is insoluble in potassic hydrate. 
MALIC ACID. $\mathrm{H}_{2} \mathrm{C}_{4} \mathrm{H}_{4} \mathrm{O}_{5} .134$.

73. Malate of lead is difficultly soluble in water

Reactions.-When malic acid is heated, it froths, pungent acid vapors being set free, and crystals of maleic and fumaric acids are condensed in the colder parts of the tube.

Malates give no precipitate with potassic salts, nor with calcic hydrate or sulphate, even on boiling.

With calcic chloride no precipitate is formed unless the solution is concentrated and the mixture is boiled; if this precipitate, $\mathrm{CaC}_{4} \mathrm{H}_{4} \mathrm{O}_{5}, 2 \mathrm{H}_{2} \mathrm{O}$, is dissolved in a very little hydrochloric acid, ammonia added, and the mixture boiled, the calcre malate is re-precipitated; but if it is dissolved in considerable acid, no precipitate is formed on adding ammonia and boiling; alcohol will precipitate the salt from this solution.

Quantitative estimation.-An approximate determination of malic acid may be made by adding calcic hydrate in excess to its highly concentrated solution, free from citric, tartaric, or sulphuric acid, and then adding considerable alcohol, collecting the precipitate on a dried and weighed filter, washing with alcohol, drying at $100^{\circ} \mathrm{C}$., and weighing.

The residue contains $\left.6 \% .44^{\circ}\right|_{0}$ of malic anhydride, $\mathrm{C}_{4} \mathrm{H}_{4} \mathrm{O}_{4}$.

LACTIC ACID. $\mathrm{HC}_{3} \mathrm{H}_{5} \mathrm{O}_{3} .90$.

74. All lactates are soluble in water; only zincic lactate is somewhat difficultly soluble in cold water.

Reactions.-Lactates are blackened when heated.

If a liquid containing free lactic acid is boiled with zincic oxide or carbonate, the filtered solution will deposit a crystalline crust on its surface, or acicular crystals, on cooling. 
Quantitative estimation.-This acid in the free state may be determined by a rolumetric process, the same as for the determination of acetic acid. The solution, free from acetic or other free acid except lactic acid, is titrated with the standard sodic solution. Each eubic centimetre of sodic solution required corresponds to $0.81 \mathrm{grm}$. of the anhydrous acid, $\mathrm{C}_{6} \mathrm{H}_{10} \mathrm{O}_{5}$.

To remove acetic acid as well as carbonic from the soiution, before estimating the lactic acid, evaporate a portion of the liquid in the water-bath with the addition of pure quartz sand and with constant stirring towards the end of the operation; continue to heat the dry residue until no more acid odor is given off, then treat it with water, filter, and wash the sand on the filter as long as the washings are acid, and determine lactic acid in the filtrate with the standard sodic solution as above.

URIC ACID. $\mathrm{H}_{2} \mathrm{C}_{5} \mathrm{H}_{2} \mathrm{~N}_{4} \mathrm{O}_{2}+4$ aq. 304 .

75. This acid is but slightly soluble in water, and is insoluble in alcohol. Alkaline urates are soluble in water; others are insoluble.

Reactions. - If uric acid or a urate is heated with moderately strong nitric acid, the mixture filtered if not clear, the filtrate carefully evaporated to dryness, and the residue moistened with ammonia, a beautiful purple color (murexide) appears.

In urinary sediments, uric acid may often be recognized under the microscope by the rhombic six-sided plates, or right-angled four-sided prisms of a brown to a golden yellow color, which it forms.

Quantitative estimation.-Precipitate the uric acid from the solution containing it by the addition of hydrochloric acid, if no albumen is present; in case it is present, use acetic or phosphoric acid instead of hydrochloric. Let the mixture stand 36-48 hours, and collect the pre$5^{*}$ 
cipitated acid on a dried and weighed filter, and add 0.045 mgr. to the amount of uric acid found, for every cubic centimetre of wash-water passed through the filter.

If hippuric acid was present, it must be dissolved out of this precipitate by treating it several times with alcohol of $\left.83^{\circ}\right|_{0^{\circ}}$.

HIPPURIC ACID. $\mathrm{HC}_{9} \mathrm{H}_{8} \mathrm{NO}_{3} .179$.

76. This acid is slightly soluble in cold water, but readily soluble in boiling water and in alcohol, and slightly soluble in ether.

Ferric and plumbic hippurates are quite insoluble in water; all others are soluble.

Quantitative estimation.-Precipitate the concentrated solution of the acid with hydrochloric acid, and let the mixture stand in the cold 48 hours; collect the precipitate on a dried and weighed filter, wash it with small portions of very cold water, until the washings are colorless and give only a faint turbidity with argentic nitrate, dry at $100^{\circ}$, and weigh. For every 6 c.c. of wash-water that passed through the filter add $0.01 \mathrm{grm}$. to the amount of hippuric acid found.

If uric acid is present, the precipitate, after being weighed, must be treated with alcohol, and the residue of uric acid weighed again. The difference between the two weights will be the hippuric acid.

For a better method of separating the two acids see urine, $\S 113, h$.

TANNIC ACID.

7\%. Tannic acid is soluble in water, alcohol, and ether; alkaline tannates are soluble in water, but others are difficultly soluble.

Reactions.-Tannic acid gives a violet-black precipi- 
tate with ferric salts. It also gives a white precipitate when poured into a solution of gelatine; as long as the gelatine is in excess, this precipitate is soluble in the supernatant liquor when heated, while if the acid is in excess, it is much less soluble.

If a piece of fiesh skin, deprived of its hair by caustic lime, is left for several hours in contact with a solution of tannic acid, the latter is completely absorbed, so that the liquid will give no color with ferric salts.

Quantitative estimation.-The tannic acid in a solution may be determined with considerable accuracy by comparing the specific gravity of the solution before and after it has been in contact with powdered skin.

The solution must be as clear as possible and not too dilute; such a one will answer, for example, as may be obtained by exhausting 20 to 40 grms. of tanner's bark with water, and diluting to 400 or 500 c.c.

Determine the weight of the extract obtained from a weighed quantity of the bark, and then determine the specific gravity of the solution accurately with the piknometer, or specific-gravity bottle $(\$ 34, a)$. Then weigh out 100 c.c. of the solution in a flask, and weigh out also a quantity of finely divided skin, equal to about four times the amount of tannic acid that is supposed to be in this quantity of the solution; this amount can be ascertained approximately from Table IV, taking as the per cent of tannic acid that which is found against the number representing the specific gravity of the original solution, just determined.

Soften the skin by soaking it in water, enclose it in a linen bag and press ont the water, add it to the weighed solution in the flask, close the flask and shake the mixture vigorously, filter through a linen cloth and determine the specific gravity of the filtrate. To the difference between the specific gravity before and after treatment with the skin, add one, seek for the number so obtained in the 
column headed specific gravity at $15^{\circ} \mathrm{C}$., in Table IV, and against that will be found the per cent of tannic acid in the solution examined. A simple calculation will then give the per cent of the acid in the bark.

To prepare the powder of skin required in this analysis, wash a piece of skin, that has been prepared for tanning by treatment with lime and other agents, with water, stretch it on a board, dry it with the aid of a gentle heat, and rasp it with a coarse file. Keep the powder in a well stoppered bottle.

\section{CELLULOSE. $\quad \mathrm{C}_{12} \mathrm{H}_{20} \mathrm{O}_{10}$. 324 .}

78. Cellulose is insoluble in water, dilute acids or alkalies, alcohol, ether, or oils. It is soluble in an ammonic solution of cupric oxide, and is precipitated from this solution in the form of colorless flakes.

Strong sulphuric acid, composed of four parts of acid and one of water, disintegrates it at ordinary temperatures without coloring it, and, after a time, changes it into dextrine. With iodine solution this disintegrated cellulose, before its passage into dextrine, gives a violet-blue color.

Quantitative estimation.-Cellulose is estimated quantitatively by freeing it as completely as possible from all other substances, and weighing the residue as pure cellulose; the best method yields results, however, that are about $\left.1^{\circ}\right|_{\text {o }}$ too high.

A quantity of 3 to 4 grms. of the substance is exhausted with water, alcohol, and ether, successively, as long as each of these solvents takes anything into solution, and is then macerated $10 \mathrm{or}^{\circ} 12$ days in a glass-stoppered bottle, at a temperature not above $15^{\circ} \mathrm{C}$., with $12 \mathrm{grms}$. of nitric acid (Sp. Gr. $=1.1)$, and $0.8 \mathrm{grm}$. of potassic chlorate; water is then added, the mixture is filtered, and the filter is well washed, first with cold and afterwards with hot water: the contents of the filter are then rinsed 
into a beaker and digested about an hour, at $60^{\circ} \mathrm{C}$., with ammoniacal water containing 50 parts of water to one of common ammonia; the mixture is filtered through a dried and weighed filter, the contents of the filter washed with the same ammoniacal water until the washings are colorless, then with pure water, with alcohol, and finally with ether, dried at $100^{\circ} \mathrm{C}$., and weighed.

This cellulose often contains as much as from 0.5 to 0.7 ${ }^{\circ} \%_{0}$ of albuminoids, and a very small per cent of inorganic matters.

\section{STARCII. $\mathrm{C}_{12} \mathrm{H}_{20} \mathrm{O}_{10} . \quad 324$.}

79. Starch, as long as it retains its natural form, is insoluble in water, alcohol, and ether. In contact with hot water the starch grains swell up, and, if a larger quantity of water is then added, a small portion of the starch remains in solution.

Starch may be converted into a soluble modification by boiling it with water under pressure, by heating it a short time with dilute sulphuric acid, or by the action of diastase at ordinary temperatures.

Dry starch is colored blue or black by a solution of iodine in potassic iodide. The color is destroyed by alcohol, potassa, or hydrosulphuric acid, or by heat; if not heated too long, the blue color reappears as the solution cools.

Quantitative estimation.-Starch is usually determined by conversion into glucose, either by malt or sulphuric acid, and the subsequent determination of the glucose with Fehling's solution.

1. By malt.-To prepare the extract of malt, crush 6 grms. of fresh malt in a mortar, digest with lukewarm water, filter, and wash the filter with water of $60^{\circ}$ or $70^{\circ}$, and divide the clear filtrate, after mixing it well with the washings, into two exactly equal parts. Mix a quantity 
of the substance to be examined containing about $\mathbf{2 . 5}$ grms. of starch with water, heat to $70^{\circ} \mathrm{C}$, add one of the portions of the extract of malt, put the other portion into another flask, and digest both precisely alike 3 or 4 hours on the water-bath, at a temperature of about $60^{\circ}$ or $70^{\circ}$ C. Then bring both liquids to about 200 c.c. by addition of water, add 20 c.c. of a solution of basic plumbic acetate $(\S 24, a)$ to each, shake vigorously, add water again until the volume of each liquid is exactly 500 c.c., at a temperature of nearly $15^{\circ}$, let the mixture stand until the solid matters settle, and then determine the glucose in an aliquot part of each liquid with the aid of the standard Fehling's solution ( $\S 81$ ). 10 c.c. of that solution correspond to $0.045 \mathrm{grm}$. of starch. The two liquids will contain equal quantities of glucose, produced from the malt; therefore, the difference between the amounts of glucose found in the two, or the corresponding difference between the amounts of starch, will be the amount of starch in the substance analyzed.

2. a. By sulphuric acid.-Dry the substance thoroughly, and digest a quantity of it, supposed to contain about 2.5 grms. of starch, 2 hours on the water-bath, with 50 times its weight of a dilute sulphuric acid, containing $1^{\circ} \%_{0}$ by volume of concentrated acid, then filter, and wash the residue on the filter carefully. This residue is composed mostly of cellulose. Dilute the filtrate and washings to 200 c.c., add about 16 c.c. of concentrated sulphuric acid, and digest again 7 or 8 hours on the water-bath, at $\mathbf{9 5}^{\circ}$, or until a drop of the solution gives no blue color with a solution of iodine. If the solution is highly colored, add 20 c.c. of plumbic acetate, shake vigorously, make the volume of the liquid up to 500 c.c., let the mixture stand if it is necessary to clarify the solution, and determine the glucose in the clear supernatant liquid with the standard Fehling's solution, 10 c.c. of which correspond to 0.045 grm. of starch $(\S 81)$. 
The process of previous digestion with a more dilute acid separates the starch more completely from the cellulose, the former being converted into the soluble modification, while the latter remains unchanged. (Krocker.)

b. Wolff's process.-Digest 2.5 to 4 grms. of the substance with 100 c.c. of water, and 12 to 16 drops of concentrated acid, 24 hours on the water-bath, then seal the liquid up in glass tubes and heat 12 hours in an oil-bath to $120^{\circ} \mathrm{C}$, , then dilute, decolorize with plumbic acetate, and so on as directed in $a$.

3. Dragendorff gives the following method for separating and determining starch and the other matters with which it is usually associated.

Pulverize about 2.5 grms. of the substance that has been dried at $100^{\circ}$, mix the powder with about 30 grms. of a solution of about 6 parts of potassic hydrate in 95 parts of absolute alcohol, and digest the mixture 24 hours at $100^{\circ} \mathrm{C}$. in a sealed tube, or in a flask that can be closed air-tight; filter the contents of the flask, while hot, through a dried and weighed filter, wash the residue thoroughly, first with hot absolute alcohol, then with cold alcohol of ordinary strength, and finally with distilled water, mixed with a little alcohol if gummy substances are present in notable quantity, dry the filter, first at $50^{\circ}$, and then at $100^{\circ}$, and weigh. The difference between this weight and that of the substance taken gives the amount of albuminoids, fat, sugar, and a part of the mineral salts.

The insoluble residue, with the filter tom in shreds, is heated with water containing $\left.5^{0}\right|_{0}$ of hydrochloric acid until a drop of the liquid gives no blue color with solution of iodine, the mixture is filtered again through a dried and weighed filter, dried at $100^{\circ}$, and weighed. The second loss of weight gives the amount of starch; it was converted into dextrine by the acid and dissolved out; a very small quantity of mineral matters might pass into solution also, and, if great accuracy is required, the 
amount of these can be determined by evaporating the solution of starch and inorganic salts to dryness, and incinerating the residue at a low red heat ( $\S 91$ ).

Or, the starch may be extracted with a concentrated solution of malt instead of with acid, in which case no inorganic salts will be taken into solution. Prepare the solution of malt and perform the operation as directed above.

If much mucus is present, a concentrated solution of sodic chloride mixed with $\left.5^{\circ}\right|_{0}$ of hydrochloric acid should be used instead of pure water and acid.

\section{GUM.}

89. The gums, which abound in the juices of plants, are very soluble in water, forming thick, viscid solution :; they are insoluble in alcohol.

Quantitative estimation.-This depends upon their insolubility in alcohol. A quantity of from 500 to 1000 c.c. of the aqueous extract of the substance in which the gum is to be determined is evaporated almost to dryness on the water-bath, and the moist residue is digested with alcohol of 80 to $85^{\circ} \%$ until it is no longer colored by matters taken into solution.

Sugar is dissolved, while gum, albuminoids, and some inorganic salts, remain unaffected; collect the insoluble substance on a dried and weighed filter, dry at $100^{\circ} \mathrm{C}$, and weigh. Then incinerate this residue at a low red heat ( $\$ 91)$, and subtract from the total weight of the residue insoluble in alcohol, the sum of the weights of the ash just determined, and the albuminoids, which are determined by another process ( $\S 85)$. The remainder may be considered as gum, mixed with some vegetable acids.

GLUCOSE. GRAPE SUGAR. $\mathrm{C}_{6} \mathrm{H}_{12} \mathrm{O}_{6} \mathrm{H}_{2} \mathrm{O} . \quad 180+18$.

81. This sugar is soluble in water, and somewhat soluble in aqueous alcohol. 
It is colored dark brown when heated with a strong solution of sodic hydrate.

If triturated with cold concentrated sulphuric acid, it is dissolved without being blackened.

If a concentrated solution of glucose is mixed with cobaltic nitrate and a small quantity of fused caustic soda, the solution remains clear on being boiled.

If baric hydrate is added to an alcoholic solution of sugar, a white precipitate is formed.

If a little caustic soda is added to a solution of glucose, and then, drop by drop, a dilute solution of cupric sulphate, a deep blue liquid is formed ; but after a few moments a yellowish or red precipitate of hydrated cuprous oxide is separated. A solution containing 0.00001 of glucose will give a notable red precipitate on the addition of soda and a few drops of cupric sulphate; 0.000001 of glucose in the solution gives a red tint to it with the above reagents.

Quantitative estimation.-This may be effected by making use of the delicate reaction just described. One equivalent of glucose will reduce ten equivalents of cupric oxide to cuprous oxide; if, then, we know the quantity of cupric oxide that has been reduced, we can calculate the corresponding amount of sugar. For this determination, a standard solution of cupric oxide containing an excess of alkali is commonly used, or Fehling's solution, as it is often called.

Dissolve 34.639 grms. of pure, crystallized cupric sulphate in about 200 c.c. of water ; make another solutionof 173 grms. of pure, crystallized potassic sodic tartrate in 480 c.c. of a solution of sodic hydrate (Sp. Gr. =1.14). Add the first solution gradually to the second, and dilute the mixture to 1000 c.c. Each 10 c.c. of this solution corresponds to $0.05 \mathrm{grm}$. of glucose. Keep the solution in small, well-stoppered bottles, in a dark place; the bot- 
tles should be filled to the top, so that no carbonic acid can be absorbed.

Before using the solution, boil about 10 c.c. of it with about 40 c.c. of water, or of a dilute solution of sodic hydrate if there is any reason to believe that carbonic acid has been absorbed; there should not be the least change in the liquid when subjected to this trial.

To perform the analysis, put 10 c.c. of the cupric solution in a porcelain dish, and add 40 c.c. of water, or of a solution of sodic hydrate if it was found necessary to add this in testing the solution; heat the mixture until it boils gently, and allow the sugar solution, which should be colorless and not acid, and should not contain more than $\left.{ }^{1}\right|_{2}$ to $\left.\left.{ }^{3}\right|_{4}{ }^{0}\right|_{0}$ of sugar, to drop in from a burette or a pipette, graduated into $\left.{ }^{~}\right|_{10}$ c.c., so slowly that the boiling will not be stopped. After the addition of the first few drops, the fluid shows a greenish-brown tint; as more sugar solution is added, the precipitate becomes more copious, acquires a reddish tint, and subsides more speedily; when it presents a deep red color, remove the lamp, allow the precipitate to settle, and give the dish an inclined position, so that the color of the supernatant liquid can be more readily distinguished over the white porcelain surface ; if no blue or bluish-green color is seen, probably enough of the solution of sugar has been added. To be sure, test a small portion of the clear liquid with a drop of the solution from the burette; if a yellowish-red precipitate appears on heating, which, at first, may look like a cloud in the liquid, pour the contents of the tube back into the dish again, and continue to add the sugar solution until the reaction is completed. Then the solution in the dish should contain neither copper nor sugar, nor a brown product resulting from the decomposition of the latter; filter off a portion of it while still hot; the filtered liquid should have no brown tinge; one portion, heated with a drop of the standard cupric solu- 
tion, should produce no change in it; another portion should give no red coloration or precipitate with potassic ferrocyanide, nor a black one with ammonic sulphide. If these tests do not indicate a satisfactory termination of the analysis, it should be repeated with a fresh quantity of 10 c.c. of the cupric solution.

The amount of solution of sugar required to reduce the cupric oxide in this quantity of the cupric solution contained $0.05 \mathrm{grm}$. of glucose.

Generally, the first result obtained is only an approximation; in the second trial, add at once nearly the whole amount of sugar solution required, and then test the liquid after each addition of two drops at a time.

(Freenius.)

\section{LEVULOSE. FRUIT SUGAR. $\mathrm{C}_{6} \mathrm{H}_{12} \mathrm{O}_{6}$.}

82. This sugar is very soluble in water and aqueous alcohol. It behaves like glucose with an alkaline cupric solution, and is determined quantitatively in the same manner.

SACCHAROSE. CANE SUGAR. $\mathrm{C}_{12} \mathrm{H}_{22} \mathrm{O}_{11}$. 342 .

83. This sugar is more soluble in water and aqueous alcohol than glucose.

It is not turned brown by strong alkaline solutions.

If triturated with cold concentrated sulphuric acid, it is turned black, and sulphurous acid is evolved.

If a concentrated solution of saccharose is mixed with cobaltic nitrate and a small quantity of fused caustic soda, and boiled, a violet-blue precipitate is formed. The presence of a very small quantity of glucose prevents the formation of this precipitate.

If sodic hydrate is added to a solution of saccharose, and a few drops of cupric sulphate, a deep blue solution is obtained that remains unchanged on standing in the cold; if the sodic hydrate is largely in excess, the solution can be boiled a short time without change. 
Saccharose is converted into glucose and levulose when heated with very dilute sulphuric acid, by treatment with yeast, or even by long boiling of its aqueous solution alone.

Quantitative estimation.-This may be effected by first converting the saccharose into glucose and levulose, and then determining the amount of these with the standard cupric solution.

The solution, containing about 2.5 grms. of saccharose, is diluted to about 250 c.c., 12 drops of concentrated sulphuric acid are added, and the mixture is heated 3 hours on the water-bath, with renewal of the water as it is evaporated $(\S 36)$. If, after this operation, the solution has a dark color, as may often be the case, add 20 c.c. of the solution of plumbic acetate $(\$ 24, a)$, shake the mixture well, dilute to exactly 500 c.c., let it stand awhile, and use the clear supernatant liquid for the determination of glucose $(\S 81)$.

If it does not need clarifying with plumbic acetate, neutralize the free acid with sodic carbonate, dilute to exactly 500 c.c., and determine glucose as above.

10 c.c. of the standard cupric solution correspond to $0.0475 \mathrm{grm}$. of saccharose.

In case a solution contains both glucose and saccharose, and it is desired to determine the amount of each, estimate the glucose at once by titration with the cupric solution; then convert the saccharose into glucose, as above, and titrate the solution again; the last determination gives the sum of the glucose originally in the solution and that which was derived from the saccharose.

\section{LACTOSE. MILIK SUGAR. $\mathrm{C}_{12} \mathrm{H}_{24} \mathrm{O}_{12}$.}

84. This sugar is soluble in water, but not in cold alcohol.

It reduces an alkaline solution of cupric oxide like glucose, but in a different proportion. It is converted into glucose by dilute acids. 
Quantitative estimation.-Convert it into glucose by digesting its solution about 2 hours with a little sulphuric acid, and then determine the glucose with the standard cupric solution.

10 c.c. of the solution correspond to $0.05 \mathrm{grm}$. of lactose.

\section{ALBUMINOIDS OR PROTEIN COMPOUNDS.}

85. Some of these substances are soluble in water, others are insoluble. Most metallic salts precipitate them from their solutions, or coagulate the solutions, as it is termed.

All of them are dissolved by boiling concentrated hydrochioric acid, and the solution takes a violet color if access of air is allowed.

All of them are colored yellow by concentrated nitric acid, and by iodine.

They are colored red by a solution of mercuric nitrate (Millon's test); this is the most delicate test for these bodies; albumen, dissolved in 100,000 parts of water, may be detected by this reagent.

If a small quantity of an albuminous substance is treated with dilute potassic hydrate, one or two drops of a dilute solution of cupric sulphate added, and more potassa until the mixture is alkaline, and the whole is well mixed together, a violet precipitate appears, which dissolves after a little agitation; in the presence of a carbo-hydrate, as sugar or starch, the color is bluish, and the blue tint is deeper, the more of the carbo-hydrate is mixed with the albuminoid. (Journal für Prakt. Chemie, 102, 376.)

When heated, these substances give off the odor of burnt horn or hair.

Distinctive reactions.-Albumen is precipitated when its neutral solutions are heated to $70^{\circ} \mathrm{C}$., or the solution is coagulated; if alkaline, the solution needs to be neutral- 
ized by acetic acid before this reaction can be obtained; if the solution is very dilute, the presence of albumen will be shown by a flocculent precipitate, or a mere turbidity, on being boiled. A solution of albumen is coagulated also by plumbic acetate or cupric sulphate, but not by acetic acid.

Cusein is not precipitated from its solutions by heat, except that a film is formed on the surface of the boiling liquid; it is precipitated by acetic and other acids, and the precipitate is soluble in an excess of acetic acid.

Fibrine is precipitated from its solutions spontaneously, when they are removed from the influence of vital forces.

Quantitative estimation.-As it is almost impossible to separate all of an albuminoid from its solution or fiom matters mixed with it, pure and unaltered, or in the form of any insoluble precipitate of a definite composition, the amount of albuminous matters in a substance is usually estimated from the amount of nitrogen in it.

Albuminoids contain, on an average, $\left.16^{\circ}\right|_{0}$ of nitrogen; therefore, the total weight of the albuminoid is $\frac{100}{16}=6.25$ times that of its nitrogen. Assuming, then, what is generally true, that all the nitrogen present in the dried plant is part of an albuminoid, we multiply the weight of nitrogen found in the substance by 6.25 for the weight of the albuminoids.

Determination of Nitrogen.-The method most generally applied in this case, as well as in agricultural analyses generally, is that of Varentrapp and Will, as modified by Peligot, in which the nitrogen is converted into ammonia by ignition with soda-lime, and the ammonia is absorbed by a measured quantity of a standard acid; the ignition is performed in a thick-walled tube of hard Bohemian glass, about $40 \mathrm{~cm}$. long, and $12 \mathrm{~mm}$. in diameter, drawn out into a slender beak at one end that is bent upwards. 
a. First clean and dry the tube thoroughly, and seal up the point of the beak; then put in the throat, where the beak widens out into the tube, a loose plug of freshly ignited asbestus; rinse the tube out with a little soda-lime, about half fill it with the same reagent, freshly ignited and still warm, empty this soda-lime into a warm, dry mortar, and mix intimately with it, by gentle trituration, without much pressure, a carefully weighed quantity of from 0.2 to $0.5 \mathrm{grm}$. of the fincly powdered and well-dried substance; the quantity to be taken depends upon the richness of the substance in nitrogen; fill about $3 \mathrm{~cm}$. of the tube with soda-lime, and transfer this mixture into it from the mortar, by scooping it up carcfully with the open end of the tube, over a sheet of dark-colored glazed paper ; carefully rinse the mortar and pestle into the tube with several small portions of the soda-lime, and finally, when the tube is filled to within about $4 \mathrm{~cm}$. of the end, close it with another plug of freshly ignited asbestus, and rap it gently on the table several times, in order to secure an open space in the upper part of it for the passage of gases.

$b$. In some cases, as in the analysis of Peruvian guano for example, the evolution of ammonia is liable to begin as soon as the substance and soda-lime are brought together. If there is danger of this, fill about $10 \mathrm{~cm}$. of the tube with soda-lime, which should be but very slightly warm, if at all, then put in the substance, fill $10 \mathrm{~cm}$. more with the reagent, and mix the two together as rapidly as possible by means of a wire, bent in the form of a corkscrew at the end; if this is moved backwards and forwards, and twisted round a few times, through the substance and the soda-lime, a very perfect mixture can be quickly made; before taking the wire out, put in about $10 \mathrm{~cm}$. more of soda-lime, and work the corkscrew back and forth through this to clean it, and then finish filling the tube as in $a$. 
With the aid of the burette, put 20 c.c. of the standard sulphuric acid in the bulbed tube $\mathrm{C}$ (fig. 5), and add water until the bulbs are about $\left.{ }^{1}\right|_{3}$ filled; the quantity of the liquid should not be so great, however, as to incur any danger of loss when the gases evolved from the combustion-tube pass rapidly through, or when, as sometimes

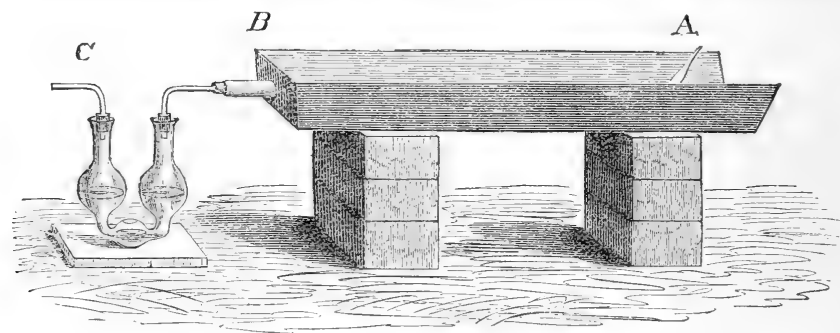

Fig. 5.

happens, there is a sudden retrograde current towards the combustion-tube at the close of the operation.

When the bulbed tube is properly filled, hold it so that the liquid rises higher in one arm than in the other, connect it with the combustion-tube by the soft, well-fitting cork, that has been already fitted to the small horizontal tube of the bulbed apparatus, and lay the combustiontube on a level table; if the connection is not tight, the acid will slowly assume the same level in both arms of the bulbed tube.

The apparatus being tight throughout, and a small furnace full of live charcoal coals being rearly, the combustion-tube is introduced into the iron combustion-furnace (fig. 5), so that only about $5 \mathrm{~cm}$. of the tube remains outside the furnace at $B$, and the whole is slightly inclined towards that end, so that any water, condensing in the small tube of the bulbed apparatus, will flow down into the bulb beyond.

A movable screen being placed over che tube in the funnace, about $8 \mathrm{~cm}$. from the end $B$, this end is surround- 
ed with fresh, live coals, large coals being used to bridge over the top, in order that there shall be no weight there on the tube when softened by heat, to bend it inwards and close the passage above the soda-lime.

When this part of the tube is red-hot, move the screen along about $8 \mathrm{~cm}$., and apply more coals in the same manner as around the first $8 \mathrm{~cm}$. of the tube.

When that part of the tube is approached, where the mixture of soda-lime and substance is contained, care must be exercised in applying the coals, so as not to have too rapid an evolution of the gas; there is little danger that any ammonia will pass through the acid unabsorbed, but it will be safer not to have so rapid a flow of gases that the bubbles in the bulbed apparatus cannot be counted; nevertheless, a continuous current should be maintained, and, all the while, the front end of the tube must be kept well heated by supplying fresh coals as often as is necessary.

When the tube has been heated throughout, and quite intensely around the mixture of substance and soda-lime, and the passage of bubbles through the acid has ceased, break off the point of the beak at $\mathrm{A}$, and draw a considerable quantity of air through the whole apparatus by applying suction at the mouth of the bulbed tube, in order to carry all ammonia remaining in the combustiontube into the acid; disconnect the bulbed tube from the other, add a little cochineal, and then the standard sodic solution until the acid is almost neutralized, empty the contents of the bulbs into a beaker, rinse with a little water, and finish the titration ( $\$ 45)$.

For each cubic centimetre of the acid that was neutralized by the ammonia set free, the substance analyzed contained $0.014 \mathrm{grm}$. of nitrogen.

When very great accuracy is required, the ammonia shouid be collected in hydrochloric acid, oily matters filtered out, if any are seen in the acid after the combustion 
is finished, the bulbs rinsed out with alcohol, and the ammonia determined with the aid of platinic chloride $(\S 47, a)$.

If the substance is very rich in nitrogen, it must be mixed with an equal quantity of pure sugar, in order to avoid the danger of an impetuous retrograde current in the bulbed tube, when the evolution of gas ceases and the whole apparatus is filled with ammonia-gas.

UREA. $\mathrm{CH}_{4} \mathrm{~N}_{2} \mathrm{O} .60$.

86. Urea is very soluble in water and alcohol, but difficultly soluble in ether.

Reactions. - When heated it gives off ammonia.

Nitric or oxalic acid causes the formation of a white precipitate in concentrated solutions of urea.

Quantitative estimation.-The volumetric method of Liebig, with mercuric nitrate, is easily and quickly executed and yields accurate results.

To prepare the standard solution of mercuric nitrate, heat an excess of mercury with concentrated nitric acid, concentrate the solution, and, on cooling, crystals of mercurous nitrate will be deposited; pour off the motherliquor, wash the crystals, first with dilute nitric acid, and then with cold water, dissolve them in pure nitric acid, and heat the solution until a drop of it gives no precipitate or turbidity with sodic chloride; evaporate the solution on the water-bath to the consistency of a syrup, dilute it with 10 volumes of water, let it stand 24 hours, and filter if any precipitate is formed.

To determine the strength of this solution, dissolve 10.864 grms. of pure, ignited sodic chloride in 1 litre of water; dilute 10 c.c. of the mercuric solution with 90 c.c. of water, put 10 c.c. of this diluted solution in a small beaker, add 4 c.c. of a cold saturated solution of sodic phosphate, and quickly, before the precipitate caused by this reagent has time to become crystalline, allow the so- 
lution of sodic chloride to flow in from a burette with constant stirring, until the precipitate disappears, and the solution becomes clear again. Each cubic centimetre of the sodic solution required corresponds to $0.02 \mathrm{grm}$. of mercuric oxide; on the basis of this determination, then, the amount of mercuric salt in the diluted solution, and the strength of the concentrated solution, can be estimated.

Now, to bring the mercuric solution to a urea standard, it must be diluted so that 1 litre will contain $\% 2 \mathrm{grms}$. of mercuric oxide; dilute the solution almost to this point, and then compare it with a solution of urea of known strength. For this purpose, dissolve 2 grms. of pure urea, dried at $100^{\circ} \mathrm{C}$., in water, dilute the solution to 100 c.c. and put 15 c.c. of this solution in a beaker; in another small beaker, wash a few crystals of sodic bicarNonate with a considerable quantity of cold water, and, after pouring this off, add just enough water to make a thin paste with the salt; have ready also a piece of clean glass, with its under surface coated with asphaltum varnish.

Now, allow the mercuric solution to flow slowly from the burette into the solution of urea, with the addition from time to time of a small quantity of dry sodic carbonate, in order to nearly, but not quite, neutralize the nitric acid that is set free; the solution must all the while have a slight acid reaction. To ascertain whether all the urea is precipitated, transfer a drop of the solution, on the end of a glass rod, to the glass plate, and cover it with a drop of the paste of sodic bicarbonate; if no yellow color appears in a few seconds, wash the test-drop back with the smallest possible quantity of water, and, after adding a little more mercuric nitrate, test again with the sodic bicarbonate; the first trace of a yellow color, that appears as soon as the two drops come together, indicates that sufficient mercuric chloride has been added. The standard mercuric solution is to be diluted so that 1 cubic centimetre corresponds to $10 \mathrm{mgr}$. of urea, or to 
0.5 c.c. of this solution of urea of known strength that has been prepared.

M. Byasson (Chemical News Amer. Repr., 4, 143) prepares this standard solution by dissolving exactly 72 grms. of pure red oxide of mercury, or mercuric oxide, in 100 grms. of nitric acid diluted with half its weight of water, evaporates the solution at a gentle heat until acid vapors appear, and then makes the volume up to one litre at $15^{\circ} \mathrm{C}$; if the dilution causes a slight turbidity, a few drops of nitric acid will remove it. In this way, he states, a solution will be obtained in which all the mercury is present as mercuric nitrate, and with as small an excess of acid as possible; while, if prepared by dissolving mercury in nitric acid, it is liable to contain mercurous nitrate.

As this mercuric solution is also to be used, in analyses of urine, to determine the sodic chloride, it should also be titrated with reference to this. Take 10 c.c. of a solution of sodic chloride containing $\left.2^{0}\right|_{0}$ of the salt or 0.2 grm., add to it 3 c.c. of the standard solution of urea, prepared as above, and 5 c.c. of a cold saturated solution of pure sodic sulphate, and allow the mercuric solution to flow from the burette into this mixture with constant stirring, until there is a permanent turbidity in the liquid; the amount of mercuric solution required for this corresponds to the 0.2 grm. of sodic chloride; calculate the amount of sodic chloride that corresponds to 1 c.c. of the standard mercuric solution, and mark it on the label of the bottle.

For the determination of urea in a solution containing it and free from phosphoric and hippuric acids, proceed with 15 c.c., as directed for determining the standard of the solution with reference to urea, after having first determined the sodic chloride, which is commonly present, by the amount of the standard solution required to produce permanent turbidity; use the dry sodic carbonate to maintain the neutrality of the solution, the paste of the 
bicarbonate to ascertain the point of saturation with mercuric chloride, and so on in the manner already described.

The results obtained, however, must be corrected for very dilute or very concentrated solutions of urea, since the standard mercuric solution is adapted for such solutions only as contain $\left.2^{\circ}\right|_{0}$ of urea; if the solution is more concentrated than this, the yellow color appears prematurely; if more dilute, it does not appear so soon as it - should.

If the reaction indicating saturation was obtained with 10 c.c. or less of the mercuric solution, subtract the product of 0.08 into the whole number of cubic centimetres required, from this total quantity ; if the reaction was obtained with less than 15 c.c. but with more than 10 c.c., subtract also, in addition to the above product, the product of 0.06 into the number of cubic centimetres required above 10 ; if more than 15 c.c. were required, but less than 20, subtract also, from the total amount used, the product of 0.04 into the number of cubic centimetres above 15 , in addition to the above two products. (Rautenberg, Fies. Zeitschrift, 4, 500.) The final remainder, multiplied into 0.01 , will give the amount of urea in the 15 c.c. of solution tested.

In case the solution is more than $\left.2^{\circ}\right|_{0}$ strong, then more than 30 c.c. of the standard mercuric solution will be required; for each cubic centimetre of the standard solution used above 30 c.c., ${ }^{1}{ }_{2}$ c.c. of water must be added to the mixture, before taking ont a sample drop to be tested with the paste of sodic carbonate.

\section{FATTY SUBSTANCES.}

8\%. Fats are insoluble in water, somewhat soluble in strong alcohol, and very soluble in ether.

(9)uantitative estimation.-This is effected by heating the finely divided substance with $2-3$ volumes of ether 
(Sp. Gr. = 0.7\%), evaporating the etherial solution of fat to dryness, and weighing the residue.

Several portions of ether must be used, and the extraction is best conducted in a flask provided with tubes like a washing-bottle, and which is connected with the lower end of a Liebig's condenser ( $\$ 36)$.

The extraction may not be considered as ended until a drop of the last filtrate leaves no residue when evaporated on a watch-glass. The solutions, if not perfectly clear as they came from the filtering flask, should be filtered through pape:. The chlorophyll in the green parts of plants goes into solution with the fat, but it may be removed by filtration through bone-black.

The clear etherial extracts may be collected in a graduated cylinder, and the fat determined in an aliquot part of the well-mixed liquid by evaporation to dryness, drying the residue at $100^{\circ} \mathrm{C}$, and weighing.

ALCOHOL. $\mathrm{C}_{2} \mathrm{H}_{6} \mathrm{O} .46$.

88. Alcohol is miscible wîh watcr in all proportions.

Quantitative estimation.-This is effected by distilling the alcohol off, and estimating it in the distillate by the specific gravity.

a. To 10 c.c. of the solution to be examined, which must contain no free volatile acid, as acetic, for example, add its volume of water, and subject the whole to distillation in a small flask connected with a small Liebig's condenser. Collect the distillate in a specific-gravity bottle with a mark on it, indicating a capacity of 10 c.c. When somewhat less than half the liquid has been distilled over, remove the specific-gravity bottle from the tube of the condenser, bring the temperature of the distillate to $15^{\circ} \mathrm{C}$., fill up to the mark with water, and weigh. Knowing the weight of 10 c.c. of water at this tempera- 
ture (weight of 1 cubic centimetrc $=0.999183 \mathrm{grm}$. ), we can calculate the specific gravity of this distillate, that contains all the alcohol that was in the liquid examined, and from Table V, learn the per cent of alcohol in the distillate. Then the per cent of alcohol by weight in the solution examined is readily calculated if the weight of 10 c.c. of that solution is known.

Griffin, in his examination of wines (J. J. Griffin, Chemical Testing of Wines and Spirits), used 25 c.c. of the alcoholic liquid, adder its volume of water to it, made the volume of the distillate up to 50 c.c., and determined its specific gravity.

If the substance to be examined contains free acetic acid, add a little soda to the liquid before distillation. The distillate should have no acid reaction.

b. The alcohol in a wine may be approximately estimated by evaporating a measured quantity to about half its bulk, adding water until the original volume is restored, and determining the specific gravity of this liquid; then subtract the number by which this specific gravity is greater than one, from the specific gravity of the alcoholic liquid itself, and take the remainder as the specific gravity of the mixture of alcohol and water in that liquid, and get the per cent of alcohol corresponding to this specific gravity from Table $\mathrm{V}$. To illustrate the principle, suppose a wine is examined whose specific gravity equals 0.9951 ; after evaporation down to one-half, and adding water until the original volume is restored, the specific gravity is 1.0089 .

$$
0.9951-0.0082=0.9869 .
$$

Against the specific gravity of 0.9882 in the table, the per cent of alcohol is found to be 8 . 


\section{CHAPTER IV.}

Spectal Methods of Analysis.

COURSE OF QUALITATIVE ANALYSIS.

89. The following course of analysis is designed as a general guide in qualitative analytical work. Only a single reaction for each substance is mentioned in it, and that is generally the most delicate one; for fuller details in regard to this particular reaction, and for a few other ones that may in some cases be applied as confirmatory tests, the student is referred to Chapter III.

He should, before undertaking to work with the aid of this course, thoroughly familiarize himself, by actual observation, with the behavior of the different acids and bases with reagents, so that he may know what is indicated by any particular reaction, the moment he sees it.

The mode of working with the aid of the scheme given below is best explained by an example. Suppose we have a solid containing $\mathrm{Cl}, \mathrm{P}_{2} \mathrm{O}_{5}, \mathrm{SO}_{3}, \mathrm{~K}, \mathrm{Fe}$, and $\mathrm{Mn}$. Beginning with 1 in the left-hand column of figures, in the course for the detection of the acids, the first question is, whether the substance is a solid or a solution. It being the former, we are referred, in the right-hand column of figures to 2 ; going then to 2 , in the left-hand column, we find that the solubility of the substance is to be tested; we apply the solvents in the order there indicated, and find that it is soluble in dilute nitric acid, when we are referred to 6 ; going to 6 , in the left-hand column, we get no gritty resiche on evaporation to dryness, and therefore no silicic acil is present; passing on to $\%$, to which we are referred next, we ges no such reaction as is dc- 
scribed there, nor such as in 8 ; therefore, carbonic acid and sulphur are absent; we do get, however, the fine white precipitate as described in 9, and note sulphuric acid as present; we also get a yellow precipitate in 10 , and malie a note of phosphoric acid as present; we do not get the reaction in 11 , but get a white precipitate in 12, the formation of which, under the circumstances, indicates that cyanogen, iodine, ferrocyanogen, or chlorine, may be present; a precipitate would be given also by sulphur, if that were present, but the test for this element has already been made; we do not find the first three substances named above, and learn in 16 that, consequentiy, chlorine is present; we find no nitric acid in 17, and, as the substance is not blackened when heated as directed in 18 , no organic acids are present, and we have finished the examination for the acids.

Passing to the detection of the bases, we have the question in 1 already answered for us, with this small difference, that, in the examination for the bases, a hydrochloric-acid solution is preferable to a nitric-acid solution; going on to 3 , we add sulphuric acid, and get no reaction, even after the mixture of substance and reagent has stood some time; no lead or barium, and, at the most, only traces of calcium, can be present; passing on to $\gamma$ we find no ammonium; we get the violet color, indicating potassium, in 9, after having properly prepared the solution as directed in 8; and so working on, we find no copper in 10 , but do get iron in 11, and manganese in 15 , and after that, nothing more before reaching the end of the course.

It will be noticed that sulphuretted hydrogen and ammonic sulphide, and also the blowpipe, are used but little or not at all in this course of analysis; there are sufficiently good reasons why their use should be dispensed with, if it can be done without impairing the reliability of the work.

The plan of the course for the bases corregponds in the $6^{*}$ 
main with that of Zettnow. (Poggendorf's Annalen, 103, 324.)

The attention of the analyst is called to Table $\mathrm{X}$, where the average and extreme composition of agricultural materials and products are given; by consulting this table he can ascertain what he may expect to find in any substance under examination, that is used in, or produced by, agriculture, and whether or not he must needs work with special care, or with large quantities of the substance, in order that a small quantity or traces of any element or compound shall not escape detection.

\section{A.}

DETECTION OF ACID ELEMENTS AND ACIDS.

1. a. The substance is a solution; this solution will

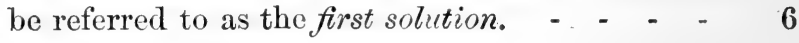
b. Not a solution. - $\quad$ - $\quad$ - $\quad$ - $\quad$ - $\quad$ - 2

2. $a$. The substance is soluble in water, or in dilute or concentrated nitric or hydrochloric acid; this solution will be referred to as the first solution. $\quad-6$

$b$. It is partially soluble in water or acids, as indicated by the residue left undissolved even after heating, and by the distinct residue left on evaporation of a drop of the solvent with which the substance has been treated. Treat a larger portion of the finely divided substance with another portion of the solvent, filter, and mark the filtrate F 2. With the contents of the filter go to - - - - 3

c. It is quite insoluble in water or acids. - - $\quad 3$

3. A portion of the insoluble substance, in the shape of a very small fragment, if possible, rather than a fine powder, is fused for a considerable time in a bead of phosphorus-salt on platinum wire; the 
fragment is not entirely dissolved, but remaius visible in the bead, retaining its original form. Also, when the substance in powder is fused in a bead of sodic carbonate on the platinum wire, the bead froths, carbonic acid being set free. Both these reactions together indicate Silrcic. - - $\quad 4$

4. A small portion of the original substance, finely pulverized, is made into a paste with concentrated sulphuric acid in a leaden tray, the tray is covered with a picee of Bohemian glass coated with wax, and from which the coating has been removed in a few places with a sharp-pointed instrument, and the whole is gently heated for about a half an hour. The glass is found to be corroded where the wax was removed (see $\$ 68$ ). Fluorine. -

5. The insoluble substance has black particles in it, that are entirely or partially consumed when heated on platinum foil. (Coal.) Carbor. - - -

6. Evaporate a portion of the first solution or of $\mathrm{F} 2$ to dryness, after adding hydrochloric acid, if not already present, ignite the residue gently, moisten it with concentrated hydrochloric acid, let stand a short time, add considerable water, and digest the mixture. A white powder, or perhaps a reddish one if much iron is present, remains undissolved, that feels gritty under the glass rod. Soluble Silicic

\%. The addition of dilute sulphuric acid to a small quantity of the original substance causes effervescence, that accompanies the evolution of a colorless gas; a drop of lime-water, suspended on the end of a glass rod, and held above the liquid in the test-tube, is made turbid. Carbonic. - - - -

8. In the same experiment a colorless gas is evolved, having an offensive odor, and blackening a piece of 
moistened lead-paper that is held in the month of the tube. (Hydrosulphuric.) Sulpirur. - - -

9. The first solution, or $\mathrm{F} 2$, after acidification with hydrochloric acid, if not already acid, gives a white, finely pulverulent precipitate with baric chloride. Sulphuric.

Sulphuric acid may be found also in the insoluble substance in the course of the examination for bases.

10. If a very small quantity of the solution of the substance is added to ammonic molybdate, a pale yellow precipitate is formed, at cnce, or after some time, a part of which adheres strongly to the sides of the tube; the precipitate is soluble in ammonia. Phosphoric.

11. To a portion of the hot solution, containing a slight excess of acid, add about twice its volume of alcohol, and then dilute sulphuric acid or ammonic sulphate, and filter if any precipitate is formed, heat the filtrate until the alcohol is expelled, add ammonia in slight excess, and then acetic acid until the ammonia is more than neutralized, and finally calcic sulphate. A fine white precipitate appears, at once, or after some time. Oxalic.

12. To a small portion of the dilute nitric acid solution of the substance, or of the aqueous solution acidified with nitric acid, add argentic nitrate.

$a$. No precipitate is formed. (Traces of cyanogen or iodine may perhaps be found by applying the tests in $12 b$, and 13.)

b. A precipitate is formed.

Treat a small portion of the original substance with a little dilute sulphuric acid, in a watch-glass, and quickly invert another watch-glass, with a 
drop of ammonic sulphide, saturated with sulphur, in its centre, over the first one; after a few minutes evaporate this drop of ammonic sulphide to dryness with a gentle heat, and moisten the dry residue with ferric chloride. A deep red color appears. Cranogen. - $\quad$ - $\quad$ - 13

13. To a portion of the aqueous solution or extract of the substance, add two or three drops of potassic dichromate, or enough to give a pale yellow color to the liquid, and then a few drops of concentrated hydrochloric acid. A drop of this mixture on starch-paper colors it blue. Iodrve. - - - 14

14. A portion of the first solution gives, with ferric chloride, a deep blue precipitate, unaffected by dilute acids, but decomposed by sodic hydrate with the conversion of the blue color into a reddish one. Ferrocyanogen. - $\quad$ - $\quad$ - $\quad$ - $\quad$ - 15

15. a. No very decided reaction was obtained in 12 for cyanogen

b. A decided reaction was obtained for cyanogen. To the dilute nitric acid extract of the substance, or the aqueous extract acidified with nitric acid, add argentic nitrate as long as a precipitate is formed, filter, wash the precipitate a little, dry it, and ignite it gently in a porcelain crucible until it is fused, pour a little water and a few drops of dilute sulphuric acid over the fused mass after it is cool, put a piece of zine in contact with it, and let the whole stand some time; finally filter, acidify the filtrate with nitric acid, and add argentic nitrate.

a. No precipitate. - - - - - $\quad$ - 17

b. A white precipitate is formed; no iodine or ferrocyanogen has been found. Chlorine. - - 17 c. A precipitate is formed, but it is not white, 
or iodine or ferrocyanogen has been found. - $\quad 16$

16. $a$. The precipitate in 12 was white, and no cyanogen, iodine, or ferrocyanogen, has been found. Chlorine.

b. Not white, or one or more of these substances was found; treat the precipitate obtained in 15 , or, if cyanogen was absent, that obtained in 12, with ammonic hydrate, filter, and add dilute nitric acid to the filtrate until acid reaction. A white precipitate appears, which, if abundant, collects in curdy flakes on agitating the mixture. Chlorine. 17

1\%. Treat a portion of the original substance with a little dilute sulphuric acid if it is a solid, or with concentrated acid if it is a solution, add copper turnings, and heat the mixture. Red fumes are evolved, which may be more readily perceived on holding the tube over white paper, and looking through it lengthwise. Nitric.

18. a. A portion of the solid substance, when quickly heated to a high temperature on platinum foil, is blackened, with separation of carbon, and an odor of barning organic matter is given off.

b. Not blackened. Absence of acetic, tartaric, and other organic acids. Finis. - - - - B.

19. A portion of the solid or solution gives acetic ether when heated with concentrated sulphuric acid and alcohol; the pleasant aromatic odor of this ether may be most readily distinguished from that of common ether, which is formed at the same time, after the liquid has become quite cold. Acetic.

20. To a portion of the first solution, that must be tolerably concentrated, add ammonia until it is faintly alkaline, filter if not clear, add a little ammonic 
chloride, then calcic chloride, agitate the mixture vigorously, and let it stand 10-20 minutes.

a. No precipitate is formed. - - - - $\quad$ - 21

7. A white precipitate is formed; filter, and mark the filtrate F. 20. Digest the precipitate in the cold, with sodic hydrate, with fiequent agitation, dilute, filter, and boil the filtrate. A white gelatinous precipitate is formed; test it with ammonia and argentic nitrate (§ 71). TARTARIC. - $\quad 21$

21. To F. 20, or to the clear mixture of original solution and ealcic chloride obtained in 20 , add considerable alcohol.

a. No precipitate. Finis. - - - - B.

b. A white precipitate is formed; filter, wash the precipitate with a little alcohol, dissolve it in a small quantity of dilute hydrochloric acid, add ammonia in slight excess, and boil the liquid some time.

ac. No precipitate.

bb. A white precipitate is formed; filter the liquid while boiling hot, and mark the filtrate F. 21. Dissolve the precipitate on the filter in a very little dilute hydrochloric acid, add ammonia in slight excess, and boil this mixture. A similar white precipitate is formed again. Ciтric. - - -

22. F. 21, or the solution obtained in 21 that gave no precipitate on boiling, may contain malic acid. Add considerable alcohol to it.

a. No precipitate is formed. Finis. - - B b. A white precipitate is formed. Probably Matrc. To be sure, treat the precipitate with acetic acid, add alcohol, filter the liquid if not clear, add plumbic acetate to the filtrate, and ammonia until the liquid is neutral, filter out the precipitate, wash it, 
suspend it in water through which a current of sulphuretted hydrogen is passed, filter, evaporate the filtrate to dryness on the water-bath, and heat the residue, supposed to be malic acid; maleic acid should be formed (\$ 73). - - _ - B.

B.

DETECTION OF THE BASIC ELEMENTS.

1. a. The substance is a solution, or it is soluble in water, or dilute or concentrated hydrochloric or nitric acid. This solution will be referred to as the first solution.

b. Not soluble, or only partially soluble; separate the soluble from the insoluble part by filtration; this filtrate will be referred to as the first solution.

2. This insoluble substance was found, in the examination for acids, to consist entirely of carbon.

Not. Dry it, mix it intimately with four parts of potassic and sodic carbonate, and a little sodic nitrate, fuse the mixture 10-20 minutes on platinum foil, and exhanst the fused mass with hot water; decant off this aqueous extract, wash the residue once or twice by decantation, then treat it with very dilute hydrochloric acid, and evaporate the mixture to dryness; moisten this second residue with concentrated hydrochloric acid, and, after a while, add water, heat, and finally separate this acid solution from the insoluble silica, by filtration.

Acidify the aqueous extract of the fused mass, obtained above, with hydrochloric acid, and test a small portion of it for sulphuric acid with baric chloride; if a fine white precipitate is formed, and lead or barium is subsequently found among the 
basic elements, the insoluble sibstance was composed, at least in part, of plumbic or baric sulphate; if lead or barium is not found, but calcium is, then the insoluble substance consisted, at least partly, of calcic sulphate, which requires considerable water or dilute acid for its complete solution; if no sulphuric acid is found, the insoluble substance contained only silica or silicates, besides, possibly, a fluoride and carbon.

Mix the acid solution, filtered from the silica as above, and the remainder of the aqueous extract together, and without filtering out any precipitate that may be formed, proceed with the analysis as in 3 , if it is desired to analyze this solution separately, in order to ascertain the composition of the insoluble part of the suibstance; but it will not be found, in any case, to contain arsenic or ammonium, nor will copper or zine be likely to be found in it, and not in any case unless it contained silica ; lead and barium may be present as sulphates, and the latter possibly as a silicate.

Potassium and sodium cannot, of course, be tested for in this solution; if it is desired to examine the insoluble substance with respect to the presence of these metals, the silicate must be attacked with hydrofluoric acid or a fluoride, in the manner directed for the quantitative analysis of silicates. $(\S 58, c$.

If it is not necessary to analyze this solution separately, it may be mixed at once with the first solution, reserving, however, a portion of this latter for the examination for the alkaline metals. - - 3

3. Heat a portion of the nearly nentral, first solution to boiling, add to it about its volume of alcohol, or twice its volume if the solution is very dilute, 
and then add dilute sulphuric acid as long as a precipitate is formed.

a. No precipitate is formed, even after vigorous agitation and some time; expel the alcohol from the liquid by boiling it a few minutes, and mark it F. 3.

b. A white precipitate is formed; let the mixture stand awhile, filter the liquid while hot, boil the filtrate a few minutes to expel the alcohol, and mark it F. 3.

4. Agitate the precipitate obtained in 3 vigorously with considerable water, filter, and add ammonic oxalate to the clear filtrate. A white precipitate indicates CALCIUMr.

5. Treat the contents of the filter in 4 with ammonic tartrate, heat gently, filter, acidify the filtrate with acetic acid, and add a little potassic dichromate. A yellow precipitate indicates Lead. - 6

6. Wash the residue on the filter in 5 well, boil it about 10 minutes with 8-10 times its bulk of sodic carbonate, add water, filter, wash the contents of the filter very carefully, pour a little dilute hydrochloric acid over this residue, and add calcic sulphate to the solution that passes through. A fine white precipitate, or a turbidity, indicates Barrum.

$\%$ Put about a third of F. 3, or a corresponding amount of the first solution, into a small flask, add baric hydrate as long as it gives a precipitate, and then a little more, so as to be sure of an excess, heat the mixture, and hold a picee of moistened red litmus-paper or yellow turmeric-paper in the tube. The paper is colored blue or brown. AxMONIUMr.

8. Heat the mixture in 7 until all or nearly all the ammonia is expelled, filter, add a little baric hy- 
drate to the filtrate, to be sure that no further precipitation will be produced, then add ammonic carbonate as long as a precipitate is formed, avoiding, however, a great excess of the reagent, heat and filter, and evaporate the filtrate nearly to dryness.

A drop of this filtrate, evaporated to dryness in the platinum wire loop, gives a yellow color to the flame of a Bunsen's gas-burner. Sodrusr. - - -

9. In a similar experiment the flame is violet, or violet-red when seen through blue glass. Potassium. 10

10. To a small portion of F. 3, add ammonia very carefully until the free acid is just neutralized, and then a little ammonic sulphide, drop by drop, with constant agitation, and heat the mixture.

$a$. No precipitate is formed at any time.

(Traces of copper, arsenic, iron, and manganese, may perhaps be found by applying the tests described in $10 \mathrm{~b}, 12,14$, and $15 \mathrm{~b}$ ).
b. A precipitate is formed.

To a small portion of F. 3, add ammonia until the well-mixed liquid smells strongly of the reagent, and let the precipitate settle if any is formed. The clear supernatant liquid is blue. Copper. - - $\quad 11$

11. In the same experiment a red flocculent precipitate is obtained, the color of which may, however, not appear, in case much copper is present, until it has been collected on a filter and washed a few times. Irox.

12. If copper has been found in notable quantity, put the remainder of F. 3 in a small flask, add two or three pieces of pure zinc, and close the flask with a perforated cork, in which is a glass tube drawn out to a fine jet. 
If copper was not found, take only a small part of F. 3 for this trial.

Care must be taken not to inhale the gas from the flask, if there is any reason to suspect that arsenic is present.

After the hydrogen has been erolved a few minutes, wrap a towel around the flask, ignite the jet of gas, and hold a cold porcelain surface in the flame. Black lustrous spots are deposited on the porcelain surface where the flame comes in contact with it. Arsenic.

13. a. Copper was not found, and only a small portion of F. 3 was taken for the test in 12. - - - $\quad-14$

b. Copper was found, and a large portion of F. 3 is under examination. Allow the action of the zine to continue 10-15 minutes, or until all the copper is precipitated; a much longer time may be required if the solution contains a notable quantity of nitric acid ; finally filter the liquid from the precipitated metal, and mark the filtrate F. 13. - - 14

14. Add a little nitric acid to a portion of F. 13 , or of F. 3, if there is no F. 13 and the first solution did not already contain free nitric acid in excess, and heat the mixture to boiling.

a. An unmistakable reaction for iron was obtained in 11 .

b. Not. To a small portion of this solution add potassic sulphocyanate. A deep red color appears. Irox.

15. To a large pertion of the solution obtained in 14, add ammonic carbonate in excess.

a. The precipitate which may have been formed at first is entively re-dissolved by the excess of the reagent, and the solution remains quite clear, even after a hot digestion of 12 hours. 
b. Not. Filter the precipitate out, wash it with hot water, dry a large portion of it, and mix it intimately with three or four times its bulk of a mixture of equal parts of potassic and sodic carbonate, and of potassic or sodic nitrate, and fuse the mixture well on platinum foil. The fused mass is bluish green. MaNGaNese.

If the substance contains little or no copper or iron, this reaction for manganese may sometimes be obtained with the original substance, when not obtained here $(\S 53)$.

16. Boil the fused mass on the platinum foil with two or three cubic centimetres of water, until it is loosened from the foil, filter, add dilute nitric acid to the filtrate, drop by drop, as long as any effervescence is produced, and then add ammonia very slowly and carefully, until, after stirring well, the liquid has a faint alkaline reaction; heat the mixture a few minutes, and let it stand a long time in a warm place, if no precipitate appears at first. A white flocculent precipitate is formed, at once, or after some time. Aluminium.

1\%. To another portion of the first solution add sodic hydrate in excess, boil, and filter; to the filtrate add a few drops of ammonic carbonate, and then ammonic chloride in excess, boil the mixture as long as any odor of ammonia is giren off, and a portion of the filtered liquid gives no further precipitate on being boiled still more; filter the whole, and add potassic ferrocyanide to the filtrate. A white precipitate or a turbidity appears. Zinc. 18

18. $a$. The substance contains no phosphoric acid, or only: traces of it.

$b$. It does contain a notable quantity of this acid. Add ferric chloride to another portion of F. 13, or 
to a corresponding quantity of F. 3 , if there is no F: 13, until a drop of the mixture gives a reddish precipitate with ammonia.

19. To the solution to which $\mathrm{Fe}_{2} \mathrm{Cl}_{3}$ has been added (18), or to the remainder of the filtrate F. 13, if no $\mathrm{P}_{2} \mathrm{O}_{5}$ was present in the substance, or to a corresponding quantity of $\mathrm{F} .3$, if there is no $\mathrm{F} .13$, add ammonic carbonate until a slight permanent precipitate remains after vigorous stirring; if no precipitate appears, the reagent may be added until it is in slight excess, and the solution is faintly alkaline.

a. No ferric salt has been added to the solution, and it remains quite clear, or only a fine white precipitate is formed after boiling it.

b. A flocculent precipitate is formed; heat the solution to boiling, add a boiling solution of sodic acetate as long as a precipitate is formed, and filter the hot liquid immediately; mark this filtrate F. 19.

20. a. Calcium has been found.

b. Not. To test for traces of the metal, add ammonic sulphide to the filtrate from the precipitate by sodic acetate, or, if this precipitation was not found to be necessary in 19 , to the liquid containing ammonic carbonate in slight excess, after acidification with acetic acid if not clear, filter out any precipitate that may be formed, and add ammonic chloride and oxalate to the filtrate; a fine white precipitate, insoluble in acetic acid, indicates $\mathrm{C}_{\boldsymbol{\Lambda} \mathbf{L}}$ crusr (traces).

21. Add ammonic chloride and carbonate to F. 19, or to the liquid already containing ammonic carbonate in slight excess, and which gave no flocculent precipitate with the reagent, boil the mixture, fil- 
ter, add ammonia in excess to the clear and cooled filtrate, filter again if this reagent produces any precipitate, add hydric disodic phosphate to the filtrate, agitate the mixture vigorously, and set it aside for several hours if no precipitate appears at first. A white crystalline precipitate appears, that, if formed slowly, adheres to the sides of the tube; with the magnifying glass, and usually with the unassisted eye, the crystals are seen to be slender prisms. Magnesium.

Finis. 


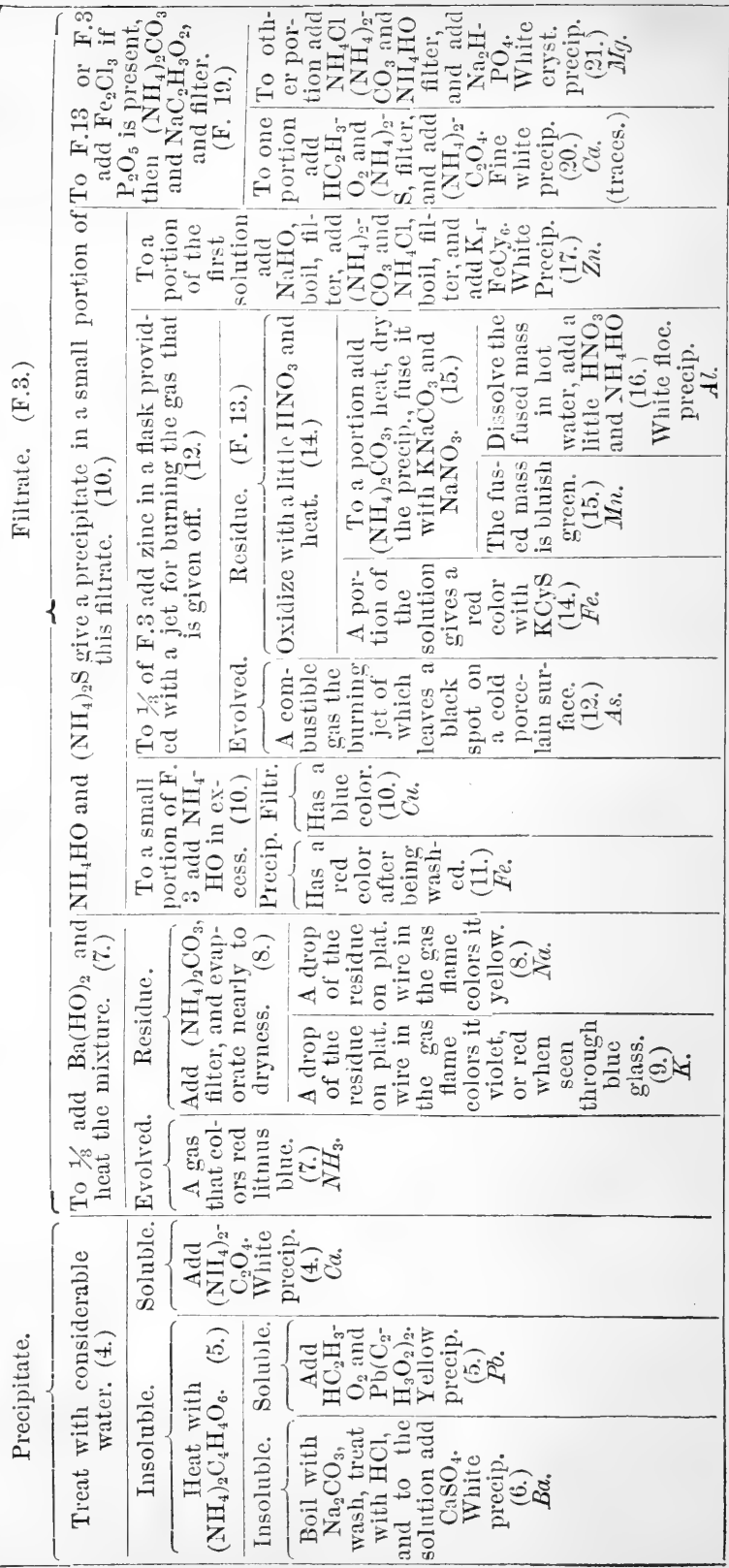


C.

For the mode of occurrence of the substances for whose detection directions are given in the preceding pages, in agricultural materials and products, consult Table $\mathrm{X}$, except in case of the following, which are not widely distributed, or whose occurrence presents comparatively less interest, because they have not been quantitatively estimated in these materials or products.

Acid, acetic, besides occurring in vinegar, which results from the action of the air on alcoholic liquors, is found among the products of the putrefaction, or of the destructive distillation of organic matter.

Acid, citric, is found in lemons, and in most other acid fruits, such as gooseberries, cherries, etc.

Acid, lactic, is the acid of sour milk, and is found also in some animal juices, and sometimes in urine.

Acid, malic, is found in unripe apples, and in most unripe fruits, together with citric acid, and also in potatoes, in many roots, and in the stems and leaves of many plants, such as rhubarb, tobacco, etc.

Acid, tartaric, is found, like malic acid, in many fruits, and particularly in the grape ; it occurs also in the roots, stems, and leaves, of many plants.

Arsenic may be found occasionally in superphosphates, where it was derived from the sulphuric acid used in the manufacture of the article; it is also a frequent and dangerous ingredient of bright green pigments.

Barium may sometimes be found as a silicate in some common rocks, and hence in soils.

Copper may sometimes be found in culinary products where vessels made of the metal or its alloys have been used; it is a frequent and harmful ingredient of bright green pickles 
Cyanogen is sometimes to be found among the products of the decomposition of nitrogenous organic matter in the presence of strong bases, particularly if the decomposition has been aided by heat.

Ferrocyanogen is a product of the decomposition of nitrogenous animal matters by heat, in the presence of a strong base and iron.

lodine is very widely but sparingly diffused.

Lead may sometimes be found in water that has been in contact with it, and in superphosphates; in this latter case it is derived from the sulphuric acid used in the manufacture of the fertilizer; it is also a common ingredient of pigments.

Manganese occurs in nearly all soils, and is generally found, at least in trices, in plants, and whatever is produced from them.

Zinc may occur in soils in the neighborhood of beds of zinc ore, and in the ashes of plants grown on such soils.

II.

SPECIAT METHODS OF QUANTITATIVE SEPARATION OF SUBSTANCES.

Under this head a few special methods of quantitative separation of substances, that often occur in agricultural chemical analysis, are described with full details and directions, and in a manner convenient for reference. In this way much repetition is avoided in the chapters treating of special analyses.

By consulting Table $\mathrm{X}$, at the close of the book, tho analyst may ascertain how much he will probably find of each of the constituents of the compound he is about to analyze, and, knowing the strength of his reagents, he can form some idea as to the quantities of these to be used to produce complete precipitation. 


\section{DESICCATION.}

90. One of the more frequent determinations in agricultural analysis is that of water, ash, and organic matter.

In the elimination of water, or the desiccation of the substance or solution, the object may be to determine the hygroscopic water of the substance, or it may be the estimation of the total amount of solid matter in a solution.

a. For the estimation of hygroscopic moisture, dry the substance well in the air, so that it shall be thoroughly air-dried, or under a bell-jar over sulphuric acid, as may be directed in each special case; then heat a weighed quantity of it in a watch-glass in the steam or air-bath to the temperature indicated in each case, as long as it loses weight; while weighing the substance, it should be enclosed between two watch-glasses that fit well together by their ground edges.

$b$. Sometimes, as in the case of gypsum containing no volatile matters but water, the substance can be ignited at once in a covered crucible. A gentle heat should be applied at first, and the temperature should be gradually raised, at least almost to a red heat in some cases.

$c$. When the substance contains a large amount of water, as in the ease of the green parts of plants, it is best to dry a large, weighed quantity in a drying-chamber, at from $60^{\circ}$ to $80^{\circ} \mathrm{C}$, determine the loss of weight at this temperature, and then proceed as in $a$, with from 3 to 6 grms. of this partly dried substance.

d. Sometimes the substance to be dried contains other volatile ingredients, as ammonia for example; in this case the desiccation must be performed in a current of dry air, or an inactive gas, like hydrogen, by means of which the rolatile products are carried into some absorbing solution. Procure a deep water-batn, through which a tube of the same material passes laterally, and projects 
a little beyond the sides; weigh the substance out in a small porcelain or platinum boat, and insert the boat in a glass tube open at both ends, and drawn out and bent down at one end ; put this glass tube in the copper tube of the water-bath, immerse the end of the glass tube, that is bent downwards, in a measured quantity of standard sulphuric acid, and connect the other end with an apparatus from which diy hydrogen is evolved. Apply heat to the waterbath, and when the desiccation is completed, remove the boat, rinse the glass tube into the flask containing the acid, boil the acid a little to expel carbonic acid, that might have been carried orer with the ammonia, and titrate with soda solution in the usual manner $(\S \mathbf{4 5}, c)$.

$e$. For the estimation of the amount of solid substances in a solution, evaporate a measured or weighed quantity on the water-bath, and dry the residue at the temperature indicated in each particular case; this temperature may range all the way from $100^{\circ}$ to $180^{\circ} \mathrm{C}$.

$f$. If the liquid contains other volatile matters besides water, as in the case of urine, which may give off ammonia when heated, put it in a porcelain or a platinum boat, which has been previously about two-thirds filled with coarsely pounded and well-washed glass or coarse quartz sand, dried at $100^{\circ}$, and weighed, and carry on the evaporation as in the case of a solid evolving ammonia when heated $(d)$.

g. If the solution contains substances that are decomposed at a temperature above $100^{\circ}$, and yet it is difficult to dry the residue left on evaporation of the liquid thoroughly at that temperature, imbed the dish containing the residue in sand that is heated to $100^{\circ} \mathrm{C}$., put the whole over a dish of concentrated sulphuric acid under the receiver of the air-pump, and exhaust the air; after the sand has cooled, repeat the process with a fresh quantity of heated sand, and so on as long as there is any loss of weight. 
$h$. If the substance in solution is liable to form hard clumps on drying that retain water mechanically enclosed, and yet the residue cannot be heated much above $100 \mathrm{C}$, mix it with $\left.{ }^{1}\right|_{5}$ or $\left.^{1}\right|_{6}$ of its weight of rather finely pulverized crystallized gypsum, or of pure ignited baric sulphate, that has been artificially prepared, or with 3 or 4 times its weight of well-washed fine sand. If gypsum is used, it should be tested beforehand, to see whether it loses any weight at $100^{\circ}$. The mixture should be well stirred as the evaporation approaches dryness. Heat the residue at $100^{\circ}$ in the usual manner as long as it loses weight.

INCINERATION, OR ESTIMATION OF ORGANIC MATTER.

91. The dried residues obtained in the preceding section are often examined for organic matter by ignition until this matter is burned away, or incineration.

$a$. The ignition is performed in a platinum dish or crucible at as low a temperature as possible, with provision for the access of air to the substance along the surface of the lid of the crucible, as directed for the incineration of filters $(\S 40)$; or a piece of platinum foil may be bent so as to rest on the bottom of the dish and on the rim, and extend some distance beyond the latter.

b. A portion of the original solid substance may be incinerated at once in the muffle furnace, as described in $\S 123, c$, under preparation of the ash of plants for analysis. Then, on subtracting from the loss of weight in this trial the amount of water in the quantity of substance taken, as may be calculated from the results of the estimation of hygroscopic water in another portion of the substance, the remainder will be the organic matter, or other volatile matter besides water.

c. A part of the carbon sometimes obstinately resists 
combustion; to eliminate this, one of two courses may be followed.

1. Exhaust the mixture of ash and coal with hot water, collect the insoluble part on the filter, wash, dry, and ignite it; the coal will generally be found to burn much more readily atter this treatment, and the ash can moreover be heated to a higher temperature than before without fear of loss. Add the ash so obtained to the aqueous extract and washings, craporate to dryness, ignite gently, and weigh.

2. Or, weigh the mixture of ash and unconsumed carbon, determine carbonic acid $(d)$ in the whole or a portion of it, collect what is insoluble in the nitric acid in the determination of the carbonic acid, on a dried and weighed filter, wash it well, dry at $110^{\circ} \mathrm{C}$., weigh, ignite until the carbon is completely burned, and weigh again. The loss of weight gives the unburned carbon in that portion of the original ash taken; calculate the amount of coal for the whole quantity of the original mixture of ash, including carbonic acid and coal, and deduct it from the same.

c. A portion of the carbon in the organic part of the substance ignited may remain behind in combination with the metallic oxides as carbonic acid; since this does not properly belong to the ash or inorganic part of the substance, it should be determined and deducted from the total weight of the ash.

For this purpose estimate the carbonic acid $(\$ 60)$ in a portion of the ash, or the whole of it, according to the quantity in hand, calculate the amount for the whole quantity of the ash, if only a portion was used for the analysis, and deduct it from the same.

A substance may, however, contain a notable quantity of carbonic acid before ignition, as, for example, a soil with carbonate of lime in it. In this case the ignited residue should be moistened with ammonic carbonate, 
carefully dried, gently ignited, and weighed, and the operation must be repeated as long as there is any gain in weight, in order to be sure that there is at least as much carbonic acid in the substance after ignition as before. Then determine carbonic acid in the ash, or a portion of it, and in a portion of the original substance; the excess in the ash over what was in the quantity of substance taken is to be subtracted from the weight of the ash.

$e$. Small quantities of organic matter, as in water, may be determined by the following volumetric process ( $K u b e l$, Fresenius's Zeitschrift, 6, 252).

Dissolve about $0.4 \mathrm{grm}$. of crystallized potassic permanganate in 1 litre of water, and also $0.398 \mathrm{grm}$. of pure oxalic acid in 1 litre of water.

Put 100 c.c. of distilled water and 10 c.c. of a dilute sulphuric acid, containing 30 grms. of concentrated acid in 100 c.c., in a flask of about 300 c.c. capacity, heat the mixture to boiling, add 3-4 c.c. of the permanganate solution, boil the red liquid 5 minutes, remove the lamp, and add 10 c.c. of the solution of oxalic acid; potassic permanganate is then cautiously added from a burette or pipette, with constant stirring, until a faint red color appears throughout the liquid. The total amount of permanganate added, corresponding to the 10 c.c. of the oxalic acid solution, $=2$ milligrammes.

Now, to make a determination of organic matter in a sample of drinking water, for instance, boil 100 c.c. of the water in a flask of 400 or 500 c.c. capacity, down to $\left.{ }^{2}\right|_{3}$ its initial volume, to decompose ammoniacal compounds that are very liable to be present in such a water, by means of the calcic carbonate that is also nearly always present; add distilled water until the original volume is nearly restored, and 10 c.c. of the dilute sulphuric acid; heat to boiling, add 5 or 6 c.c. of the permanganate solution, and boil 5 minutes, whereby the red color should not be destroyed; then ald 10 c.c. of the oxalic acid, and restore 
the red color by adding the permanganate solution from the burette as before. The permanganate added this time is consumed in oxidizing, not only the 10 c.c. of oxalic acid that was added to the solution, but also other organic matter, and therefore more permanganate will be required than when the oxalic acid was mixed with distilled water, as in the first experiment. Multiply the number of milligrammes of permanganate in this additional quantity of the solution used, by 5 , for the organic matter, expressed in milligrammes. The determination is only an approximate one, since different kinds of organic matter require different amounts of oxygen for their complete oxidation, while in the above estimation it is assumed that the same amount is consumed by the same quantity of organic matter of whatever kind.

92. Estimation of Sulphur (and Chlorine) in Organic Compounds.

Fuse 2 parts of a mixture of pure caustic potassa free from sulphuric acid (or chlorine) with ${ }^{1} l_{8}$ part of pure potassic nitrate in a silver dish, with the addition of a little water. When the mixture is cold, add 1 part ( 3 to 4 grms.) of the finely pulverized substance, fuse the whole with constant stirring with a silver spatula, and continue the application of the heat until the mass has become quite white; if it does not readily become so, a little more potassic nitrate may be added.

Dissolve the fused substance in dilute nitric acid, evaporate to dryness, and eliminate silica $(\S 58, \alpha, 1)$, and in the filtrate from this, precipitate the sulphuric acid, into which the sulphur in the original substance has been converted by oxidation, with baric chloride ( $\S 59)$, or with baric acetate, if chlorine is to be determined in the filtrate from the baric sulphate; the chlorine in this filtrate is precipitated by argentic nitrate $(\S 63, a)$.

93. Separation and determination of Potassium, Sodi- 
um, Calcium, Magnesium, Alnminium, Iron, and Manganese, and Phosphoric and Sulphuric acids.

This is one of the most frequently recurring separations in agricultural chemical analysis.

For the best general methou of separation in each particular case, the analyst will be referred to one of the tables at the end of this section, in which the whole course to be followed will be marked out in a few words, while more detailed descriptions will be given in the following paragraphs of some of the necessary manipulations mentioned in the table.

A. Precipitation of aluminu, $\mathrm{Al}_{2} \mathrm{O}_{3}$, ferric oxide, $\mathrm{Fe}_{2} \mathrm{O}_{3}$, and phosphoric acid (anhydride), $\mathrm{P}_{2} \mathrm{O}_{5}$, and estimation of the two bases.

If the substance contains a notable proportion of organic matter, this should first be destroyed in the solution, and the iron completely oxidized to ferric oxide at the same time, by treatment with an active oxidizing agent.

This oxidation may be effected by passing chlorine gas through the solution until it is nearly saturated; if this course is followed, the solution should be heated afterwards, until the excess of chlorine is entirely expelled.

Or, instead of using chlorine, the solution may be evaporated nearly to dryness, and sodic or potassic hydrate added in slight excess, and sodic carbonate and a little sodic or potassic nitrate; then dry the mixture completely in a platinum dish, and ignite the residue gently until the organic matter is destroyed; exhaust the mass with water, treat it with dilute hydrochloric acid, add this solution and the washings to the aqueous one, and proceed as directed below for the estimation of ferric oxide, etc. If a residue remains that is insoluble in hydrochloric acid, dry, ignite, and weigh it, and add the amount to the silicic acid already obtained. 
1. Case in which there is enough alumina and ferric oxide present to combine with all the phosphoric acid. The filtrate from the precipitate by sodic acetate, obtained in a qualitative test in the manner described below, gives no reaction for phosphoric acid with ammonic molybdate.

To the not too concentrated solution add sodic carbonate with constant stirring, until a few scattered flakes of a precipitate remain permanent, heat to boiling, remove the lamp, and add immediately an excess of a boiling hot solution of sodic or ammonic acetate; this reagent precipitates all the $\mathrm{Al}_{2} \mathrm{O}_{3}, \mathrm{Fe}_{2} \mathrm{O}_{3}$, and $\mathrm{P}_{2} \mathrm{O}_{5}$; filter rapidly while hot, and wash the contents of the filter with boiling water, containing a little ammonic acetate; dissolve the precipitate, without drying it, in hot, dilute hydrochloric acid, wash the filter out well, mix the solution and washings by vigorous stirring, add water, if it is necessary, to bring the liquid to such a volume that it can be conveniently divided in two equal parts, and mix carcully again by stirring, divide it accurately, precipitate one part with ammonia in slight excess, as directed for the precipitation of alumina ( $\$ 51)$, filter, wash with hot water, dry, ignite precipitate and filter separately, and weigh; the result, multiplied by two, gives the total amount of $\mathrm{Al}_{2} \mathrm{O}_{3}, \mathrm{Fe}_{2} \mathrm{O}_{3}$, and $\mathrm{P}_{2} \mathrm{O}_{5}$ in the undivided solution.

Reduce the ferric to ferrous oxide in the other half of the solution, and estimate the iron with potassic permanganate $(\S 52, b)$; or, as a sulphuric-acid solution is better adapted for that process, this half of the solution may be precipitated with ammonia also, and the precipitate washed, and dissolved, without drying it, in dilute sulphuric acid. The amount of ferric oxide being estimated from the result, multiply by two and thus get the quantity of $\mathrm{Fe}_{2} \mathrm{O}_{3}$ in the undivided solution.

The difference between the total weight of $\mathrm{Al}_{2} \mathrm{O}_{3}$, $\mathrm{Fe}_{2} \mathrm{O}_{3}$, and $\mathrm{P}_{2} \mathrm{O}_{5}$, and the sum of the $\mathrm{Fe}_{2} \mathrm{O}_{3}$, as determined above, and the $\mathrm{P}_{2} \mathrm{O}_{5}$ to be determined in another portion 
of the solution and estimated for the amount of solution taken for this analysis, will give the $\mathrm{Al}_{2} \mathrm{O}_{3}$.

2. In case there is not $\mathrm{Fe}_{2} \mathrm{O}_{3}$ and $\mathrm{Al}_{2} \mathrm{O}_{3}$ enough present to combine with all the phosphoric acid, more iron must be added, until a drop of the liquid, on a watch-glass, gives a reddish precipitate with a little ammonia, and the amount of iron so added is to be subtracted from the total amount found subsequently. This addition of iron is most conveniently made in the form of a carefully measured quantity of an accurately titrated solution of ferric chloride $\left(\mathrm{Fe}_{2} \mathrm{Cl}_{6}\right)$, about $\left.{ }^{1}\right|_{5}$ the strength of the reagent ordinarily used. Proceed then as in 1.

B. The method of removing phosphoric acid by means of metallic in admits of the determination, in a convenient mamner, of this acid, and alumina, ferric oxide, manganous oxide, lime, and magnesia, in the same portion of the solution.

On evaporating to dryness to remove silica, after moistening the dried residue with concentrated hydrochloric acid in the usual manner, ald nitric acid, dilute with water, filter, wash the insoluble silica on the filter, evaporate the filtrate and washings nearly to dryness, or until all the hydrochloric acil is expelled, dissolve the residue in concentrated nitric acil, heat the solution to boiling in a beaker covered with a large watch-glass or an inverted funnel, and add pure tin in small grains, and in small portions at a time, to an amount about six times as great as that of the phosphoric acid supposed to be present, digest the mixture 5 or 6 hours in a warm place, dilute and decant the clear supernatant liquid on the filter, and wash the precipitate, containing stannic oxide, stannic phosphate, and perhaps some alumina and ferric oxide, several times by decantation with boiling dilute nitric acid, and finally with a little water; then digest it with ammonic sulphide, wash the undissolved aluminic hydrate and ferrous sulphide first with hot ammonic sulphide, and then 
with water to the successive portions of which less and less ammonic sulphide is added; dissolve it in dilute hydrochloric acid, and add the solution to the first filtrate from the stannic oxide, etc., containing the main part of the alumina and ferric oxide.

The solution obtained by treating the precipitated stannic oxide and phosphate, etc., by ammonic sulphide, contains all the phosphoric acid (Bceber, Zeitschrift für. die gesammten Naturwissenschaften, 1864, 293. Fresenius's Zeitschrift, 4, 122) ; if its volume has been increased to a considerable bulk by the washings of the precipitate of aluminic hydrate and ferrous sulphide, concentrate it by evaporation, filter again if not clear, and precipitate the phosphoric acid with magnesia mixture in the usual manner $(\S 61, a)$.

In the filtrate from the precipitated stannic oxide and phosphate, etc., determine the bases, as directed in A, C, and $\mathrm{D}$, except that, since the precipitate by sodic acetate in A contains no phosphoric acid, the difference between the total weight of the precipitate by ammonia, and the weight of the ferric oxide, as determined by potassic permanganate, gives the alumina.

The method is not applicable in the presence of hydrochloric acid or chlorides.

C. Precipitation of manganic binoxide, $\mathrm{MnO}_{2}$, in the filtrate from the precipitate by sodic acetate in $\mathbf{A}$.

Heat this filtrate, which should be fiee from ammonic salts, and tolerably concentrated, to 50 or $60^{\circ} \mathrm{C}$., and conduct chlorine gas through it until it is saturated, or as long as any precipitate is formed ; filter out the precipitate, add more sodic acetate to the filtrate, pass chlorine through again, and add this second precipitate to the first, if any is obtained. Wash the precipitated manganic hydrate first by decantation and then on the filter, dry this, separate the precipitate from it as completely as possible, burn it and dissolve the ash and the precipitate in concentrated 
hydrochloric acid, remove any great excess of acid by evaporation, and precipitate the solution with sodic carbonate. $(\S 53$.

Heat the filtrate from the precipitate by chlorine as long as any odor of the gas is perceived.

D. Precipitation of lime, $\mathrm{CaO}$, and magnesia, $\mathrm{MgO}$, in the filtrute firom the precipitate by sodic acetute $(\Lambda)$ or by chlorine (C). Neutralize the solution with ammonia if it is acid, and proceed as directed in $\$ 50 b$ to precipitate lime with ammonic oxalate, and magnesia with hydric disodic phosphate.

E. Separation and determination of sulphuric acid (anhydride), $\mathrm{SO}_{3}$. Precipitate the acid with baric chloride in the slightest possible excess, and preserve the washings with water alone, while those with cupric acetate may be thrown away. $(\S 59$.)

F. Estimation of phosphoric acid (anhydride), $P_{2} O_{5}$, in the filtrate from the precipitate by baric chloride.

Add ammonia in slight excess only, if much iron or aluminum is present, otherwise a mixture of ammonia and ammonic carbonate, as long as a precipitate is formed, digest the mixture a considerable time until the free ammonia is expelled, wash the precipitate well, dissolve it, without drying it, in nitric acid, and eliminate $\mathrm{P}_{2} \mathrm{O}_{5}$ with ammonic molybdate. $(\S 61 . b$. $)$

G. Elimination of the alkaline metals as chlorides.

(1.) Precipitate $\mathrm{SO}_{3}$ by the slightest possible excess of baric chloride, if this has not already been done; evaporate the mixture on the water-bath until most of the fiee acid has been removed, add pure milk of lime in slight excess, digest some time on the water-bath, and filter out the precipitated $\mathrm{Fe}_{2} \mathrm{O}_{3} \mathrm{Al}_{2} \mathrm{O}_{3} \mathrm{MgO}$, and, $\mathrm{SO}_{3}$ and $\mathrm{P}_{2} \mathrm{O}_{5}$. Wash the precipitate as long as the washings make argentic nitrate turbid, precipitate the excess of lime in the concentrated filtrate and washings, by ammonic carbonate con- 
taining excess of ammonia, let the precipitate settle, filter, evaporate to dryness, and ignite; dissolve the residue in water, and precipitate again with ammonia and ammonic carbonate, filter, evaporate to dryness, and ignite; and repeat this operation as long as these reagents cause any turbidity; finally, ignite gently, weigh the alkaline chlorides thus obtained, and determine potassium and sodium in the mixture by the indirect process $(\$ 46 d)$, or, if greater accuracy is desired, precipitate potassium with platinic chloride $(\S 46 b)$.

(2.) Precipitate the $\mathrm{SO}_{3}$ in the boiling solution with baric chloride in slightest possible excess, if this has not already been done, evaporate the mixture on the waterbath until most of the free acid is removed, add some water and then ammonia and ammonic carbonate as long as a precipitate is formed, and finally a little ammonic oxalate, digest on the water-bath, filter, and wash the contents of the filter carefully. Evaporate the filtrate and washings to dryness ( $\S 37$ ), ignite the residue to expel ammoniacal salts, weigh roughly, and add a quantity of a concentrated solution of pure oxalic acid that contains enough of the acid to make quadroxalate with an amount of potassa equivalent to all the bases present, evaporate to dryness, and ignite again. By this process, magnesia and traces of lime, baryta, ferric oxide, etc., that may possibly be present, are rendered insoluble in water. Treat the ignited residue with a small quantity of boiling water, throw it on a filter, wash it with several small portions of boiling water, as long as anything is dissolved, add hydrochloric acid in slight excess to the filtrate and washings, evaporate to dryness, and ignite the residue of alkaline chlorides gently, weigh, and determine potassium and sodium by the indirect process $(\S 46 d)$, or with platinic chloride $(\S 46 b)$.

If, when these chlorides are dissolved in water, a clear solution is not obtained, or if the solution has a basic re- 
action, it should be evaporated to dryness and the residue treated with oxalic acid again.

(3.) According to Stohmann (Fresenius's Zeitschrift, 5, 306), potassium may be separated out at once by platinic chioride fiom a solution containing only alkalies and alkaline earths.

Having precipitated the sulphuric acid completely as above in the boiling solution of about 10 grms. of the substance, filter out the precipitate if the quantity of it is large; if but small, let it remain in the liquid; dilute the liquid, when cool, to 1000 c.c. and mix the whole thoroughly together. To 100 c.c. of the clear solution add an amount of platinic chloride containing about 2 grms. of the metal, evaporate the mixture nearly to dryness, and proceed as directed for the separation of potassium and sodium by platinic chloride $(\$ 46)$ ). The method is based upon the fact that the double chlorides of calcium, barium, and magnesium, and platinum, are soluble in water and alcohol, as well as the double chloride of sodium and platinum.

H. Separation of phosphoric acid alone.

(1.) Evaporate the hydrochloric acid solution, containing no great excess of iron over the phosphoric acid, to dryness on the water-bath, to eliminate silica, moisten the perfectly dried residue with about 2 c.c. of concentrated hydrochloric acid, and, after a while, add about 10 c.c. of concentrated nitric acid $(\mathrm{Sp} . \mathrm{Gr} .=1.2)$ for every 0.15 grm. of phosphoric acid supposed to be present, dilute with water, filter if necessary, and wash the residue of insoluble silica; evaporate the filtrate and washings nearly to dryness, dissolve the residue in about half as much concentrated nitric acid as was added before, and proceed to precipitate phosphoric acid with ammonic molybdate (§ 61 b). (Fresenius's Zeitschrift, 4, 404.)

(2.) To the solution of the phosphate add ferric chloride in slight excess over the phosphoric acid, if there is not 
already enough alumina and ferric oxide present, so that, when the solution is nearly neutralized with sodic hydrate, heated to boiling and precipitated with sodic acetate in excess, the filtrate gives no reaction for phosphoric acid.

Nearly neutralize the solution with sodic hydrate or carbonate, heat to boiling, and add sodic acetate in excess, filter the mixture while hot, wash with boiling water containing a little ammonic acetate, dissolve, without igniting, in dilute hydrochloric acid, wash the filter out carefully, dilute the solution moderately, add rather a large quantity of citric acid, and then an excess of ammonia; if enough citric acid is present, the solution remains clear. Finally, add magnesia mixture to the solution, and precipitate phosphoric acid in the usual manner. (\$61 a.)

The solution should not contain too large an excess of hydrochloric acid, and a great excess of citric acid must bo avoided also. The method gives the best results when the proportion of phosphoric acid is large, as compared with the alumina and ferric oxide; if these oxides are present in large quantity, it may be necessary to re-dissolve the precipitate by magnesia mixture in hydrochloric acid, add citric acid, and re-precipitate the phosphoric acid by ammonia and a little magnesia mixture.

(3.) In solutions containing a great excess of ferric oxide, it is better to reduce a portion of this, at least, to ferrous oxide before precipitation with sodic acetate.

Heat the acid solution to boiling, remove the lamp, add a solution of sodic sulphite until the liquid is quite colorless, and sodic carbonate produces a white precipitate; then boil the mixture as long as any odor of sulphurous acid is evolved, nearly saturate the acid with sodic carbonate, add a few drops of chlorine water, then sodic acetate in excess, and finally more chlorine water drop by drop, until the liquid is reddish, and boil; the precipitate contains all the alumina and phosphoric acid, mixed with but little ferric oxide; filter it out quickly, wash it with a lit- 
tle hot water, and dissolve it, without ignition, either in nitric acid and eliminate phosphoric acid with the aid of ammonic molybdate $(\S 61, b)$, or in hydrochloric acid and precipitate the phosphoric acid with magnesia mixture in the presence of citric acid, as above.

(4.) If there is a large proportion of phosphoric acid in the substance, and comparatively little ferric oxide and alumina, the nitric acid solution, obtained as in 1, may be treated with metallic tin, as described in $B$.

94. Schemes for the quantitative separation of $K$., $N a$.,

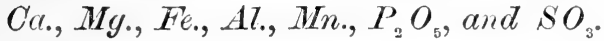

The purpose of these schemes is, to present a birdseye view of the various courses to be followed for the separation of the bases and acids given in this list.

For the details of the manipulation the analyst should always follow up the references given in the schemes and in $\S 93$, unless he is perfectly familiar with these details, and knows them, as it were, by heart.

The capital letters in the schemes refer to paragraphs in $\S 93$, the small letters to other parts of the schemes themselves. 
I.

PIIOSPHORIC ACID IS OT IS NOT IN EXCESS OVER THE ALUMINA AND FERRIC OXIDE.

Divide the filtrate from the silica in three parts, a, b, and c.

1. Precipitate $\mathrm{SO}_{3} \mid$ 1. First add $\mathrm{Fe}_{2} \mathrm{Cl}_{6}$ in 1 1. First add an aceuwith $\mathrm{BaCl}$, filter. (E.) slight excess over the $\mathrm{P}_{2}$ - rately titrated solution

2. Precipitate $\mathrm{P}_{2} \mathrm{O}_{5} \mathrm{O}_{5}$ if $\mathrm{Al}_{2} \mathrm{O}_{3}$ and $\mathrm{Fe}_{2} \mathrm{O}_{3}$ are of $\mathrm{Fe}_{2} \mathrm{Cl}_{6}$ in proper together with Fe,Ca, not already present in quantity (see A, 2) if ete., with $\mathrm{NH}_{4} \mathrm{HO}$, or excess (see $\mathrm{A}, 1$ ); then $\mathrm{Al}_{2} \mathrm{O}_{3}$ and $\mathrm{Fe}_{2} \mathrm{O}_{3}$ are not $\mathrm{NH}_{4} \mathrm{HO}$ and $\left(\mathrm{NH}_{4}\right)_{2}$-eliminate the acid,

$\mathrm{CO}_{3}$, filter. (F.)

3. Eliminate $\mathbf{K}$. and Na. as chlorides,

\begin{tabular}{c|c|c|c|c|}
$a$. & $\beta$. & of $\mathrm{NH}_{4} \mathrm{HO}$ & of $\mathrm{NaHO}$ \\
by treat- by evapo- & in slight ex- until nearly
\end{tabular}

ment wiges-neutral, pre-

ment with ration to

milk of

lime, $\mathrm{NH}_{4}$

$\mathrm{HO}$ and

$\left(\mathrm{NH}_{4}\right)_{2}$ tion, solu- with $\mathrm{NaC}_{2}$ addition of oxalic

$\mathrm{CO}_{3}$, filtra-acid, ignition, evap-tion, soluoration to tion in dryness, water, fil- $\mathrm{MoO}_{3}$. ignition. tration, $\mathrm{H}, 1$. $\mathrm{G}, 1$. and ignition. G, 2. cipitate in $\mathrm{HNO}_{3}$ and precipita- $\mathrm{H}_{3} \mathrm{O}_{2}$ if alliation of $\mathrm{P}_{2} \mathrm{O}_{5}$. lies are to vith $\left(\mathrm{NH}_{4}\right)_{2}$ be determined in tiltrate); dissolve precipitate in $\mathrm{HCl}$, precipitate $\mathrm{P}_{2} \mathrm{O}_{5}$ with magnesia mixture and citric acid. H, 2 .

2. Treat filtrate from (From the prec. by precipitate by $\mathrm{NH}_{4} \mathrm{HO}$ in $\left(\mathrm{NH}_{4}\right)_{2} \mathrm{C}_{2} \mathrm{O}_{4}$. $)$ Concen$a$ or $\mathrm{NH}_{4} \mathrm{C}_{2} \mathrm{H}_{3} \mathrm{O}_{2}$ in $\beta$ as trate and precipitate under $a$, if it is desired $\mathrm{Mg}$. with $\mathrm{Na}_{2} \mathrm{H}, \mathrm{PO}_{4}$ to repeat the determina- (D). tion of alkalies.

II.

A LARGE EXCESS OF BOTH ALUMiNA AND FERIIC OXIDE IS PREsent.

Divide the filtrate from the silica in three parts, a, b, and c.

\begin{tabular}{|c|c|c|}
\hline a. & $\mathrm{b}$. & c. \\
\hline $\begin{array}{l}\text { 1. Precipitate } \mathrm{SO}_{3} \text { with } \mathrm{Ba} \text { - } \\
\text { Cl and filter. (E.) } \\
2 \text {. Eliminate } \mathrm{K} \text { and } \mathrm{Na} \text { as } \\
\text { chlorides. See Scheme I, } \\
a, 3 \text {. }\end{array}$ & $\begin{array}{l}\text { Treat this } \\
\text { portion as } \\
\text { direeted in } \\
\text { Scheme I } \\
\text { under } c \text {. }\end{array}$ & $\begin{array}{l}\text { Reduce the ferric to fer- } \\
\text { lous oxide with sodic sul- } \\
\text { phite }(\mathrm{H}, 3) \text {, precipitate all } \\
\text { Al and } \mathrm{P}_{2} \mathrm{O}_{5} \text { together with } \\
\text { little } \mathrm{Fe} \text {, and eliminate } \mathrm{P}_{2} \mathrm{O}_{5} \\
\text { as under } \alpha \text { or } \beta \text {, Scheme } \mathrm{I}, b \text {. }\end{array}$ \\
\hline
\end{tabular}


III.

No ALUMINA IS PRESENT, AND PHOSPHORIC ACID IS IN EXCESS OVER THE IRON.

Divide the filtrate from the silica in two parts, $a$ and $b$.

\begin{tabular}{|c|c|}
\hline \multirow[t]{3}{*}{$\begin{array}{l}\text { a. } \\
\text { Determine } \\
\mathrm{SO}_{3}, \mathrm{P}_{2} \mathrm{O}_{5}, \mathrm{~K} \\
\text { and } \mathrm{Na}, \text { as } \\
\text { under } \alpha \text {, } \\
\text { Scheme I. }\end{array}$} & $\begin{array}{l}\text { 1. Add an accurately titrated solution of } \mathrm{Fe}_{2} \mathrm{Cl}_{6} \text {, nearly } \\
\text { neutralize the solution with } \mathrm{Na}_{2} \mathrm{CO}_{3} \text {, precipitate Fe and } \\
\mathrm{P}_{2} \mathrm{O}_{5} \text { with } \mathrm{NaC}_{2} \mathrm{H}_{3} \mathrm{O}_{2}(\mathrm{~A}) \text {; dissolve the precipitate in } \mathrm{HCl} \text {, } \\
\text { divide solution in two equal portions, } a \text { and } \beta \text {. }\end{array}$ \\
\hline & \begin{tabular}{c|c}
$2 a \cdot$ \\
Determine Fe with per- \\
$\begin{array}{c}\text { Determine } \mathrm{P}_{2} \mathrm{O}_{5} \\
\mathrm{MoO}_{3}(\mathrm{H}, 1) \text { or eit } \\
\text { magnesia mixture }\end{array}$
\end{tabular} \\
\hline & $\begin{array}{l}\text { In, in the filtrate fi } \\
\text { in }: 2,3 \text {, and } 4 \text {, u }\end{array}$ \\
\hline
\end{tabular}

IV.

No ALUMINA OR MANGANESE IS PRESENT, AND PHOSPHORIC ACID IS IN EXCESS OVER THE IRON.

Proceed as in III, except that the elimination of manganese by chlorine may be omitted.

$\mathrm{V}$.

TO DETERMINE ALL WITHOUT DIVIDING THE SOLUTION.

1. To the filtrate from the silica add the titrated solution of ferric chloride, if necessary, (see $\$ 93, \mathrm{~A}, 2$ ), nearly neutralize the solution with $\left(\mathrm{NH}_{4}\right)_{2} \mathrm{CO}_{3}$, precipitate $\mathrm{Fe}, \mathrm{Al}$, and $\mathrm{P}_{2} \mathrm{O}_{5}$, with $\mathrm{NH}_{4} \mathrm{C}_{2} \mathrm{H}_{3} \mathrm{O}_{2}$, dissolve the precipitate in $\mathrm{HCl}$, and divide the solution in two equal portions; precipitate one portion with $\mathrm{NH}_{4} \mathrm{HO}$, and get total $\mathrm{Al}, \mathrm{Fe}$, and $\mathrm{P}_{2} \mathrm{O}_{5}$; heat the ignited residue in a mixture of 8 parts of concentrated sulphuric acid and 3 parts of water, add water, and determine Fe in this solution with potassic permanganate $(A)$; eliminate $\mathrm{P}_{2} \mathrm{O}_{5}$ in the other portion of the solution, with the aid of ammonic molybdate, or magnesia mixture in the presence of citric acid. (H.)

2. First Filtrate. (From the precip. by $\mathrm{NH}_{4} \mathrm{C}_{2} \mathrm{H}_{3} \mathrm{O}_{2}$.) Eraporate to dryuess and ignite the residue until ammonic salts are completely expelled; dissolve in water acidified with $\mathrm{HCl}$, nearly neutralize the solution with $\mathrm{Na}_{2} \mathrm{CO}_{3}$, add $\mathrm{NaC}_{2} \mathrm{H}_{3} \mathrm{O}_{2}$, and precipitate $\mathrm{Mn}$ by $\mathrm{Cl}$. (C.)

3. Second Filtrate. (Fiom the precipitate by $\mathrm{Cl}$.) After removing excess of $\mathrm{Cl}$ by heat, precipitate $\mathrm{Ca}$ with $\left(\mathrm{NH}_{4}\right)_{2} \mathrm{C}_{2} \mathrm{O}_{4}$. (D.)

4. Third Filmate. (From the precip. by $\left.\left(\mathrm{NH}_{4}\right)_{2} \mathrm{C}_{2} \mathrm{O}_{4}\right)$. Precipitate $\mathrm{SO}_{3}$ with $\mathrm{BaCl}$. (E.) 
5. Fourth Filtrate. (From the precip. by $B a C l$.) Remove excess of $\mathrm{Ba}$ with $\left(\mathrm{NH}_{4}\right)_{2} \mathrm{CO}_{3}$, evaporate filtrate to dryness, ignite, treat with $\mathrm{H}_{2} \mathrm{C}_{2} \mathrm{O}_{4}$, (see $\mathrm{G}, 2$ ), ignite, exhaust with water, and treat this solution for the estimation of the alkalies, as directed for the treatment of the corresponding solution in $\mathrm{G}, 2$.

6. Dissolve the residue that has been exhausted by water as above, in dilute $\mathrm{HCl}$, filter if necessary, and precipitate $\mathrm{Mg}$ in the filtrate with $\mathrm{Na}_{2} \mathrm{H}$ $\mathrm{PO}_{4}(\S 50, a)$.

VI.

TO Determine AlL EXCEPT MANGANeSe, Without DIVIDING THe SOLUTION.

Proceed as under $\mathrm{V}$, except that the evaporation to dryness, ignition, and treatment with $\mathrm{Cl}$ for the estimation of Mn, are to be omitted.

VII.

TO DETERMINE ALL EXCEPT MANGANESE AND PHOSPHORIC ACID, WITHOUT DIVIDING THE SOLUTION.

Proceed as under VI, except that no $\mathrm{Fe}_{2} \mathrm{Cl}_{6}$ need be added, and that one portion of the solution of the precipitate by $\mathrm{NH}_{4} \mathrm{C}_{2} \mathrm{H}_{3} \mathrm{O}_{2}$ is to be used for the estimation of the sum of the $\mathrm{Fe}$ and $\mathrm{Al}$ only, and the other portion for the determination of $\mathrm{Fe}$. (A.)

\section{VIII.}

TO DETERMINe ALL EXCEPT ALUMiNiun AND MANGANESE Without DIVIDING THE SOLUTION.

Proceed as under VI, except that one portion of the solution of the precipitate by $\mathrm{NH}_{4} \mathrm{C}_{2} \mathrm{H}_{3} \mathrm{O}_{2}$ is to be used for the estimation of $\mathrm{Fe}$, and the other for that of $\mathrm{P}_{2} \mathrm{O}_{5}$. (A, H.)

IX.

DETERMINATION OF ALL, AND ELIMINATION OF PHOSPHORIC ACID BY THE TIN PROCESS.

Divide the filtrate from the silica in two parts, $a$ and $b$.

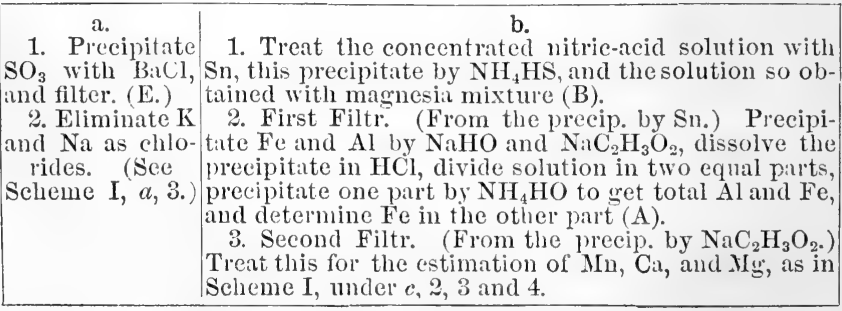




\section{§5. SoILs.}

$\mathrm{X}$.

To DETERMNe ALL EXCEPT MANGANESE, Without DIVIDING THE SOLUTION.

a. Eliminate $\mathrm{P}_{2} \mathrm{O}_{5}$ from the filtrate from the silica, by means of $\mathrm{Sn}$ (VIII, b).

b. First Filtr. (From the precip. by Sn.) Precipitate Al and Fe with $\mathrm{NH}_{4} \mathrm{HO}$ and $\mathrm{NH}_{4} \mathrm{C}_{2} \mathrm{H}_{3} \mathrm{O}_{2}$, and treat this precipitate as directed for the treatment of the corresponding one by $\mathrm{NaC}_{2} \mathrm{H}_{3} \mathrm{O}_{2}$ in VIII, b.

c. Second Filtr. Treat this, for the estimation of $\mathrm{Ca}, \mathrm{SO}_{3}, \mathrm{~K}, \mathrm{Na}$, and $\mathrm{Mg}$, as directed in Scheme $\mathrm{V}, 3,4,5$ and 6 .

\section{CHAPTER V.}

\section{ANALYSIS OF SOILS AND ROCKS.}

I.

SOILS.

95. The following general method of analyzing soils, by Emil Wolff, was approved at the annual meeting of German Agricultural Chemists in Göttingen, in 1864, and is given in full in his work on agricultural analysis, referred to in the preface.

In his introductory remarks, Prof. Wolff writes : "Of course it is not essential that the experienced chemist should follow strictly all the methods for the separation and quantitative estimation of particular components of the soil, that are given here as guides for the beginner in chemical analysis, and are used by me; those methods may be modified in many cases without impairing the accuracy of the analytical work. But it is necessary that all chemists who undertake accurate analyses of soils should agree to follow the same course in regard to 
certain important points, in order that the results obtained by different workers may be comparable with each other, or possess any lasting practical, or scientific value.

"Such essential points, concerning which agricultural chemists should aim to agree, are, the manner in which the sample of the soil is to be taken from the field, the preparation of the same, and the quantity to be taken for analysis, the manner of performing the mechanical silt $(S \mathrm{chlamm})$ analysis, the methods of determining the coefficients of absorption of the more important elements of plant-food, and, above all, the preparation of the solutions or extracts of the soil that are to be subjected to chemical analysis."

He says also in another place:

"Although I recognize the need of a large number of full and complete analyses of soils, and of improving or amplifying some of the methods given here, in order to perfect our scientific knowledge of the soil, yet an abridgment of the following course will usually answer for all practical purposes; for such an abridged course, it will be sufficient, for example, to examine only that part of the soil that is soluble in cold or hot concentrated hydrochloric acid, with perhaps the addition of a mechanical analysis; but even in this case, the previous preparation of the soil and of the solutions to be analyzed should be made in accordance with the directions given below, at least until other methods become as generally approved and adopted."

\section{PREPARATION OF THE SAMPLE FOR ANALYSIS.}

96. Make an excavation in the soil $30-50 \mathrm{~cm}$. decp, or through to the subsoil, and 30-50 $\mathrm{cm}$. square, with one side as nearly rertical as possible, and take a slice from this side of uniform thickness throughout, weighing 4-5 kilos. The subsoil lies below the depth generally reach- 
ed by the plough, and is usually readily distinguished from the upper soil by its physical characters, among which a lighter color is prominent, owing to the absence of humus. If this subsoil is to be examined, a sample of it should be taken out in the same manner as directed for the upper soil, to the depth of about $60 \mathrm{~cm}$., and the depth of the cavity noted.

The sample is taken, according to the object of the analysis, either

a, from one or from several spots in the field, in order to subject each sample to a separate analysis; or

$b$, for an average representation of the soil of the whole field; in this ease, several portions of earth are taken from points distributed in a regular manner over the field, all of which are most carefully mixed together, and 4-6 kilos. of the mixture, free from any large stones, are preserved as the average sample.

If the character of the soil varies materially in different parts of the field, samples from several spots should be analyzed separately.

A small portion of the sample should be put at once in a well-stoppered bottle; the remainder may be allowed to become air-dried, by exposing it in a thin layer, in summer, to the common temperature in the shade, or, in winter, to that of a warm room, or a moderately warm drying-chamber, heated to $30^{\circ}-40^{\circ} \mathrm{C}$.; in either case it should be carefully protected from dust.

At the time of taking the sample of the soil, observations should be made in regard to the following points:

a. The geognostic origin of the soil.

b. The nature of the underlying strata, to the depth of 1-2 metres, if practicable.

$c$. The meteorology of the locality-by consulting meteorological records, if possible; otherwise, by the general opinion of the neighborhood; in this connection, the 
height of the locality above the level of the sea should be noted also.

d. The management and rotation of erops in previous years.

$e$. The character of the customary manuring.

$f$. The amount of the crops removed in the preceding year, and, if possible, the average amount of each of the more important crops yielded by the field.

g. The practical judgment of neighboring farmers in regard to the ficld.

Having taken the sample to the laboratory, separate the stones and larger pebbles from the finer parts by the hand, or by sifting with a very coarse sieve, and examine them with reference to their mineralogical character, weight and size, making note, in this last respect, of the number that are as large as the fist or larger, the number as large as an egg, a walnut, hazel-nut, and pea, or give the percentage of each by weight.

Pulverize the air-dried soil in a mortar with a wooden pestle, and separate the fine earth out by a sieve with meshes $3 \mathrm{~mm}$. wide; this sieve should have a tightly fitting cover of sheep-skin stretched over a hoop, and it should be covered in the same manner underneath, so that no dust can escape during the process of sifting.

Wash the pebbles and vegetable fibres remaining on the sieve with water, dry and weigh the residue, and examine the pebbles mineralogically; the water with which this gravel was washed should be evaporated to dryness at a temperature not exceeding $50^{\circ} \mathrm{C}$. towards the close of the evaporation, and the residue mixed with what passed through the dry sieve.

This sifted fine earth is reserved for all the processes hereinafter described, and is kept in well-stoppered bottles, marked air-dried fine earth. 
SILT ANALYSIS.

97. This air-dried fine earth may be separated, still further, into portions of different degrees of fineness by a series of sieves, or, in a quicker and better manner, by the process of silt analysis.

a. To perform this with Nöbel's apparatus (fig. 6), weigh out 30 grms. of the air-dried soil, and boil it for a long time with water, until the lumps are completely broken up; the operation may be facilitated by gentle trituration with a small pestle; in the case of very sandy soils, it will be finished in half an hour, but for very heavy clay soils, two or three hours may be required.

When this is completed throw the whole mixture of soil and water on a sieve with meshes $1 \mathrm{~mm}$. wide, rinse the residue on the sieve well with water, dry it at $100^{\circ} \mathrm{C}$., and weigh it; that which passes through the sieve, and the washings, are reserved for the silt analysis proper.

The water reservoir of Nöbel's apparatus should hold about 10 litres, and the siphon tube that enters it should extend down just far enough to allow 9 litres of water, and no more, to flow out; the other arm of the siphon should be $60 \mathrm{~cm}$. long, and should have just as large a bore as the tube of the funnel with which it is connected. The relative capacities of the four silt funnels, Nos. $1,2,3$, and 4 , are $1: 8: 26: 64$; together, they hold 5 litres; the mouth of the largest funnel where the water finally flows out of the apparatus should be provided with a tube drawn out to a point, that is filed off until the orifice is of such a size that, when all the funnels are filled with water, and the connection with the reservoir is made as above directed, 9 litres will flow through in exactly 40 minutes.

A large flask or beaker must be provided to receive the water as it flows out of the largest funnel.

The fine earth, that passed through the sieve with 8 
meshes $1 \mathrm{~mm}$. wide, is stirred up with water; in case there is reason to suppose that funnel No. 2 will not hold all this mixture of soil and water, a part of the latter, holding only the finest particles in suspension, may be put in funnel $\mathrm{No} .3$; then pour the rest of the mixture, just after it has been well stirred, into the second funnel,

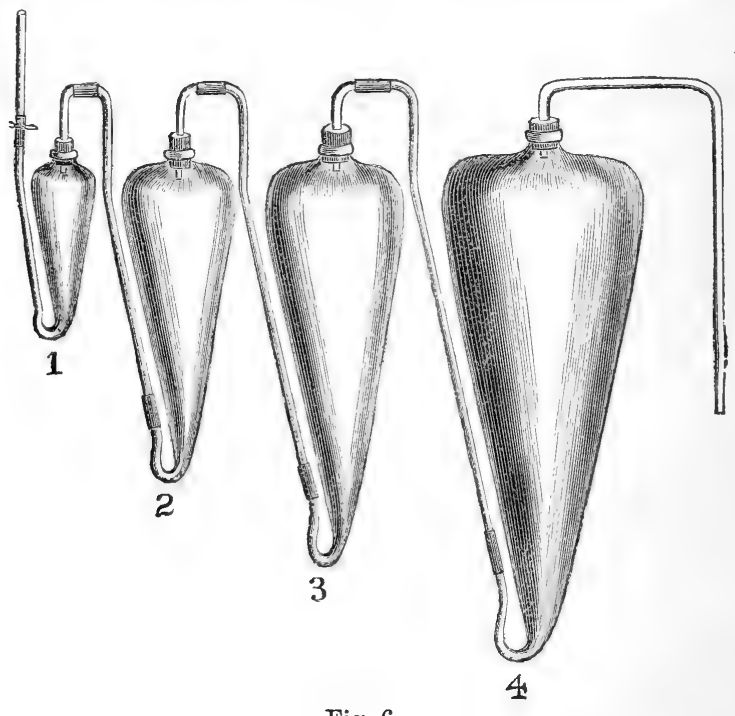

Fig. 6.

while any very coarse sand remaining in the beaker may be rinsed into the first funnel; but it is better to put the whole in the second funnel, if possible.

All the funnels are then filled with water, the connections carefully made between them with gum tubing, and the siphon leading from the reservoir is filled and connected with the smallest funnel. As soon as 9 litres of water have passed through, the connection with the reservoir is closed by means of a clamp on the gum tube. The whole apparatus is then allowed to stand about five hours, until the solid matters in the funnels have 
settled to the bottom; then draw off the clear supernatant liquid from each funnel with a siphon, and transfer each portion of the sediment to a separate evaporating dish, except that the contents of funnels 1 and 2 should be mixed together; dry each portion at $125^{\circ} \mathrm{C}$., and weigh it. After this, ignite each one and weigh again, and thus determine the amount of organic matter in it.

By this operation the soil is separated into at least five portions, of different degrees of fineness.

1. The residue on the sieve.

2. The contents of funnel No. 2.

3. ". " " " "No.3.

4. "6 "6 "6 No. 4.

5. The sediment deposited from the water that flowed through the whole apparatus, and the still finer portions remaining suspended in the water even after several hours. These two may be separately determined, if it is desired, by collecting, drying, and weighing the sediment that is deposited after several hours, and then estimating the still finer portion that remains in suspension, together with the hygroscopic water of the soil, by the difference between the 30 grms. of soil taken originally, and the sum of these five residues; then on subtracting from this remainder the hygroscopic water, as determined in another portion of the soil, we have the weight of the sixth portion; or, the fifth and sixth may be estimated together, in a similar manner, and without collecting the sediment deposited in the beaker.

To clarify this liquid more speedily, A. Müller (Journal für Prakt. Chemie, 95, 92; Fresenius's Zeitschrift, 5, 243) recommends the following process. Prepare a solution of an ammoniacal soap, with the aid of stearic acid, ammonia, and alcohol, add it to the turbid liquid until the mixture gives considerable foam when violently agitated, then acetic acid until the reaction of the liquid is decidedly acid, and stir or shake the whole vigorously; 
the fatty acid that is set free by the aretic acid envelopes the fine particles of earth, and the flocculent sediment can be filtered out without difficulty. The fatty acid may then be removed from the other solid matters, with which it is mixed, by ignition, or by treatment with alcohol, and the residue will represent the finest portion of the soil.

b. The following method of silt analysis, by Dietrich (Fresenius's Zeitschrift, 5, 296) is preferred by some to that described above; the apparatus may be easily constructed out of the ordinary stock of the laboratory.

The water is caused to flow, under a constant pressure of 1 metre, through a series of four tubes of different sizes, and inclined to the horizon at different angles, as follows ;

\begin{tabular}{|c|c|c|c|}
\hline $\begin{array}{l}\text { Number } \\
\text { of } \\
\text { the tube. }\end{array}$ & Length. & Diameter. & $\begin{array}{c}\text { Angle between its axis } \\
\text { and a } \\
\text { horizontal plane. }\end{array}$ \\
\hline $\begin{array}{l}1 \\
2 \\
3 \\
4\end{array}$ & $\begin{array}{ll}17 & \mathrm{~cm} . \\
34 & 66 \\
51 & 6 \\
68 & 6\end{array}$ & $\begin{array}{l}2.8 \mathrm{~cm} . \\
4 \\
5.2 \text { ، } \\
6.4 \text { ، }\end{array}$ & $\begin{array}{l}90^{\circ} \\
67.5^{\circ} \\
45^{\circ} \\
22.5^{\circ}\end{array}$ \\
\hline
\end{tabular}

Each tube is drawn ont at one end so that a rubber tube can be attached to it, while the other end is closed with a rubber cork, through which a short glass tube passes; each tube is connected with the next larger one by a rubber tube passing from the corked end of the former, which is at the same time the upper end, to the lower, tapering end of the latter, and the water flows from the upper end of one tube to the lower end of the next larger one. Each rubber tube is cut in the middle of its length, and the cut ends are connected together by a short glass tube; each rubber tube also has a clamp on it, by means of which the flow of the water can be regulated. The $30 \mathrm{grms}$. of soil, prepared as for the silt analysis with Nöbel's apparatus, are put in the first 
tube, and the flow of the water through the apparatus is continued until it comes away from the last tube tolerably clear. The remainder of the operation is conducted in the same manner as when using Nöbel's apparatus.

THE CHEMICAL ANALYSIS.

98. The soil for this analysis should always be taken in its natural, air-dried condition, without previous ignition to expel the organic matter, since the ignition may at the same time alter very materially the effect of the agents employed for solution.

a. Hygroscopic water and other volatile matter.Determine the amount of water expelled at $100^{\circ} \mathrm{C}$. from 10 grms. of soil $(\$ 90)$, and then ignite the dried residue to determine water chemically combined or otherwise retained at $100^{\circ} \mathrm{C}$, humus, and volatile mineral substances (§91); the ignited residue should be treated with ammonic carbonate, if a qualitative test reveals the presence of carbonic acid in the soil, and carbonic acid should be determined in the ash $(\S 91, d)$.

A. Müller allows but little value to this estimation of water of hydrates in the soil, and organic matter, even when combined with the determination of carbonic acid both before and after ignition.

b. Estimate carbonic acid in 5-10 grms. of soil, dried at $100^{\circ}(\S 60, b)$.

c. Determine the total nitrogen in 5-10 grms of soil, dried at $100^{\circ}$, by combustion with soda-lime ( $\left.\$ 85\right)$.

A. Müller mixes the soil with about an equal quantity of caustic potash or soda, instead of with soda-lime, but fills the rest of the tube with soda-lime in the usual manner; in this way he avoids the use of very long combustion-tubes.

If much nitrate is present in the soil, and but little hu- 
mus, it will be safer to add $0.2-0.4$ grm. of pure cane sugar to the sample in which nitrogen is determined; otherwise some of the nitrogen may escape conversion into ammonia; a small pqrtion of the sugar should be ignited by itself with soda-lime, either to determine the amount of nitrogen it contains, or to be sure of its freedom from that impurity.

d. In order to determine the solubility of the various elements of plant-food in the soil, it is necessary to treat it successively with different solvents, and with these of various degrees of strength; in order that the results obtained by different chemists may be compared with each other, it is absolutely essential that these solvents should be applied in the same order and in the same manner.

A convenient and useful order is the following:

1. Cold, distilled water, $\left.{ }^{1}\right|_{t}$ saturated with carbonic acid.

2. Cold concentrated hydrochloric acid (Sp. Gr. = 1.15).

3. Boiling concentrated hydrochloric acid of the same strength.

4. Hot concentrated sulphuric acid.

5. Hydrofluoric acid.

The solutions obtained by the treatment of the soil with these agents in succession will be found to differ very much in their composition, and to yield data for very interesting deductions in regard to its natural fertility.

Unless, however, a very complete analysis is desired, but one of these solutions, viz., that in cold coneentrated hydrochloric acid, need be examined quantitatively; next to this, the solution jin hot hydrochloric acid is of greatest importance; we shall, therefore, consider the treatment of these first of all.

Solution in Cold Concentrated Hydrochloric Acid.

99. Put 450 grms. of air-dried soil in a large, glass- 
stoppered bottle, and pour over it 1500 c.c. of pure concentrated hydrochloric acid $(\mathrm{Sp} . \mathrm{Gr} .=1.15)$, and shake the mixture frequently during a digestion of 48 hours, at the common temperature of the working-room; then let it stand until 1000 c.c. of at least a tolerably clear liquid can be poured off or drawn off with a siphon; this quantity of the solution represents $\left.{ }^{2}\right|_{3}$ of 450 grms., or 300 grms. of the soil taken for the analysis; dilute the liquid with its volume of water, and filter it.

If the soil contains a very large proportion of calcic carbonate, the cold acid solution may be filtered off after dilution with its volume of water, and the whole quantity used for the analysis, representing the whole of the soil taken; in this case, wash the insoluble residue carefully first with cold and then with hot water, dry it at $100^{\circ} \mathrm{C}$, and weigh, to determine the proportion of the soil insoluble in cold acid; 5-10 grms. of this may be ignited, to determine the organic matter in the insoluble portion; then reserve the rest for treatment with sodic carbonate, to determine soluble silica, and with hot concentrated acid.

Evaporate the solution to dryness with the addition of a few drops of concentrated nitric acid towards the close of the evaporation, to oxidize ferrous oxide and organic matters, and eliminate silica $(\S 58, a, 1)$.

Dilute the filtrate from the silica to 1000 c.c., and analyze it according to Scheme II., § 94 , taking 400 c.c. for $a, 200$ for $b$, and 400 for $c$.

In $b$, a slight insoluble residue often remains, on dissolving the precipitate by sodic acetate in hydrochloric acid; in this case, dry the residue, ignite it and the filter, digest the ash a long time with concentrated hydrochloric acid, filter if necessary, and add the filtrate to the remainder of the solution of the precipitate by sodic acetate in hydrochloric acid, ignite and weigh the insoluble residue, if there is any, and add it to the silicic acid. 
If the soil is very rich in organic matter, it will be better to treat 500 c.c. of the solution with sodic carbonate and potassic nitrate, or with chlorine, as directed in $\S 93, \mathrm{~A}$, and use $\left.{ }^{2}\right|_{5}$ of the solution finally obtained for $b$, omitting, of course, the determination of the alkalies in this portion of the solution unless the oxidation was effected with chlorine, and $\left.{ }^{3}\right|_{5}$ for $c$.

Sometimes, however, when there is not a very large proportion of organic matter present, and the above treatment for oxidation is not followed, traces of organic matter are contained in the solution of ferric oxide obtained in $b$, for estimation with permanganate; where great accuracy is required therefore, it would be well, after having titrated the ferric solution once, to reconvert the ferric oxide into ferrous, with zine or sulphurous acid, titrate the solution again, and to repeat this until a constant result is obtained. The same mode of procedure should be followed, also, in estimating the strength of the permanganic solution.

In accurate soil analyses, the phosphorie acid should be estimated twice.

In a complete soil analysis, it is desirable to determine the silicic acid, which, after treatment of the soil with cold concentrated hydrochloric acid, is soluble in a concentrated solution of sodic carbonate.

For this purpose, take $5-10 \mathrm{grms}$. of the residue that was insoluble in the acid, in case of a soil rich in carbonates; or, digest 25 grms. of the air-dried soil with three times the quantity of cold concentrated acid, 48 hours in the cold, filter, and wash the contents of the filter perseveringly, first with cold and afterwards with hot water, and use this residue.

Boil this insoluble substance and also an equal amount of the original air-dried soil, with sodic carbonate, in tho manner described for the separation of sand and silica $(\S 58, a, 2)$. The difference between the amounts of 
silicic acid dissolved in the two cases furnishes a means of estimating the extent of the action of the cold acid on the silicates in the soil.

\section{Treatment of the Soil with Carbonated Water.}

100. To determine only the total quantity of organic and inorganic matters in the soil, soluble in water containing carbonic acid in solution, without reference to the composition of the dissolved substances, put 500 grms. of air-dried soil in a flask that can be well stoppered, and pour over it as much carbonated water as will make, together with the hygroscopic water in the soil, 2000 c.c. The water should be ${ }^{1}$ saturated with carbonic acid, by saturating 500 c.c. at the common temperature and pressure, and mixing this with 1500 c.c. of pure water. When thus prepared, the water is more nearly like that in the soil, whose action we wish to imitate.

Leare the soil and water in contact with each other three days, with frequent agitation, then pour off 1000 c.c. of as clear a liquid as possible, representing $250 \mathrm{grms}$. of soil, and filter through a double filter, while keeping the fumel well covered with a glass plate. Evaporate the clear filtrate to dryness at a temperature below boiling, dry the residue at $125^{\circ} \mathrm{C}$., weigh, ignite, and after treatment several times with ammonic carbonate and gentle ignition, weigh again. The difference between the two weights gives the amount of organic matter dissolved by the carbonated water.

The carbonic acid is determined in the ignited residue, as in $\S 60$.

If a detailed chemical examination of the solution in carbonated water is to be made, at least $1500 \mathrm{grms}$. of soil must be taken instead of 500 , and the water in the same proportion. After three days, pour off 4000 c.c. of the clear supernatant liquid, representing two-thirds of the soil, let it stand 24 hours in well-closed and full bottles, filter as directed aborc, and without disturbing $8 *$ 
. the sediment at the bottom of the bottles. If a clear filtrate is not obtained in this way, it must be evaporated down to 400 or 500 c.c., just barely supersaturated with hydrochloric acid while still hot, and then filtered again.

Evaporate the solution to dryness, with the addition of a few drops of nitric acid towards the close of the evaporation, to peroxidize the iron and destroy organic matter, and eliminate silicic acid. $(\S 58, a, 1$.

Treat the filtrate from the silica as in Scheme I., $\$ 94$. Alumina, ferric oxide, and phosphoric acid, are usually present, however, in such small quantities in this solution, that it is hardly worth while to determine at least the first two.

Interesting results may be obtained by the successive treatment of the same portion of soil with carbonated water, and a chemical examination of each solution; the proportion may thus be learned in which the more important elements of plant-food are taken up by the successive aqueous extracts, and data are obtained for estimating, not only the general richness of the soil in valuable elements of plant-food, such as phosphoric acid and potassa, but also the relation between the immediate fertility of the soil and the durability of its fruitfulness.

A very great decrease in the amount of the elements of plant-food in the second and third extracts, as compared with the first, would indicate that the fertility of the soil would be very much lessened in a single season. If, on the contrary, there is but little diminution observed even in the fifth extract, the power of the soil to produce crops will probably remain about the same, year after year, for a long time.

To obtain these successive extracts, replace the 4000 c.c. that were poured off for the first extract, by an equal quantity of fresh water $\frac{1}{4}$ saturated with carbonic acid as before, let stand three days with frequent shaking, pour 
off 4000 c.c. again, and repeat this operation for the third and fourth time, or even more, as may be desired.

Ulbricht found, that after the third or fourth extract, the amount dissolved, at least by distilled water free from carbonic acid, remained nearly constant, and that tho composition of one of these last extracts would furnish the means for estimating the lasting fertility of the soil.

It will usually answer to examine quantitatively the first, third, fifth, and seventh extracts by carbonated water.

Interesting results may be obtained also by treating the soil in the manner above directed with water containing $0.5 \mathrm{grm}$. of ammonic chloride in the litre, in addition to the usual charge of carbonic acid.

\section{Treatment of the Soil with llot Concentrated Iydrochloric Acid.}

101. If the soil contained a very large proportion of calcic carbonate, the residue insoluble in cold acid may be treated with hot acid; otherwise the separation of the insoluble from the soluble part by filtration is too difficult, and it is better to begin with a fresh portion of soil. Pour 300 c.c. of concentrated acid over 150 grms. of the air-dried soil, or over the whole of the residue insoluble in cold acid in case carbonates were present in large quantity, in a large flask, add a few drops of nitric acid to oxidize slimy matters that might obstruct the filter, heat to boiling with constant agitation, and continue to boil gently for exactly an hour; dilute the solution with twice its rolume of water, and, after letting the mixture stand quietly for a short time, decant the liquid into a filter that is double at the bottom; treat the insoluble residue in the flask at least three times with boiling water, filter the liquid each time, and finally bring the residue itself on the filter, and wash it thoroughly with boiling water.

Evaporate the solution and washings to dryness, with 
the addition of a few drops of nitric acid towards the close of the evaporation, to destroy organic matter and oxidize ferrous salts, and eliminate silica. $(\$ 58, a, 1$.

Examine the filtrate from the silica, which is to be made up to 1000 c.c. and well mixed, according to Scheme II., § 94 .

Or, in order to have a larger quantity of solution for the determination of phosphoric and sulphuric acids, the analysis may be performed by Scheme I., in which $a$ and $b$ may be united, and the sulphuric acid determined as usual, while half the filtrate from the precipitate by ammonia for phosphoric acid will answer for the determination of the alkalies.

\section{Examination of the Residue Insoluble in Hot Ilydro- chloric Acid.}

102. Dry it, and remove it from the filter as completely as possible, burn the latter, and weigh ash and residue, and separate the carefully prepared mixture of the two into three accurately weighed portions of 10 grms. $(a)$, 10-15 grms. (b), and 15-20 grms. (c).

a. Ignite this portion, to determine the amount of mineral matter insoluble in the hot acid.

$b$. In this portion determine the silica soluble in carbonated alkali. $(\S 58, a, 2$.

c. Pour five times its weight of concentrated sulphuric acid over this portion, heat until the excess of acid is removed, and the residue forms a light, dry powder; the evaporation of the acid should be performed slowly and with constant stirring, and should require from six to eight hours. Moisten the residue freely with concentrated hydrochloric acid, remove this acid by long heating in the water-bath, boil the residue repeatedly with water to which a little hydrochloric acid has been added, filter, and wash the insoluble residue carefully.

Examine the solutions and washings, after concentration, according to Scheme VII., $\S 94$. 
The amount of lime is usually small. Wolff directs that the filtrate from the precipitate of calcic oxalate be evaporated to dryness, the residue ignited gently in a platinum dish, to expel ammoniacal salts, dissolved in dilute acid, and any silicic acid that may appear as an insoluble residue be filtered out; then add ammonia in slight excess to the filtrate, filter out any floceulent precipitate of alumina that may also appear, and finally determine sulphuric acid with baric chloride.

This treatment of the soil with sulphuric acid serres to determine the amount of clay in it, and Wolff has found, by repeated trials, that the clay is completely decomposed if the operation is carefully performed. IIe gives importance to the determination, for it furnishes data for controlling the results obtained by the silt analysis, and because it gives valuable information in regard to the degree of insolubility of the other constituents of the soil, and particularly the alkalies.

The process is a good connecting link between the treatment with hydrochloric acid on the one hand and hydrofluoric acid on the other.

\section{Examination of the Residue Undecomposed by Sul- phuric Acid.}

103. a. Dry this residue at $100^{\circ}$, burn the filter by itself, and weigh the ash and residue; mix them well together, and, in half of the mixture, determine silica soluble in alkaline carbonates. $(\S 58, a, 2$.$) The silicic acid$ thus found, together with the small quantity in the hydrochloric and sulphuric acid solutions, gives, in connection with the alumina found in the same solutions, an approximate estimate of the pure anhydrous clay in the soil. This amount of silicic acid is, in general, too large in proportion to that of the alumina, for a part of it was combined with ferric oxide, lime, etc.

The clay that is decomposed by the sulphuric acid 
alone is very nearly pure, while it is that which is dissolved by the hydrochloric acid that contains too much silica.

Ignite the other half of the residue, to determine the amount of mineral matters insoluble after treatment with sulphuric acid.

Pulverize the ignited mass very finely in an agate mortar, separate the finer from the coarser portions by levigation $(\S 36)$ with distilled water, pulverize the coarse part again, and repeat the levigation; when in this way the whole is reduced to the finest possible powder, evaporate the water to dryness with the matters in suspension in it, weigh out $3-4$ grms. of the well-dried residue, and treat it with hydrofluoric acid or ammonic fluoride $(\S 58, c)$.

Examine the solution thus oltained according to Scheme VII., \& 91. The determination of ferric oxide will, however, be necessary only when the precipitate by ammonia is yellowish or reddish.

If, as is usually the case, the solution is found to contain only traces of lime and magnesia, the amount of feldspathic minerals and of pure quartz sand in this insoluble part of the soil can be estimated from the amount of alkalies found; and, from the amount of aluminic silicate, it may be judged how perfectly the clay was decomposed by the previous treatment with sulphuric acid.

b. According to A. Müller, the relative proportion of silicates and quartz sand in a soil can be determined with accuracy by digestion with phosphoric acid at a certain temperature; all the silicates are decomposed by this treatment, and the silica is separated in a gelatinous form while the quartz sand remains unchanged.

For this purpose a syrupy acid is required containing $40-\left.45^{\circ}\right|_{0}$ of anhydrous acid; it may be obtained by concentrating the commercial acid.

The insoluble residue to be treated with the acid must be very finely pulverized, but it need not be levigated; 
the amount of phosphoric acid required depends upon the amount of silicates present, and at least 15-20 grms. should be taken for $\mathbf{0 . 5}-1.0 \mathrm{grm}$. of the substance. The mixture is heated in a platinum dish in an air-bath to 190-200 C., and digested five or six hours at this temperature, while constantly stirred with a platinum spatula.

The resulting mass is boiled several times with water containing $\left.1^{0}\right|_{0}$ of sodic hydrate, the clear liquid decanted off each time, and the sandy residue itself is finally brought on the filter and washed carefully with acid, alkali, acid again, and finally with water, ignited and weighed.

\section{MISCELLANEOUS ESTIMATIONS.}

104. $\alpha$. Inmus.-Weigh out 5-10 grms. of the airdried soil, pour over it 200 c.c. of water in the flask of the apparatus for determining carbonic acid $(\$ 60, b)$, and 30 c.c. of concentrated sulphuric acid; shake the mixture gently and let it stand some time until it has become quite cold, meanwhile changing the air in the flask sereral times by blowing into it, so as to remore all the carbonic acid expelled from carbonates in the soil by the stronger acid.

Now, put $7-8$ grms. of coarsely pulverized potassic dichromate in the flask (or, better still, 5 grms. of pure chromic acid), or such a quantity that there will be $\mathbf{1 7}$ parts of chromic acid for one of organic matter, as determined, approximately at least, in the beginning, by ignition $(\$ 98, a)$; apply a gentle heat, and proceed to collect the carbonic acid evolved as in $\$ 60, b$, except that a $U$ tube filled with iron wire should be interposed between the flask and the $\mathrm{U}$ tube $f f^{\prime}$, to absorb chlorine, and except, also, that no nitric acid need be added to the substance. Towards the close of the operation, boil the contents of the flask five minutes, and finally draw air through in the usual manner. The carbonic acid is 
set free by the oxidation of the humus by the chromic acid.

Since humus contains on an average $58^{\circ} \%_{0}$ of carbon, multiply the quantity of carbonic acid found by 0.4702 , for the amount of humus.

The difference between the sum of the humus and the nitrogen and the total loss suffered on ignition (§98) gives the amount of water, chemically combined or otherwise retained at $100^{\circ} \mathrm{C}$.

Some information in regard to the nature of the organic matter, and the extent to which decay has progressed, may be obtained by comparing the amount of humus, or of the carbon in it, with that of the nitrogen, by a microscopic examination of the various products of the silt analysis and by the loss suffered by these c: ignition, and also by the following tests.

1. The reaction of the soil or of the humus contained in it, which is tested by allowing moistened lumps of the soil to remain in contact with carefully prepared blue and red litmus-paper; a change from blue to red may be caused by carbonic acid, but, if the red color remains after the paper is thoroughly dry, the change was due to acids of the humus, unless the soil gives the same reaction after gentle ignition, in which case it may have been caused by acid sulphates.

2. Mix 100 grms. of the soil with 200 c.c. of a standard ammoniacal solution of calcic nitrate of such a strength that 200 c.c. contain 1 grm. of lime, and an amount of ammonia chemically equivalent to this amount of lime. After frequent shaking of the mixture in the course of 24 hours, filter, and determine lime in a measured quantity of the filtrate; the lime that is missing was, according to Knop, absorbed by the humus, and may be taken as an approximate measure of the amount of the same.

3. To determine the amount of organic matter, mainly 
in the form of humus, that is extracted from the soil by water or alkaline solutions, the following method is given by Schulze. Boil 10 grms. of soil 15 minutes with 200 c.c. of a solution containing $0.5^{\circ} \%_{0}$ of potassa, bring the volume of the whole to 250 c.c., pour the liquid on a dry filter, or through dry, fine-grained sand with which the throat of the funnel is stopped; put 4-6 c.c. of the filtrate in a flask of about 200 c.c. capacity, dilute with about 100 c.c. of water, and determine organic matter in 100 c.c. of this solution by means of standard solutions of potassic permanganate and oxalic acid $(\S 91, e)$.

b. Ammonia.-The amount of ammonia existing already formed in soils is nearly always very small, since it is so readily converted into nitrates.

To determine it by Schlössing's method $(\$ 47, b)$, treat 50 grms. of soil with 40 c.c. of a cold saturated solution of sodic hydrate. After 48 hours remove the acid from under the bell-jar, titrate it, stir the soil in the watchglass, put another measured portion of acid in the proper vessel, and, after 48 hours, titrate this also with the standard sodic solution. If no more ammonia was set free during the second period, the first determination may be considered sufficient; if more was set free, it should be added to the first quantity found, and a new portion of acid should be put in, in the place of the last, and tested after 48 hours.

It may also be desirable to estimate the ammonia that is set free on heating the soil with magnesia. Pour 500 c.c. of water containing 5 grms. of freshly ignited magnesia over $100 \mathrm{grms}$. of soil, mix the whole well together, and proceed to distil off the ammonia $(\S 47, c)$.

Probably no great reliance can be placed on any method of determining ammonia in soils.

c. Nitric acid.-The accurate determination of nitric acid is not difficult, as the nitrates are so easily extracted from the soil by water. 
To 1000 grms. of the soil add water enough to make 2000 c.c. with that already in the soil, shake the mixture frequently in the course of 48 hours, decant and filter 1000 c.c. through a dry filter, add some sodic carbonate to the filtrate, evaporate the solution to a small bulk on the water-bath, and divide the residue into two equal parts. Determine nitric acid in each portion, representing 250 grms. of soil, in the usual manner ( $\$ 62 a)$.

d. Chlorine.-To determine this, add enough water to 300 grms. of the air-dried soil to make 900 c.c. with what is already contained in it, shake the mixture frequently in the course of 48 hours, decant and filter 450 c.c. of the liquid, add a little sodic carbonate to the filtrate, evaporate to about 200 c.c., filter again, supersaturate the filtrate, which represents 150 grms. of soil, with nitric acid, and precipitate the ehlorine in the acid solution with argentic nitrate (\$63). Treat the precipitate as one produced in the presence of organic matter.

e. Sulphr.-It often happens that a much larger amount of sulphuric acid is found in the soil after ignition than before, indicating that a notable quantity of sulphur exists there as sulphuret, or in some organic combination. To determine the total amount of sulphur in the soil, mix with 50 grms. of it, 1-2 grms. of pure saltpetre, moisten the mixture in a platinum dish with a solution of pure potassic or sodic hydrate, free particularly from sulphates, dry, and heat gradually to a red heat; when the mass is cool, boil it with. dilute hydrochloric acid to which a little nitric has been added, evaporate to dryness, and eliminate silica in the usual way, but without weighing it; add water to the filtrate from the siliea, and precipitate sulphuric acid with baric chloride.

$f$. Hydrated aluminic and rerric oxides,-To determine the quantity of these substances, that, according to Knop, play so important a part in the absorbent action 
of the soil for valuable elements of plant-food, treat 100 grms. of the soil with 200 c.c. of a hot solution containing in one litre $100 \mathrm{grms}$. of tartaric acid, $10 \mathrm{grms}$. of oxalic acid, and ammonia in slight excess; shake the mixture frequently for 15 minutes, filter, and determine aluminic and ferric oxide in a measured quantity of the filtrate (\$52). The oxalie acid in the solvent serves to prevent lime from being taken up by the tartaric acid. In order to prevent alumina also from being dissolved, Müller recommends the use of Seignette salt instead of ammonic tartrate.

g. Ferrous oxide.-To determine this at least approximately, pour 60 c.c. of hot concentrated hydrochloric acid over 30 grms. of soil in a flask; after having added a few crystals of sodic carbonate, if the soil contains but little carbonate, close the flask with a cork through which passes a short tube bent at a right angle, put the flask in an inclined position on the lamp-stand, and boil the mixture some time. Add a considerable quantity of ammonic chloride to the solution, whereby the tendency of the ferrous oxide to absorb oxygen is very much lessened, dilute with a large quantity of hot water, almost neutralize the acid with ammonia, and precipitate the ferric oxide in the solution with as little sodic acetate as possible $(\S 93, A, 1)$; filter the hot liquid rapidly through a large, coarse filter, and wash the contents of the filter several times with hot water; heat the filtrate and washings to boiling, add some hydrochloric acid, oxidize the ferrous oxide by the addition of a few crystals of potassic chlorate, remove the lamp, and precipitate this solution with sodic acetate, filter, wash, and weigh. The ignited residue is ferric oxide, from which the corresponding amount of ferrous oxide can be calculated. 
ABSORPTIVE PROPERTIES OF THE SOIL.

105. To determine the coefficients of absorption of the soil for the more important elements of plant-food, treat 125 grms. of the air-dried soil with 500 c.c. of a $\left.{ }^{1}\right|_{10}$ atomic solution, that is, a solution containing in 1 litre $\left.{ }^{1}\right|_{10}$ of an equivalent expressed in grammes, of ammonic chloride; shake the mixture frequently during a cold digestion of 24 hours, decant and filter as large a portion of the liquid as possible, and determine the loss of the salt in a measured aliquot part of the filtrate. In some cases it is desirable also to make a complete analysis of this filtrate in order to learn what elements have taken the place of the ammonium in the solution.

Make similar experiments with potassic chloride, magnesic chloride, calcic chloride, hydric disodic phosphate, sodic chloride, and sodic silicate.

Or, according to Knop's methorl, dissolve together potassic and calcic nitrate, common potassic phosphate, and magnesic sulphate, in a litre of water, in such a proportion that the solution shall contain 1.5 grms. of each compound, estimated as anhydrous salt. Treat $195 \mathrm{grms}$. of soil with 500 c.c. of this solution, shake the mixture frequently during 24 hours, filter off 300 or 400 c.c., and make a complete analysis of the solution, according to Scheme I., $a$ and $b$, and determine chlorine in the usual manner in another portion of the same solution (§63).

\section{STATEMENT OF TIIE RESULTS OF TIIE ANALYSIS.}

106. The following Scheme is intended to assist the analyst in putting together the results of a soil analysis; it is conformed mainly with the directions given by Wolff, and the perentages, though hypothetical, do not differ much from the average results of the later analyses of soils that have been made; as the plan is given merely 
$\S 106 . \quad$ StATEMENT OF RESULTS OF ANALYSIS. 189

for the purpose of illustrating the manner of stating the results of the analysis, many of the determinations which are described in the foregoing pages are not noticed here. With this partial guide, no difficulty will be found in stating the whole result of the work in an intelligible manner.

MECHANICAL ANALTSIS.

100 parts of the air-dried soil yielded

Water, expelled at $100^{\circ}, 9.3 \pm$

Residuc on $3 \mathrm{~mm}$. sieve, 6.05 , containing volatile matter........... 0.1

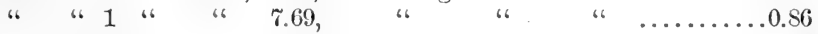

Silt in Funnel No. $2, \quad 34.95$,

" " " " " $303, \quad 17.7$

" " " $\quad$ " $4,5.65$,

$66 \quad 66$

$66 \quad 6$

3.73

$66 \quad 66$

2.16

81.38

Fine clay and finest sand, 18.62

$66 \quad 66$

100.00 Total loss on ignition of soil dried at $100^{\circ}$ 
CHEMICAL ANALYSIS.

100 parts of the soil dried at $100^{\circ}$ yielded

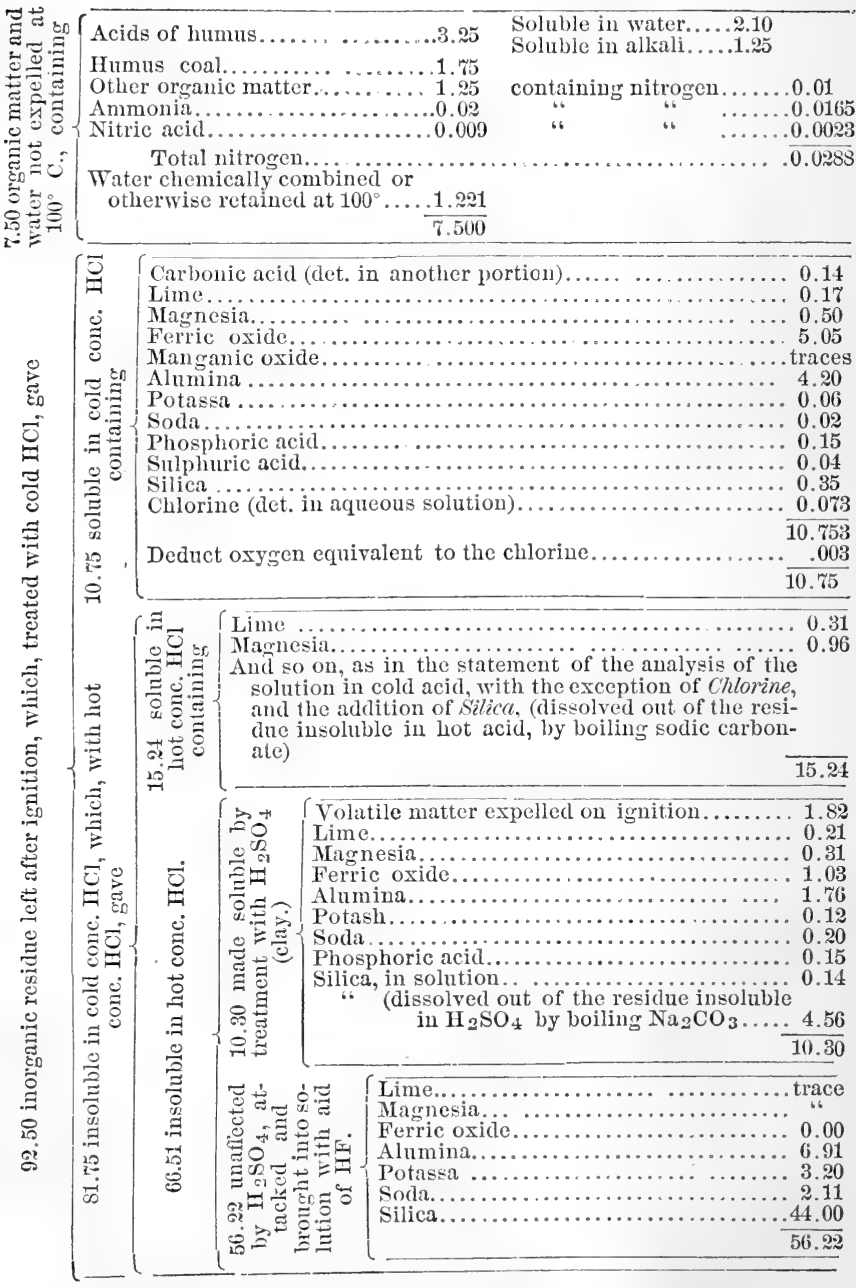


100 parts of soil dried at $100^{\circ} \mathrm{C}$. contain of clay $\mathrm{Al}_{2} \mathrm{O}_{3} 2 \mathrm{SiO}_{2}$, $2 \mathrm{H}_{2} \mathrm{O}$, estimated from the alumina and silica dissolved by acids (See Table III).

a. In the hydrochloric acid solutions.................... 4.56

b. " " sulphuric acid solution....................... 4.41

100 parts of soil dried at $100^{\circ}$ contain of

a. Potassa feldspar, $\mathrm{K}_{2} \mathrm{O}, 3 \mathrm{SiO}_{2}, \mathrm{Al}_{2} \mathrm{O}_{3}, 3 \mathrm{SiO}_{2}$, estimated fiom the potassa in the solution by hydrofluoric acid. (See Table III.).18.94

b. Soda feldspar, $\mathrm{Na}_{2} \mathrm{O}, 3 \mathrm{SiO}_{2}, \mathrm{Al}_{2} \mathrm{O}_{3}, 3 \mathrm{SiO}_{2}$, estimated from the

soda in the solution by hydrofluoric acid.................17.85

c. Clay, undecomposed by the previous treatment with sulphuric acid, estimated from the alumina in the solution by hydro-

fluoric acid in excess of what is required for the feldspars... 0.30

d. Pure quartz sand, estimated from the silica in excess orer what

is required for the feldspars and clay....................19.11

(Estimated also from the determination made with the aid of phosphoric acid).

100 parts of soil dried at $100^{\circ} \mathrm{C}$. yielded to water $1 / 1$ saturated with carbonic acid

Volatile matter, expelled on ignition of the residue left by eraporation of the extract............................. 0.15

Mineral matters..................................... 0.19

$\overline{0.34}$

THE PHYSICAL QUALITIES OF THE SOIL.

10\%. Experiments for testing the physical qualities of the soil, and for comparing different soils in respect to these qualities, should be made with soils of the same degree of dryness and mechanical division, and with tolerably large quantities, and the observations should be made under circumstances resembling those as closely as possible, by which the soil is affected in the field. The following methods have been carefully tested by Wolff himself, and he vouches for their reliability.

The soil must be completely air-dried, pulverized in a porcelain mortar with a wooden pestle, or rubbed between the hands to break up the lumps that were formed in drying, and passed through a sieve with meshes $3 \mathrm{~mm}$. wide. 
a. Relation of the Soil to Vapor of Water.-1. Power of retaining hygroscopic water in its pores.-This is measured to some extent by the determination of hygroscopic moisture ( $\$ 98)$. The proportion of humus remaining about the same, the power of the soil to retain moisture is very closely related to the amount of clay it contains, while this power is greatly increased by an increased proportion of humus.

2. It may be interesting to observe the relation of this property of the arr-tried soil to the temperature.For this purpose, spread a layer of soil, accurately weighed, about $3 \mathrm{~mm}$. thick over the bottom of a shallow zinc tray, and note the changes in weight from day to day, when it is exposed to direct sunlight while protected from eurrents of air, or when exposed to a temperature of $20^{\circ}, 30^{\circ}$, and $40^{\circ} \mathrm{C}$.

Also, expose the soil to an atmosphere that is saturated with moisture, by putting it in the same shallow tray together with a shallow vessel of water, under a bell-jar, and weighing it three or four times every 24 hours. An empty tray of the same size should be put under the same bell-jar, and any changes in the weight of this deducted from the differences in the weight of the other.

Sandy soils and loams usually become nearly saturated in an experiment like this, in the first 24 hours, and change but little in weight thereafter.

The quantity of water absorbed varies of course with the temperature, and with the kind of soil; but these variations are confined within narrower limits than when the soils are exposed to the air under ordinary circumstances. The amount of water absorbed from this saturated atmosphere ranges between 0.2 and $2.5^{\circ} \%_{0}$ of the weight of the completely dry soil.

The same soil, in its tray, may be exposed to the night air, to determine the amount of water that it will condense from the atmosphere under these circumstances; 
§ 10\% THE PHYSICAL QUALITIES OF THE SOIL. 193

careful observations should be made, at the same time, of the temperature, the clearness of the sky, and the amount of the dew-fall, and the experiment should be performed over a grass plot as well as over a freshly stirred soil.

With an average dew-fall, the amount of water taken up by a soil above what it contains in the air-dried state varies, with different kinds of soil, between 0.4 and $1.8^{\circ} \%_{0}$ of the weight of the completely dried soil.

Finally, to sest the effect of the depth of the soil on its power of absorbing moisture under these different circumstances, sereral trays or boxes, of say $\left.{ }^{1}\right|_{2},\left.1^{1}\right|_{2}, 3$, and $6 \mathrm{~cm}$. deep, and $5 \mathrm{~cm}$. square, may be filled with air-dried soil, in all cases equally dry and finely pulverized, and the whole exposed to the ordinary atmospherie influences, or to a saturated atmosphere, or to the night air, in the manner directed above.

By such experiments we may determine how much moisture is absorbed by layers of soil of different thicknesses within a certain length of time, how far the moisture penetrates into different soils in equal times, and how long a time is required to saturate layers of different thicknesses in a saturated atmosphere.

b. The Relation of time Soll to Liquid Water in its Pores.-1. To determine the power of the soil to retain liquid water in its pores, construct a zinc box, $17 \mathrm{~cm}$. deep, and $3 \mathrm{~cm}$. square, and picree its bottom with numerous small holes; lay over this bottom a piece of moistened fine linen, and weigh the box; then put in a small quantity of the properly dried and pulverized soil, tap the box gently on the table a few times, and proceed in the same manner until the box is full, and weigh again. Then immerse the bottom of the box in water to the depth of 3-4 mm.; the water appears at the surface of the soil sooner or later, according to the nature of the latter; let the apparatus remain in the water until it suf- 
fers no further change in weight, and then calculate the amount taken up by 100 parts of the air-dried soil.

As this box, with its wet soil, is used subsequently for experiments in the course of which the soil is dried again, this trial may then be repeated; some soils shrink, while drying, to a greater extent than others, and it will be found that, in this second trial, the power of holding water will not be the same as at first. The difference, however, is but slight.

The power of a soil to hold liquid water increases with the proportion of humus, but diminishes as the quantity of clay increases. A strong clay soil may retain $27.3^{\circ} \mathrm{I}_{0}$, a moderately heavy soil $30-\left.31^{\circ}\right|_{0}$, a sandy loam $33-\left.36^{\circ}\right|_{0}$, a black loam, rich in humus, $\left.41^{\circ}\right|_{0}$. When some soils, that had been tested as above, were tested also in their natural position in the field, after a rain of 14 days, when they might be supposed to be saturated, they were found to contain $10^{\circ} \psi_{0}$ less than was indicated by the results of experiments in the laboratory; hence, the determinations made with small quantities in zine boxes, appear to have value only in so far as they enable us to compare the water-holding powers of different soils.

\section{To determine the readiness with which water evap-} orates from the soil, the wet or damp soil may be exposed, in a shallow tray, to the air, at the common summer temperature, or at that of the laboratory; but so long as a considerable proportion of water is present, the rate of evaporation remains about the same for all soils, provided only that the same amount of surface is exposed; it is also very slow, months being required to bring 100 150 grms. of soil, in a layer no more than $4-6 \mathrm{~cm}$. thick, to the condition of air-dried soil.

When, however, natural circumstances are more closely imitated, and a sufficiently thick layer of soil is experimented with and exposed to the usual alternation of direct sunlight and shade, the characteristic differences of soils 
appear. For a standard of comparison it would be well to carry on, simultancously, one or two similar trials with soils of a marked character, such as a very strong clay soil and a very sandy one, that have been tested before in this respect.

To make the determination, use the zine box filled with wet soil, that was obtained in testing the water-holding power; put each box with its contents in a second box of thick pasteboard, into which it just fits, and then put all these pasteboard boxes close together in a third wooden box, just as deep as the zine boxes; provide the wooden box with a cover, in which holes are so cut that, when the cover is on the box, only the surface of earth in each zine box is exposed.

Put the whole where the sun's rays can fall on the soil, and weigh each zinc box with its contents every two or three days, and during a length of time varying from two to four weeks, according to the weather; frequent observations of the temperature and the state of the sky should be made, while the evaporation is going on.

It will be observed that, in the beginning, the rate of evaporation is about the same for all the varieties of soil under examination, even when exposed to the rays of a hot sun; after a time the sandy soils begin to lose weight more rapidly than those in which clay or humus predominates; the difference increases up to a certain point, and then begins to diminish, until, after a time, the rate of evaporation is nearly the same again for all; this continues for a time, and then the clay and humus soils begin to lose water more rapidly than the light loam, because the latter is, by this time, nearly air-dry.

It is of course more important to watch carefully the rate of evaporation, from the time when it begins to differ in the different soils, to the time when it again becomes about the same for all. 
3. To determine the ease with which water percolates through the soil, construct a zinc box about $25 \mathrm{~cm}$. high and $3 \mathrm{~cm}$. square, with a funnel-like bottom; put some cotton in the bottom, so as to close up the throat of the funnel, and fill the narrow tube, and extend out a little at the mouth of the latter. Fill the funnel above the cotton with coarse quartz sand, moisten the cotton and sand with water, and weigh the apparatus; then carefully fill the box with the properly prepared earth, putting in small quantities at a time, and tapping the box on the table after each portion is added; when the box is filled to within $9 \mathrm{~cm}$. of the top, weigh the whole again; then, just saturate the soil by carefully pouring on water in small quantities at a time, until it appears at the bottom; when it has ceased to drop through, weigh the box and its contents again, and the result may be used to confirm that obtained before for the water-holding power of the soil.

Now carefully fill the box with water to within $1 \mathrm{~cm}$. of the top without disturbing the surface of the soil, cover with a glass plate, and observe how long a time is required for 50 c.c. of water to pass through. If the operation is repeated, by filling the box with water again, after the first quantity has passed through, it will be found that a somewhat longer time is required; three such tests may be made, and the mean of the three results taken.

\section{To determine the rapidity with which water will} move upwards in the soil, fill a glass tube about $80 \mathrm{~cm}$. high and $1.5-2 \mathrm{~cm}$. in diameter, graduated in cubic centimetres, and closed at its lower end with a piece of fine linen that is tied over the end, with the air-dried soil, tapping the tube gently on the table while filling it; then immerse the lorrer end of the tube in water $3-4 \mathrm{~mm}$. deep, and observe how long a time is required for the water to rise to a height of 70 or $80 \mathrm{~cm}$, , or how high 
§ 10\%. THE PHYSICAL QUALITIES OF THE SOIL. $19 \%$

the water will rise in $24 \mathrm{or}^{\circ} 45$ hours; it will be found to rise more slowly in humus and clay soils than in light, sandy ones.

\section{The rapidity with which water will make its way} downwards in the soil may be determined in the same tube, partly filled with a fresh quantity of earth; fill the tube above the soil with water to the depth of $4-8 \mathrm{~cm}$, and note the time required until it has reached a given depth, or how soon the water disappears from the surface of the soil, snd also how far a given quastity, that is insufficient to make its way through and moisten the soil quite to the lower end, will penetrate downwards.

It will be found that the same quantity of water will go furthest in a fine loam or a sandy soil.

c. The Pelation of the Soll to Heat.-1. To determine the power of the soil to absorl heat, fill a cubical zinc box, about $6 \mathrm{~cm}$. square, with soil, expose it several hours to the direct rays of the sun on a hot day, carefully observe the temperature in the sun during the experiment, and the clevation of temperature in the uppermost centimetre of the soil. The zinc box should be inclosed in a box of thick pasteboard, and this in a wooden box, to prevent access of heat at the sides.

It may also be interesting to observe the heating power of the sun's rays on the soil, while it is in a more or less moist condition, say with 5,10 , or $\left.20^{\circ}\right|_{0}$ of water, more than that naturally present in the soil. Such determinations may be made by exposing about $50 \mathrm{grms}$. of the moistened soil for several hours in a glass flask to the direct rays of the sun, and noting the changes of temperature.

2. The power of the soil to conduct heat may be determined by putting the same box, as used in the previous experiment, into hot water, anả observing how long a time elapses before the temperature of the earth in the 
centre of the box has reached a given point, say $70^{\circ}$ or $80^{\circ} \mathrm{C}$.

3. The power of the soil to retain leat may be determined by exposing the box of heated soil, obtained in either of the preceding experiments, to the common temperature of the air in the shade, and observing how long a time is required for the soil in the middle of the box to cool to the temperature of the air, or to a given point, as $20^{\circ}$ or $25^{\circ} \mathrm{C}$.

The behavior of the soil with respect to the heat of the sun and of the atmosphere is of great agricultural importance, and should be more carefully examined than has hitherto been the case, by the careful performance of experiments like those described above, and by series of observations on the temperature of the soil in the field at various depths, ranging from $3 \mathrm{~cm}$. down to one metre or more.

d. Tine Specific Gravity of the SoIL. - 1. This may be determined in the usual manner for a powder $(\S 35, b)$.

A soil rich in humus is specifically the lightest, and coarse sandy soils are the heaviest.

2. The absolute weight of the soil is determined by filling a glass ressel, or a cubical zinc box, whose weight and capacity are known, with it, tapping the vessel occasionally on the table while filling it, and weighing it. The weight of a cubic metre or a cubic foot can then be calculated from the result; the apparent specific gravity can be estimated by the ratio between the weight of this volume of soil and that of an equal volume of water.

3. The apparent specife gravity of the soil dried at $100^{\circ} \mathrm{C}$. may be estimated by subtracting the volume of the water contained in the quantity of air-dried soil that was weighed in this experiment from the volume of the soil, and then a volume of water equal to the remainder is taken for the divisor, and the weight of the soil dried at $100^{\circ}$ for the dividend. 
§ 10\%. THE PHYSICAL QUALITIES OF THE SOIL. 199

4. The porosity of the soil, or the ratio between the volume of the solid particles and that of the spaces in it filled with air or moisture, is estimated by dividing the apparent specific gravity of the soil, dried at $100^{\circ}$, by the real specific gravity. Or if, for example, $2.5445=$ the real specific gravity of a certain soil, and 1.099 its apparent specific gravity, then from the proportion,

$$
2.5445: 1.099=100: 43.2,
$$

we get the volume of the solid particles in 100 parts of the soil, and $100-43.2=56.8=$ the volume of the pores.

The porosity of the soil, just as it lies in the field, may be estimated in a similar manner, by taking as the volume of the soil the space that was occupied by the quantity taken out to be weighed.

\section{To determine the volume occupied by the soil when} completely saturated with water, determine the volume of $40-50$ grms. of the air-dried, pulverized soil in a graduated tube, that was filled with the earth in small portions at a time, with occasional tapping on the table, shake the soil up well with water containing $0.5^{\circ} \%_{0}$ of ammonic chloride; then let the whole stand quietly, while the solid particles collect together in the lower part of the tube, and observe the volume occupied by this wet soil. By dividing the second volume by the first, the result is put in a convenient form for comparison.

e. Consistency, Tenacity, and Adhesive Power of тнE SorL.-The consistency of the soil when dry, its tenacity, and the force with which it adheres to wood and iron, are very important qualities; but it is hardly possible, by any of the methods in use for estimating them, to get even approximately accurate results with small quantities of soil. The following methods were devised and used by Schübler thirty years ago.

1. To determine the consistency of the soil, or the force with which its particles cohere together when dry, 
knead a small portion of it into a thick dough with water: and, with a spatula, make several prisms $5 \mathrm{~cm}$. long, and $1 \mathrm{~cm}$. square on the end; let them dry in the air; and then observe what weight must be laid on the back of a knife in order to force it through each one. The same prisms may be used to determine how much the soil shrinks on drying, by noting the difference between their lengths when wet as at first, and after they are dry.

\section{To determine the force with which the soil adheres} to wood or iron, fill a cubical zine box about $6 \mathrm{~cm}$. square and deep, whose bottom is pierced with small holes, and covered with a piece of linen, with the soil, shaking it down frequently while filling; then immerse the bottom of the box in water, and, when no further increase of weight is observed, lay a smooth piece of beech wood, 3 $\mathrm{cm}$. square, on the wet surface of the soil, press it down for the space of ten minutes, by a weight of $100 \mathrm{grms}$., attach the disk to one arm of a balance, and observe what weight must be put in the pan connected with the other arm, in order to detach the disk from the soil. Try a similar experiment with a disk of iron.

EXPERIMENTS WITH PLANTS IN CONNECTION WITH ANALY. SIS OF SOILS.

108. The further development of soil analysis on one hand, and its simplification on the other by eliminating useless or unnecessary determinations, can be accomplished only by combining suitable experiments with modes of culture and manuring, and growing plants, with accurate analyses of the soils used.

In the field but little can be done in this way, since so much care and labor are required, in order to obtain a tolerably fair representative sample of the soil, even of a small plot.

Not seldom, however, a more luxuriant vegetation is 
observed in one part of a field than in another, although the nature of the soil and the mode of treatment are apparently the same throughout; in such a case, much may possibly be learned, by a careful comparison of the amounts of the crops taken from the two parts of the field, and a search for the cause of the difference by a careful examination of the soil. Of course the nature of the subsoil should be ascertained, down to the depth of a metre or so, in order to be sure that the cause of the phenomenon does not lie there, perhaps in some accumulation of water, or a great difference in the mechanical or physical characters of this subsoil.

Actual experiments with manures and growing plants, to be combined with soil analysis, are best made in boxes of soil that has been carefully sifted and mixed; a perfect sample of such a soil can be obtained without difficulty.

The wooden boxes to contain the soil for these experiments may be made about one metre deep, and half a metre square, and with several holes through the bottom. They should be set in the ground in a grass plot, so that they will project but $3-5 \mathrm{~cm}$. above the surface. The soil with which they are to be filled should be pulverized when in a very moderately moist condition, by rubbing it between the hands, or with a wooden pestle in a porcelain mortar, and passed through a sieve with meshes 6-8 mm. wide; an ample quantity of it should be provided, so that there may be enough for the analysis and for all possible contingencies, besides what is required to fill up the box.

To fill the box, put a layer of gravel $5-8 \mathrm{~cm}$. thick over the bottom, and then add the soil, pressing it down gently, as it is put in in small portions at a time; then pour a quantity of rain-water over the soil, equal to about half that which it can retain in its pores; stir up the surface and fill with more soil, up to the edge of the box, and, if possible, bcfore sowing the seed, or putting $9^{*}$ 
in plants, let the whole stand several weeks, so that it may settle together and assume a perfectly natural condition.

If the boxes, when put in place, are not surrounded by grassy turf, the same plants as those cultivated in them should be grown around them, so that there can be no disturbing influences from fresh soil.

When the seed is to be sown, put in more fresh soil if it is necessary, in order to bring the surface up even with the edge of the box. In sowing the seed, and in the subsequent cultivation of the plant, the usual rules of good culture should be observed as far as possible, as respects depth of sowing, distance apart of the plants, and other matters. For experiments with the cereals, which are of the greatest importance, oats and rye are best, since these plants are less liable to disease, or to be destroyed by birds.

The following are a few of the great number of interesting experiments that can be performed in these boxes of prepared soil.

Three or four soils may be prepared, differing greatly in the amount of sand and clay they contain, but closely resembling each other as regards the lime and humus. Not only the quantity of the crop should be observed, but also its quality, such as, in the cereals, for example, the proportion of grain, straw, and chaff, of light and heavy grains, the specific gravity of the grain, the number of the stalks and the degree of maturity attained by them, the weight of the stubble and main roots, and the proximate chemical composition of the different parts of the plant.

With such observations as these, combined with an accurate knowledge of the composition of the soil, we should soon learn whether any direct relation exists between the proportion of plant-food in the soil, that is soluble in water or cold or hot hydrochloric acid, and 
the quantity or quality of the crop, or whether, as is probably the case, the proportion between the clay and these soluble substances, or, in other words, the physical character of the soil, exerts a controlling influence on its fertility.

It would be well to perform three experiments of the same character with each kind of soil, partly for the purpose of securing greater certainty in the results, and partly that the same soil may be used afterwards for other experiments.

To test the question whether the substances in the soil that are soluble in pure or carbonated water exert any essential influence on its immediate productiveness, a trial may be made with a soil in its natural condition, and with the same or a similar soil, after it has been exhausted with water in the manner described for the preparation of an aqueous solution for chemical analysis $(\$ 100)$. As, however, it would be rery inconvenient to exhaust such a quantity of soil in this way, as would be required to fill one of the boxes, this experiment may be performed with but $7-10$ kilos. of soil, in smaller boxes, or in glass vessels. The plants should be watered with distilled water during the progress of the experiment.

Valuable results may be obtained from experiments in which equal quantities of assimilable plant-food are added to different varieties of soil.

The action of a full and complete provision of the elements of plant-food on one kind of plant grown in the different soils, should first be examined. For such a complete manuring, we need only to mix together acid potassic phosphate, calcic nitrate, potassic nitrate, and magnesic sulphate, so that the relative proportions of the bases in the mixture will be the same as in the ash of the plant to be cultivated.

For this purpose, the boxes and soils employed in previous years for trials with soils containing different 
amounts of sand and clay may be used; one box of each kind of soil should have nothing added to it, so as to have a standard with which to compare the effect of the manuring in other soils of the same nature. From the average crops of the preceding year in all the boxes, an estimate may be made of the quantity of plant-food to be added.

The soil to be manured is taken out of the box to the depth of $30 \mathrm{~cm} .\left.{ }^{1}\right|_{4}$ of this is intimately mixed with the aqueous solution of the salts to be added, and this in its turn is intimately mixed with the remaining $\left.{ }^{3}\right|_{4}$ of the soil, by rubbing the two together carefully between the hands; the whole is then put back into the box.

Instead of the solution of the above salts, the actual practice with manures may be more closely imitated by making an aqueous extract of a superphosphate, determining the amount of phosphoric acid in the solution, and dissolving therein the proper amounts of crude potassic chloride, sodic nitrate, and magnesic sulphate.

In a similar manner, the effect of an increased proportion of humus in the soil may be studied, by letting some sawdust of a soft wood, free from resin, partly decay, making an aqueous extract of this, or of some other suitable substance rich in humus, and mixing this solution with the soil in the way already described.

Other matters that might be profitably studied in this connection are, the effect of lime, of the concentrated commercial manures, and the relation between the coefficients of absorption of the soil for the various elements of plant-food, and its fertility. 
ROCKS AND TIIE PRODUCTS OF THEIR WEATIIERING.

109. The object of analyzing a rock, for agricultural purposes, may be to estimate the total amount of its constituents, or to determine its solubility and the readiness with which it would be disintegrated and converted into soil on exposure to the air. The method of the analysis would be much the same as that already described for the analysis of soils. A qualitative cxamination should precede the quantitative one, in order to learn the best way of bringing the mineral into solution, as well as what substances are to be separated and determined.

The examination of the products of the weathering of a rock should be conducted in the same manner as a regulat soil analysis, by treating it with the same solvents in the same succession.

The three more important substances that come under this head are marl, limestone, and clay, and some special directions for the analysis of each may be useful.

\section{MARL.}

As this substance is used by the farmer in its natural condition, it should be taken in a similar condition, for analysis, viz., air-dried and unignited. If taken fresh from the pit, it should be allowed to lie for a long time exposed to the air on filter-paper, until thoroughly dry.

The most useful of the determinations mentioned below are those of phosphoric acid and the alkalies, and the mechanical analysis.

The mechanical analysis. For this, which is of much importance, since the value of a marl usually depends largely on the fineness of the division of its particles, treat 30-50 grms., according to the amount of calcic car- 
bonate contained in it, with dilute hydrochloric acid in a flask, as long as there is any effervescence, wash the residue, boil it half an hour with water, and then subject it to the silt analysis ( $\$ 97$ ).

Or, if it is desired to determine the fineness of division of the calcic carbonate in the marl, the whole may be subjecter to the silt analysis without previous treatment with acid, and then the carbonate can be determined in the contents of each funnel.

If the marl does not fall to a fine powder in water, it must first be sifted, as directed for the preparation of the soil for the silt analysis.

For practical purposes, the following rough method of estimating the fineness of the marl will often answer.

After treating $10 \mathrm{grms}$. of the marl with hydrochloric acid as long as there is any effervescence, pour a considerable quantity of water over the residue, with constant stirring, let the sand and heavier particles settle, and decant the turbid liquid holding clay in suspension; repeat the same operation with the residue several times, until "the water is clear after the sand settles to the bottom, collect the latter on the filter, ignite, and weigh as coarse sand.

\section{The chemical analysis.}

a. Water,-Dry about 10 grms. of the substance at $100^{\circ} \mathrm{C}$., and determine the loss of weight.

b. Carbonic acid.-Determine this in $\mathbf{2 - 4}$ grms., as directed in $\S 60$.

For practical purposes, the following method will usually yield sufficiently accurate results.

Weigh out 2-3 grms. of the marl in a flask of about 100 c.c. capacity, moisten it with a little water, carefully lower into the flask a small test-tube, $\left.{ }^{3}\right|_{4}$ filled with hydrochloric acid, in such a way that no acid can escape into the flask, and weigh the whole; then canse the acid to flow out of the test-tube into the flask by inclining the 
latter, and, while the efferrescence continues, let the flask lie in an inclined position, with the end of the test-tube partly stopping up its mouth. When the efferrescence has ceased, blow air into the flask to remove the carbonic acid gas, weigh the whole again, and count the loss as carbonic acid; the results will be within $\left.0.25^{\circ}\right|_{0}$ of the truth.

c. Lime and Magnesia.-Digest 2-3 grms. of the wellpulverized marl with dilute hydrochloric acid, and examine the solution more particularly for lime and magnesia, as under $b$, Scheme IV., $\S 94$.

d. Phosphoric acid and the alkalies.-Allow 300 c.c. of concentrated hydrochlorie acid $(\mathrm{Sp} . \mathrm{Gr} .=1.15)$ to act on 100 grms. of the well-pulverized marl in a large flask, for 48 hours at common temperatures, with frequent agitation; (or, take $120 \mathrm{grms}$. of soil and 360 c.c. of acid, if ferric oxide and alumina are to be determined, and estimate them in $\left.{ }^{1}\right|_{6}$ of the solution obtained; this determination, however, will not generally be important).

Decant the solution from the insoluble residue, dilute with some water, filter, put the insoluble residue on the filter, and wash it first with cold and afterwards with hot water. Evaporate the filtrate to dryness, and remove silicic acid.

Examine the filtrate from the silica as under $b$, in Scheme I., $\& 94$.

If the marl contains a large proportion of clay, some of the phosphoric acid may remain undissolved by the cold concentrated acid. In this case, boil about 50 grms. of the marl one hour with 150 c.c. of concentrated acid, filter, eliminate silica, and proceed to determine phosphoric acid, as above.

The insoluble residue, left after treatment of the marl with cold acid, and composed of clay and sand, is dried in the air-bath, left for a considerable time exposed to the air, and weighed. If from this we subtract the weight of coarse sand, obtained by the rough method in the 
mechanical analysis, we have left the amount of fine sand arid clay.

Treat this residue in the same manner as directed in $\S \S 102$ and 103 for the treatment of the corresponding part of the soil.

e. A determination of humus is generally unnecessary, but if desired, can be conducted as directed in $\S 104$.

$f$. A determination of nitrogen will rarely be needed, but may be made in the usual manner, with 5-10 grms. of the marl.

g. Some marls, particularly such as are rich in clay, and contain but little sand, are much more effective after having been gently ignited. To test the marl in this respect, heat it to a low red heat in a muffle, with free access of air, and then make an aqueous extract of the ignited mass by treating 500 grms. of it with 2000 c.c. of distilled water, with frequent agitation during a cold digestion of 48 hours. Then filter off $\left.{ }^{4}\right|_{5}$ of the solution, or 1600 c.c., for the cletermination of the alkalies; evaporate this solution to dryness, eliminate silica in the usual manner, and estimate the alkalies in the filtrate from the silica $(\S 93, \mathrm{G}$.$) .$

Another portion of $100 \mathrm{grms}$. of the ignited marl may be treated with 300 c.c. of concentrated hydrochloric acid in the cold, in the manner already directed, to estimate phosphoric acid, and, if desired, the alkalies again.

$h$. Analyses of the green sand marl of New Jersey. (Cook.)

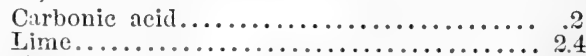

Magnesia........................... 0.4

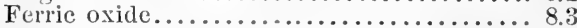

Alumina........................... 6.1

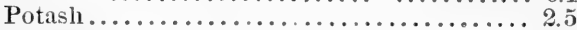

Sulphuric acid........................ 0.9

Phosphoric acid..................... 1.4

Silica [soluble].....................20.2

Silica [insoluble sand] ................. 49.9

Water............................. 
LIMESTONE AND LIME.

110. a. If it is desired to examine the changes that a limestone has undergone in weathering, or to ascertain what it contains that may contribute to the fertility of the soil, it should, of course, be taken in its natural, airdry, unignited condition.

Pulverize it, and treat from 150 to 300 grms., according to the proportion of clay or other silicates present, with cold and hot concentrated hydrochloric acid, with sulphuric acir, and so on, in the manner directed for the analysis of soils. The cold hydrochloric acid dissolves all the carbonates, commonly all the phosphoric acid, but only a small portion of the alkalies, cren if a considerable amount of these is present. But this small quantity that is taken into solution should be determined, and the estimation can be effected, after removal of the silica, in the usual manner (Scheme I., $a$ or $b, \S 94$ ).

The residue, insoluble in cold hydrochloric acid, is of great importance, agriculturally considered, for it is not seldom rich in potassa, and it should be examined with the aid of the silt analysis, as well as of hot hydrochloric acid, sulphuric acid, and hydrofluoric acid $(\$ \$ 101,102$, 103). In one ease, over $50^{\circ} \%_{0}$ of potassic feldspar was found in the sandy insoluble residue of a dolomitic limestone; in another case little but pure quartz.

b. By "burning" the limestone, it is essentially changed with respect to the solubility of its constituents, and particularly the alkalies, which become soluble in larger measure. Therefore, when a limestone is to be applied to the soil after being burned, it should be burned before being analyzed; this may be accomplished by igniting it in a Hessian crucible through the bottom of which a hole has been broken, until, after cooling, a piece of it falls completely to a fine powder when moistened with about a third of its weight of water. 
1. In this burned limestone, determine the alkalies soluble in water by treating 150 grms. with 1500 c.c. of distilled water, with frequent agitation during a digestion of 24 hours. Then pour off 1000 c.c. of the supernatant liquid, as clear as possible, filter, if the liquid is not perfectly clear, remove silica as usual $(\$ 58, a)$, by evaporation to dryness and treatment with hydrochloric acid, and climinate the alkalies as chlorides $(\$ 93, \mathrm{G})$.

2. Digest another portion of 100 to $150 \mathrm{grms}$. of the burnt lime, according to its richness in silicates, 48 hours in the cold, with three times its weight of concentrated hydrochloric acid, filter the mixture, and wash the residue, first with cold, and then with hot water. Determine phosphoric acid and the alkalies in this solution (Scheme I., $\S 94)$; no ferric chloride need be added.

It sometimes happens that a considerable separation of gelatinous silica renders the filtration of the hydrochloric acid solution very difficult. In this case, evaporate the whole mixture to complete dryness, moisten the residue with concentrated acid, let it stand awhile, boil with dilute acid, filter, and examine this filtrate for phosphoric acil and alkalies, as above. The solution will contain all that would ordinarily be dissolved by both cold and hot hydrochloric acid.

Treat the residue, insoluble in cold hydrochloric acid, with hot acid, if not already so treated, and then with sulphuric and hydrofluoric acids ( $\S 101,102$, and 103).

c. To determine whether a limestone will yield good mortar lime, digest $\mathbf{4 - 5}$ grms. with dilute hydrochloric acid, evaporate the whole to dryness, after adding a ferw drops of nitric acid, boil the residue with acidified water, filter, wash, ignite, and weigh. A good limestone, for this purpose, should not leave more than 5 to $\left.10^{\circ}\right|_{0}$ of insoluble matter.

The solution may be examined for alumina, ferric oxide, 
lime, and magnesia, according to Scheme I., §94; manganese need not be noticed unless a qualitative analysis reveals its presence in considerable quantity.

A determination of carbonic acid may be made to control the results of the other part of the analysis.

All the bases found should be calculated as carbonates in making up the final statement.

c. To determine whether a limestone will make a good hydraulic cement, the course described in the preceding paragraph should be followed; but the alkalies should be determined also, and the residue, insoluble in hydrochloric acid, should be examined with the aid of sulphuric and hydrofluoric acids (§ $\S 102$ and 103). $\quad 50-60$ grms. of the stone should be taken for treatment with hydrochloric acid. And, as the chemical analysis alone will not furnish perfectly safe information in regard to the fitness of the stone for the purpose in question, portions of it should be ignited at various temperatures, and the resulting lime in each case pulverized and made into little balls with water, either alone or with sand, and tested under water, to see whether it hardens properly.

$e$. If the cement already prepared is given for examination, it will be important to determine the amount of gelatinous silica set free by the hydrochloric acid, as well as the lime, alumina, and aikalies. $20-25$ grms. of substance will usually answer for the analysis, since the stone is rendered more soluble by the ignition that is required to convert it into cement.

Boil the residue, that is insoluble in hydrochloric acid, with sodic carbonate $(\S 58, a, 2)$, pulverize what is insoluble in this agent very finely, and treat it with hydrofluoric acid. 
CLAY.

111. This should be taken for analysis in its natural, air-dried condition, and examined by the same processes as have been given for the mechanical analysis of soils, and their treatment with acids. Different clays are very differently affected by these agents.

Conclusions in regard to their agricultural value must be based upon their relative solubility in the acids used, and the composition of the part that is soluble in hydrochloric acid, and of that which is made soluble by treatment with sulphuric acid.

For technical purposes it will usually answer to treat 10-15 grms. of the clay with 6-8 times its weight of concentrated sulphurie acid, evaporate the mixture to complete dryness, exhaust the residue with dilute hydrochloric acid, climinate silicic acid from this solution, and estimate alumina, ferric oxide, manganese, lime, magnesia, and the alkalies, according to Scheme I., $a$ and $c, \S 94$, omitting the estimation of phosphoric acid, and consequently the addition of ferric chloride; determine also the silica soluble in alkaline carbonate in the residue that is insoluble in hydrochloric acid above.

Burnt clay may sometimes be profitably applied as a fertilizer, or an amendment. The examination of such a clay should be conducted in the same manner as described for burnt marl $(\S 109, f)$; particular attention should be paid to the amount of alkalies soluble in water, and in cold and hot hydrochloric acid.

The proportion of phosphoric acid is not usually any larger than in arable soils. 


\section{CHAPTER VI.}

F E R T I L I Z E R S.

I.

PRODUCTS OF THE FARII-YARD.

FARMI-YARD MANURE.

112. In the examination of farm-yard manure, the part soluble in water, and that which is insoluble in this agent, should each be examined by itself, for it is important to know the relative proportion and composition of these two portions.

To procure a sample of the manure, take sereral small portions from different parts of the pile, mix them all carefully together, breaking up the lumps while working the mass over, and preserve $3-4$ kilos. for examination.

a. Water.-Dry 1000 grms. of this in the dryingchamber, powder the residue as much as possible, or cut it up with shears, weigh the whole, dry about 50 grms., accurately weighed, at $100^{\circ} \mathrm{C}$, and calculate the loss of weight for the whole 1000 grms. Grind this dried substance to a powder in a steel mill.

b. Organic matter.-Ignite $6-8$ grms. of this powder with the usual precautions, including the determination of carbonic acid and coal $(\S 91)$.

c. Carbonic acid.-Determine this in 5 grms. of the powder $(\S 60)$.

d. Nitrogen.-Determine this in $1 \mathrm{grm}$. of the powder. The small amount of nitric acid in the manure will be almost completely converted into ammonia during the combustion, in the presence of so large a proportion of carbonaceous organic matter. The nitrogen in the ammonic 
carbonate, that is volatilized during the process of drying, and which is determined in the aqueous extract of a portion of the original manure, should be added to that obtained by combustion with soda-lime, in order to get the total nitrogen.

e. Ammonia.-Determine this by the distillation of 15-20 grms. of the dried and ground manure, with $1 \mathrm{grm}$. of freshly ignited magnesia, and water, and the estimation of the ammonia in the distillate by titration $(\S 4 \%, c)$.

f. Sulphur and sulphuric acid.-Determine total sulphur in the manure by fusion of $3-4$ grms. of the powder with potassic nitrate $(\$ 92)$.

g. Aqueous extract of the manure-Pour 3000 c.c. of water over a second portion of $1000 \mathrm{grms}$. of the fresh manure, mix the whole well together, let the mixture stand quietly several hours, and decant the supernatant liquid. In order to wash the residue without using too much water, put it in a large funnel, which is stopped in the throat with asbestus, and below with a cork, press it down, pour water over it, and work the whole over gently with a pestle; after a time, remove the cork, and let the liquid run off, and repeat the operation until the water that passes away is almost colorless. Reserve the residue in the funnel for further treatment.

Filter the whole quantity of the liquid with which the fresh manure was treated through linen, make the volume of the filtrate and washings up to 6000 c.c., and, if necessary, filter again through paper.

1. Ammonic salts.-Determine volatile ammonic salts (ammonic carbonate) in 300-600 c.c. of the aqueous extract, by distilling off about $\left.{ }^{2}\right|_{3}$ of it in the proper apparatus ( $\$ 47)$, without adding any alkali, and titrate the distillate with the standard sodic solution as usual.

Determine non-volatile ammonic salts by adding 1-2 grms. of freshly ignited magnesia, or 10-15 c.c. of milk of 
lime to the remainder of the liquid in the retort, distilling off $\left.{ }^{1}\right|_{3}$ of the water, collecting the ammonia in the usual manner, and titrating the distillate.

The total amount of ammonia in the aqueous extract may be determined also by Schlössing's method; evaporate 200 c.c. of the liquid down to 50 c.c. after adding a slight excess of hydrochloric acid, and proceed with this concentrated solution in the usual manner $(\S 4 \%, b)$.

2. Nitric acid.-To determine this in the aqueous extract, evaporate 500 c.c. down to a small bulk, and proceed with this concentrated solution according to Schlössing's method $(\S 62, a)$.

\section{Total amount of Ary substance in solution.-Evap-} orate the remainder of the extract to dryness in a weighed platinum dish, on the water-bath, and determine the total amount of matters in solution.

4. Orgamic matter.-Ignite $3-4$ grms. of this residue, to determine organic and inorganic matter (\$91), and determine carbonic acid and chlorine in the ash $(\S 60, c)$.

5. Carbonic acid.-Determine this in 2-3 grims. of the residue obtained in $3(\S 60)$.

6. Nitrogen.-Determine this in $1 \mathrm{grm}$. of the residue obtained in 3 , by combustion with soda-lime ( $\$ 85)$.

7. Chlorine,-This may be partially volatilized in the process of incineration; an accurate estimation of it, therefore, requires its determination in a portion of the aqueous extract itself. 100 c.c. of this may be taken, or $0.5-1$ grm. of the residue obtained in 3 , dissolved in water. Add nitric acid to the solution, in slight excess, and precipitate chlorine with argentic nitrate; treat the precipitate as directed for the case in which much organic matter was present in the solution ( $\$ 63)$.

Instead of following this course, a small portion of the residue obtained in 3 may be fused with potassic nitrate before precipitation with argentic nitrate (\$92). 
8. Ferric oxide, etc.-Ignite the remainder of the residue obtained in 3 , dissolve the ash in hydrochloric acid, eliminate silica by evaporation to dryness, and exarnine the filtrate from the silicic acid according to Scheme I., $\S 94$.

$\bar{h}$. The total residue, insoluble in water, obtained in $g$, is dried in the steam-chamber, exposerl to the air 24 hours, and weighed in this air-dried condition; then cut up the fibrous parts of it with the shears, and grind the whole to a fine powder in the porcelain mortar or steel mill.

1. Water.-In 10 grms. of this powder determine hygroscopic water by heating to $110^{\circ} \mathrm{C}$.

2. Organic matter.-Ignite the dry residue obtained in $a$, and determine the loss ( $\$ 91)$, and determine carbonic acid and chlorine, if desired, in the ash.

3. Nitrogen.-To determine the nitrogen in undecomposed organic matter in the manure, a part of which might be insoluble in water, and hence found here, ignite 1-2 grms. of the powder with a considerable proportion of soda-lime $(\S 85)$.

4. Ferric oxide, etc.-Ignite $30-40$ grms, of the powdered insoluble residue in a platinum dish, and in $3-6$ grms. of the properly prepared ash $(\$ 123, c)$, according to the proportion of sand present, eliminate silica and sand, and analyze the remainder according to Scheme I. or II. 
$i$. Analyses of farm-yard manure by Voelcker.

\begin{tabular}{|c|c|c|c|c|}
\hline 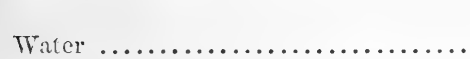 & & 66.17 & $R_{0}$ & ed. \\
\hline 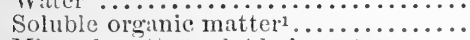 & & $\begin{array}{r}00.16 \\
2.48\end{array}$ & & \\
\hline Miner:al matter soluble in water....... & & & & \\
\hline $\begin{array}{l}\text { Silica (soluble) ........... } \\
\text { Calcic phosphate, } 3 \mathrm{CaPO}\end{array}$ & 0.237 & & 0.254 & \\
\hline 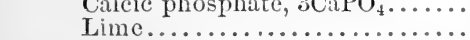 & 0.006 & & $\begin{array}{l}0.38 \% \\
0.117\end{array}$ & \\
\hline Magnesia. & 0.011 & & 0.047 & \\
\hline Potassa. & 0.573 & & 0.446 & \\
\hline Soda. . & 0.051 & & 0.023 & \\
\hline Sodic chloride. & 0.030 & & 0.037 & \\
\hline Sulph & 0.055 & & 0.058 & \\
\hline Carbonic acid (and loss).. & 0.218 & & 0.106 & \\
\hline & & 1.0 & & 0.47 \\
\hline Insoluble orgmic matter ${ }^{2} \ldots \ldots \ldots \ldots$ & & 25.76 & & 12.82 \\
\hline 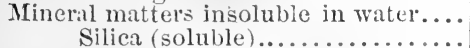 & & & & \\
\hline Silica (insoluble, and sand).... & 0.964 & & $\begin{array}{l}1.42 t \\
1.010\end{array}$ & \\
\hline Ferric oxide and alumina.. & 0.418 & & 0.673 & \\
\hline $\operatorname{Lim}$ & 1.120 & & 1.667 & \\
\hline Mas & 0.143 & & 0.091 & \\
\hline Pot & 0.099 & & 0.045 & \\
\hline Sod: & 0.019 & & 0.038 & \\
\hline Sulp & 0.061 & & 0.063 & \\
\hline Phos & 0.178 & & $0.27 t$ & \\
\hline Carbonic acid (and loss).. & 0.484 & & 1.295 & \\
\hline & & 4.05 & $=$ & 6.58 \\
\hline & & 100.00 & & 100.00 \\
\hline & & 0.149 & & 0.2 \\
\hline 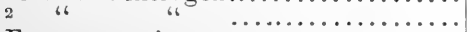 & & 0.494 & & 0.30 \\
\hline $\begin{array}{l}\text { Free } \\
\text { Amn }\end{array}$ & & $\begin{array}{l}0.340 \\
0.880\end{array}$ & & 0.046 \\
\hline Ami & & & & \\
\hline
\end{tabular}

FRESH ANIMAL EXCREMENTS.

URINE.

113. The following method is designed more particnlarly for the analysis of the urine of herbivorous animals, but it may be applied in the examination of that of carnivorous animals and man, also.

a. Specific Gravity.-Determine this in the usual manner by comparing the weights of equal volumes of the urine and of water $(\S 34)$, or with the urometer, a species of hydrometer constructed expressly for this purpose; 
when this instrument is used, all foam must be carefully removed from the surface of the liquid, by filter paper.

A difference of $4^{\circ} \mathrm{C}$. in the temperature of the liquid usually makes a difference of about $1^{\circ}$ in the reading of the urometer.

The specific gravity of urine ranges between 1.01 and 1.04 .

b. Total amount of dry substance in solution.-Determine this by evaporating a weighed quantity in a current of dry hydrogen in such a manner as to estimate the ammonia that is expelled at the same time $(\S 90 ; d)$. Take 4-6 c.c. of the urine, accurately weighed. The evaporation to dryness is completed in 4-5 hours.

In human urine, that has an acid reaction due to acid sodic phosphate, the ammonia may be assumed to have been derived from urea, and by multiplying the amount of it by 1.765 , the corresponding amount of urea will be obtained. But in the urine of herbivorous animals the ammonia resulting from this decomposition must be estimated by the difference between the ammonia set free on evaporation to dryness, and that found in the urine by direct determination. Generally, however, these quantities of ammonia are very small, and can be left out of consideration.

The non-volatile matter in this residue left on evaporation is determined by evaporating a fresh quantity of 100 c.c. of the urine in a platinum dish, and igniting the residue $(\S 91,1)$; determine carbonic acid in the ash in the usual manner.

c. Carbonic acid (free and combined).-Determine this in two portions of 100 c.c. of the fresh urine. To one portion add baric chloride containing ammonia in excess, and to the other baric chloride alone; heat both mixtures nearly to boiling, collect the precipitates on dried and weighed filters, wash them, and dry them at $100^{\circ}$, weigh, 
and determine carbonic acid in 1-2 grms. of cach precipitate in the usual manner; the first precipitate contains the total carbonie acid, the second only the combined.

c. Nitrogen.-The residue left in the boat in $b$ may be used for the determination of nitrogen, or another portion of 5-10 c.c. of the urine may be acidified with oxalic acid, mixed with ignited gypsum, and evaporated to dryness. In the former case this second residue will contain only so much of the nitrogen as was not expelled in the form of ammonia during the desiccation; in the latter, the oxalic acid will prevent the escape of any nitrogen as ammonia. The dry substance may be completely rinsed off the sides of the dish with some of the soda-lime used in the combustion.

Or, this method of Voit may be used. Weigh out about 5 c.c. of the urine, mix it in a shallow dish with a sufficient quantity of fine quartz sand to absorb it all, put the dish under the receiver of an air-pump, and exhaust the air; the whole becomes quite dry in a few hours and may be pulverized casily, and completely loosened from the sides of the dish and mixed with the soda-lime.

The combustion may be performed in a short combustion-tube and very rapidly, without fear of losing any of the ammonia.

e. Actual ammonia.-Determine this by Schlössing's method in 20 c.c. of the urine, after filtration to remove slimy or sedimentary matters $(\S 47, b)$. In the fresh urine of horned cattle, the actual ammonia does not amount to more than $0.009-0.01^{\circ} \mathrm{l}_{0}$, but in human urine it ranges as high as 0.078 to $\left.0.143^{\circ}\right|_{0^{\circ}}$

$f$. Complete analysis of the ash.-Evaporate 200-500 grms. of the urine to dryness, incinerate the residue, and examine the ash as directed in Scheme IV., § 94. The ash of the urine of herbivorous animals is poor in alkaline earths, and 8-10 grms. will be required for their determi- 
nation. In the urine of ruminants, phosphoric acid is found in hardly determinable quantity, while in that of swine and often of calves, it is present in larger quantity, and should be estimated.

g. Chlorine and urea.-These are determined with the aid of the standard solution of mercuric nitrate. The urine must first be freed from phosphoric and hippuric acids.

Acidify 200 c.c. with nitric acid, boil the mixture to expel the carbonic acid, neutralize the nitric acid with freshly ignited magnesia, and cool the liquid to the temperature of the room, by immersing the flask in cold water; transfer the liquid to a graduated cylinder, rinse the flask into the cylinder and bring the rolume of its contents to 220 c.c.; add 30 c.c. of an aqueous solution of ferric nitrate of such a degree of concentration that, with this quantity of the solution added, the salt will be slightly in excess; the excess may be recognized by a weak reaction of the solution on a slip of filter paper soaked in a dilute solution of potassic ferrocyanide; too large an $c x-$ cess of the ferric salt will be indicated by a re-solution of the precipitate that was formed at first, on its addition; filter the liquid immediately through a large, dry, ribbed filter, and to 150 c.c. of the filtrate add 50 c.c. of a solution of baryta mixed with a little calcined magnesia, filter again, and for each determination of sodic chloride and urea take 15 c.c. of this filtrate, corresponding to 9 c.c. of urine.

1. Chlorine (common salt).-Acidify exactly 15 c.c. of the liquid with a drop of nitric acid, and allow the standard solution of mercuric nitrate to flow in from the burette, with constant stirring until a permanent turbidity appears. A mere opalescent appearance of the liquid, which may be presented even in the beginning, is easily distinguished from the cloudy turbidity which is the real indication of saturation. 
Estimate the amount of sodic chlorine or of chlorine on the basis of the standard of the solution already determined $(\S 86)$.

2. Uiea.-In a sceond portion of 15 c.c. of the liquid, proceed to determine urea with the same standard solution $(386)$. Subtract from the total amount of standard solution required the amount used in 1 , and also make the correction required for dilution of the solution.

h. Hippuric acid.-Evaporate 200 c.c. of the urine down to 50 c.c., and precipitate the acid as direeted in $\S$ 76. It may be well to first digest the urine with animal charcoal in the proportion of 2 grms. of chareoal to $10 \mathrm{c}$. c. of the liquid, in order to decolorize it.

There are usually only traces of uric acid in the urine of herbivora, and it need not be estimated; but in the urine of carnivora, the proportion of uric acid generally exceeds that of the hippuric.

According to the process of Meissner and Shepard, for separating these two acids, evaporate the urine until it begins to crystallize, add so much absolute alcohol to the hot liquid that a further addition eauses no more precipitation, let the mixture cool, and filter it ; the best absolute alcohol must be used, and it must not be spared, else succinic acid may remain in solution with the hippuric and cause trouble. Evaporate the alcoholic solution, at first in a flask on the water-bath, until all the alcohol and the water are expelled and only a brown syrup remains, that solidifies to a crystalline mass on cooling; extract this mass, while yet warm and liquid, with ether and a few drops of hydrochloric acid added after the ether, agitate the mixture violently, and repeat the process two or three times with fresh portions of ether. If the alcohol and water were not carefully removed in the preceding evaporation, some of the urea will pass into this etherial solution.

Collect all the etherial extracts, distil off most of the ether, and let the rest evaporate spontaneously in the air. 
Hippuric acid appears then in the form of landsome crystals. If the crystals are not colorless, or they are not readily formed, dilute the residue, left by the evaporation of the ether, with water, boil the mixture with lime-water, filter, concentrate the colorless filtrate, and precipitate the hippuric acid by hydrochloric acid in excess.

i. Phosphoric acid.-1. This may be determmed directly in the urine, with the standard uranic solution. Filter the urine, if necessary, add 5 c.c. of sodic acetate to 50 c.c. of the filtrate, and titrate the mixture with uranic acetate as usual $(\S 61, c)$.

2. To obtain a more accurate determination, add the magnesia mixture to 50 c.c. of the clear urine, collect and wash the precipitate in the usual manner, dissolve it, without drying, in acetic acid in not too great excess, dilute the solution to 50 c.c. with watcr, add 5 c.e. of the solution of sodic acctate, and titrate as before. with the uranic solution $(\S 61, c)$.

3. To determine the phosphoric acid that is combined with alkaline earths only, to 100-200 c.c. of the urine, according to its strength, ard ammonia until alkaline reaction ensues, let the mixture stand 12 hours, and collect and treat the precipitate in the manner described in 2. In another precisely equal quantity of urine, the precipitate by ammonia is ignited and weighed; the amount of magnesic pyrophosphate in this mixture may be estimated by multiplying the amount of phosphoric acid in it, as determined above, by 2.1831, subtracting the sum of the phosphates from this product, and multiplying the remainder by $2.522 \%$. If it is desired to determine lime and magnesia directly, dissolve the mixture of the phosphates, obtained above by precipitation with ammonia, without drying it, in as small a quantity of acetic acid as possible, precipitate the lime by ammonic oxalate, and the magnesia as phosphate again by excess of ammonia. 
k. Sulphuric acid.-Heat 50-100 c.c. of the urine, add some nitric acid, and then baric chloride in slight excess $(\S 59)$.

l. Sulphur.-To determine total sulphur, mix 50 c.c. of the urine in a silver crucible with solid caustic potash and a little saltpetre; evaporate the mixture cautiously to dryness, ignite the residue strongly until it is quite white, exhaust it with water, and determine sulphuric acid in the filtered solution, in the usual manner.

$m$. Carbon and Hydrogen.-Absorb 10 c.c. of the urine by fine quartz sand that has been previously boiled with acid, washed, and ignited, dry the mixture, and burn it with plumbic chromate. (See Fresenius's Quantitative Analysis.)

\section{SOLID EXCREMENTS.}

114. The solid excrements of the herbivora are examined by almost precisely the same methods as are given for the analysis of fodder $(\S 129)$.

In the determination of woody fibre, owing to the presence of resinous matters it is often necessary to boil the substance with alcohol before treating it with dilute acid and alkali.

Microscopic examinations are often useful in the examination of these excrements, in order to ascertain what parts of the plants, that were consumed as fodder, remain undigested. For this purpose, it is well to knead a portion of the substance in a linen bag under cold water until the latter is no longer made turbid. Starch, crystals of difficultly soluble salts, and grains of sand, may be looked for in the sediment deposited from the water used in washing, after long standing, while sugar, gums, lactic acid, etc., may be sought for in the solution; the residue in the bag may be examined with the microscope, with or without previous boiling with alcohol to remove resinous matters. 


\section{II.}

\section{COMIERCIAL CONCENTRATED MANURES.}

115. The determinations of phosphoric acid, potassa, and nitrogen, are the most important in the cxamination of these manures.

$a$. The method first recommended by Pincus for estimating phosphoric acid by means of a standard solution of uranic acetate can be applied in the analysis of guanos, bone-meal, bone-black, bone-ash, and most of the superphosphates, so long as but little ferric oxide or alumina is present. The method descrres to be generally followed, for it is quickly executed and sufficiently accurate, and because it is desirable that all estimations of phosphoric acid, in the numerous forms in which it is presented to the public; should be made according to a common plan.

The preparation of the standirid solution and the manner of conducting the analysis have been already described $(\S 61, c)$.

For the determination, 50 c.c. of the solution to be testcd are generally taken, and 10 c.c. of the solution of sodic acetate added. If the quantity of the precipitate that is formed on the addition of this reagent and boiling is quite small, it may be filtered out, washed, dried, and ignited; the residue may be regarded as ferric phosphate, $\mathrm{FePO}$, containing $\left.4 \% .02^{\circ}\right|_{0}$ of phosphoric acid $\left(\mathrm{P}_{2} \mathrm{O}_{5}\right)$. The volumetric process is carried out with the filtrate from this precipitate. If the precipitate of ferric phosphate is not slight, a gravimetrical process is safer $(\$ 93, H)$.

The volumetric process, uncler suitable circumstances, gives results that are within $1 \mathrm{mgr}$. of the truth. 
In case a large quantity of phosphoric acid is present, or much free acid, 10 c.c. of the acetate may not be sufficient to saturate all this acil with soda. The brown color will appear, then, before all the phosphoric acid is precipitated; but it is diffused through the entire drop, and does not present a well-defined brown zone where the drop of the test solution and of the ferrocyanide come together; in this case add 5 c.c. more of sodic acetate, and it will be found that, in case free mineral acid wors present, more of the uranic solution must be added before the brown color appears. In order to be sure in regard to this matter, it will always be well, aftcr having reached the point of saturation, to add 5 c.c. more of sodic acetate, heat the mixture to boiling, and test a drop of the solution with the ferrocyanide. If a brown color appears, the result first obtained was correct. Even 30 c.c. of sodic acetate may be added without sensibly impairing the accuracy of the work.

b. The examination for potıssa may be conducted according to either of the methods described in $\S 93, G$. The third method, in which platinic chloride is used to separate potassa from the alkaline earths, is more particularly applicable in the examination of the native potash salts, of which such extensive beds have been discovered in Germany, and from which large quantities are taken for agricultural purposes.

$c$. The determination of the nitrogen is always made by combustion with soda-lime (\$85).

d. Fresenius (Quantitative Chemische Analyse, 894) gives the following good plan for stating the results of the analysis of a superphosphate; a similar plan can be followed, with such variations as may be necessary in each particular case, in stating the result of the analysis of any commercial fertilizer. 


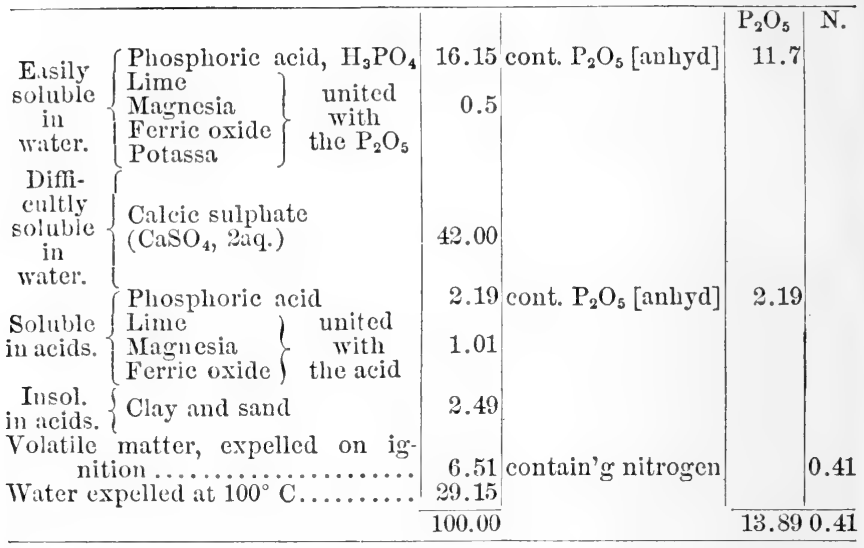

TARIFF OF PRICES OF COMMERCIAL FERTILIZERS.

e. In 185\%, A. Stöckhardt, of Tharand, published a tariff of prices of commercial fertilizers, with the aid of which, in a very simple manner, the cost of the manure could be compared with its real value; in this tariff, the estimation of the money value of each of the three important constituents of these fertilizers in general, was based upon the price that would have to be paid for it in other and also commercial forms, containing a known and often guaranteed proportion of the substance. The per cent composition of a fertilizer being known, the purchaser could then tell, on consulting the tariff, whether he was required to pay any more for the number of pounds of nitrogen or phosphoric acid in 100 pounds of the article he was buying, than he would have to pay for the same number of pounds of nitrogen in the form of sulphate of ammonia, from the gas-works, for example, or of phosphoric acid in the bone-black of the sugar refiners.

A greatly improved form of this tariff, which was put out by Stöckhardt in 1866 (Chemische Ackersmann, 1866, 
226), is given below, with the prices estimated in gold per pound.

The editor greatly regrets that he has not had the time or the opportunity to make a careful examination of the various forms in which nitrogen, phosphoric acid, and potash, are to be had in this country, so that this tariff might be conformed therewith, and answer the same purpose for the American farmer that the original one does for the farmers throughout Germany. But, nevertheless, the values allowed for these three substances in the tariff as it stands are not far out of the way. Prof. Johnson (Report to the Secretring of the State Board of Agriculture, on Commercial Munues, April, 1869) gives the following values in gold: potash, 4 cents; soluble phosphoric acid, 121.2 cents; insoluble, $4 \frac{1}{2}$ cents; nitrogen, 17 cents. The mean of the four values of nitrogen in Stöckhardt's tariff is 17.9 cents.

Prof. Johnson says very truly in the same report, "The farmer will not often err in refusing to lay out his money for any article whose cost much exceeds the calculated value," with reference to his own tariff; and the same may as well be said of the scale of prices adopted in this work.

\begin{tabular}{|c|c|c|}
\hline & rm in which the substance exists in the fertilizer. & $\begin{array}{l}\text { Price } \\
@ 1 b .\end{array}$ \\
\hline Phospl & ic acid, soluble in water, as in superphosphate & in gold. \\
\hline & 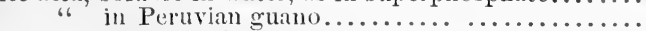 & $.10^{2}$ \\
\hline 6 & 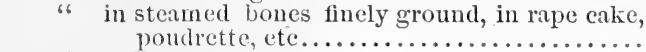 & $.081 / 4$ \\
\hline 6 & "6 in Baker guano...... & $.071 / 2$ \\
\hline 6: & "6 in coarse bone meal, fresh human urine, etc.. & .07 \\
\hline 6 & 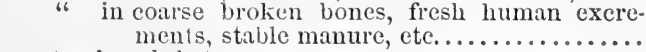 & $.051 / 2$ \\
\hline otas & potassic sulpliate & $.06 \frac{1}{2}$ \\
\hline & as potassic chloride and in other forms. & $.051 / 2$ \\
\hline Nitrog & $\begin{array}{l}\text {, easily soluble, or in compounds that are readily de- } \\
\text { composed, as ammonia, nitrates, dried blood, }\end{array}$ & \\
\hline “ & in fin & $.191 / 4$ \\
\hline$\therefore$ & 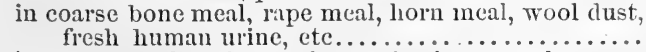 & $.161 / 3$ \\
\hline "6 & $\begin{array}{l}\text { in coarse broken bones, horn shavings, woolen rags, } \\
\text { fresh hum:m excrements, stable manure, etc..... }\end{array}$ & $.15 \% / 4$ \\
\hline
\end{tabular}


According to this tariff, the money value of 100 pounds of the superphosphate whose composition is given above, would be estimated as follows :

11.7 lbs. soluble phosphoric acid @121/2 cts.

2.19 " insoluble

(6) $6671 / 2$ 6

.32

.41 " nitrogen

" $19 \frac{1 / 4}{4}$ "6

.08

$\$ 1.86$

The value of a ton of 2000 pounds, at the same rate, would be $\$ 37.20$ in gold.

BONE-MEAL.

116. Bone-meal, as found in commerce, is prepared either from nearly or quite fresh bones, from bones that have been exposed to the air for some time, or from those that have been steamed or boiled; the first kind contains much fat and gelatine, and is usually quite coarse; the third kind has lost nearly all its fat and much of its gelatine, and is quite fine; while the second occupies a position between the other two in all respects.

a. Water,-Desiccate about 5 grms, if of the common kinds of steamed bone-meal, at $100^{\circ}$.

b. Non-volatile matter.-Ignite the dried residue in $a$ and treat the ash with ammonic carbonate, to restore carbonic acid that was expelled by heat $(\S 91, d)$.

c. Nitrogen.-Burn 0.5-0.8 grms. of the finely powdered meal with soda-lime $(\$ 85)$.

c. Phosphoric acid.-Dissolve 3-4 gims. of the ash obtained in $b$ in as little nitric acid as possible, with the aid of heat; filter the solution into a 250 c.c. flask, wash the sandy insoluble residue, ignite, and weigh it. Fill the 1lisk with distilled water up to the 250 c.c. mark, mix its contents well together, and determine phosphoric acid in 50 c.c. of this solution, with the standard uranic solution $(\$ 115, a)$. In order to saturate the free acid, it will be well to add 20 c.c. of the sodic acetatc. If a coarse, splintery 
bone-meal is under examination, a larger quantity, about 50 grms., should be incinerated in order to get the ash for treatment with acid.

e. Complete analysis of the ash.-Treat a portion of the solution obtained in $d$ according to Scheme IV., \&9t, taking 50-100 c.c. for $a$ and the same for $b$. This cxamination is, in general, unnecessary, if the only object of the analysis is to determine the agricultural value of the article.

f. Fat.-Exhaust a weighed quantity of the finely pulverized meal with ether, dry the residue at $125^{\circ} \mathrm{C}$, and count the loss as fitt $(\$ 8 \%)$.

g. Gelatine.-The gelatinous substances may be estimated by the difference between the total loss on ignition and the sum of the water and fat.

h. Fineness of division of the meal.-The value of bone-meal depends not only upon its chemical composition, but also upon the fineness of the powder.

To test the substance in this respect, it should be passed through sieves of different degrees of fineness; and it is important that all chemists should use sieves of the same kind, so that the results obtained by different persons can be compared with each other.

Wolff recommends the use of the three finest sieves of the set made by Hugershoff, in Leipzig, the first of which (I) has 1089 meshes in a square centimetre, the second (II) 484 meshes, and the third (III) 256. The residue, that will not pass through the coarsest sieve, should be cxamined, in order to see whether it is made up largely of grains which would pass through a little coarser sieve still, or of large splinters.

One bone meal of excellent quality, analyzed by Wolff, contained $60^{\circ} \%_{0}$ of $\mathrm{No}$. I., $20^{\circ} \%_{0}$ of No. II., and $10^{\circ} \%_{0}$ of No. III. 
BONE-BLACK, BONE-ASH, PHOSPHORITE.

11\%. A. Bone-black, after it has been used by the sugar refiner's, usually comes into the market as a manure. Pulverize $30-40$ grms. of it for examination.

a. Water,-Desiccate $3-4$ grms. for a considerable time at $150^{\circ} \mathrm{C}$.

b. Non-volatile matter.--Ignite the dried substance obtained in $a$, and treat the residue with ammonic carbonate, to restore carbonic acid expelled during the ignition $(\S 91)$.

c. Carbonic acid.-Estimate this in 3 grms. $(\S 60)$.

d. Nitrogen.-Burn 0.5 to 0.8 grm. with soda-lime $(\S 85)$.

e. Phosphoric acid, etc.-Digest the contents of the flask in $c$, after adding a little more nitric acid, several hours on the water-bath; filter the liquid into a 250 c.c. flask, wash the residue with hot water, dry it at $150^{\circ}$, weigh, ignite, and weigh again. The loss on ignition gives approximately the amount of charcoal, and the residue left after ignition is to be considered as sand, though it may be tested with nitric acid to see whether any more is soluble.

Dilute the contents of the flask to 250 c.c., mix all parts of the solution well together, and determine phosphoric acid in 50 c.c. with the uranic solution $(\S 115, a)$.

$f$. Complete analysis of the ash. - Treat a portion of the solution obtained in $e$, or a solution obtained in the same manner, as directed in Scheme IV., § 94, taking 100 c.c. for $a$ and the same for $b$.

\%. Chlorine may be determined in a portion of the solution obtained in $e$, by precipitation with argentic nitrate $(\S 63)$.

$h$. Calcic hydrate.-It is sometimes desirable to determine this in the bone-black. Moisten a portion of the 
original substance with a solution of ammonic carbonate, evaporate the mixture very carefully to dryness in a covered crucible, repeat the operation several times, and ignite, finally, to a dull red heat, not strong enough to burn the coal. Determine carbonic acid in this residue; the difference between the quantity found here and in $c$ represents an equivalent quantity of calcic hydrate or caustic lime, $\mathrm{CaO}, \mathrm{H}_{2} \mathrm{O}$.

B. Bone-ash should be treated as directed for the ash of bone-meal, with the addition of determinations of moisture and of carbonic acid, for the purpose of estimating the calcic carbonate.

C. Phosphorite, coprolites.-Phosphorite, and other minerals containing phosphoric acid, are usually mixed with oxides of iron and alumina to such an extent that the acid cannot be determined volumetrically.

a. Phosphoric acid.-To determine this alone, Fresenius gives the following directions. (Fresenius's Zeitschrift, 6, 404).

Heat about $0.5 \mathrm{grm}$. of the finely pulverized mineral in a small flask about an hour on the water-bath, with 8-10 c.c. of concentrated (fuming) hydrochloric acid, and evaporate the mixture to dryness in the usual manner for climinating silica $(\S 58, a, 1)$; moisten the residue with 2 c.c. of hydrochloric acid, add, after a short time, 10 c.c. of concentrated nitric acid (Sp. Gr. 1.2), dilute with water, filter and wash the insoluble residue; eraporate the filtrate and washings almost to dryness, dissolve the residue in 5 c.c. of nitric acid, transfer the solution to a beaker, rinse out the evaporating dish with a little water, and then with the solution of ammonic molybdate; add, in all, 150-200 c.c. of this reagent, and proceed with the elimination of the acid as directed in $\S 61, b$.

b. Complete analysis.-Digest $5-10$ grms. of the wellpulverized mineral with hydrochloric acid, filter out the 
insoluble substance, dry it, boil it repeatedly with sodic carbonate, to dissolve out the silicic acil $(\S 58, a, 2)$, and treat this insoluble residue with $6-8$ times its weight of sulphuric acid to decompose the clay, as directed under soil analysis (§ 102). Evaporate the solution in hylrochloric acil obtained above to dryness, and eliminate and weigh the silica $(\$ 58, a, 1)$, and examine the filtrate from the silica, as directed in Scheme I., except that manganese need not be determined, unless a qualitative test reveals its presence in notable quantity.

GUANO.

118. A. Peruvian or other ammoniacal guanos.Pulverize 200-500 grms. until the whole will pass through a tolerably fine sieve.

c. Water.-Estimate this in 1-2 grms. in such a manner as to collect the ammonia that is expelled at the same tims by the heat $(\$ 90, d)$. The amount of ammonia given off is usually from $1-\left.2^{\circ}\right|_{0}$ of the weight of the guano.

b. Non-volatile matters.-Ignite $6-8$ grms. carefully in a platinum crucible $(\S 91)$.

c. Nitrogen.-Burn $0.5 \mathrm{grm}$. with soda-lime. The mixture should be made as quickly as possible in the tube, and the bulbed tube attached immediately, to prevent any loss of ammonia $(\S 85, b)$.

d. Actual ammonia.-Determine this in 1 grm. by Schlössing's process $(\S 47, b)$.

e. Phosphoric acil, etc.-Digest the ash obtained in $b$ with nitric acid, filter out the sand, wash, ignite, and weigh it, and dilute the filtrate to 250 c.c.

Determine phosphoric acid in 50 c.c. of this filtrate, by the volumetric method $(\S 115, a)$.

For another method of estimating phosphoric acid alone, mix 1 part of guano (1-2 grms.) with 1 part of sodic car- 
bonate and 1 of nitre, fisse the mixture carefully, dissolve the residue in water, and evaporate the solution to dryness on the water-bath; treat this residue with hydrochloric acid and water, as in eliminating silicic acid $(\$ 58, a, 1)$; filter, add ammonia to the filtrate until it is in slight excess, then acetic acid until the calcie phosphate precipitated by the ammonia is dissolved; and then, without filtering out the small amount of ferric phosphate, determine phosphoric acid by the volumetric method. (Fresenius.)

$f$. Complete analysis. - Treat a portion of the solution obtained in $c$, or one obtained in like manner, after elimination of silicic acid, according to Scheme IV., \$94.

$\%$ Solubility in water.-Heat $10 \mathrm{grms}$ of the powdered guano with 200 c.c. of water, filter at once through a weighed filter, wash the contents of the filter with hot water, as long as the water has any yellow color and leaves a residue when evaporated; dry and weigh the insoluble residue. Subtract the sum of the water and the insoluble substance from the total weight of the guano, and the remainder will be the soluble matter; and, if the insoluble residue is ignited and the ash weighed and sul)tracted from the total amount of ash, the amount of soluble non-rolatile matters will be given by the remainder. (Fresenius.)

$h$. Uric acid.-Digest the part of the guano that is insoluble in water with a weak solution of sodic hydrate; filter the mixture, precipitate the uric acid in the filtrate with hydrochloric acid, and proceed as directed in $\$ \% 5$, with the washing of the precipitate.

$i$. Oxalic acid.-Expel the carbonic acid from a weighed portion of the guano with sulphuric acid, neutralize the excess of acid with sodic hydrate entirely free from carbonic acid, and estimate oxalic acid with sulphuric acid and manganic binoxide $(\S 69)$.

k. Narks of a good Peruvian guano.-It forms a loose, 
yellowish-brown powder mixed with soft lumps of various sizes, which, when broken, exhibit white veins on the fractured surface, or sometimes a foliated crystalline appearance.

If a small quantity is heated with a few drops of dilute nitric acid and the mixture is evaporated to dryness at a gentle heat, a fine, purple-red colored residue is left, indicating the presence of uric acid $(\S \% 5)$.

It gives a good reaction for ammonia with solic hydrate or lime.

By digestion with water, about half is dissolved, forming a dark-yellow solution; if the guano is poor, a lightyellow solution is obtained. This solution gives the usual ractions for ammonia, lime, magnesia, and sulphuric acid.

It loses $60-70^{\circ}$ 。 when ignited, and leaves a grayishwhite ash that evolves but little carbonic acid when treated with nitric acid, and leaves but from $1-\left.3^{\circ}\right|_{0}$ of matters insoluble in acid, and contains $5-\left.10^{\circ}\right|_{0}$ of fixed alkaline salts.

Baker guano, and other phosphatic guanos.-These are examined in the same mannel as the Peruvian guano, 'xcept that, since they contain but a very small proportion of nitrogen and alkaline salts, the determination of phosphoric acid alone answers for the estimation of their agricultural value. This may generally be made by the volumetric process.

\section{SUPERPHOSPHATES.}

119. These are generally mixtures of calcic sulphate, calcic chloride, tricalcic phosphate, ferric phosphate, monocalcic phosphate, organic matters containing nitrogen, coal and water.

Mix the sample well together, breaking up all the lumps between the fingers or in the mortar.

a. Water.-Desiccate $3-4$ grms. for a considerable time at $150-160^{\circ}$ C. $(\S 90)$. 
b. Non-volatile matters.-Ignite the dry residue obtained in $a(\S 91)$.

c. Nitrogen.-This should be determined, in case the phosphate was prepared from Perurian guano or bonemeal, or it is claimed that it contains nitrogenous matter. Ignite $0.5-1$ grm. with soda-lime.

d. Actual ammonia.-Determine this, if present, by Schlössing's process, in 1-2 grms. $(\S 47, b)$.

e. Phospheric acid.-The value of a superphosphate depends chiefly upon the amount of phosphate that it contains that is soluble in water, and, when the article was prepared from bone-black, bone-ash, phosphorite, or Baker guano, the determination of soluble phosphate suffices for the estimation of its value. But when made from steamed bones, wholly or in part, there is commonly from $5-6^{\circ} \%_{0}$ of insoluble phosphate which should be taken into account. It appears that sometimes the proportion of soluble phosphate diminishes when the article is kept for a long time; if, therefore, an unexpectedly small amount is found, a determination of the insoluble phosphate should be made also, in order to estimate fairly the value of the fertilizer.

1. To estimate the soluble phosphate, triturate $10 \mathrm{grms}$. of the well-mixed sample with 200-300 c.c. of water, applying pressure enough with the pestle to break up the limps, but not to pulverize the hard grains; let the mixture stand some time, pour off the clear supernatant liquid through a filter, and repeat the exhaustion with water as long as an acid reaction is communicated to a fresh portion; finally, put the whole insoluble residue on the filter, dry it at $100^{\circ}$, and weigh it; bring the volume of the aqueous extract to 1000 c.c.

Determine phosphoric acid by the volumetric method in 100 c.c. of this solution, first precipitating and filtering out the ferric phosphate, if but a small quantity is formed, and dry and weigh this precipitate; $\left.47.02^{\circ}\right|_{0}$ of it is phos- 
phoric acid. If the superphosphate was made from a phosphatic guano, this precipitate of ferric phosphate will generally be too large to allow an accurate volumetric estimation of phosphoric acid, and a gravimetrical method should be followed.

$\left(\S 93, H_{.}\right)$

2. To estimate the insuluble phosphate, treat 20 grms. of the substance with water to which 20 c.c. of nitric acid $($ s. Gr. $=1.4)$ have been added, and digest the mixture several hours on the water-bath. If a sufficient quantity of acid was added, the insoluble residue left after digestion can be plainly seen, when stirred up, to consist of nothing but heary sand and particles of coal; if the solution appears to be incomplete, add 10 c.c. nore of the acid and heat the mixture again several hours; finally, filter the solution into a litre flask, and when the filtrate is cool, bring its rolume up to 1000 c.c.; determine phosphoric acid by the volumetric method $(\$ 115, a)$ in 50 c.c. of this solution, using 20 c.c. of sodic acctate.

This result gives the total amount of phosphoric acid in the superphosphate, and, as the soluble phosphate has already been determined, the amount of insoluble phosphate is readily estimated.

The insoluble residue of sand in this examination may ke ignited and weighed.

$f$. Complete analysis.-Examine the aqueous solution prepared above, if it is particularly desired to learn its composition, according to Scheme IV., §94, taking 100 c.c. for $a$, and 100 c.c. for $b$ with previous trentment with sodic carbonate and potassic nitrate; also determine chlorine in 50 c.c. of the solution, by precipitation with argentic nitrate ( $\$ 63)$.

Or, for a more complete analysis, including the determination of what is soluble in acid with what is soluble in water, examine the nitric-acid solution obtained in $e$ according to Scheme IV., except in case the phosphate contains much organic matter, when it would be better to 
analyze a solution of the ash obtained in $b$, in nitric acid. S'ulphuric acid and chlorine, however, must always be determined in the nitric-acid solution of the original substance.

GYPSUM.

129. $a$. Water.-Ignite 2 grms. of the finely pulverized gypsum gently.

b. Hasoluble matters.-Digest 2 grms., likewise finely powdered, with very dilute hydrochloric acil, as long as anything appears to be dissolved, filter out the insoluble sand and clay, wash well with hot water, dry, ignite, and weigh the insoluble residue.

c. Sulphuric acih, ferric oxide, lime, etc.-Divide the acid solution in two equal parts, and in one precipitate sulphuric acid with baric chloride $(\S 59)$, and in the other, after dilution with water and heating with a little concentrated nitric acid, precipitate ferric oxide and alumina, with ammonia in slightest possible excess (§ 51). Filter the precipitate out quickly, so as to avoid the precipitation of calcic sulphate in the alkaline solution, wash it well, and then weigh it after ignition. Immediately on filtering out this precipitate by ammonia, add ammonic oxalate, in excess to the filtrate to precipitate the lime $(\$ 49, a)$, and estimate magnesia in the filtrate from the lime, in the usual way with hydric disodic phosphate $(\S 50,6)$

d. If there is a considerable precipitation of ferric oxide by ammonia, some calcic sulphate is very liable to be mixed with it. In this case, it is better to boil about 1.5 grms. of the finely powdered gypsum an hour with a solution of 6-8 grms. of pure sodic carbonate; by this operation, if the gypsum was properly pulverized, it is completely converted into calcic carbonate. Filter, wash the contents of the filter well with hot water, and precipi- 
tate the sulphuric acid in the filtrate with baric chloride; transfer the filter with its contents to a deep beaker, and dissolve the carbonate in dilute hydrochloric acid with the usual precautions, filter, wash well, dry, ignite, and weigh the residue of sand and clay. Determine lime and magnesia in the filtrate in the usual manner $(\S 50, b)$.

e. Alkalies.-To determine these in gypsum, boil 10 grms. repeatedly with dilute hydrochloric acid, filter, and eliminate the alkalies as chlorides $(\S 93, \mathrm{G}$.).

$f$. A determination of carbonic acid will furnish means of estimating the amount of calcic carbonate in the gypsum; take 5-10 grms. for the analysis ( $\$ 60)$.

SALT. POTASII COMPOUNDS.

121. A. Salt. a. Water.-Gently ignite $3-4$ grms, well pulverized, in a platinum crucible that is kept well covered, and carry the temperature finally to a dull red.

b. Complete analysis.-Dissolve $10 \mathrm{grms}$. in hot water, filter the solution into a litre flask, and wash, dry, ignite, and weigh the insoluble residue.

This residue consists mostly of sand and clay. If gypsum is contained in it, digest it with dilute hydrochloric acid as long as anything appears to be dissolved, filter the solution, add ammonia in excess to the filtrate, filter out the precipitated ferric oxide and alumina, precipitate lime in the filtrate by ammonic oxalate, and sulphuric acid in the filtrate from the calcic oxalate by baric chloride after acidification with hydrochloric acid.

Bring the volume of the aqueous solution of the salt, obtained above, to 1000 c.c., and determine lime and magnesia in 400 c.c. $(\S 50, b)$, and chlorine in another portion by the volumetric process $(\S 63, b)$. Dilute 300 c.c. with more water, acidify it with hydrochloric acid, and examine the solution for sulphuric acid and the alkalies $(\S 93$, 
$\mathrm{E}$ and $\mathrm{G})$. The determination of potassa in common salt is generally unnecessary.

B. Potassa salts.-Dissolve 10 grms. in hot water, and determine potassa at once with platinic chloride in a portion of the solution $(\S 93, \mathrm{G}, 3)$.

For the complete analysis, or the determination of water, proceed as directed for the analysis of salt.

CHILI SALTPETRE.

122. $a$. Water,-Desiccate 3 grms. at $110^{\circ} \mathrm{C}$.

b. Complete analysis.-Treat 20 grms. of the pulverized salt with hot water, filter the solution into a litre flask, collect the insoluble residue on a dried and weighed filter, wash it well with hot water, dry it at $125^{\circ} \mathrm{C}$., weigh it, and then ignite it at a low temperature, and weigh the ash. These results give the amount of insolitble sand and clay, and, approximately, the organic matter.

Bring the volume of the aqueous solution to 1000 c.c., determine sulphuric acid and chlorine in two portions of 200 c.c. each, by precipitation with baric chloride (§59) and argentic nitrate $(\S 63)$, and lime and magnesia in another portion of 500 c.c. $(\S 50, b)$.

$c$. Soda.-This may be estimated by the difference between the total amount of substance taken, and the sum of the acids, water, organic matter, and the other bases; or it may be estimated by converting all the bases into sulphates, in the manner described for converting potassa into sulphate (\$44), and weighing the mixture of the salts; then subtract from this the sum of the weights of calcic and magnesic sulphate, as estimated from the determination of those bases, already made, and the remainder will be the sodic (and potassic) sulphate.

d. To determine approximately the amount of potassa, if any is present, dissolve this residue of mixed sulphates 
in very dilute hydrochloric acid, determine sulphuric acid in the solution by precipitation with baric chloride ( $(59)$, deduct so much of the sulphuric acid as is estimated to have been combined with the lime and magnesia, and deduct also the corresponding quantity of sulphates from the total amount of sulphates, and with these remainders estimate the potassa and sola by the formula for the indirect determination of these bases $(\$ 46, e)$.

e. Niture acid. - This may be determined by Schlüssing's process in 10-20 c.c. of the aqueous solution obtained in $b$, or by fusion of about 2 grms. of the salt with silicic acid ( $(62)$. This estimation an be dispenscd with, since the weight of the nitrates equals the difference between the total amount of salt taken, and the sum of the sulphates and chlorides, as already determined.

f. If the Chili saltpetre is adulterated with salt, its solution will give an abundant precipitate with argentic nitrate; if adulterated with soda (sodic carbonate) it will give the reaction for carbonic acid; if with magnesic sulphate (Epsom salts), it will give a decided reaction for sulphuric acid and for magnesia; and if with sodic sulphate (Glauber's salt), it will give a decided reaction for sulphuric acid, but none for magnesia. 


\section{CHAPTER VII.}

\section{A N A L Y IS OF A SHES.}

I.

ASHES OF PLANTS.

123. To prepare the plant for incineration, it must first be most carefully cleaned; and too much care cannot be taken in this respect, for if any particles of sand or clay are left adhering to the object, the accuracy of the analysis is of course thereby greatly impaired, or the analysis itself is rendered much more difficult of execution.

a. Roots and tubers must be cleaned with a soft brush, under a current of water, and be afterwards repeatedly rinsed off with distilled water, and immediately dried with a soft cloth. The dust is removed from stems and leaves, when possible, by wiping them with a soft cloth. Seeds, particularly the larger kinds, may be put in distilled water for a few minutes, and immediately, before the water can have time to penetrate them, put on a sieve to drain, laid on filter paper and dried as quickly as possible between soft cloths.

b. To dry the green parts of plants and fleshy roots, hang them on threads in a drying-chamber, the roots being cut in thin slices. Tuber's may be dried in the same way. Roots and tubers so dried are then coarsely pulverized in the mortar, while leaves and stems are cut up with clean shears; seeds are broken up to a coarse powder in a mortar.

c. The incineration is best effected in shallow platinum trays, that are heated over the gas-lamp, or in large castiron muffles, about $50 \mathrm{~cm}$. long and $13 \mathrm{~cm}$. wide, built 
into an appropriate furnace in such a manner as to be heated mostly at the sides and on the top. The heat must, at first, ba kept very low for several hours, or even days, while the substance is slowly charred; the coal, when so slowly formed, takes a more porous consistency. When the evolution of gases has nearly ceased, the heat may-be gradually raised, but not at any time to a perceptible red; in this way, at least in the incincration of most of the fodder-plants, roots, and woods, that yield an ash rich in carbonates, a perfect combustion is obtained without fusing the ash. In case some coal remains, that resists combustion without applying too high a heat, exhaust it with hot water two or three times; the washed residue is usually very easily burned. Then either add the aqueous solution just obtained to the ash, evaporate the mixture to dryness on the water-bath, ignite the residue very gently, and weigh it; or weigh the last ash, and bring the aqueous extract of the coal to a certain volume, and for each part of the subsequent analysis, mix together equal fractional parts of ash and extract.

Substances rich in silica, as the grasses, and the stems and chaff of cereals, and also seeds rich in alkaline phosphates, are with difficulty made to yield an ash that is free from coal. Such substances should first be charred at a very low temperature; then, without disturbing the coal in the dish, moisten it with a cold saturated solution of baric hydrate, dry the moistened mass, and ignite it in the muffle at a barely visible red heat; the completion of the incineration generally requires from 8 to 12 hours. Enough baryta water must be added, by moistening and drying the coal several times, so that the ash will contain about half its weight of baryta. The addition of this substance almost entirely prevents the escape of the chlorine, effects a more speedy combustion of the coal, makes the silicates decomposable by acids, and insures the presence of phosphoric acid in the ash in a readily determinable form. 
§124. ASH RICH IN CARBONATES, POOR IN SILICA. 243

The whole quantity of the ash, in whatever way obtained, should be most carefully pulverized and mixed together before any sample is taken for analysis.

\section{A. ASH RICH IN CARBONATES, AND POOR IN SILICA.}

124. a. Carbonic acid.-Determine this in 1-2 grms., using nitric acid to expel the carbonic acid.

$b$. Chlorine.--Estimate this in the nitric-acid solution obtained in $a$, after filtering out the insoluble portion.

c. Silica, sand, and coal.-Moisten a portion (3-4 grms.) in a flask, with concentrated nitric acid, add concentrated hydrochloric acid, and digest the mixture for a long time at an almost boiling heat. Rinse the whole into an evaporating dish, evaporate to dryness, moisten the residue with hydrochloric acid, and proceed to eliminate and determine silica, sand, and coal, as directed in $\S 58, a, 3$.

If the ash contains no sandy particles, as may be shown by the absence of any grittiness when the residue, insoluble in hydrochloric acid, is stirred with the glass rod, the boiling with sodic carbonate may be omitted, and nothing need be done but collect the silica on a weighed filter, dry it at $110^{\circ}$, weigh it, and ignite, and weigh it again, to determine the unconsumed carbon that may be mixed with it.

If there are more than a few centigrammes of this carbon in three or four grammes of the ash, the substance has not been properly incinerated, and very unreliable results may be obtained in the analysis, particularly as regards the phosphates and the alkalies.

d. Complete analysis.-Bring the filtrate from the insoluble portion to a volume of 500 c.c., and examine it according to Scheme IV., $\S 94$. If more than traces of manganic oxide are present, and it is desired to estimate this base, proceed according to Scheme III., $\S 94$. 
B. ASH RICH IN SILICA, MIXED WITH BARYTA.

a. Determine carbonic acid and chlorine, and prepare the solution for the complete analysis, precisely as under A.

The residue, insoluble in hydrochloric acid, on eliminating silica in the usual way, contains, besides sand and unconsumed carbon, baric sulphate, in which is the sulphuric acid of the ash, and it must be treated accordingly. Collect it on a dried and weighed filter, wash it, dry it at $110^{\circ} \mathrm{C}$, and weigh. Then treat it with sodic carbonate $(\S 58, a, 2)$; but, as the baric sulphate is not readily decomposed by the carbonated alkali, the boiling must be repeated several times, with fresh portions of the carbonate, the insoluble part allowed to settle completely after each boiling, and the clear liquid decanted without transferring any notable quantity of the solid to the filter; when the filtered liquid gives no reaction for sulphuric acid, after acidification with hydrochloric acid, the decomposition may be considered as ended; if the portion with which the test is made gives a reaction with baric chloride, it should be put back into the liquid to be boiled.

Transfer the silica and coal to the filter, after the boiling is finished, pour dilute hydrochloric acid over it as long as there is any effervescence, wash the filter carefully with water, dry at $110^{\circ}$, weigh, ignite, and weigh again, and so estimate sand and unconsumed carbon, as under $\mathbf{A}$.

Evaporate the alkaline solutions and washings to dryness, and eliminate silica ( $\$ 58)$, and determine sulphuric acid in the filtrate from the silica, with the aid of baric chloride $(\$ 59)$.

c.b. Complete analysis.-Examine the solution obtained in $a$, and filtered from the silica, etc., according to Scheme 
III. or IV., § 94, with these exceptions, that sulphuric acid need not be determined under $a$, and that, before precipitating lime by ammonic oxalate, the barium should be removed by precipitation with a very dilute sulphuric acid, containing but one part of acid in $300-400$ of water; the precipitated baric sulphate should be examined for lime by heating the moist precipitate with ammonic carbonate, washing it, and then treating it with dilute hydrochloric acid, neutralizing the acid with ammonia, and adding ammonic oxalate.

\section{Miscellaneous Determinations.}

a. Sulphur.-A part of this is volatilized during the process of incineration. In order, therefore, to determine the total amount in the plant, treat 4-5 grms. of the dry substance with fused potassic hydrate and nitrate (§92).

\section{$b$. Sulphuric acid, already formed in the plant.-A} few cultivated plants contain more than mere traces of this acid. To determine it, and also the chlorine, if it is desired, prepare an extract of the plant by water containing $\left.{ }^{1}\right|_{20}$ of nitric acid.

Draw out one end of a glass tube, about $60 \mathrm{c.m}$. long and $1-\left.1^{1}\right|_{2} \mathrm{~cm}$. in diameter, in such a manner that a rubber tube and clamp can be attached, after the fashion of a Mohr's burette. Close the throat of the tube, where it begins to taper into the smaller tube, with a plug of cotton that has been previously boiled in the acidulated water, such as is to be used for the extraction. Put 8-10 grms. of the dried substance in the tube, fill the latter with the acidified water, and let the two remain in contact several hours; then open the clamp, let some of the water run off, add fresh acidified water, and repeat the operation until the extract gives at the most the merest opalescence with argentic nitrate. 
In this acid solution precipitate sulphuric acid with baric acetate, and chlorine with argentic nitrate in the filtrate from the baric sulphate; treat this last precipitate as one produced in the presence of organic matter, if it is at all abundant.

125. The following method of incineration and analysis is given by Reichhardt, by which the volatilization of any mineral matters is avoided, as well as the addition of anything to the ash to facilitate incineration.

1. Carefully char enough of the dried substance to yield 2 grms. of ash, pulverize the coal, and exhaust it with several portions of hot water.

a. Add argentic nitrate to this extract immediately.

b. Exhaust the coal with water containing a little nitric acid, wash with the same, and add this extract to $a$.

2. Incinerate the coal completely, and exhaust the ash, first with water, and then with moderately concentrated nitric acid, and add these extracts to those obtained in $\mathbf{1}$.

3. Determination of sulphur and chlorine.-The precipitate by argentic nitrate, in these extracts, contains the sulphur that was present in a soluble form in the plant, and the chlorine. Acidify the mixture of precipitate and liquid with nitric acid, if not already acid, collect the precipitate of argentic sulphide and chloride on a dried and weighed filter, wash it well, and add the filtrate and washings to those obtained in 4 , below.

Treat the precipitate on the filter with ammonia, by which the argentic chloride is dissolved, wash the insoluble argentic sulphide, dry it at $100^{\circ}$, and weigh. It contains $12.9^{\circ} \%_{0}$ of sulphur.

Precipitate argentic chloride in the ammonic extract, by nitric acid in excess, and treat the precipitate in the usual manner (§63).

4. Heat the residue, insoluble in nitric acid in 2 , with 
concentrated hydrochloric acid, and filter. By mixing this filtrate with that obtained in 3 , the excess of silver is precipitated, and may be removed from the solution by filtration.

5. Treat the residue, insoluble in hydrochloric acid, as directed in $\S 58, a, 3$, for the separation of silica, sand, and coal.

6. Eliminate the silica in the hydrochloric solution filtered from the excess of silver in 4 , in the usual manner $(\S 58, a, 1)$, and examine the filtrate from the silica according to Scheme III. or IV., $\S 94$, according to whether manganese is or is not to be determined.

126. Statement of results.--So much sodium as is necessary to combine with all the chlorine should be considered as so combined, while the remainder of the sodium is given as sodic oxide.

If there is not sodium enough for this purpose, take enough of the potassium to combine with what chlorine is left, and give the remainder of the potassium as potassic oxide.

The manganese is to be given as manganous manganic oxide, $\mathrm{Mn}_{3} \mathrm{O}_{4}$.

The sand and coal are accidental ingredients of the ash, and therefore the percentage composition should be calculated with reference to what is left after subtracting these from the weight of ash taken for analysis.

The percentage composition should moreover be given with reference to the remainder left after subtracting the carbonic acid also, since this is not properly one of the mineral substances found in the plant, but results from the combustion of the organic acids.

The first statement enables one to judge of the accuracy of the analysis, and the second gives the real composition of the mineral matter found in the particular plant examined. 
Analysis of the ash of hops. (Wheeler.)

\begin{tabular}{|c|c|c|}
\hline & $\mid \begin{array}{c}\mathrm{CO}_{2}, \text { coal } \\
\text { ete. } \\
\text { included. }\end{array}$ & $\begin{array}{l}\mathrm{CO}_{2} \text {, etc., } \\
\text { dedueted. }\end{array}$ \\
\hline 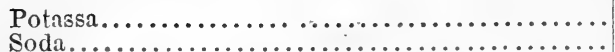 & 37.79 & 44.33 \\
\hline 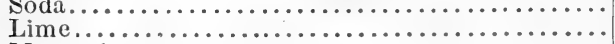 & 11.36 & 13.33 \\
\hline Magnesia. & 1.27 & $\begin{array}{r}1.49 \\
1.49\end{array}$ \\
\hline Ferric oxide............... & 0.48 & 0.56 \\
\hline Manganous manganic oxide............... & trace. & \\
\hline Alumina...................... & trace. & \\
\hline Phosphoric acid.... & 12.67 & 14.86 \\
\hline 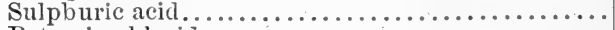 & 1.98 & 2.32 \\
\hline Potassic chloride............................ & 8.48 & 9.94 \\
\hline Sodic chloride.......... & 1.21 & 1.41 \\
\hline Silicic acid.............. & 10.02 & 11.76 \\
\hline 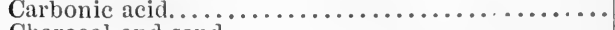 & 12.50 & \\
\hline 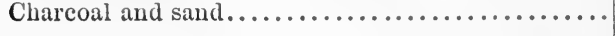 & 1.91 & \\
\hline (n........................ & $\begin{array}{r}99.67 \\
9.14\end{array}$ & 100.00 \\
\hline
\end{tabular}

THE ASH OF ANIMAL SUBSTANCES.

12\%. Animal substances are incinerated with difficulty, particularly when they fuse before they become charred; the attempt should be made, however, to burn them without the addition of any agents.

First char the dry substance in a platinum dish, raising the heat very slowly, so as to avoid fusion, if possible; when the charring has attained such a point that water is no longer colored when left for a time in contact with the coal, break the coal up into a coarse powder, and boil and wash it several times with water, acidified with a little nitric acid in case no carbonates are present, or carbonic acid is not to be determined; then dry the coaly residue and complete the incineration in the muffle, at a barely visible red heat.

Sometimes it will be found necessary to repeat the exhaustion with water and heating in the muffle several times, before the incineration can be completed. 
This process, will, however, hardly succed in many cases, and usually only when the ash yielded by the substance is rich in alkaline carbonates or sodic chloride, or when but a small quantity of the substance is incinerated in order to determine the total amount of ash. Since a considerable proportion of alkaline phosphates is often present, which is converted into pyrophosphate during the incineration, it is generally necessary to treat the charred substance with baryta water, in the manner directed for the incineration of vegetable substances rich in phosphates.

In the analysis of the ash, proceed as directed for the analysis of ashes of plants, with the exception that, since silicic acid and sand are rarely present, the work is somewhat simplified. The total sulphur should be determined in a portion of the substance that has been heated with potassic hydrate and nitrate (§92).

\section{III.}

ASHES OF FUEL.

128. a. Carbonic Acid.-Determine this in 2 grms.

b. Chlorine.-Determine this in the nitric-acid solution obtained in $a$.

c. Complete Analysis.-Conduct this as directed for the analysis of the ash of plants poor in silica. $\left(\S 124, c, d_{0}\right)$ The estimation of potassa and phosphoric acid is of most importance in respect to the agricultural value of the ashes. 10-15 grms. of wood ashes, or 15-25 grms. of peat or coal ashes, should be treated with acid, in order to prepare a sufficient quantity of the solution.

d. Potassa.-For a volumetric determination of potassa that will answer very well for practical purposes, treat 6.91 grms. of the wood ashes in a flask of about 300 c.c. capacity with 5-6 grms. of caustic lime and $40-60$ c.c. of $11^{*}$ 
water, and heat the mixture to boiling. Filter the solution into a graduated cylinder, and wash the insoluble residue with sufficient water to make the volume of the solution exactly 100 c.c., when properly cooled. Titrate 10 c.c. of this solution with the normal acid $(\S 44, f)$, subtract 0.3 c.c. for the excess of lime, and then multiply the number of cubic centimetres required by 10 , for the per cent of potassic carbonate.

Peat and Coal Ashes are usually very poor in alkalies and phosphoric acid. Their agricultural value depends more particularly on the amount of calcic sulphate (gypsum), and calcic carbonate and phosphate, which they contain.

Many kinds of peat leave ashes that are rich in gypsum; in such cases it is well to boil about 2 grms. of the ashes an hour, with a solution of 6-8 grms. of sodic carbonate, and determine sulphuric acid in the aqueous solution so obtained, and lime in the hydrochloric solution of the residue insoluble in water. 


\section{CHAPTER VIII.}

FODDER AND FOOD.

I.

FODDER.

129. In the examination of fodder, it is very desirable that chemists should follow a common method.

The processes of analysis that have been perfected at the experimental station, Weende, by Henneberg, Stohmann, Rautenberg, Kühn, Aronstein, and Schulze, commend themselves for general use.

a. Preparation of the Sample for Analysis.-In order that the sample may fairly represent a large quantity of the fodder, a handful should be taken here and there from all parts of the pile or the field, till 15-20 such portions are obtained: $\operatorname{mix}$ the whole well together, and take about 1 kilo. of dry fodder or 3-4 kilos. of green for the sample.

Cut it up with shears, weigh it, dry it for several days in a drying-chamber at $50-60^{\circ}$, expose it to the air 24 hours, and weigh it again in this air-dried condition.

b. IIygroscopic Water.-Grind 50 to $100 \mathrm{grms}$. of the dry substance quickly in a steel mill and desiccate 10 grms. of this powder at $110^{\circ} \mathrm{C}$.

$c$. Non-volatile Matter.-Incinerate the dried substance obtained in $b$, subtract carbonic acid and coal, and calculate the non-volatile matter in the fodder as it was taken for analysis.

130. Reduce the rest of the air-dried substance to a fine powder, by alternate grinding and sifting, and preserve it in well-stoppered bottles.

a. Water,-Desiccate 3-5 grms. of this powder at 
$110^{\circ} \mathrm{C}$, and calculate the amount of dry substance in the powder.

b. Protein Compounds.-Ignite 0.7 to $1 \mathrm{grm}$. with soda-lime $(\S 85)$.

c. Fatty Substances.-Extract these from 6-8 grms., by ether $(\S 87)$.

d. Crude Cellulose-Boil a quantity of the powder containing about 3 grms. of dry substance, half an hour, with 200 c.c. of dilute sulphuric acid, containing $1.25^{\circ} \%$ of monohydrated acid, in a flask that is attached to the lower end of a Liebig's condenser; let the mixture stand till the solid particles settle to the bottom; draw the clear liquid off into a beaker, as completely as possible, with a small siphon, and finally with a pipette; pour 200 c.c. of water over the residue in the flask, boil again half an hour in the same manner as before, and as before let the solid particles settle and remove the clear liquid; repeat this operation once more.

Then boil the substance in the same way with 150 c.c. of water and 50 c.c. of a solution containing $50 \mathrm{grms}$. of fused caustic potash in the litre, and afterwards twice with 200 c.c. of water, removing the liquid each time in the same manner as described for the sulphuric acid, but putting these alkaline washings in a beaker by themselves; finally, bring the residue on a dried and weighed filter. Then, with the siphon, draw off the clear alkaline liquid from any sediment that may have been deposited in it; transfer this sediment to the same filter, and wash the whole, as long as the washings have an alkaline reaction; then add the sediment in the beaker containing the acid washings, after drawing off the clear liquid with the siphon, and wash again, as long as the washings have an acid reaction. Wash the contents of the filter successively with alcohol and ether; dry the filter and its contents at $110^{\circ}$, weigh, incinerate the residue, and weigh 
the ash. The difference between the total weight of the insoluble residue and that of the ash equals the crude cellulose or fibre.

The residue obtained in this way is a mixture of cellulose with various other substances. When obtained from the grasses it is comparatively the purest, but contains $2-\left.3{ }^{0}\right|_{0}$ of protein compounds. When prepared from clover, it contains $5-\left.6^{\circ}\right|_{0}$ of the same substances; but even after subtraction of these albuminoids, the residue contains 1- $7^{\circ} \%_{0}$ more carbon than pure cellulose.

131. a. Dry Matter Soluble in Water--To determine the amount of substance soluble in water, boil 10-20 grms. with 10-12 successive portions of $200-300$ c.c. of water in a flask that is connected with the lower end of a Liebig's condenser $(\$ 39, c)$, and after each boiling, separate the water as quickly as possible from the residue; all the portions of water are afterwards passed through a ribbed filter, that is pierced with the glass rod and replaced by a new one as often as it becomes choked up, so that the filtration shall proceed as rapidly as possible. Bunsen's method of filtration can be used in this case to great advantage.

The extraction should, at any rate, be finished in one day, so that the solution may not begin to mould before it is examined.

Evaporate 200 c.c. of the extract almost to dryness, in a platinum dish, on the water-bath; complete the desiccation on hot sand, under the receiver of the air-pump $(\S 90)$, and weigh the residue.

b. Non-volatile Matter Soluble in Water,-Incinerate the residue obtained in $a$. Generally an ash free from coal can be obtained; if not, filter out and weigh the coal in the usual manner, and subtract it and the carbonic acid from the total residue.

An excess of mineral matters is always found in this 
solution, for the water dissolves some of the glass with which it comes in contact.

If it is not desired to subject the residue insoluble in water to further treatment with alcohol and ether, as below, it can be dricd and weighed, and ash and nitrogen determinations made with portions of it; then, by subtracting the amount of ash and nitrogen found in it from what was found in the original substance, the amount that should be found in the aqueous extract may be estimated, and thus the tedious evaporation of a portion of that extract to dryness be avoided; or the two sets of determinations may be made to control each other ; the difference between the amount of substance taken for extraction with water and the weight of the insoluble substance, above determined, will give the amount soluble in water.

Or, since the alcohol and ether used for extracting the residue insoluble in water, as below, usually take up but traces of mineral matters, we can, in case these solvents take but a few per cent of that residue into solution, consider the residue insoluble in alcohol and ether as containing the same amount of ash ingredients as the residue insoluble in water only, and the determination of the ash in this will answer the same purpose as if estimated in the first insoluble residue.

c. Nitrogen in Forms Soluble in Water.-Evaporate 500-1000 c.c. of the aqueous extract to a syrup, on the water-bath, absorb the residue by as small a quantity of calcined gypsum as possible, collect the whole in a watchglass, dry it for a while at $88-90^{\circ} \mathrm{C}$., and ignite the residue with soda-lime $(\S 85, a)$.

d. Actual Ammonia.-Determine this in a portion of the aqueous extract, by Schlössing's method. Acidify 300 c.c. of the extract with hydrochloric acid, and concentrate it. A more accurate result may be obtained by Knop's method of setting free the nitrogen and measuring 
its volume in the azotometer. (See Fresenius's Quantitative Analysis.)

$e$. Sugar and Gum in Aqueous Extract.-Evaporate 500 to 1000 c.c. nearly to dryness, as quickly as it can be done without loss, and, if possible, in a space where the air can be rarefied, and exhaust the moist residue with alcohol of $80-\left.85^{\circ}\right|_{0}$, by repeated boiling with fresh portions of the solvent, as long as it is colored. Filter the liquid, add water to the filtrate, expel the alcohol by heat, filter through animal charcoal, if necessary, bring this filtrate to a certain volume, and estimate glucose and saccharose (§81).

Dry the residue insoluble in alcohol at $100^{\circ} \mathrm{C}$., weigh, and incinerate it. Subtract the ash and protein compounds, as may be estimated from determinations already made, from the total amount of the residue insoluble in alcohol, and call the remainder gum and vegetable acids.

$f$. Nitric Acid.-To control the determination of nitrogen already made in a portion of the aqueous extract, nitric acid may be determined, in addition to the ammonia already estimated; thus it may be learned how much of the nitrogen is present in the form of these inorganic substances.

Evaporate 500-1000 c.c. of the aqueous extract to a small bulk, and determine nitric acid by Schlössing's method $(\S 62, a)$.

Frühling and Grouven (Landwirthsch. Versuchs-Stctionen, 9,9$)$ prepare the aqueous extract of the plant, particularly for the determination of nitric acid, as follows: Put 100-500 grms. of the finely divided but not ground air-dried substance in strong beakers of a capacity of two litres; add enough $\left.50^{\circ}\right|_{0}$ alcohol, so that the whole mass of the solid will be completely covered, when pressed down firmly with a pestle and kept down by a plate weighted with a glass filled with mercury. 
After 12 hours, pour off the dark-colored liquid, wrap the solid mass in a linen bag, and, with a powerful screwpress, force out the remainder of the alcohol. Pour diluted alcohol over the press-cake 4 or 5 times, and each time press the liquid out completely. In this way 1-2 litres of a highly-colored alcoholic extract are obtained. Heat the liquid almost to boiling till all the alcohol is volatilized, evaporate it to a small bulk, add an excess of rather thick milk of lime, and boil the mixture for some time; allow the precipitate to subside, draw off the clear liquid with a siphon, filter the remainder through linen, and wash the residue well; heat the solution thus obtained, pass carbonic acid through it, boil and filter; evaporate the filtrate to a small bulk, and use the whole of it for the determination of nitric acid by Schlössing's process $(\S 62, a)$, in case there is reason to believe that but little is present; or a part of it may be used for this purpose, and the remainder treated as directed above for the examination of the aqueous extract.

132. If it is desired to estimate still more in detail the non-nitrogenous substances in the fodder, boil the residue that is insoluble in water $(\S 131, a)$, first with common, and then with absolute alcohol, so long as the washings are colored; then extract this second residue with ether; these extractions can be most conveniently made with the aid of the washing-bottle filtering arrangement $(\S 39, c)$.

a. Evaporate both the extracts, or aliquot parts of them, to dryness, to determine the amounts taken into solution.

b. Crude Cellulose.-Treat $2-4$ grms. of the residue that has been exhausted with alcohol and ether above, as directed in $\$ 78$.

In case solid excrements are being analyzed to determine the amount of cellulose in them as compared with fodder, a longer maceration is advisable, for 14-16 days, instead of 12-14. 
c. Starch.-Wash 2 grms. of the powdered substance on a filter, with cold water, and then, if much gluten is present, wash with alcohol containing sulphuric acid, and finally with water. Treat the residue with dilute sulphuric acid or malt, to convert the starch into glucose, and estimate the glucose with the standard cupric solution $(\S 81)$.

The difference between the sum of the weights of the cellulose, protein compounds, and mineral ingredients in the dried substance, and the weight of the substance insoluble in water, alcohol, and ether, gives the amount of difficultly soluble non-nitrogenous matter's, of which starch will form a considerable part.

Analysis of the Pea. (Voelcker.)

\begin{tabular}{|c|c|c|c|}
\hline \multirow{3}{*}{ Water................................. } & Pea. & Pod. & Vine. \\
\hline & 14.1 & 13.68 & 16.03 \\
\hline & 2.5 & 2.75 & 4.93 \\
\hline Protein compounds............ & 23.4 & 7.12 & 8.86 \\
\hline Fat................ & 2.0 & 1.09 & 2.34 \\
\hline Cellulose (fibre).... & 10.0 & 53.71 & 42.79 \\
\hline Starch.................... & 37.0 & & \\
\hline 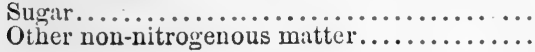 & $\begin{array}{l}2.0 \\
9 .\end{array}$ & 21.65 & 25.06 \\
\hline & 100.00 & 100.00 & 100.00 \\
\hline
\end{tabular}

BEETS, TURNIPS.

133. To estimate the value of these for fodder, determinations of water, albuminoids, mineral matters, cellulose, and the total amount of other non-nitrogenous matters, are important.

For the manufacture of sugar, the estimation of this ingredient is of greatest importance.

The part of the beet that is insoluble in water consists mostly of cellulose and pectose, while in the aqueous solution, sugar, inorganic salts, and albuminoids, are to be found.

a. Water,-Slice the roots after they have been proper- 
ly cleaned; or, if they are very large, select 15-20 from the lot, cut each one in halves from top to bottom, and take a thin slice from the inside of each half.

If sugar is to be determined for technical purposes, the crown and end of the root should be cut off, in the manner practised at the manufactory, before slicing it.

Weigh quickly the whole number of slices thus obtained, to the amount of 500-1000 grms., and dry them on threads in the drying-chamber at a temperature of $60-70^{\circ}$ C. Pulverize this dried substance coarsely, mix it well together, and weigh the whole quantity, determine hygroscopic water in a portion of 5-6 grms., and keep the rest in well-stoppered bottles.

\section{b. Non-volatile matter, nitrogen, fat, crude cellulose.}

-Determine these as directed under Fodder (\$ $\mathbb{1 2 9}, c$, $\S 130, b, c, d)$.

c. Pectose compounds. - These are estimated by the difference between the weight of the dry substance and the sum of the weights of the above-named substances in $b$, and the sugar.

d. Sugar,-Boil 2-3 grms. of the powdered substance with several fresh portions of $80-85^{\circ} \%_{0}$ alcohol, as long as anything appears to be taken into solution; pour each portion of alcohol through a filter that has beer dried at $100^{\circ}$ and weighed, and finally put the whole insoluble substance on the same filter, wash it with hot alcohol, dry it at $100^{\circ}$, and weigh, ignite it, and weigh the ash. The amount of organic matter, burned off by the ignition, can then be estimated; it consists almost entirely of sugar.

To determine the sugar more accurately, add considerable water to the alcoholic solution, heat the mixture on the water-bath until the alcohol is entirely evaporated, dilute the residue to about 300 c.c., add 5-6 c.c. of concentrated sulphuric acid, heat the mixture 3 hours on the water-bath, neutralize the free acid with sodic carbonate, 
and determine glucose in an aliquot part of the solution, having first added water, if necessary, to make the volume of the solution one that can be easily divided into aliquot parts; calculate the result obtained for saccharose, if the root examined was the sugar beet; in other roots, and in the sap of plants, glucose is found, as well as canc sugar, and the determination should be made accordingly (\$ 83).

To examine the root in its fresh state for sugar, enclose a weighed quantity of the finely grated root in a flannel bag, and press the sap out of it; weigh the press-cake, and determine water in one portion of $20-30$ grms. by desiccation at $100^{\circ}$; on the basis of this determination, the amount of sugar still remaining in the cake can be estimated, the solution in the cake being of course of the same strength as that expressed.

Weigh or measure the sap that was pressed out, and determine sugar in an aliquot part of it.

In the case of the sugar beet, it may be assumed with tolerable safety that it contains $94^{\circ} \%_{0}$ of water, and we may therefore express a small quantity of the sap from a weighed quantity of the grated root, and determine sugar in 50 c.c. of it, in the usual manner ( $\S 83)$.

An approximate estimation of sugar in beets may be made by determining their specific gravity according to the method described in $\S 3 \tilde{5}, e$.

Take 10-12 beets from different parts of the lot, clean them carefully, cut each one in four equal sections, across its longitudinal axis, and use the second piece from the top for the determination of the specific gravity. The temperature of the saline solution should be about $18^{\circ} \mathrm{C}$.

The relation between the specific gravity of the beet and the percentage of sugar, as well as of total dry substance, is given in Table VI.

When, in these estimations of sugar with the cupric solution, the solution of sugar is not properly clarified by the plumbic acetate, heat a measured quantity of it nearly 
to boiling, add a few drops of milk of lime, whereby a heavy precipitate is usually produced; then filter the liquid through granular animal charcoal, free from dust, and repeat this filtration until the solution is sufficiently decolorized. If any evaporation of the water is avoided in the course of this operation, the sugar can be determined at once in a measured portion of the filtrate; otherwise, the coal must be well washed, the filtrate and washings perfectly mixed, and the estimation of the sugar, for the whole amount of solution taken originally, based upon the ratio between the volume of this solution and that in an aliquot part of which the sugar is determined with the cupric solution.

e. Ammonia.-Treat 30 c.c. of the sap with enough plumbic acetate to effect complete precipitation, filter the liquid, and use 20 c.c. of the filtrate for the determination by Schlössing's process $(\S 47, b)$.

$f$. Nitric acid.-Determine this according to Schlössing's process $(\S 62, a)$, in $10-20$ c.c. of the concentrated sap, containing not more than 2-2.5 grms. of organic matter; an amount of ferrous chloride, containing 6-7 grms. of metallic iron, should be used for 1 grm. of dry substance in the quantity of sap taken.

Hugo and Ernst Schulze found it best to make an alcoholic extract of from 4-10 grms. of the dried and powdered root, according to its richness in nitric acid, with $90^{\circ} \%_{0}$ alcohol, with the aid of heat; the extract was evaporated to dryness, the residue dissolved in water, and the solution filtered, if necessary; nitric acid was determined in this filtrate. (Landaoirthsch. Tersuchs-Stationen, 9, 447.)

g. Starch.-Some roots, and particularly carrots, contain a notable quantity of starch. To estimate it, mash an amount of the root containing 3-4 grms. of dry substance with cold water, rinse the mixture into a beaker, add more water, stir the whole, and let it stand half an 
hour; decant the supernatant liquid on a dried and weighed filter, and fually transfer the insoluble residue to the same filter' wash the filter well with cold water, remove most of the water from its contents by pressure between folds of filter-paper, dry the whole at $100^{\circ}$, and weigh. Treat the filter and its contents with extract of malt, and determine glucose in the product (§ 81).

\section{POTATOES.}

134. Prepare them for examination as directed in $\S 133, a$.

a. Water.-Dry 250-500 grms. of the potatoes, and determine hygroscopic water also, as directed in $\S 133, a$, in the examination of roots.

b. Dry substance soluble in water.-Cut several potatoes very fine, and crush $30 \mathrm{grms}$. of the carefully mixed sample with cold water, in a mortar, and separate the soluble fiom the insoluble part in the same manner as directed in $\S 133, g$.

Dry the insoluble residue at $100^{\circ} \mathrm{C}$, weigh it, incinerate it in the muffle (§ 123,c), and weigh the ash; thus we have determined the organic and the inorganic matter insoluble in water. The difference between the weight of the dried insoluble residue and the amount of substance taken gives the weight of soluble matter in it.

Bring the aqueous solution to any easily divisible volume, and heat about $\left.{ }^{1}\right|_{3}$ of it to boiling. Albumen is precipitated, and may be collected on a weighed filter, dried at $100^{\circ}$, and weighed.

Evaporate the filtrate from the albumen to dryness on the water-bath, weigh the residue, ignite it, and weigh the ash; thus organic and inorganic matters, soluble in water, are determined.

c. Albuminoids.-Evaporate another third of the soltition almost to dryness, mix the moist residue with calcined 


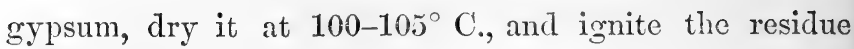
with soda-lime $(\S 85)$.

d. Starch.-Determine this, together with a small quantity of gum, in $8.5-4$ grms. of dry substance (\$ 79).

For technical purposes, it is often sufficient to determine the specific gravity of the potato, in order to estimate approximately the goodness of the tuber, or the amount of dry substance and starch that it contains.

Determine the specific gravity as directed in $\S 35$, e. The temperature of the saline solution should be about $16^{\circ} \mathrm{C}$. The relation between the specific gravity and the amount of dry substance and starch is given in Table VII. Potatoes that have been affected by disease cannot be examined in this way unless the diseased parts are cut out.

Artichokes may be examined in the same way as potatoes, except that the aqueous extract of the former should be more carefully examined for glucose. The inulin in the artichoke is converted into glucose somewhat more casily than the starch in potatoes.

\section{SEEDS. MEAL. FLOUR.}

135. Seeds are crushed in a mortar or ground to a fine powder in the steel mill.

a. Water.-Desiccate 5-10 grms. of the powder, and preserve the rest in well-stoppered bottles.

b. Non-volatile matter, protein compounds, fat, crude cellulose. - Estimate these precisely as directed for the examination of fodder $(\S 129, c, \S 130, b, c, d)$.

$c$. Dry substance soluble in water.-Determine this as directed in $\S 134, b$, with 20 grms. of the powder.

d. Starch.-Follow any of the methods described in $\S 79$.

Or, wash 2 grms. of the powder on a filter, first with cold water, then with alcohol containing sulphuric acid, 
to take out the gluten, and again with water; then pierce the filter with the glass rod, wash its contents into a flask, tear the filter into shreds, and boil it by itself with water containing 4 or 5 drops of $\left.20^{\circ}\right|_{0}$ sulphuric acid, and finally add it to the contents of the flask; the total amount of solution thus obtained should not be over 100 c.c.; proceed as usual with the conversion of the starch into glucose $(\S 79)$.

In most seeds there is but little gum or sugar; one can therefore proceed at once to treat the seeds with alcohol acidified with sulphuric acid, as above, remove the alcohol by heat, and convert the starch into glucose.

\section{IIILK.}

136. a. Water,-Boil 50 grms. of the milk with 8 grms. of powdered crystalline gypsum, or with $30-40$ grms. of baric sulphate $(\S 90, h)$, and after the coagulation has taken place, evaporate the mixture to dryness on the water-bath, with constant stirring towards the end of the operation, and dry the residue at $100^{\circ}$ as long as it loses weight.

Or, the desiccation may be completed on hot sand in rarefied air $(\S 90, g)$.

b. Total non-volatile matter,-Evaporate $30 \mathrm{grms}$. of the milk to dryness, with the addition of a little acetic acid, and incinerate the residue in the muffle at the lowest. possible temperature.

c. Protein compounds. - These may be estimated by the remainder left after subtracting the sugar, butter, and ash, from the total dry substance; this residue consists mostly of casein. Or, nitrogen may be estimated in the usual manner $(\S 85)$ in the residue left on evaporating $6-7$ grms. of the milk to dryness with powdered gypsum or baric sulphate, as above.

Albumen is contained in milk in but small proportion; 
in the case of some diseases, it occurs in larger quantity. To estimate it, coagulate 100 grms. of the milk with rennet, at a temperature of about $45^{\circ} \mathrm{C}$., filter out the precipitate, and wash it, and heat the filtrate and washings to boiling. Collect the precipitated albumen on a dried and weighed filter, dry it at $100 \mathrm{C}$., and weigh it.

d. Butter-Dxtract the residue obtained in $a$ with ether $(\S 87)$.

Various other and shorter processes are given for testing the goodness of milk in this respect, in one of which the cream is estimated by volume.

Provide a shallow glass dish in the form of an inverted bell-jar, with a ground glass plate to cover it and prevent evaporation of the milk, and a narrow orifice below, closed with a glass stopper; a graduated cylinder holding 100 c.c. will also be needed.

Put 100 c.c. of cooled milk into the dish, and let it stand 24 hours, at a temperature of $12-15^{\circ} \mathrm{C}$.; then loosen the stopper below, and let the milk flow out from underneath the cream into the graduated cylinder. After about $\left.{ }^{3}\right|_{4}$ of the milk has run out, stop the flow for a few minutes, to allow the cream to collect together somewhat, and then let the milk flow out again, but only drop by drop, until the cream appears at the opening; the quantity by which the milk now collected in the cylinder is less than the original 100 c.c. represents the cream, and the percentage of cream by volume can be estimated. $1^{\circ} \%_{0}$ by volume corresponds very nearly to one-fourth ${ }^{\circ}{ }_{0}$ of butter in the milk, by weight.

If a glass dish, like that described above, cannot be obtained, any shallow dish that can be well covered will answer, and the milk can be withdrawn from under the cream by a small siphon, with a rubber tube and clamp at the end of the longer arm to regulate the flow of the liquid. 
Vogel's optical milk test.-This process meets with very general acceptance. It depends upon the fact that the light is intercepted by water containing a smaller proportion of milk, the richer the milk is in butter.

The apparatus required consists of a measuring flask, with a mark on the neck, indicating a capacity of 100 c.c., a test-glass, for holding a sample of the milk and water between the eye and the light, which should have parallel glass sides, ${ }^{1} l_{2} \mathrm{~cm}$. apart, so that the thickness of the layer of milk looked through will be exactly $\left.{ }^{1}\right|_{2} \mathrm{~cm}$., a pipette graduated in $\left.{ }^{2}\right|_{4}$ cubic centimetres, and holding 4-5 c.c., and a box about $16 \mathrm{~cm}$. long and wide, with a slit in one side, in front of which, and $40 \mathrm{~cm}$. distant, the stearin candle is placed; the opposite side of this box is so cut out to fit the face that, when the glass containing the milk is put in the box, all light can be excluded while an observation is made, except that coming through the slit from the candle; the inside of the box should be painted black.

To perform the test, fill the 100 c.c. flask with distilled water up to the mark, add to it 3 c.c. of the well-stirred sample of the cooled milk, and mix the two together thoroughly by vigorous agitation; fill the test-glass with this mixture, put it in the dark box, and make the observation, placing the eye close to the test-glass, and the candle against a dark background. If the light can be seen, pour the test sample back into the flask, add $\left.{ }^{2}\right|_{2}$ c.c. more of milk, and make another observation; continue to operate in this manner, adding $\left.{ }^{1}\right|_{2}$ or $\left.{ }^{1}\right|_{4}$ c.c. of milk each time, until the light is no longer visible.

The relation between the number of cubic centimetres of milk required and the per cent of butter is given in Table IX. This per cent is calculated by the formula $\frac{23.2}{y}+0.23$, in which $y=$ the number of cubic centimetres of milk required. If 5.5 c.c. or more of milk were used to produce opacity, it is probable that the milk was 
watered. It is rare that less than 3 c.c. of cow's milk will be needed.

e. Sugar.-Collect the residue, insoluble in ether, in $d$, on a dried and weighed filter, dry it at $100^{\circ} \mathrm{C}$, , boil it four or five times with fresh portions $\left(150\right.$ c.c. each) of $\left.80^{\circ}\right|_{0}$ alcohol, and weigh this insoluble residue on a dried and weighed filter, after drying it at $100^{\circ} \mathrm{C}$. The loss of weight, after extraction with alcohol, gives the lactose approximately. The residue on the filter will be mainly casein and insqluble salts, together with the baric sulphate or gypsum, with which the milk was evaporated.

Or, to determine the lactose more accurately, dilute 20 grms. of the milk with twice its volume of water, heat the liquid to $40^{\circ} \mathrm{C}$, coagulate the casein with 4 drops of acetic acid, collect the coagulum on a linen filter, and wash it well with water. Dilute the filtrate and washings to 200 c.c., and determine lactose in the usual manner, in a measured volume of the liquid, previously filtered if necessary (§84).

f. Lacto-protein, butter, casein, etc.-Millon and Commaille give this process for estimating the protein compound peculiar to milk, and for the determination of other substances also.

Dilute 20 grms. of milk with 4 volumes of water, add 5-6 drops of acetic acid, stir the mixture well, filter out the coagulum, wash it two or three times on the filter with as little water as possible, and then with $40^{\circ} \%_{0}$ alcohol. Separate the precipitate from the filter, diffuse it in absolute alcohol, collect it again on a dried and weighed filter, and extract the butter by ether containing $\left.{ }^{1}\right|_{10}$ of absolute alcohol, that is poured over the contents of the filter. Evaporate the etherial extract, to estimate the butter taken into solution, and dry the casein on the filter at $100^{\circ} \mathrm{C}$., and weigh it.

Heat half the filtrate from the first coagulum, or the 
whey, to boiling, filter out the coagulated albumen on a dried and weighed filter, wash it first with water, then with alcohol, and finally with ether, dry it at $100^{\circ} \mathrm{C}$., and weigh it.

To the filtrate add a solution of mercuric nitrate, with care to avoid an excess of the reagent. Lacto-protein is precipitated, together with mercuric oxide; collect the precipitate on a weighed filter, wash it once with water containing $1^{\circ} \omega_{0}$ of nitric acid, then with pure water as long as the filtrate is colored by hydrosulphuric acid, then with alcohol, and finally with ether; finally dry it at $100^{\circ}$ C., and weigh it. $60^{\circ} \%_{0}$ of it is to be estimated as lactoprotein.

Determine milk sugar in one-fourth of the whey (\$84).

Evaporate the remaining fourth to dryness in a platinum dish, dry the residue at $100^{\circ}$, and weigh it, ignite it, and weigh again. Subtract the ash, albumen, lacto-protein, and milk sugar, from the total amount of matter in solution in the whey, and call the remainder undetermined extractive matter.

\section{BUTTER. CHEESE.}

13\% $a$. Water.-Dry 50 grms. of the finely divided substance at $100^{\circ} \mathrm{C}$. as long as it loses weight; butter is more easily dried if a weighed quantity of quartz sand is mixed with it.

b. Fat.-Extract this with ether in the usual manner ( $\$ 87$ ), collecting the insoluble residue on a weighed filter.

c. Casein.-Wash the residue, insoluble in ether, well with water, evaporate the aqueous solution to dryness, dissolve the residue again in water, and, if any of it is insoluble, collect this on the same filter, and wash the whole again; dry the contents of the filter at $100^{\circ}$, and weigh, ignite, and weigh again, and call the difference between the first and second weighings, casein. 
d. Salt.-By evaporating the aqueous extract obtained in the preceding operation, or an aliquot part of it, to dryness, and igniting and weighing the residue, the amount of salt in the butter or cheese may be estimated.

\section{VINEGAR.}

133. The only constituent of vinegar which it is usually desired to estimate quantitatively is the acetic acid.

a. For this estimation, proceed as directed in $\S 70$. Good vinegar should contain about $5 \%^{\circ}$ of this acid.

The vinegar should give no reaction for sulphuric or hydrochloric acid, after acidification with nitric acid. If it has been adulterated with these acids, they will of course saturate a portion of the standard sodic solution.

b. Free sulphuric acid in vinegar may be detected and determined by adding baric carbonate to it, filtering, washing the contents of the filter, and then treating the residue with hydrochloric acid; the excess of baric carbonate that was used will be dissolved by the acid, while, if any free sulphuric acid was present, baric sulphate will remain urdissolved; it may be washed and weighed in the usual manner ( $\S 59)$. 


\section{CHAPTER IX.}

WOOL.

139. a. The sample for examination.-Take a sample from each one of several sheep just before the time of shearing, and after the animals have been washed in the customary manner, and from the following parts of each animal-the leaf, the side, the middle of the chine bone, the withers, the neck close to the nape, the middle of the thigh, and the middle of the belly; each specimen should be taken from a spot an inch in diameter, and be cut off close to the skin, put at once in a large glass tube of known weight, that can be well stoppered, and weighed when taken to the laboratory. The number of the particular animal and the spot from which the sample was taken should be marked on a label on each tube.

If the wool is to be examined with respect to its physical properties, or by one who is experienced in handling it and judging its value, two other samples should be taken from each animal, and from the same spots, one before the washing, and the other afterwards, and all samples should be preserved and labeled in the manner prescribed above.

The sample from each part of the animal is to be examined by itself, but if it is desired to determine only the average quality of the wool of the flock, the several samples from like parts of the different sheep may be examined together.

If a sample of unwashed wool is to be examined, weigh each one, determine the water in a small portion by desiccation at $100^{\circ}$, and wash the other portion gently in cold, soft water until the water is no longer made turbid, dry it, and weigh it in the air-dried state. The subsequent treatment is the same as for the washed wool. 
b. Water.-Dry $3-4$ grms, at $100^{\circ} \mathrm{C}$, and weigh it.

c. Wash a quantity of the wool in a manner similar to that practiced in the fuctory. For this purpose prepare a solution of 3 parts of hard soap and 2 of crystallized sodic carbonate, in 100 of distilled or rain-water, lieat 20 parts of this solution to $50-55^{\circ}$, put 1 part of wool in it, and stir the mixture gently for 15 or 20 minutes, while the solution is maintained at the same temperature; then take the wool out, wash it in several portions of water, dry it in the air, spread it out on fine wire gauze, tap the gauze gently underneath several times, pick off adhering particles of forcign matters with the pincettes, dry the residue at $100^{\circ} \mathrm{C}$., and weigh it. If, after this treatment, the wool still feels greasy, it should be washed again in a somewhat stronger bath. Finally extract any remaining fat with carbonic disulphide or ether, dry the residue again at $100^{\circ}$, and weigh it.

d. Treat another portion of the wool in the reverse manner, that is, first with ether $(\S 87)$, and then, after drying and weighing the residue, wash it in the bath of soap and soda. Determine the fat in the etherial solution, or an aliquot part of it.

$e$. Determine the ash in the residue of $c$ and $d$ in the usual manner $(\$ 12 \%)$. Examine this ash for sand by digestion with hydrochloric acid, and boiling with sodic carbonate $(\$ 58)$.

$f$. To determine the specific gravity of the pure wool obtained in $c$ and $d$, weigh it first in air and then in carbonic disulphide of known specific gravity $(\S 35, b, d)$.

TANNER'S BARK.

140. a. Preparation of the sample.-Cut the bark to be examined, lengthwise, in very thin shavings.

b. Water,-Desiccate 1-2 grms. at $100^{\circ} \mathrm{C}$.

c. Tannic acid.-Pour 100 c.c. of water over the dried 
substance obtained in $b$, and digest the mixture in a flask, 15 minutes at a boiling heat, filter, and repeat the same operation twice with the residue. Evaporate this aqueous extract to dryness on the water-bath, with the addition of a few drops of acetic acid, extract the residue with strong alcohol, filter the liquid, evaporate the filtrate until the alcohol is expelled, and dissolve the residue in distilled water; by this treatment pectose is removed from the aqueous extract. Determine tannic acid in the solution finally obtained $(\S 7 \%)$.

\section{CHAPTER $\mathrm{X}$.}

\section{BEVERAGES.}

\section{I.}

WATER.

141. For a complete analysis of water, we must refer to Fresenius's Quantitative Analysis for directions, while we confine ourselves here to such special determinations as possess a more direct domestic or agricultural interest.

a. Total Dry Substance in Solution.-Evaporate 500 grms. of the water to dryness, in a platinum dish, at a temperature at all times below boiling; dry the residue at $130^{\circ} \mathrm{C}$., and weigh it; ignite it, moisten the residue two or three times with a concentrated solution of ammonic carbonate, drying it each time cautiously; finally ignite the residue gently, and weigh the total non-volatile dry substance.

Or, instead of treatment with ammonic carbonate, dissolve the ignited residue in water in the crucible, pass a 
slow current of carbonic acid through it for a while, and dry the residue for a considerable time at $150-180^{\circ}$.

This determination of organic matter in water is considered by some good chemists as possessing no great value.

b. Potassa.-The estimation of this in water used for irrigation is sometimes important. For this purpose, evaporate $2000-4000$ c.c. of the water to dryness, eliminate the silica in the usual way, and the alkalies as chlorides in the filtrate from the silica $(\S 93, \mathrm{G})$.

c. Ammonia.-To determine this in rain-water, evaporate $2000-3000$ c.c. down to 200 c.c., after acidifying the water very slightly with hydrochloric acid, add an excess of freshly prepared sodic hydrate, or of baric hydrate, to the residue, and distil the ammonia off in the usual manner $(\S 47, c)$.

Determine the ammonia in the distillate with the aid of platinic chloride, or by the indirect process with the Nessler solution.

To insure greater accuracy, the whole operation should be repeated without the wate:; and with the same amount of sodic or baric hydrate and platinic chloride or Nessler's solution; if any ammonia is thus found, it is due to impurities in the reagents, and should be subtracted from the amount obtained in the first experiment.

If the water is a colored one, derived from some other source, add calcic chloride, sodic carbonate, and a few drops of potassic hydrate before distilling.

c. Nitric Acid.-Evaporate 2000-4000 c.c. of the water, after having added some sodic carbonate, filter out the precipitate, if any is formed, wash it well, evaporate the filtrate and washings to a small bulk, and determine the acid by Schlössing's process $(\S 62, \alpha)$.

e. Organic Matter, -Evaporate 100 c.c. of the water down to about 60 c.c., in a flask of 500 c.c. capacity, in order to decompose ammoniacal compounds by the calcic 
carbonate that is nearly always present, add water till the original volume is about restored, and proceed to titrate the solution for the organic matter with potassic permanganate ( $\$ 91)$.

A good drinking water should not contain more than $3-4$ parts of organic matter in 100,000 parts.

If, on adding to 100 c. c. of the water 2 or 3 drops of concentrated sulphuric acid and a little of a freshly prepared mixture of potassic iodide and boiled starch, the water is colored blue, nitrous acid is present, and a correction must be made in the determination of the organic matter. For this purpose add 10 c.c. of the dilute sulphuric acid to 100 c.c. of the water, and then add permanganic solution till the first trace of a red color appears. The amount of the standard solution required for this must be subtracted from the total amount required in the first trial.

The presence of nitrous acid in drinking water should, however, be regarded with suspicion, for it indicates that the water, perhaps, contained nitrogenous organic matter, from which it may not yet be entirely freed; such organic matter is far more harmful than that containing no nitrogen.

Other prominent methods of making this important determination of organic matter, and particularly nitrogenous matter, in water, have not yet been sufficiently tested to justify their insertion here, although, without doubt, good methods will soon be worked up out of the material now in hand. Many good chemists still allow some value to the indications that are furnished by the permanganic test relative to the badness of the water in sanitary respects, while others have no confidence in it. Other substances besides nitrous acid may increase the amount of permanganic solution that is reduced, and so give too large an amount of organic matter, as ferrous sulphate, for instance.

f. Lime.-To determine this base, which, in one form or $12 *$ 
another, is the source of the largest part of the hardness of water, add a little hydrochloric acid to 100-500 c.c., heat the mixture, and precipitate and determine lime with the aid of ammonic oxalate, in the usual manner $(\S 49, a)$.

Or, by a more speedy though somewlat less accurate method, to 100 c.c. of the water in a 300 c.c. flask, add 25 c.c., or, if the water is very hard, 50 c.c. of a $\left.{ }^{1}\right|_{10}$ atomic solution of oxalic acid, then add ammonia until the reaction of the liquid is faintly alkaline, and heat the mixture until it boils.

After the liquid has cooled, add distilled water up to the 300 c.c. mark, mix the whole well together, filter the liquid through an unmoistened filter into a dry glass, putting the first portions of the filtrate on the filter again, if turbid, as is often the case. To 200 c.c. of the clear filtrate, in a capacious flask, add 10 c.c. of concentrated sulphuric acid, heat the solution to $50-60^{\circ} \mathrm{C}$., and determine the excess of oxalic acid in it with the aid of the standard permanganic solution (§69). By multiplying the number of cubic centimetres of the standard solution used by 1.5, the amount that would have been required for the whole solution is obtained. Each cubic centimetre of the solution of oxalic acid that did not require to be decomposed by the permanganate, was engaged in the precipitated calcic oxalate, and corresponds to $0.0028 \mathrm{grm}$. of lime.

g. Hardness of the Water.-1. Clark's methoct. This, though a convenient method of determining the hardness of water, does not give highly accurate results; it is, however, generally used.

The scale of hardness is expressed by the number of milligrammes of lime in $100,000 \mathrm{mgrs}$, or $100 \mathrm{grms}$. of water, that are required to produce the different degrees of hardness, and this hardness is estimated by the amount of soap precipitated from a standard solution of the same. 
The Standard Solution of Soap.-Mix together 150 parts of lead plaster and 40 parts of potassic carbonate, exhaust the mass with alcohol, filter the liquid, evaporate the filtrate on the water-bath, and dissolve the residue in 50 parts of $\left.56^{\circ}\right|_{0}$ alcohol. Dissolve, also, $0.523 \mathrm{grm}$. of pure and dry baric chloride in water, and dilute the solution to one litre.

Provide a bottle of about 200 c.c. capacity, with a wellfitting glass stopper, and a mark on the side to indicate a capacity of 100 c.c., put 100 c.c. of the solution of baric chloride in this bottle, and add the solution of soap from a burette or a graduated pipette, with frequent agitation, until an abundant delieate lather appears that lasts five minutes. The shaking of the bottle should always be performed in the same manner; the best way is to grasp the stopper and the neck with one hand, and the bottom with the other, and shake it up and down.

Having tested the strength of the solution of soap, dilute it with $\left.56^{\circ}\right|_{0}$ alcohol to such an extent that 45 c.c. are necessary to produce the lather with 100 c.c. of the solution of baric chloride; this quantity of the latter solution produces the same degree of hardness as 12 mgrs. of lime.

Lxamination of a Sample of Water.-If a hard spring water is to be examined, put 10 c.c. of it into the bottle described above, and add distilled water up to the 100 c.c. mark; if it is a soft river water, fill the bottle up to this mark with the water alone; then add the solution of soap from the burette, as above. Add at first larger quantities of the standard solution at a time, but, towards the close, the agitation should be repeated after each 0.5 or 1 c.c. that is added, and finally between each drop or two.

On repeating the experiment, in case but little of the standard solution was used, take 25 to 50 c.c. of the water, but not a quantity that will require more than 45 c.c. of the standard solution; in this second trial add, at once, 
all but 1-2 c.c. of the solution of soap that will be required, and then allow it to flow in drop by drop only, until the reaction is ended.

The relation between the quantity of the standard solution used and the hardness of the water is given in Table VIII. If the water tested was diluted with distilled water, the hardness is to be taken as many times greater as the volume of the water was increased by the dilution.

If a water contains more than 12 parts of lime in 100,000 , the first addition of the solution of soap to it causes the formation of a flocculent precipitate, and it must be diluted as above before the test is made; if less than this proportion of lime is present, only an opalescence appears in the liquid on adding a drop of the solution of soap.

With respect to the hardness of water, we have to distinguish the total hardness, which is caused by the total amount of lime in the water, and the permanent hardness, caused by salts of lime that are not precipitated when the liquid is boiled, such as calcic sulphate and chloride. To determine this permanent hardness, boil 300 to 500 c.c. of the water half an hour, in a flask of twice the capacity, replacing the water, as it is evaporated, by fiesh distilled water; after the liquid has cooled, make its volume the same as that with which the operation was begun, by adding more water, mix the whole well together, filter the liquid, and determine the permanent hardness in an aliquot part of it, as above.

2. Fleck's method.-This apparently convenient method depends upon the fact that, when a solution of soda-soap in alcohol is added to a solution of a calcic salt, a neutral sodic salt is formed, and that, as soon as all the calcic salt is decomposed, the addition of more soda-soap will turn red litmus blue. (Fresenius's Zeitschrift, 7, 351.)

The Standard Solutions.-Solution of Soap.-Cut 50 
grms. of pure Marseilles soap in thin slices, pour 500 c.c. of $\left.r 4^{\circ}\right|_{0}$ alcohol over it, and heat the mixtures; the soap should be free from sodic carbonate or hydrate, and its solution should, therefore, give no precipitate or black color with mercurous nitrate. Filter the solution, if it is not perfectly clear. Prepare a saturated solution of calcic sulphate, and to 100 c.c. of it add 10 drops of a solution of litmus (or cochineal); boil the liquid five minutes and add the standard nitric acid from a burette, drop by drop, until the blue color is changed to red; then add the solution of soap from another burette until the blue color reappears.

The solution of soap is now to be made of such a strength that 20 c.c. of it will be required to produce the blue color, with 100 c.c. of the solution of calcic sulphate. If, for example, 15 c.c. were required in the above experiment, 5 c.c. of alcohol must be added to every 15 of the solution of soap to make the standard solation.

100 c.c. of the saturated solution of gypsum contain $240 \mathrm{mgrs}$. of calcic sulphate; each cubic centimetre of the soap solution, representing $1^{\circ}$ of hardness, corresponds, therefore, to 12 mgrs. of calcic sulphate.

The standard nitiv acid is conveniently made of such a strength that 0.1 c.c. neutralizes 1 c.c. of the standard solution of soap. 0.05 c.c. of nitric acid, corresponding to $0.5^{\circ}$ of hardness, has to be used in excess to produce a permanent red; therefore, 0.5 should be subtracted from the total amount of soap solution used.

Examination of a Sample of Water.-If the water contains calcic carbonate, boil 100 c.c. in a beaker or flask, until the carbonate is precipitated; then, without filtering, add 10 drops of litmus solution (or cochineal), and add the nitric acid precisely as in estimating the strength of the solution of soap, as first made; the litmus will not be colored permanently red until all the calcic carbonate is dissolved; therefore, the number of cubic 
centimetres of acid required for this represents the ternporary hardness. After adding the proper quantity of nitric acid, proceed to add the standard solution of soap, in the same manner as when determining the strength of this solution with the aid of calcic sulphate.

Suppose that, in treating 100 c.c. of the water in this manner, 0.2 c.c. of nitric acid were required to produce a permanent red color, and 8 c.c. of the solution of soap to change the red to blue; 2 c.c. of the latter were necessary to decompose the calcic nitrate resulting from the action of the 0.2 c.c. of nitric acid on the calcic carbonate, and 6 c.c. to decompose the calcic sulphate; subtracting 0.5 c.c., as above directed, for the excess of nitric acid, we have $2^{\circ}$ for the temporary hardness, and $5.5^{\circ}$ for the permanent hardness of the water examined.

$10^{\circ}$ of hardness indicates a hard water ; the hardness of river water is usually from $2^{\circ}$ to $6^{\circ}$.

\section{II.}

WINE.

142. a. Specific Gravity.-Determine this carefully with the specific-gravity bottle.

b. Dry Substance in Solution.-Evaporate 20 grms. to dryness with gypsum $(\S 90, h)$.

c. Total Non-volatile Matters.-Evaporate 200-500 grms. to dryness on the water-bath, and incinerate the residue in the usual manner; determine carbonic acid in the ash.

d. Complete Analysis of the Ash.-This is rarely important, but may be made according to Scheme I., § 94 .

e. Protein Compounds.-Evaporate 100 grms. with gypsum $(\S 90, h)$, and ignite the residue with soda-lime $(\S 85)$. 
f. Alcohol. -Estimate this in 10 or 25 c.c. of the wine, adding a few drops of soda, or enough to change the color of the wine completely, and about $0.06 \mathrm{grm}$. of tannin; the soda neutralizes the free acid, and the tamnic acid prevents frothing. For the manner of conducting the distillation, see $\S 8 \%$.

g. Sugar.-This may be determined in 100 grms. of the wine directly, in the usual manner (\$ 81), after decolorizing the liquid by contact with $2-3$ grms. of bone-black, and filtering.

Or, the wine may be decolorized in this manner (Grininin). Dilute the red wine to about half the extent required for the determination of sugar, ald enough milk of lime to make the liquid alkaline, and agitate the mixture well; then add about one-tenth as much of a solution of basic plumbic acetate as was taken of the wine, and shake the mixture again; finally add one-third as much of a solution of alum, containing 1 part of salt in 20 of water, as was required of the plumbic solution, dilute the mixture to any volume easily divisible into aliquot parts, mix the whole together by violent agitation, let it stand until the solid matters settle, and then decant enough of the supernatant liquid into a dry filter for the determination of the sugar.

If the wine is a light-colored one, nothing need be added but sodic carbonate until it is alkaline.

Cane sugar exists in wine only when it has been purposely added. It can be estimated, if present, in the usual way (§83).

If the wine is neutralized with lime, and alcohol added to precipitate malic and succinic acids, a little barytawater will give a precipitate in the filtrate, which is more or less abundant, according to the amount of sugar present $(\S 83)$.

h. Gum (and sugar), etc.-Evaporate $100 \mathrm{grms}$. of the wine to a syrup on the water-bath, exhaust the residue 
by digestion with several portions of alcohol, as long as a fresh portion is colored, and estimate the gum in the insoluble residue as directed in $\S 80$.

Half of the alcoholic extract may be evaporated to dryness, the residue weighed, and then incinerated, and the ash weighed; thus the total volatile and non-volatile (organic and inorganic) matter, soluble in alcohol, may be estimated.

Sugar may be determined in the other half of the alcoholic extract, after adding water and heating the liquid on the water-bath until all the alcohol is expelled ( $\S 81$ ).

$i$. Tannic acid.-This acts upon the cupric solution, used in determining sugar, precisely as sugar does, 3.7 parts reducing as much cupric oxide as 5 parts of sugar. Tannic acil is absorbed when the wine is decolorized by contact with bone-blask; the difference, then, between the amount of cupric solution required with and without treatment with bone-black, will give, approximately, the amount of tannic acid. But in many cases the wine would be too dark-colored to admit of a determination of sugar by the cupric solution without treatment with the decolorizing agent, and there are, moreover, other substances in the wine that are removed by the charcoal, and that, at the same time, act on the cupric solution. When, however, the determination can be made, it answer's very well for the comparison of different wines with each other, since the proportion of the other reducing agents does not seem to vary much.

$k$. Free acids. - Titrate 100 grms. of the wine with the standard sodic solution.

Then mix another portion of 100 grms. with clean sand, and evaporate it to dryness on the water-bath, with constant stirring, and heat it as long as any odor of acetic acid is evolved; dissolve the residue in water, and titrate the solution with the standarl sodic solution. The dif- 
ference between the amounts of sodic solution required in the two trials represents the acetic acid.

Estimate $0.06 \mathrm{grm}$. of acetic acid, $\mathrm{HC}_{2} \mathrm{H}_{3} \mathrm{O}_{2}$, for every cubic centimetre of this difference, and $0.075 \mathrm{grm}$. of tartaric acid, $\mathrm{H}_{2} \mathrm{C}_{4} \mathrm{H}_{4} \mathrm{O}_{6}$, for every cubic centimetre of the sodic solution required after the acetic acid was expelled.

Griffin (Chemical Testing of Wines and Spirits) determined the free acid as follows, with a $\left.{ }^{1}\right|_{10}$ atomic solution of ammonia for the standard solution, and an extract of logwood for the coloring matter.

Take two portions of wine, of $\% .5$ c.c. each, and add to each, if it is a white wine, 125 c.c. of water, or, if it is a red wine, 250 c.c., or more, according to the depth of the color; then add exactly the same quantity of the extract of logwood to each portion, which gives a color to the wine very much like that obtained by painting paper with raw sienna; add the alkaline solution from the burette to one portion, keeping the other at hand for comparison, with constant stirring; when the color suddenly changes to a reddish-brown, like that obtained by bumt sienna on paper, the point of saturation is reached. Now, repeat the experiment with the other portion of the wine, adding all but 2-3 c.c. of the required quantity of standard ammonic solution at once, and then drop by drop, until the acid is saturated.

Each cubic centimetre of the alkaline solution required corresponds to 0.1 of an equivalent of free acid, or, if we call it all tartaric acid, as it is, mostly, $0.00 \% 5 \mathrm{grm}$; and in this case the number of cubic centimetres used gives at once the number of grammes of acid (tartaric) in the litre of wine.

Good wines contain 4-6 grms. of free acid in the litre (300-400 grains of crystallized tartaric acid, Griffin). In poor wine years, the proportion of free acid often rises as high as $10-12$ grms. in the litre.
l. Tartar. $-\Lambda$ dd 40 c.c. of $90^{\circ} \%_{0}$ alcohol to 20 c.c. of 
the wine, let the mixture stand several days in a wellclosed bottle, and then titrate 30 c.c. of the clear liquid with the standard sodic solution; subtract 0.3 c.c. from the amount of soda required, and then subtract this remainder from the amount that would be required, as in $k$, to neutralize the total free acid in 10 c.c. of wine; this second remainder represents the quantity of acid that was removed from the wine by treatment with alcohol; for each cubic centimetre of this remainder calculate 0.1881 grm. of tartar.

Griffin estimated tartar by cvaporating 100-200 c.c. of the wine to dryness, incinerating the residue, determining potassic carbonate in the ash with the aid of the standard acid, and allowing one equivalent of tartar for every equivalent of potassic carbonate thus found in the ash.

He estimated it also by adding 25 c.c. of alcohol and as much ether to 10 c.c. of wine, letting the mixture stand 24 hours, collecting the precipitate on a dried and weighed filter, drying it at $100^{\circ} \mathrm{C}$., and weighing it; all but about $0.002 \mathrm{grm}$. of the tartar will be precipitated in this way.

m. Total tartaric acid.-Evaporate 100 c.c. of the wine to about half its volume, precipitate the acid by limewater in slight excess, filter the precipitate out, boil it with a solution of potassic carbonate, filter the liquid, evaporate the filtrate somewhat, acidify it with acetic acid, precipitate the potassic tartrate with considerable alcohol, and collect and treat the precipitate as directed in $\S \gamma 1$.

n. Malic acid.-This is contained in the filtrate from the calcic tartrate in $m$. To determine it, evaporate this filtrate down to one-third, and precipitate the calcic malate with alcohol, as directed in $\S 73$. As this precipitate will contain also the sulphuric acid, if any is present in the wine examined, a determination of this acid should be made in a portion of the wine, in the usual manner; then estimate the amount of calcic sulphate, $\mathrm{CaSO}_{4}, 2 \mathrm{H}_{2} \mathrm{O}$, in 
the precipitate obtained as above with alcohol; the remainder, after subtracting this, may be reckoned as calcic malate, although it may contain a little succinate.

The acetic acid, malic acid, and tartar, taken together, correspond very nearly to the amount of soda used in $k$, to determine the free acid, each equivalent of tartar neutralizing one equivalent of soda.

$o$. Free sulphuric acid, if present in the wine under examination, may be detected and determined in the same manner as directed in $\S 138, b$.

$p$. Total alkalies.-These may be estimated in the ash obtained in $c$, or in the following manner.

To the remaining. 30 c.c. of the filtrate from the precipitate by alcohol in $l$, add 5 c.c. of an alcoholic solution of tartaric acid, whose strength is accurately known, let the mixture stand several days, and titrate 25 c.c. of the clear supernatant liquid with the standard sodic solution; the rest of the potassa, not precipitated in $l$, and the soda, have crystallized out, with an equivalent quantity of the tartaric acid that was added; this quantity of acid will be represented by the difference between the amount of sodic solution used in this trial, and that which would be required to neutralize the free acid already in the solution (sec $l$ ), plus the 5 c.c. of tartaric acid added. For each 2 c.c. of this difference estimate $0.0471 \mathrm{grm}$. of potassa and add it to the amount in the tartar obtained in $l$.

The arerage composition of wine, according to Nessler, who examined a large number of European wines, is as follows: Alcohol, $7-\left.10^{\circ}\right|_{0}$; Sugar, $0.1-\left.0.2^{\circ}\right|_{0}$; Free acid, cstimated as tartaric, $0.4-\left.0.8^{\circ}\right|_{0}$; Malic acid, $0-\left.0.3^{\circ}\right|_{0}$; Acetic acid, $0-\left.0.3^{\circ}\right|_{0}$; Tannic acid, $0.02-\left.0.05^{\circ}\right|_{0^{\circ}}$. Total dry substance in solution, $1.5-\left.2^{\circ}\right|_{0^{\circ}}$ 


\section{TABLE I.}

\section{THE METRIC SYSTEM OF IVEIGHTS AND MEASURES.}

1.

\section{Measures of Lengtir.}

1 Metre $\quad=1 . \quad \ldots \ldots \ldots \ldots \ldots \ldots$ Metre.

1 Decimetre $=0.1 \ldots \ldots \ldots \ldots \ldots \ldots$ "

1 Centimetre $=0.01 \ldots \ldots \ldots \ldots \ldots \ldots \ldots$ "

1 Millimetre $=0.001 \ldots \ldots \ldots \ldots \ldots \ldots \ldots \ldots \ldots$ ،

1 Metre $=39.37 \ldots \ldots \ldots \ldots \ldots \ldots$. Inches.

1 Centimetre $=0.3937 \ldots \ldots \ldots \ldots \ldots$......

$1 \mathrm{Foot} \quad=30.48 \ldots \ldots \ldots \ldots$. Centimetres.

1 Inch $\quad=25.4 \ldots \ldots . . . . . .$. Millimetres.

The accompanying scales, copied from Professor

H. A. Newton's little pamphlet ('The Metric

System of Weights and Measures, with Tables. Prepared fol the Smithsonian Institution), exhibit the relative magnitude of the divisions of the metre and inches.

2.

Measures of Volume.

1 Cubic motre $=1000$.

1 Cubic decimetre $=1 . \quad \ldots \ldots \ldots$....... Litre.

1 Cubic centimetre $=0.001 \quad \ldots \ldots \ldots$. Litre.

1 Cubic centimetre $=0.06103 . .$. Cubic Inch.

1 Litre $\quad=0.88066 \ldots \ldots \ldots$..... Quart.

1 Gallon (imperial) $=4.5435$............ Litres.

1 Gallon (wine) $=3.79 \quad \ldots \ldots \ldots$..... Litres.

1 Hectolitre $=2.84 \quad \ldots . .$. . Bushels.

3.

The Weights of the Metric Srstem.

1 Kilogramme $=1000$.

1 Hectogramme $=100$.

1 Decagramme $=10$.

1 Gramme $=1$.

1 Decigramme $=0.1$

1 Centigramme $=0.01$

.........Grammes.

1 Milligramme =

1 Kilogramme =

1 Gramme

1

1 Pound

1 Ounce

1 Grain

0.001

-.......

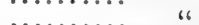

.........Gramme.

(1)

(.........

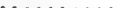

P'ds (avoirdupois.) 0.0353 . Ounce

$=15.432$..........Grains.

$=453.6 \quad \ldots \ldots \ldots$. 6 Grammes.

$=28.3$

$=64.8$

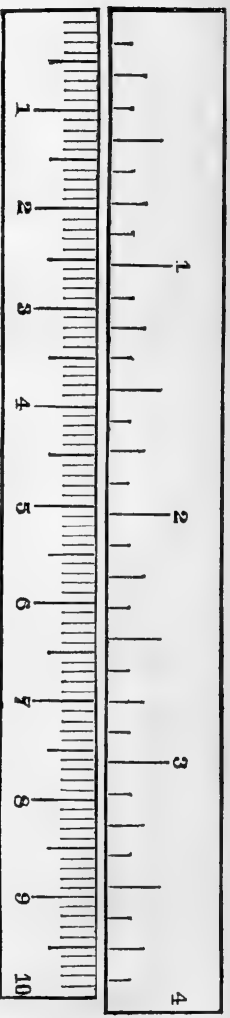

4.

AbBreviations.

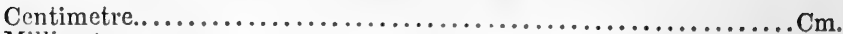

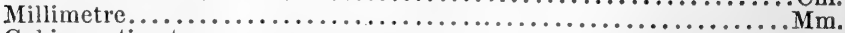

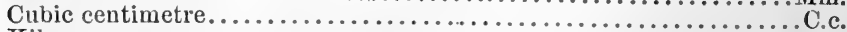

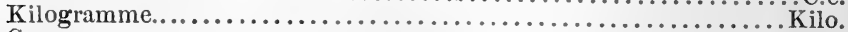

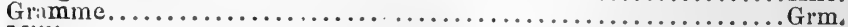

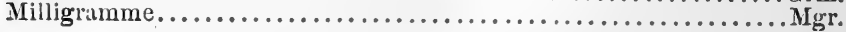




\section{TABLE II.}

THE ATOMIC WEIGHTS OF THE ELEMENTS CONCERNED IN THE QUANTITATIVE PROCESSES DESCRIBED IN THIS BOOK.

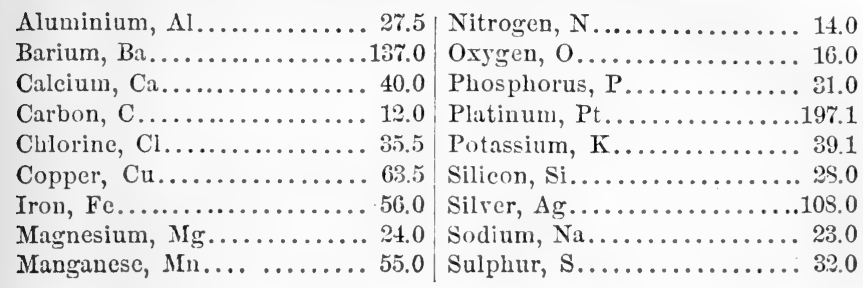

\section{TABLE III.}

FACTORS FOR ESTIMATING THE SUBSTANCE SOUGIIT FROM THE COMPOUND OBTAINED.

\begin{tabular}{|c|c|c|c|c|}
\hline $\begin{array}{l}\text { Compound } \\
\text { obtained. }\end{array}$ & Formula. & Substance sought. & Formula. & Factor. \\
\hline Alumina. . & $\mathrm{Al}_{2} \mathrm{O}_{3}$ & & $\mathrm{Al}_{2} \mathrm{O}_{3}, 2 \mathrm{SiO}_{2}$ & 25 \\
\hline Ammonia ..... & $\mathrm{NH}_{3}$ & Nitrogen. & & 0.8235 \\
\hline $\begin{array}{l}\text { Ammonio-platin- } \\
\text { ic chloride..... }\end{array}$ & $\left(\mathrm{NH}_{4}\right)_{2} \mathrm{PtCl}_{6}$ & ${ }_{6}$ Ammoni & $\mathrm{NH}_{3}$ & 0.0762 \\
\hline $\begin{array}{l}\text { Ammonio-platin- } \\
\text { ic chloride..... } \\
\text { Ammonio - platiu- }\end{array}$ & $(\mathrm{NH}$ & ${ }_{6} \mathrm{Am}$ & $(\mathrm{NH}$ & 0.1165 \\
\hline $\begin{array}{l}\text { ic chloride.... } \\
\text { Argentic chloride } \\
\text { Argentic sulphide }\end{array}$ & $\begin{array}{l}\left(\mathrm{NH}_{4}\right)_{2} \mathrm{PtCl}_{6} \\
\mathrm{AgCl} \\
\mathrm{AgS}\end{array}$ & $\begin{array}{l}\text { Nitr } \\
\text { Chlo } \\
\text { Sulp }\end{array}$ & $\begin{array}{l}\mathrm{N} \\
\mathrm{Cl} \\
\mathbf{S}\end{array}$ & $\begin{array}{l}0.0628 \\
0.2474 \\
0.1481\end{array}$ \\
\hline $\begin{array}{c}\text { Baric sulphate... } \\
\text { " } 6 \text { ". }\end{array}$ & $\mathrm{BaSO}_{4}$ & 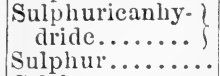 & $\begin{array}{l}\mathrm{SO}_{3} \\
\mathrm{~S}\end{array}$ & $\begin{array}{l}0.3433 \\
0.1373\end{array}$ \\
\hline Calcic carbonate. & $\mathrm{CaCO}_{3}$ & m.............. & $\mathrm{Ca}$ & 0.4000 \\
\hline & 46 & $\left\{\begin{array}{l}\text { Calcie } \\
\text { (lime }) \text { oxide } \\
\text { Calcic } \\
\text { sulphate }\end{array}\right\}$ & $\mathrm{CaO}$ & 0.5600 \\
\hline " & " & 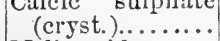 & $\mathrm{CaSO}_{4}, 2 \mathrm{H}_{2} \mathrm{O}$ & 1.7200 \\
\hline $\begin{array}{r}\text { Cilcic malate.... } \\
\qquad \ldots \text {. }\end{array}$ & $\mathrm{CaC}_{4} \mathrm{H}_{4} \mathrm{O}_{5}$ & Malic acid....... & $\begin{array}{l}\mathrm{H}_{2} \mathrm{C}_{4} \mathrm{H}_{4} \mathrm{O}_{5} \\
\mathrm{C}_{4} \mathrm{H}_{4} \mathrm{O}_{4}\end{array}$ & $\begin{array}{l}0.7791 \\
0.6744\end{array}$ \\
\hline 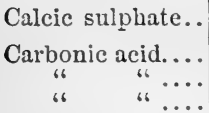 & $\begin{array}{l}\mathrm{CaSO}_{4} \\
\mathrm{CO}_{2} \\
66\end{array}$ & $\begin{array}{l}\text { Calcic oxide } \\
\text { (lime)......... } \\
\text { Calcic Carbonate. } \\
\text { Calcic hydrate... } \\
\text { Humus......... }\end{array}$ & $\begin{array}{l}\mathrm{CaO} \\
\mathrm{CaCO}_{3} \\
\mathrm{CaH}_{2} \mathrm{O}_{2}\end{array}$ & $\begin{array}{l}0.4118 \\
2.2730 \\
1.6820 \\
0.4702\end{array}$ \\
\hline
\end{tabular}




\section{TABLE III.-(Continued.)}

\begin{tabular}{|c|c|c|c|c|}
\hline $\begin{array}{l}\text { Compouud } \\
\text { obtained. }\end{array}$ & Formula. & Substance sought. & Formula. & Factor: \\
\hline xide. & $\mathrm{Fe}_{2} \mathrm{O}_{3}$ & Ferrous oxide.. & & \\
\hline erric phosphate. & $\mathrm{Fe}_{2} \mathrm{P}_{2} \mathrm{O}_{8}$ & & $\mathrm{Fe}$ & 0.5298 \\
\hline 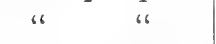 & & ic an- $\}$ & $\mathrm{P}_{0} \mathrm{O}_{5}$ & 4702 \\
\hline Ferrous oxide... & $\mathrm{FeO}$ & i ile...... & $\mathrm{Fe}_{2} \mathrm{O}_{3}$ & \\
\hline Glucose $\ldots . . . \cdots$ & $\mathrm{C}_{12} \mathrm{H}_{24} \mathrm{O}_{12}$ & $\begin{array}{l}1101 \\
\text { Sace } \\
\text { Star }\end{array}$ & $\mathrm{C}_{12} \mathrm{H}_{22} \mathrm{O}_{11}$ & 0.9500 \\
\hline $\begin{array}{l}\text { Lactic anhydride. } \\
\text { Mannesic pyro- }\end{array}$ & $\mathrm{C}_{6} \mathrm{H}_{10} \mathrm{O}_{5}$ & Lac & $\mathrm{H}_{2} \mathrm{C}_{6} \mathrm{H}_{10} \mathrm{O}_{6}$ & 1.1110 \\
\hline 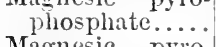 & $\mathrm{Mg}_{2} \mathrm{P}_{2} \mathrm{O}_{7}$ & oxide.. & $\mathrm{MgO}$ & 0.3604 \\
\hline $\begin{array}{l}\text { ic pyro- } \\
\text { hate...... }\end{array}$ & $\mathrm{Mg}_{2} \mathrm{P}_{2} \mathrm{O}_{7}$ & $\begin{array}{l}\text { Phosphoric anliy- } \\
\text { dride............ }\end{array}$ & $\mathrm{P}_{2} \mathrm{O}_{5}$ & 0.6396 \\
\hline $\begin{array}{l}\text { Magnesic pyro- } \\
\text { phosphate ..... } \\
\text { Manganous man- }\end{array}$ & $\mathrm{M} g_{2} \mathrm{P}_{2} \mathrm{O}_{7}$ & $\begin{array}{c}\text { Tricalcic phos- } \\
\text { phate........... }\end{array}$ & $\mathrm{Ca}_{3} \mathrm{P}_{2} \mathrm{O}_{8}$ & 1.3960 \\
\hline & $\mathrm{Nn}_{3} \mathrm{O}_{4}$ & Manganous oxide & $\mathrm{MnO}$ & 0.9801 \\
\hline $\begin{array}{l}\text { gauic oxide... } \\
\text { Nitrogen......... } \\
\text { 6 }\end{array}$ & $\begin{array}{l}\mathrm{Mn}_{3} \mathrm{O}_{4} \\
\mathrm{~N} \\
66\end{array}$ & $\begin{array}{l}\text { nic oxide. } \\
\text { nia } \ldots . . . \cdots \\
\text { com- }\end{array}$ & $\begin{array}{l}\mathrm{Mn}_{9} \mathrm{O}_{3} \\
\mathrm{NH}_{3}\end{array}$ & $\begin{array}{l}1.0850 \\
1.2140\end{array}$ \\
\hline $\begin{array}{ll}6 & \ldots\end{array}$ & 16 & $\begin{array}{c}\text { pounds........ } \\
\text { Tricalcic }\end{array}$ & & .2500 \\
\hline$\cdots \cdots \cdots$ & $\begin{array}{l}\mathrm{P}_{2} \mathrm{O}_{5} \\
\mathrm{Pt}_{6}\end{array}$ & $\mathrm{pl}$ & $\begin{array}{l}\mathrm{Ca}_{3} \mathrm{P}_{2} \mathrm{O}_{8} \\
\mathrm{NH}_{3} \\
\mathrm{~K}\end{array}$ & $\begin{array}{l}2.1830 \\
0.1725 \\
0.3968\end{array}$ \\
\hline 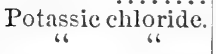 & $\mathrm{KCl}^{\mathrm{KCl}}$ & ide.... & $\mathrm{K}_{\mathrm{K}_{2} \mathrm{O}}^{\mathrm{M}}$ & $\begin{array}{l}0.5241 \\
0.6314\end{array}$ \\
\hline $\begin{array}{cc}\text { Potassic } & \text { oxide } \\
(\text { potissa }) & \ldots \ldots \ldots\end{array}$ & $\mathrm{K}_{2} \mathrm{C}$ & $a$ feld- $\quad$ & $\begin{array}{l}\mathrm{K}_{2} \mathrm{O}, 3 \mathrm{SiO}_{2} \\
\mathrm{Al}_{2} \mathrm{O}_{3}, 3 \mathrm{SiO}_{2}\end{array}$ & 5.9150 \\
\hline Potassic sulphate & $\mathrm{K}_{2} \mathrm{SO}_{4}$ & c oxide..... & $\mathrm{K}_{\mathrm{K}_{2} \mathrm{O}}^{\mathrm{K}}$ & $\begin{array}{l}0.4489 \\
0.5408\end{array}$ \\
\hline $\begin{array}{c}\text { Potassic tartrate. } \\
\text { " } " \text { " } \\
\text { Potassio - platinic }\end{array}$ & $\underset{\text { ، }}{\mathrm{KHC}_{4} \mathrm{H}_{4} \mathrm{O}_{6}}$ & $\left\{\begin{array}{c}\text { Tirtaric anhy- } \\
\text { dride................. } \\
\text { Tartaric acid... }\end{array}\right.$ & $\begin{array}{l}\mathrm{C}_{4} \mathrm{H}_{4} \mathrm{O}_{5} \\
\mathrm{H}_{2} \mathrm{C}_{4} \mathrm{H}_{4} \mathrm{O}_{6}\end{array}$ & $\begin{array}{l}0.7018 \\
0.7974\end{array}$ \\
\hline & $\mathrm{K}_{2} \mathrm{PtCl}_{6}$ & & $\mathrm{~K}$ & 0.1602 \\
\hline Potass & $\mathrm{K}_{2} \mathrm{Pt}$ & Potass & $\mathrm{K}_{2} \mathrm{O}$ & 0.1929 \\
\hline Sodic chloride... & $\begin{array}{l}\mathrm{K}_{2} \mathrm{PtCl}_{6} \\
\mathrm{NaCl} \\
66\end{array}$ & $\begin{array}{l}\text { Potassi } \\
\text { Sodium } \\
\text { Sodic o }\end{array}$ & $\begin{array}{l}\mathrm{KCl} \\
\mathrm{Na} \\
\mathrm{Na}_{2} \mathrm{O}\end{array}$ & $\begin{array}{l}0.3055 \\
0.3932 \\
0.5299\end{array}$ \\
\hline Sodic oxide(soda) & $\mathrm{Nia}_{2} \mathrm{O}$ & Soda feldspar.. \{ & $\mid \begin{array}{l}\mathrm{Na}_{2} \mathrm{O}, 3 \mathrm{SiO}_{2} \\
\mathrm{Al}_{2} \mathrm{O}_{3}, 3 \mathrm{SiO}^{2}\end{array}$ & 8.4680 \\
\hline $\begin{array}{l}\text { Sodic sulphate... } \\
\text { "“" } \\
\text { Sulphuric anhy- }\end{array}$ & $\mathrm{Na}_{2} \mathrm{SO}_{4}$ & $\begin{array}{l}\text { So } \\
\text { So }\end{array}$ & $\begin{array}{l}\mathrm{Na} \\
\mathrm{Na}_{2} \mathrm{O}\end{array}$ & $\begin{array}{l}0.3239 \\
0.4366\end{array}$ \\
\hline Tartaric acid & $\begin{array}{l}\mathrm{SO}_{3} \\
\mathrm{H}_{2} \mathrm{C}_{4} \mathrm{H}_{4} \mathrm{O}_{6}\end{array}$ & $\begin{array}{l}\text { Tartaric } \\
\text { Tartar... }\end{array}$ & $\mid$ & $\begin{array}{l}1.8750 \\
1.2540\end{array}$ \\
\hline
\end{tabular}


TABLES.

TABLE IV.

ESTIMATION OF TANNIC ACID IN BARK.

\begin{tabular}{|c|c|c|c|c|c|c|c|}
\hline $\begin{array}{l}\mathrm{Sp} \text {. Gr. at } \\
15^{\circ} \mathrm{C} \text {. }\end{array}$ & $\mid \begin{array}{c}{ }^{0} \rho_{0} \text { of } \\
\text { tannic } \\
\text { acid. }\end{array}$ & $\mathrm{Sp}_{15^{\circ} \mathrm{Gr}} \mathrm{C}$. & $\mid \begin{array}{l}{ }^{0} \%_{0} \text { of } \\
\text { tannic } \\
\text { acid. }\end{array}$ & ${ }_{15^{\circ} \mathrm{C} .}$ & $\begin{array}{l}\left.{ }^{0}\right|_{0} \text { of } \\
\text { tannic } \\
\text { acid. }\end{array}$ & $\mathrm{Sp}_{15^{\circ} \mathrm{Cl} \text {. }}$ & $\begin{array}{l}\int_{0} \text { of } \\
\text { taunic } \\
\text { acid. }\end{array}$ \\
\hline 1.0000 & 0.0 & 1.0064 & 1.6 & 1.0124 & 3.1 & 1.0188 & 4.7 \\
\hline 1.0004 & 0.1 & 1.0068 & 1.7 & 1.0198 & 3.2 & 1.0192 & 4.8 \\
\hline 1.0008 & 0.2 & $1.00 \%$ & 1.8 & 1.0132 & 3.3 & 1.0196 & 4.9 \\
\hline $1.001 ?$ & 0.3 & 1.0076 & 1.9 & 1.0136 & 3.4 & 1.0201 & 5.0 \\
\hline 1.0016 & -0.4 & 1.0080 & 2.0 & 1.0140 & 3.5 & & \\
\hline 1.0020 & 0.5 & $1.008 t$ & 2.1 & 1.0144 & 3.6 & & \\
\hline 1.0024 & 0.6 & 1.0088 & 2.2 & 1.0148 & 3.7 & & \\
\hline $1.00: 38$ & 0.7 & 1.0092 & 2.3 & $1.015 \%$ & 3.8 & & \\
\hline 1.0032 & 0.8 & 1.0096 & 2.4 & 1.0156 & 3.9 & & \\
\hline 1.0036 & 0.9 & 1.0100 & 2.5 & 1.0160 & 4.0 & & \\
\hline 1.0040 & 1.0 & 1.0104 & 2.6 & 1.0164 & 4.1 & & \\
\hline $1.00 \pm 4$ & 1.1 & $1.0108^{-}$ & 2.7 & 1.0168 & 4.2 & & - \\
\hline 1.0048 & 1.2 & 1.0112 & 2.8 & 1.0172 & 4.3 & & \\
\hline 1.0052 & 1.3 & 1.0116 & 2.9 & 1.0176 & 4.4 & & \\
\hline 1.0056 & 1.4 & 1.0120 & 3.0 & 1.0180 & 4.5 & & \\
\hline 1.0060 & 1.5 & & & $1.018 t$ & 4.6 & & \\
\hline
\end{tabular}

TABLE V.

PROPORTION BY WEIGHT OF ABSOLUTE ALCOHOL IN SPIRITS OF DIFFERENT SPECIFIC GRAVITIES AT $15.5^{\circ} \mathrm{C}$. (FOWNES.)

\begin{tabular}{|c|c|c|c|c|c|c|c|}
\hline Sp. Gr. & ${ }^{0} \%_{0}$ & Sp. Gr. & $\left.{ }^{0}\right|_{0}$ & Sp. Gr. & ${ }^{0} \%_{0}$ & Sp. Gr. & ${ }^{0} \%$ \\
\hline 0.9991 & 0.5 & 0.9802 & 13 & 0.9638 & 26 & 0.9416 & 39 \\
\hline 0.9981 & 1 & 0.9789 & 14 & 0.9623 & 27 & 0.9396 & 40 \\
\hline 0.9965 & 2 & $0.9 \pi 78$ & 15 & 0.9609 & 28 & 0.9376 & 41 \\
\hline 0.9947 & 3 & 0.9766 & 16 & 0.9593 & 29 & 0.9856 & 42 \\
\hline 0.9930 & 4 & 0.9753 & 17 & 0.9578 & 30 & 0.9335 & 43 \\
\hline 0.9914 & 5 & $0.97 \pm 1$ & 18 & 0.9560 & 31 & 0.9314 & 44 \\
\hline 0.9898 & 6 & 0.9 & 19 & 0.9544 & 32 & 0.9292 & 45 \\
\hline 0.9884 & 7 & 0.9716 & 20 & 0.9528 & 33 & $0.92 \% 0$ & 46 \\
\hline 0.9869 & 8 & 0.9704 & 21 & 0.9511 & 34 & 0.9249 & 47 \\
\hline 0.9855 & 9 & 0.9691 & 22 & 0.9490 & 35 & 0.9228 & 48 \\
\hline 0.9841 & 10 & 0.9678 & 23 & 0.9470 & 36 & 0.9206 & 49 \\
\hline $0.98: 38$ & 11 & 0.9665 & 24 & 0.9452 & 37 & 0.9181 & 50 \\
\hline 0.9815 & 12 & 0.9652 & 25 & 0.9434 & 38 & & \\
\hline
\end{tabular}




\section{TABLE VI.}

ESTIMATION OF SUGAR AND TOTAL DRY SUBSTANCE IN THE SUGAR BEET, BY THE SPECIFIC GRAVITY OF THE BEET.

\begin{tabular}{|c|c|c|c|c|c|c|c|c|}
\hline $\begin{array}{c}\text { Sp. Gl. } \\
\text { at } \\
18^{\circ} \mathrm{C} .\end{array}$ & $\begin{array}{c}0 / 0 \\
\text { Sugar. }\end{array}$ & $\begin{array}{c}\text { Total } \\
\text { dry sub- } \\
\text { stince. }\end{array}$ & $\begin{array}{c}\text { Sp. Gr. } \\
\text { at } \\
18^{\circ} \mathrm{C} .\end{array}$ & $\begin{array}{c}{ }^{0}{ }_{0} \\
\text { Sugar. }\end{array}$ & $\begin{array}{c}\text { Total } \\
\text { dry sub- } \\
\text { stance. }\end{array}$ & $\begin{array}{c}\text { Sp. Gl. } \\
\text { at } \\
18^{\circ} \mathrm{C} .\end{array}$ & $\begin{array}{c}{ }^{0} \% 0 \\
\text { Sugar. }\end{array}$ & $\begin{array}{l}\text { Total } \\
\text { dry sub- } \\
\text { stance. }\end{array}$ \\
\hline 14 & 7.00 & 12.0 & 1.038 & 11.00 & 17.3 & 1.060 & 13.75 & 20.25 \\
\hline 16 & 7.50 & & 1.040 & 11.25 & 17 & 1.062 & 14.00 & 20.50 \\
\hline 1.018 & 8.00 & 13.0 & 1.042 & 11.50 & 18.0 & 1.064 & 14.25 & 20.75 \\
\hline 1.020 & 8.25 & 13.5 & 1.044 & 11.75 & $18 . \approx 5$ & 1.066 & 14.50 & 21.00 \\
\hline $1.02 \%$ & 8.75 & 0 & 1.046 & 12.00 & 18. & 1.068 & 14.75 & 21.25 \\
\hline 1.024 & 9.00 & 14.5 & 1.048 & 12.25 & 18.75 & $1.0 \% 0$ & 15.00 & 21.50 \\
\hline 1.026 & 9.50 & 15.0 & 1.050 & 12.50 & 19.00 & & & \\
\hline 1.028 & 9.75 & 15 & $1.05 \%$ & 12.75 & 19.25 & & & \\
\hline 1.030 & 10.00 & 16 & 1.054 & 13.00 & 19.50 & & & \\
\hline & 10.25 & & 1.0 & 13.25 & 19.75 & & & \\
\hline & 10.50 & 16.6 & $1.05 \mathrm{~S}$ & 13.50 & 20.00 & & & \\
\hline 1 & 10.75 & 17.0 & & & & & & \\
\hline
\end{tabular}

TABLE VII.

ESTIMATION OF STARCH AND TOTAL DRY SUBSTANCE IN POTATOES, BY THE SPECIFIC GRAVITY OF THE TUBER.

\begin{tabular}{|c|c|c|c|c|c|c|c|c|}
\hline $\begin{array}{c}\text { Sp. Gr. } \\
\text { at } \\
18^{\circ} \mathrm{C} .\end{array}$ & Starch. & $\mid \begin{array}{c}\text { Total } \\
\text { dry sub- } \\
\text { stance. }\end{array}$ & $\begin{array}{c}\mathrm{Sp} . \mathrm{Gr} . \\
\text { at } \\
18^{\circ} \mathrm{C} .\end{array}$ & Starch. & $\begin{array}{c}\text { Total } \\
\text { dry sub- } \\
\text { stance. }\end{array}$ & $\begin{array}{c}\text { Sp. Gr. } \\
\text { at } \\
18^{\circ} \mathrm{C} .\end{array}$ & Starch. & $\begin{array}{c}\text { Total } \\
\text { dry sub- } \\
\text { stance. }\end{array}$ \\
\hline $\begin{array}{l}1.060 \\
1.062 \\
1.064 \\
1.066 \\
1.068 \\
1.070 \\
1.072 \\
1.074 \\
1.076 \\
1.078 \\
1.080\end{array}$ & $\begin{array}{r}9.54 \\
9.98 \\
10.42 \\
10.87 \\
11.32 \\
11.77 \\
12.22 \\
12.67 \\
13.12 \\
13.58 \\
14.04\end{array}$ & $\begin{array}{l}16.96 \\
17.41 \\
17.87 \\
18.33 \\
18.79 \\
19.26 \\
19.72 \\
20.18 \\
20.65 \\
21.13 \\
21.60\end{array}$ & $\begin{array}{l}1.082 \\
1.084 \\
1.086 \\
1.085 \\
1.090 \\
1.092 \\
1.094 \\
1.096 \\
1.098 \\
1.100 \\
1.102 \\
1.104\end{array}$ & $\begin{array}{l}14.50 \\
14.96 \\
15.42 \\
15.88 \\
16.35 \\
16.81 \\
17.28 \\
17.75 \\
18.23 \\
18.70 \\
19.17 \\
19.65\end{array}$ & $\begin{array}{l}22.07 \\
22.54 \\
23.02 \\
23.50 \\
23.98 \\
24.46 \\
24.94 \\
25.42 \\
25.91 \\
26.40 \\
26.88 \\
27.37\end{array}$ & $\begin{array}{l}1.106 \\
1.108 \\
1.110 \\
1.112 \\
1.114 \\
1.116 \\
1.118 \\
1.120 \\
1.122 \\
1.124 \\
1.126 \\
1.128 \\
1.130\end{array}$ & $\begin{array}{l}20.13 \\
20.61 \\
21.09 \\
21.57 \\
22.05 \\
22.54 \\
23.03 \\
23.52 \\
24.01 \\
24.50 \\
24.99 \\
25.49 \\
25.99\end{array}$ & $\begin{array}{l}27.86 \\
28.36 \\
28.86 \\
29.35 \\
29.85 \\
30.35 \\
30.85 \\
31.36 \\
31.86 \\
32.36 \\
32.87 \\
33.33 \\
33.90\end{array}$ \\
\hline
\end{tabular}

TABLE IX.

HARDNESS OF WATER.

\begin{tabular}{c|c||c|c|c|c|c|c}
\hline $\begin{array}{c}\text { C.C. of } \\
\text { soap } \\
\text { solution } \\
\text { used. }\end{array}$ & $\begin{array}{c}\text { Hard- } \\
\text { ness or } \\
\text { Mgr. } \\
\text { CaO. }\end{array}$ & $\begin{array}{c}\text { C.C. of } \\
\text { soap } \\
\text { solution } \\
\text { used. }\end{array}$ & $\begin{array}{c}\text { Hard- } \\
\text { ness or } \\
\text { Mgr. }\end{array}$ & $\begin{array}{c}\text { C.C. of } \\
\text { CaO. } \\
\text { soap } \\
\text { solution } \\
\text { used. }\end{array}$ & $\begin{array}{c}\text { Hard- } \\
\text { ness or } \\
\text { Mgr. } \\
\text { CaO. }\end{array}$ & $\begin{array}{c}\text { C.C. of } \\
\text { soap } \\
\text { solution } \\
\text { used. }\end{array}$ & $\begin{array}{c}\text { Hard- } \\
\text { ness or } \\
\text { Mgr. } \\
\text { CaO. }\end{array}$ \\
\hline 3.4 & 0.5 & 15.1 & 3.5 & 26.2 & 6.5 & 36.7 & 9.5 \\
5.4 & 1.0 & 17.0 & 4.0 & 28.0 & 7.0 & 38.4 & 10.0 \\
7.4 & 1.5 & 18.9 & 4.5 & 29.8 & 7.5 & 40.1 & 10.5 \\
9.4 & 2.0 & 20.8 & 5.0 & 31.6 & 8.0 & 41.8 & 11.0 \\
11.3 & 2.5 & 22.6 & 5.5 & 33.3 & 8.5 & 43.4 & 11.5 \\
13.2 & 3.0 & 24.4 & 6.0 & 35.0 & 9.0 & 45.0 & 12.0
\end{tabular}


TABLES.

\section{TABLE VIII.}

PER CENT OF BUTTER IN MILK, BY VOGEL'S OPTICAL MILK TEST.

\begin{tabular}{|c|c|c|c|c|c|c|c|}
\hline $\begin{array}{l}\text { C.C. of } \\
\text { milk re- } \\
\text { quired. }\end{array}$ & $\begin{array}{c}\left.{ }^{0}\right|_{0} \text { of } \\
\text { butter. }\end{array}$ & $\begin{array}{l}\text { C.C. of } \\
\text { milli } \\
\text { used. }\end{array}$ & $\begin{array}{c}{ }^{0} \text { \%o of } \\
\text { butter. }\end{array}$ & $\begin{array}{l}\text { C.C. of } \\
\text { milk } \\
\text { used. }\end{array}$ & $\begin{array}{c}{ }^{0} \%_{0} \text { of } \\
\text { butter. }\end{array}$ & $\begin{array}{l}\text { C.C. of } \\
\text { milk } \\
\text { used. }\end{array}$ & $\begin{array}{l}\%_{0} \text { of } \\
\text { butter. }\end{array}$ \\
\hline 2. & 9.5 & 4.50 & 5 & 6.50 & 3.80 & 8.50 & 2.96 \\
\hline 2.7 & 8. & 4.75 & & 5 & & 8. & 2.88 \\
\hline 3.00 & 7.96 & 5.00 & 4.87 & 7.00 & 3.51 & 9.00 & 2.80 \\
\hline 3.25 & 7.41 & 5.25 & 4.66 & 7.25 & 3.43 & 9.25 & 2.73 \\
\hline 3.50 & 6.86 & 5.50 & 4.45 & 7.50 & 3.32 & 9.50 & 2.67 \\
\hline 3.75 & 6.44 & 5.75 & 4. & 7.75 & 3.22 & 9.75 & 2.61 \\
\hline & 6.03 & 6.00 & 4.09 & 8.00 & 3.13 & & \\
\hline 4.2 & 5.70 & 6.25 & 3.94 & 8.25 & 3.04 & & \\
\hline
\end{tabular}

\section{TABLE $\mathrm{X}$.}

COMPOSITION OF AGRICULTURAL MATERIALS AND PRODUCTS IN 1000 PARTS OF THE SUBSTANCE.

From this Table the student may gain some idea of the chemical composition of the more important substances relating to agriculture; although since this composition varies so widely with varying circumstances, no great degree of precision can be claimed for statements of so general character, with whatever care they may be prepared.

The extreme and the average composition are given; the latter is to be taken, however, as indicating not the real mean of all the reliable analyses of the substance that have bcen made, but rather as an approximation to the proportion of each element or compound that is gencrally found in the substance; in some cases the proportion of a component ranged too erenly from one limit to the other of the extremes to admit of estimating any average of this kind. Fuller details may in some cases be found in the admirably arranged tables at the end of Prof. Johnson's "IIow Crops Grow." 
TABLES.

TABLE X,

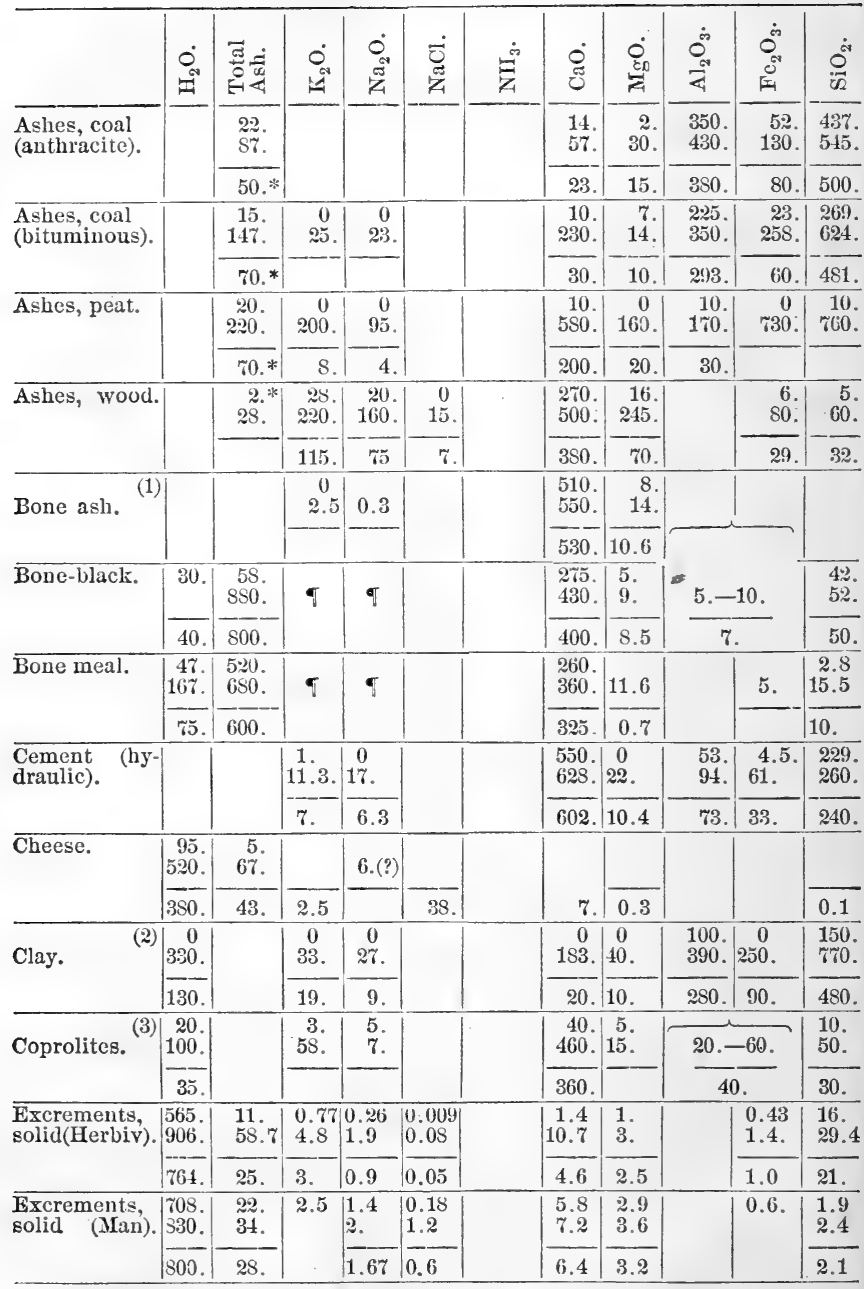

* In 1000 parts of the fuel.- Possibly present.-(1) Fluorine $36-40$, average 33; $\mathrm{K}_{2} \mathrm{O}$ and $\mathrm{Na}_{2} \mathrm{O}$ usually $0 .-(2) \mathrm{Mn}, 0-0.3 ; \mathrm{K}_{2} \mathrm{O}$ and $\mathrm{Na}_{2} \mathrm{O}$ mostly $0 .-(3)$ Fluorine, $0-50$; average 30 . 
TABLES.

TABLE X.-[Continued.

\begin{tabular}{|c|c|c|c|c|c|c|c|c|c|c|c|}
\hline & $\overbrace{\sigma_{2}}^{\dot{m}}$ & $\stackrel{0}{0}_{0^{\circ}}^{0}$ & $0_{51}^{\dot{0}}$ & $\overbrace{}^{\circ}$ & $\dot{v}$ & $\dot{0}$ & $\dot{z}$ & 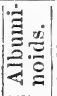 & 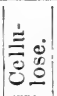 & 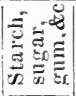 & 节 \\
\hline $\begin{array}{l}\text { Ashes, coal (an- } \\
\text { thracite). }\end{array}$ & & $\begin{array}{c}0 \\
\text { tr. }\end{array}$ & & & & & & & & & \\
\hline \multirow[t]{2}{*}{$\begin{array}{l}\text { Ashes, coal } \\
\text { (bituminous). }\end{array}$} & $\begin{array}{r}0 . \\
84 .\end{array}$ & $\begin{array}{l}0 . \\
66 .\end{array}$ & & & & & & & & & \\
\hline & 50. & 10. & & & & & & & $\therefore$ & & \\
\hline \multirow[t]{2}{*}{ Ashes, peat. } & 370. & $\begin{array}{r}0 . \\
80 .\end{array}$ & & $\begin{array}{c}0 \\
306 .\end{array}$ & & 0 & & & & & \\
\hline & 50 . & 30.1 & & & & 10. & & & & & \\
\hline \multirow[t]{2}{*}{ Ashes, wood. } & 57.8 & $\begin{array}{l}18 . \\
48 .\end{array}$ & & & & $t$ & & & & & \\
\hline & 4. & 50. & & & & 1 & & & & & \\
\hline \multirow[t]{2}{*}{ Bone ash. } & tr. & $\begin{array}{l}380 . \\
400 .\end{array}$ & & $\begin{array}{l}14 . \\
40 .\end{array}$ & & & & & & & \\
\hline & & 390. & & 30. & & & & & & & \\
\hline \multirow[t]{2}{*}{ Bone-black. } & 40. & $\begin{array}{l}100 . \\
380 .\end{array}$ & & $\begin{array}{l}15 . \\
27 .\end{array}$ & & & 5. & & & & \\
\hline & & 300. & & 17. & & & 7. & & & & \\
\hline \multirow[t]{2}{*}{ Bone meal. } & & $\begin{array}{l}180 . \\
280 .\end{array}$ & & $\stackrel{?}{6} 6$. & & & 28. & ช & & & 9 \\
\hline & & 220. & & & & & 38. & & & & \\
\hline \multirow[t]{2}{*}{$\begin{array}{l}\text { Cement (hy- } \\
\text { draulic). }\end{array}$} & $\begin{array}{c}0 . \\
18.8\end{array}$ & & & & & & & & & & \\
\hline & 10.2 & & & & & & & & & & \\
\hline \multirow[t]{2}{*}{ Cheese. } & & & & & & + & + & $\begin{array}{r}80 . \\
440 . \\
\end{array}$ & & & $\begin{array}{l}100 . \\
600 .\end{array}$ \\
\hline & & 11.5 & & & & 1 & 1 & 240. & & & 310. \\
\hline \multicolumn{12}{|l|}{ Clay. } \\
\hline \multirow[t]{2}{*}{ Coprolites. } & $\begin{array}{r}7.6 \\
10.6\end{array}$ & $\begin{array}{r}30 . \\
380 .\end{array}$ & & $\begin{array}{c}1 . \\
6 \%\end{array}$ & & traces & $\begin{array}{c}0 \\
25 .\end{array}$ & & & & \\
\hline & 9.0 & 230. & & 30. & & & & & & & \\
\hline \multirow[t]{2}{*}{$\begin{array}{l}\text { Excrements, } \\
\text { solid (Herbiv). }\end{array}$} & $\begin{array}{l}0.47 \\
1.58\end{array}$ & $\begin{array}{l}2.2 \\
0.5\end{array}$ & & & + & + & $\begin{array}{c}2.2 \\
9.0\end{array}$ & $\begin{array}{l}17 . \\
23 .\end{array}$ & $\begin{array}{r}86 . \\
110 .\end{array}$ & $\begin{array}{r}80 . \\
110 .\end{array}$ & $\begin{array}{l}10 . \\
13 .\end{array}$ \\
\hline & 0.87 & 3.6 & & & & & 4.7 & 20. & 95. & 95. & 10. \\
\hline \multirow[t]{2}{*}{$\begin{array}{l}\text { Excrements, } \\
\text { solid (Man). }\end{array}$} & $\begin{array}{l}0.3 \\
0.9\end{array}$ & $\begin{array}{r}8.5 \\
10.9\end{array}$ & & & $t$ & t & & t & + & $t$ & + \\
\hline & 0.6 . & 9.9 & & & & & 4. & & & & \\
\hline
\end{tabular}

+ Present,- T Possibly present. 
TABLE X.-[Continued.

\begin{tabular}{|c|c|c|c|c|c|c|c|c|c|c|c|}
\hline & $\begin{array}{l}0 \\
0\end{array}$ & Eี & $\begin{array}{c}0 \\
1 \\
1\end{array}$ & $\begin{array}{c}0 \\
\text { 吾 } \\
\end{array}$ & 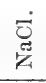 & 宏 & ల్ర & 总 & 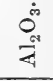 & 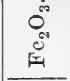 & $\overbrace{i=1}^{\circ}$ \\
\hline \multirow[t]{2}{*}{ Flesh. } & $\begin{array}{l}446 . \\
590 .\end{array}$ & $\begin{array}{l}10 . \\
37 .\end{array}$ & $\begin{array}{l}4.1 \\
5.2\end{array}$ & $\begin{array}{l}0 \\
1 .\end{array}$ & & & $\begin{array}{l}0.2 \\
0.8\end{array}$ & $\begin{array}{l}0.2 \\
0.5\end{array}$ & & & $\begin{array}{l}0.1 \\
0.3\end{array}$ \\
\hline & |524. & 22. & 4.5 & 0.7 & & & 0.3 & 0.4 & & & 0.2 \\
\hline \multirow[t]{2}{*}{$\begin{array}{l}\text { Fodder, dry, } \\
\text { graminaceæ. }\end{array}$} & 118. & $\begin{array}{r}24 . \\
111 .\end{array}$ & & & & \multirow{2}{*}{ T } & & & & $\begin{array}{l}0.13 \\
0.4 \\
\end{array}$ & \\
\hline & 150. & 66. & 17.1 & 4.7 & & & 7.7 & 3.3 & & 0.2 & 19.7 \\
\hline \multirow[t]{2}{*}{$\begin{array}{l}\text { Fodder, dry, } \\
\text { leguminosæ. }\end{array}$} & $\begin{array}{l}116 . \\
200 .\end{array}$ & $\begin{array}{l}45 . \\
80 . \\
\end{array}$ & $\begin{array}{l}10.6 \\
19.5 \\
\end{array}$ & $\begin{array}{l}0 \\
4.7 \\
\end{array}$ & & \multirow[t]{2}{*}{ গ } & $\begin{array}{l}15 . \\
31 .\end{array}$ & $\begin{array}{l}2.6 \\
7.0 \\
\end{array}$ & & $\begin{array}{l}0.3 \\
1.7 \\
\end{array}$ & $\begin{array}{l}0.6 \\
2.7 \\
\end{array}$ \\
\hline & 160. & $\% 0$ & 15.8 & 1.5 & & & 19. & 5.0 & & 0.36 & 1.5 \\
\hline \multirow[t]{2}{*}{$\begin{array}{l}\text { Fodder,green, } \\
\text { graminacex. }\end{array}$} & 690. & 21. & $\begin{array}{r}5.3 \\
11.6\end{array}$ & $\begin{array}{l}0.1 \\
1.6\end{array}$ & & \multirow[t]{2}{*}{8} & $\begin{array}{l}0.7 \\
2.7 \\
\end{array}$ & $\begin{array}{l}0.3 \\
1.9 \\
\end{array}$ & & \multirow[t]{2}{*}{$\dagger$} & $\begin{array}{r}2.1 \\
12.3\end{array}$ \\
\hline & 745. & 18. & 7. & 0.5 & & & 1.5 & 0.7 & & & 7.3 \\
\hline \multirow[t]{2}{*}{$\begin{array}{l}\text { Fodder,green, } \\
\text { leguminosæ. }\end{array}$} & $\left|\begin{array}{l}740 . \\
850\end{array}\right|$ & $\begin{array}{l}10 . \\
20 \\
\end{array}$ & $\begin{array}{l}1.0 \\
6.6\end{array}$ & $\begin{array}{l}0 \\
1.1 \\
\end{array}$ & & $\begin{array}{l}0 \\
2.6\end{array}$ & $\begin{array}{l}3.0 \\
8.5 \\
\end{array}$ & $\begin{array}{l}0.6 \\
1.6 \\
\end{array}$ & & \multirow[t]{2}{*}{$\uparrow$} & $\begin{array}{l}0.1 \\
0.6 \\
\end{array}$ \\
\hline & 804: & 12. & 1.5 & 0.4 & & & 4.9 & 1.0 & & & 0.4 \\
\hline \multirow[t]{2}{*}{ Fruits. } & $\begin{array}{l}760 . \\
880 .\end{array}$ & $\begin{array}{l}2 . \\
9 . \\
\end{array}$ & $\begin{array}{l}1.0 \\
2.4 \\
\end{array}$ & $\begin{array}{l}0 \\
0.7 \\
\end{array}$ & & & $\begin{array}{l}0.1 \\
0.4 \\
\end{array}$ & & & $\begin{array}{l}0.08 \\
0.33 \\
\end{array}$ & \\
\hline & $820 . \mid$ & 4. & 2.0 & 0.3 & & & 0.3 & 0.2 & & 0.19 & \\
\hline \multirow{2}{*}{$\begin{array}{l}\text { Guano, } \\
\text { ammoniacal. }\end{array}$} & $\begin{array}{l}100 . \\
200 \\
-\end{array}$ & $\begin{array}{l}330 \\
400\end{array}$ & $\begin{array}{l}16.0 \\
30.0 \\
\end{array}$ & 12. & & $\begin{array}{r}62 . \\
100 .\end{array}$ & & & & & \\
\hline & 140. & 344. & 20.0 & 35. & & & 12. & 8. & & & 12. \\
\hline \multirow[t]{2}{*}{$\begin{array}{l}\text { Guano, } \\
\text { phosphatic. }\end{array}$} & $\begin{array}{r}10 . \\
140 . \\
\end{array}$ & $\begin{array}{l}780 . \\
950 . \\
\end{array}$ & $\begin{array}{c}0 \\
13.0 \\
\end{array}$ & $\begin{array}{c}0 \\
39 . \\
\end{array}$ & & & 430. & $\begin{array}{c}0 \\
21 .\end{array}$ & $\begin{array}{r}4 . \\
59\end{array}$ & $\begin{array}{c}0 \\
51 .\end{array}$ & $\begin{array}{c}0 \\
13 .\end{array}$ \\
\hline & 100. & 890. & 2.5 & 6. & & & 400. & 2. & & 3.7 & \\
\hline \multirow[t]{2}{*}{ Gypsum. } & $\begin{array}{l}188 . \\
205 . \\
-\end{array}$ & & & & & & 325. & tr. & & & 50 \\
\hline & 197. & & & & & & 309. & & & & \\
\hline \multirow[t]{2}{*}{ Limestone. } & $\begin{array}{r}3 . \\
21 . \\
\end{array}$ & & $\begin{array}{l}0.03 \\
1.12 \\
\end{array}$ & $\begin{array}{l}0 \\
0 . \tau\end{array}$ & & & $\begin{array}{l}410 . \\
550 .\end{array}$ & $\begin{array}{r}3.4 \\
15.0\end{array}$ & \multirow{2}{*}{\multicolumn{2}{|c|}{ 2. -40.}} & 10.7 \\
\hline & & & 0.2 & & & & 500. & 8. & & & \\
\hline \multirow[t]{2}{*}{$\begin{array}{l}\text { Manure, fresh } \\
\text { farm-yard. }\end{array}$} & $\begin{array}{l}660 \\
610 . \\
\end{array}$ & $\begin{array}{l}34 . \\
78 \\
\end{array}$ & $\begin{array}{r}1.2 \\
12.0\end{array}$ & $\begin{array}{l}0.2 \\
2.8 \\
\end{array}$ & & & 12. & $\begin{array}{l}0.5 \\
1.7 \\
\end{array}$ & & -8 & $\begin{array}{r}7.5 \\
18.0 \\
\end{array}$ \\
\hline & 680. & 58. & 8.0 & 1.2 & & & 11. & 1.0 & & 3. & 14.0 \\
\hline \multirow[t]{2}{*}{$\begin{array}{l}\text { Manure,rotted } \\
\text { farm-yard. }\end{array}$} & 7.750. & $\begin{array}{l}70 . \\
73 . \\
\end{array}$ & & $\begin{array}{l}0.6 \\
0.8 \\
\end{array}$ & & & $\begin{array}{l}10 . \\
19 .\end{array}$ & $\begin{array}{r}1.8 \\
3.8 \\
\end{array}$ & & {[} & 23. \\
\hline & 1780. & T2. & 5.0 & 0.7 & & & 15 & 1.6 & & 7 & 22 \\
\hline \multirow[t]{2}{*}{ Marl. } & 10. & & 14.8 & 15 & & $\begin{array}{l}0 \\
0.99 \\
\end{array}$ & 520. & $\begin{array}{c}3 . \\
220 .\end{array}$ & \multirow{2}{*}{\multicolumn{2}{|c|}{$30 .-90}}$. & \\
\hline & 30. & & 1.0 & & & & & & & & \\
\hline
\end{tabular}

* In the dry substance. + Present. I Possibly present. (1) Free acid, estimated as malic acid, $1.0-20.0$; average $8.6 .-(2)$ Oxalic acid, $58-80$; average 60 . Uric acid present.-(3) Fluorine, traces. Sand 8-47-(4) Insoluble silicates and sand, $50-850$. 
TABLES.

TABLE X.-[Continued.

\begin{tabular}{|c|c|c|c|c|c|c|c|c|c|c|c|}
\hline & 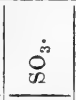 & $\begin{array}{c}\dot{0} \\
\hat{n}^{4} \\
\end{array}$ & $\begin{array}{l}\dot{0} \\
0^{c} \\
z_{1}\end{array}$ & ச் & $\dot{20}$ & $\dot{0}$ & z & 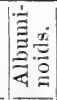 & 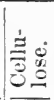 & 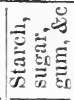 & 莡 \\
\hline \multirow[t]{2}{*}{ Flesh. } & $\begin{array}{l}0 \\
0.4 \\
\end{array}$ & $\begin{array}{l}4.3 \\
5.8\end{array}$ & & & $t$ & $\begin{array}{l}0.1 \\
0.7\end{array}$ & t & 123. & & & 210. \\
\hline & & 5.0 & & & & 0.4 & & 144. & & & 299. \\
\hline \multirow[t]{2}{*}{$\begin{array}{l}\text { Fodder, dry, } \\
\text { graminacex. }\end{array}$} & & 3.3 & $T$ & & $\begin{array}{l}1.7 \\
3.3\end{array}$ & & $t$ & $\begin{array}{r}30 . \\
180\end{array}$ & $\begin{array}{l}170 . \\
400 .\end{array}$ & 225. & 12. \\
\hline & 3.4 & 4.1 & & & 2.5 & 5.3 & & 90. & $\longdiv { 2 6 0 . }$ & 410. & 28. \\
\hline \multirow[t]{2}{*}{$\begin{array}{l}\text { Fodder, dry, } \\
\text { leguminosæ. }\end{array}$} & $\begin{array}{l}1.5 \\
5.3\end{array}$ & $\begin{array}{l}4.7 \\
9.0\end{array}$ & 0.031 & & $\begin{array}{l}0.9 \\
2.7\end{array}$ & $\begin{array}{l}1.3 \\
2.1\end{array}$ & + & $\begin{array}{r}7 \% \\
190\end{array}$ & $\begin{array}{l}190 . \\
400 .\end{array}$ & $\begin{array}{l}150 . \\
480 .\end{array}$ & 5 \\
\hline & 2.8 & 6.5. & & & $\overline{1.8}$ & 1.5 & & $\overline{140}$ & $\overline{280}$ & 330. & 30. \\
\hline \multirow[t]{2}{*}{$\begin{array}{l}\text { Fodder, green, } \\
\text { graminaceæ. }\end{array}$} & $\begin{array}{l}0.2 \\
1.2 \\
\end{array}$ & $\begin{array}{l}1.3 \\
2.4 \\
\end{array}$ & tr. & & $\begin{array}{l}0.3 \\
0.8\end{array}$ & $\begin{array}{l}0.4 \\
1.9\end{array}$ & t & $\begin{array}{l}17 . \\
60 .\end{array}$ & $\begin{array}{r}30 \\
170\end{array}$ & $\begin{array}{r}35 . \\
230 .\end{array}$ & $\begin{array}{c}3 . \\
15\end{array}$ \\
\hline & 0.7 & 1.7 & & & 0.5 & 1.0 & & 30. & 90. & 129. & 10. \\
\hline \multirow[t]{2}{*}{$\begin{array}{l}\text { Fodder, green, } \\
\text { leguminosæ. }\end{array}$} & $\begin{array}{l}0.2 \\
2.2 \\
\end{array}$ & $\begin{array}{l}0.9 \\
2.0 \\
\end{array}$ & $\begin{array}{l}0.007 \\
5.0\end{array}$ & & $\begin{array}{l}0.3 \\
0.8 \\
\end{array}$ & $\begin{array}{l}0.2 \\
1.0 \\
\end{array}$ & + & 22 & $\begin{array}{r}30 . \\
160 .\end{array}$ & $\begin{array}{r}50 . \\
140 .\end{array}$ & $\begin{array}{l}4 . \\
9 .\end{array}$ \\
\hline & 0.8 & 1.4 & & & $\overline{0.5}$ & 0.4 & & 28. & 60. & 75. & 6. \\
\hline \multirow[t]{2}{*}{ Fruits. } & & $\begin{array}{l}0.4 \\
0.7 \\
\end{array}$ & & & & $\begin{array}{l}0.1 \\
0.4 \\
\end{array}$ & t & $\begin{array}{l}3.2 \\
8.0\end{array}$ & $\begin{array}{r}28 . \\
117 .\end{array}$ & $\begin{array}{r}14 \\
120 . \\
*\end{array}$ & \\
\hline & 0.2 & 0.5 & & & 0.1 & 0.2 & & 5.0 & 49. & 64. & \\
\hline \multirow[t]{2}{*}{$\begin{array}{l}\text { Guano, } \\
\text { ammoniacal. }\end{array}$} & & $\begin{array}{r}60 . \\
13 \% \\
\end{array}$ & & & & & $\left|\begin{array}{r}80 \\
170 .\end{array}\right|$ & & & & \\
\hline & 7. & 100. & & & & & 110. & & & & \\
\hline \multirow[t]{2}{*}{$\begin{array}{l}\text { Guano, } \\
\text { phosphatic. }\end{array}$} & $\begin{array}{c}0 \\
270\end{array}$ & $\begin{array}{l}170 . \\
420 .\end{array}$ & $\frac{0}{5}$. & $\begin{array}{c}0 \\
15 .\end{array}$ & & $\begin{array}{l}0 \\
8 .\end{array}$ & $\begin{array}{l}\operatorname{tr} . \\
40 .\end{array}$ & & & & \\
\hline & 6. & 340. & 3.2 & & & 1.5 & & & & & \\
\hline \multirow[t]{2}{*}{ Gypsum. } & $\begin{array}{l}118 . \\
160 .\end{array}$ & & & $\begin{array}{l}\text { tr. } \\
30 .\end{array}$ & & & & & & & \\
\hline & 140. & & & & & & & & & & \\
\hline \multirow[t]{2}{*}{ Limestone. } & $\begin{array}{l}0.3 \\
6.7\end{array}$ & $\begin{array}{c}0.03 \\
12.0\end{array}$ & & $\begin{array}{l}310 . \\
140 .\end{array}$ & & $\begin{array}{l}0.3 \% \\
1.76\end{array}$ & $\begin{array}{l}0 \\
1.6\end{array}$ & & & & \\
\hline & 2.0 & 0.8 & & 400. & & & & & & & \\
\hline \multirow[t]{2}{*}{$\begin{array}{l}\text { Manure, fresh } \\
\text { farm-yard. }\end{array}$} & $\begin{array}{l}1.0 \\
3.0\end{array}$ & $\begin{array}{l}1.20 \\
3.0\end{array}$ & & & t & $\begin{array}{l}0.6 \\
2.0\end{array}$ & $\begin{array}{l}4.0 \\
7.4\end{array}$ & t & $t$ & $t$ & $t$ \\
\hline & 2.0 & 2.8 & & & & 0.8 & 6.0 & & & & \\
\hline \multirow[t]{2}{*}{$\begin{array}{l}\text { Manure, rotted } \\
\text { farm-yard. }\end{array}$} & $\begin{array}{l}1.2 \\
2.4\end{array}$ & $\begin{array}{l}3.4 \\
4.5\end{array}$ & + & & & $\begin{array}{l}0.2 \\
1.6\end{array}$ & 6.0 & & & & \\
\hline & 1.8 & 3.9 & & & & 0.9 & & & & & \\
\hline Marl. & $\begin{array}{c}\text { tr. } \\
15 .\end{array}$ & $\begin{array}{l}\text { tr. } \\
5\end{array}$ & & $\begin{array}{r}30 . \\
450 .\end{array}$ & & tr. & & & & & \\
\hline
\end{tabular}

* Sugar._+Present.- - Possibly present. 
TABLE X.--[Continued.

\begin{tabular}{|c|c|c|c|c|c|c|c|c|c|c|c|}
\hline & $\stackrel{0}{\circ}$ & 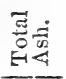 & 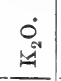 & 悹 & $\begin{array}{l}\dot{E} \\
\dot{z}\end{array}$ & $\dot{\vec{Z}}$ & ర્ટુ & $\underset{\substack{0 \\
二}}{0}$ & 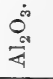 & 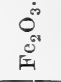 & $\stackrel{0}{i n}$ \\
\hline \multirow[t]{2}{*}{ Millk. } & $\begin{array}{l}860 . \\
875 .\end{array}$ & $\begin{array}{l}7.5 \\
8.5\end{array}$ & & & & & & & & & \\
\hline & s70. & 7.3 & 1.7 & 0.7 & & & 1.5 & 0.2 & & & \\
\hline \multirow{2}{*}{$\begin{array}{l}\text { Phosphorite } \\
\text { (Apatite). }\end{array}$} & $\begin{array}{r}4 . \\
25 .\end{array}$ & & $\begin{array}{c}0 \\
12.6\end{array}$ & $\begin{array}{l}0 \\
5.0\end{array}$ & & & 200. & $\begin{array}{l}0 \\
2.3\end{array}$ & \multirow{2}{*}{\multicolumn{2}{|c|}{$0.37-90$}} & 60. \\
\hline & 15. & & 5.6 & 3.0 & & & 440. & 1.8 & & & 50. \\
\hline \multirow[t]{2}{*}{$\begin{array}{l}\text { Plants, cereal; } \\
\text { grain. }\end{array}$} & 126. & 39. & $\begin{array}{l}3.3 \\
5.5\end{array}$ & $\begin{array}{l}0.2 \\
1.0\end{array}$ & & $\begin{array}{l}\operatorname{tr} \\
3.4\end{array}$ & $\begin{array}{l}0.14 \\
10 .\end{array}$ & $\begin{array}{l}1.8 \\
2.2\end{array}$ & & $\begin{array}{l}0 \\
0.6\end{array}$ & $\begin{array}{l}0.3 \\
12 .\end{array}$ \\
\hline & 142. & 20 & 4.6 & 0.5 & & & 0.6 & 1.9 & & 0.18 & \\
\hline \multirow[t]{2}{*}{$\begin{array}{l}\text { Plants, cereal: } \\
\text { straw. }\end{array}$} & $\left|\begin{array}{r}90 . \\
225 .\end{array}\right|$ & $\begin{array}{l}40 . \\
56\end{array}$ & $\begin{array}{r}4.9 \\
16.6\end{array}$ & $\begin{array}{l}0 \\
3.5\end{array}$ & & $\begin{array}{l}\operatorname{tr} . \dot{5} \\
1.5\end{array}$ & $\begin{array}{l}2.3 \\
5.0\end{array}$ & $\begin{array}{l}0.4 \\
2.6\end{array}$ & & $\begin{array}{r}.02 \\
2.11\end{array}$ & $\begin{array}{l}18 . \\
34 .\end{array}$ \\
\hline & 150. & 45. & 6.0 & 2.5 & & & 3.6 & 1.4 & & 1.0 & 25. \\
\hline \multirow{2}{*}{$\begin{array}{l}\text { Plants, com- } \\
\text { mercial. } \\
\text { (Iops, tobac- } \\
\text { co, etc.) }\end{array}$} & $\begin{array}{l}100 \\
300\end{array}$ & $\begin{array}{r}28 \\
198\end{array}$ & $\begin{array}{r}5.2 \\
54.1 \\
\end{array}$ & $\begin{array}{l}0.9 \\
7.3 \\
\end{array}$ & & \multirow[t]{2}{*}{ T } & $\begin{array}{r}5 . \\
73 .\end{array}$ & $\begin{array}{r}2.0 \\
20.7\end{array}$ & & $\begin{array}{l}.08 \\
3.0\end{array}$ & $\begin{array}{l}0.8 \\
19 .\end{array}$ \\
\hline & 220.1 & 50. & 15.0 & 1.6 & & & 8. & 3.0 & & 1.74 & \\
\hline \multirow{2}{*}{$\begin{array}{l}\text { Plants, } \\
\text { lerume; } \\
\text { sceds. }\end{array}$} & 128. & $\begin{array}{l}17 . \\
35 .\end{array}$ & $\begin{array}{r}6.3 \\
12.0 \\
\end{array}$ & $\begin{array}{l}0.4 \\
6.0\end{array}$ & & \multirow[t]{2}{*}{$T$} & $\begin{array}{l}0.6 \\
2.7\end{array}$ & $\begin{array}{l}0.4 \\
2.1\end{array}$ & & $\begin{array}{c}0 \\
0.48\end{array}$ & $\begin{array}{l}0.2 \\
0.4\end{array}$ \\
\hline & 144. & 25. & 9.8 & 1.0 & & & 1.5 & 1.7 & & 0.15 & 0. \\
\hline \multirow[t]{2}{*}{$\begin{array}{l}\text { Plants, } \\
\text { legume; } \\
\text { straw. }\end{array}$} & $\begin{array}{l}160 . \\
190 . \\
\end{array}$ & $\begin{array}{r}38 . \\
584 . \\
\end{array}$ & $\begin{array}{r}9.7 \\
25.9 \\
\end{array}$ & $\begin{array}{l}1.1 \\
3.9 \\
\end{array}$ & & \multirow[t]{2}{*}{ T } & $\begin{array}{r}9.5 \\
25 . \\
\end{array}$ & $\begin{array}{l}1.9 \\
4.6 \\
\end{array}$ & & $\begin{array}{l}0.09 \\
0.2 \\
\end{array}$ & $\begin{array}{l}2 . \\
3 .\end{array}$ \\
\hline & 150 & 50. & 18.9 & 2.6 & & & 15. & 3.0 & & 0.13 & 2. \\
\hline \multirow[t]{2}{*}{$\begin{array}{l}\text { Potatoes; } \\
\text { tubers. }\end{array}$} & $\begin{array}{l}50 . \\
800 .\end{array}$ & $\begin{array}{c}5.6 \\
46 .\end{array}$ & $\begin{array}{l}5.6 \\
6.7 \\
\end{array}$ & $\begin{array}{l}0.1 \\
0.4 \\
\end{array}$ & & \multirow[t]{2}{*}{ T } & $\begin{array}{l}0.2 \\
0.4\end{array}$ & $\begin{array}{l}0.3 \\
0.4 \\
\end{array}$ & & $\begin{array}{l}0.04 \\
0.06\end{array}$ & 0.2 \\
\hline & 775. & 10. & 6.1 & 0.25 & & & 0.25 & 0.35 & & 0.05 & \\
\hline \multirow[t]{2}{*}{$\begin{array}{l}\text { Potatoes; } \\
\text { tops. }\end{array}$} & $\begin{array}{l}770 \\
820\end{array}$ & $\begin{array}{l}11 . \\
16 .\end{array}$ & $\begin{array}{l}0.7 \\
2.3\end{array}$ & ฯ & & \multirow[t]{2}{*}{ T } & $\begin{array}{l}5.1 \\
5.5\end{array}$ & $\begin{array}{l}2.6 \\
2.7\end{array}$ & & & $\begin{array}{l}0.5 \\
8.5\end{array}$ \\
\hline & 697. & 14. & 1.5 & & & & 5.3 & 2.65 & & 0.21 & \\
\hline \multirow[t]{2}{*}{$\begin{array}{l}\text { Root-crops; } \\
\text { roots. }\end{array}$} & $\begin{array}{l}754 \\
920 \\
\end{array}$ & $\begin{array}{r}6 . \\
10 . \\
\end{array}$ & $\begin{array}{l}1.9 \\
4.3 \\
\end{array}$ & $\begin{array}{l}0.8 \\
2.0 \\
\end{array}$ & & \multirow[t]{2}{*}{ T } & $\begin{array}{l}0.4 \\
0.9 \\
\end{array}$ & $\begin{array}{l}0.1 \\
0.7 \\
\end{array}$ & & $\begin{array}{l}0.01 \\
0.29 \\
\end{array}$ & $\begin{array}{l}0.1 \\
0.3 \\
\end{array}$ \\
\hline & $|8 \% 5|$. & S. & 3.5 & 1.0 & & & 0.7 & 0.4 & & 0.09 & 0.2 \\
\hline \multirow[t]{2}{*}{$\begin{array}{l}\text { Root-crops; } \\
\text { tops. }\end{array}$} & $\begin{array}{l}7655 \\
920 .\end{array}$ & $\begin{array}{l}15 . \\
33 .\end{array}$ & $\begin{array}{l}3.2 \\
6.0\end{array}$ & $\begin{array}{l}0.5 \\
6.0\end{array}$ & & \multirow[t]{2}{*}{$T$} & $\begin{array}{l}1.7 \\
8.6\end{array}$ & \begin{tabular}{l|}
0.4 \\
3.3 \\
\end{tabular} & & $\begin{array}{l}0.15 \\
0.28\end{array}$ & $\begin{array}{l}0.1 \\
2.6 \\
\end{array}$ \\
\hline & 85 & 17. & 4.1 & 1.5 & & & 4.8 & 1.3 & & 026. & 1.0 \\
\hline \multirow[t]{2}{*}{ Salt. } & $\begin{array}{l}12 . \\
63 .\end{array}$ & $\begin{array}{l}937 . \\
988 . \\
\end{array}$ & $\begin{array}{l}0 \\
2.3 \\
\end{array}$ & \multirow[t]{2}{*}{ t } & $\begin{array}{l}890 . \\
994 .\end{array}$ & & $\begin{array}{l}1.15 \\
9.7 \\
\end{array}$ & $\begin{array}{l}0.2 \\
2.8\end{array}$ & $\begin{array}{l}0 \\
\text { tr. }\end{array}$ & ${ }^{0} \mathrm{tr}$. & 53.0 \\
\hline & 34. & 963. & 2.2 & & 975. & & 8.0 & 1.7 & & & \\
\hline \multirow[t]{2}{*}{$\begin{array}{l}\text { Saltpetre } \\
\text { (Chili). }\end{array}$} & $\begin{array}{r}1 . \\
20 .\end{array}$ & & \multirow[t]{2}{*}{ T } & $\begin{array}{l}330 . \\
358 .\end{array}$ & & & & & & & \\
\hline & 1 & 80 & & 340. & & & 1.0 & 0 & & & 29. \\
\hline
\end{tabular}

+ Present.- - Possibly present.-(1) Fluorine $0-49$; average 28.-(2) $\mathrm{N}_{2} \mathrm{O}_{5}$, usualiy 0 . 
TABLES.

TABLE X.-[Continued.

\begin{tabular}{|c|c|c|c|c|c|c|c|c|c|c|c|}
\hline & $\overbrace{\mathscr{X}}^{\infty}$ & $\begin{array}{c}\dot{\dot{\theta}} \\
\dot{a}^{-1}\end{array}$ & $\begin{array}{l}0^{\dot{\theta}} \\
Z^{\prime}\end{array}$ & $\overbrace{}^{\dot{c}}$ & $\dot{v i}$ & छ் & $\ddot{z}$ & 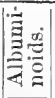 & 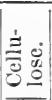 & 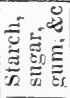 & 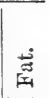 \\
\hline \multirow[t]{2}{*}{ Milk. } & & & & & & & & $\begin{array}{l}24 . \\
68 .\end{array}$ & & $\begin{array}{l}29 . \\
83 .\end{array}$ & $\overline{22 .}$ \\
\hline & 0.1 & $\overline{1.9}$ & & & & 0.7 & & 38. & & $47 . *$ & 35. \\
\hline \multirow[t]{2}{*}{$\begin{array}{l}\text { Phosphorite. } \\
\text { (Apatite). }\end{array}$} & tr. & $\begin{array}{l}300.0 \\
460.0\end{array}$ & & $\begin{array}{r}3.0 \\
43.0\end{array}$ & & $\begin{array}{l}0.0 \\
5.0\end{array}$ & & & & & \\
\hline & & 360.0 & & 25.0 & & & & & & & \\
\hline \multirow[t]{2}{*}{$\begin{array}{l}\text { Plants, cereal ; } \\
\text { grain. }\end{array}$} & $\begin{array}{l}0.1 \\
0.5\end{array}$ & $\begin{array}{r}5.5 \\
10.0\end{array}$ & 6.8 & & $\begin{array}{l}0.4 \\
1.7\end{array}$ & $\begin{array}{l}0.18 \\
0.27\end{array}$ & $\begin{array}{l}19 . \\
42.5\end{array}$ & $\begin{array}{l}5: 6 . \\
270 .\end{array}$ & 165. & $\begin{array}{l}500 \\
765 .\end{array}$ & 5. \\
\hline & 0.36 & 8.0 & & & 1.0 & 0.2 & $|\overline{20.0}|$ & 120. & 60 . & 640. & \\
\hline \multirow[t]{2}{*}{$\begin{array}{l}\text { Plants, cereal; } \\
\text { straw. }\end{array}$} & $\begin{array}{l}0.9 \\
2.5\end{array}$ & $\begin{array}{l}1.4 \\
3.8\end{array}$ & $\begin{array}{l}0 \\
5.2\end{array}$ & & $\begin{array}{l}0.9 \\
4.0\end{array}$ & $\begin{array}{l}1.2 \\
1.3\end{array}$ & $\begin{array}{l}1 . \pi \\
4.2\end{array}$ & $\begin{array}{r}6 . \\
100 .\end{array}$ & 290. & $\begin{array}{l}180 . \\
455 .\end{array}$ & $\begin{array}{r}6 . \\
25 .\end{array}$ \\
\hline & 1.4 & 2.5 & & & 2.0 & & 3.0 & 37. & $\sqrt{460}$. & 300. & 13. \\
\hline \multirow{2}{*}{$\begin{array}{l}\text { Plants, commer- } \\
\text { cial. (Hops, to- } \\
\text { bacco, etc.) }\end{array}$} & $\begin{array}{l}0.5 \\
7.7 \\
\end{array}$ & $\begin{array}{r}3.3 \\
9.0 \\
\end{array}$ & I & & $\begin{array}{l}0 \\
4.8 \\
\end{array}$ & $\begin{array}{l}0.7 \\
8.8 \\
\end{array}$ & t & 55. & & & 48 \\
\hline & 2.0 & 7.1 & & & 3.4 & 1.8 & & & & $6 \% 2$. & \\
\hline \multirow[t]{2}{*}{$\begin{array}{l}\text { Plants, lerrume; } \\
\text { seeds. }\end{array}$} & \begin{tabular}{l|l|}
0 \\
2.3
\end{tabular} & $\begin{array}{l}5.2 \\
8.1 \\
\end{array}$ & $\begin{array}{l}0 \\
\mathrm{tr} .\end{array}$ & & $\begin{array}{l}0 \\
2.5 \\
\end{array}$ & $\begin{array}{l}0.2 \\
0.6 \\
\end{array}$ & + & 300. & 145. & $\begin{array}{l}270 . \\
600 .\end{array}$ & 76. \\
\hline & 1.3 & 8.0 & & & 2.4 & 0.5 & & 250. & 97. & 400. & 32. \\
\hline \multirow[t]{2}{*}{$\begin{array}{l}\text { Plants, legume; } \\
\text { straw. }\end{array}$} & $\begin{array}{l}0.1 \\
2.8 \\
\end{array}$ & $\begin{array}{l}2.7 \\
6.1 \\
\end{array}$ & $T$ & & $\begin{array}{l}0.7 \\
2.2 \\
\end{array}$ & $\begin{array}{l}2.7 \\
8.1\end{array}$ & 18 & $\begin{array}{r}48 . \\
100 .\end{array}$ & 250. & $\begin{array}{l}170 . \\
400 .\end{array}$ & 50. \\
\hline & 2.0 & 3.8 & & & 1.5 & 4.5 & 9. & 80. & $\overline{390}$ & 300. & $\overline{18 .}$ \\
\hline \multirow[t]{2}{*}{ Potatoes; tubers. } & $\begin{array}{l}0.3 \\
0.6 \\
\end{array}$ & $\begin{array}{l}1.6 \\
2.0 \\
\end{array}$ & $T$ & & $\begin{array}{l}0.2 \\
0.94 \\
\end{array}$ & + & $\begin{array}{l}0.8 \\
3.0 \\
\end{array}$ & $\begin{array}{r}5 . \\
40 . \\
\end{array}$ & $\begin{array}{r}3 . \\
27 . \\
\end{array}$ & $\begin{array}{l}120 . \\
160 . \\
\end{array}$ & $\begin{array}{l}0.5 \\
8.0 \\
\end{array}$ \\
\hline & 0.45 & 1.7 & & & 0.9 & & 2.0 & 18. & 10 . & 190. & 3.0 \\
\hline \multirow[t]{2}{*}{ Potatoes; tops. } & $\begin{array}{l}0.6 \\
0.9 \\
\end{array}$ & $\begin{array}{l}0.6 \\
1.0 \\
\end{array}$ & 0.78 & & $\begin{array}{l}0.5 \\
0.6 \\
\end{array}$ & $\begin{array}{l}0.4 \\
0.7\end{array}$ & & t & $\dagger$ & $t_{-\infty}$ & $t$ \\
\hline & 0.75 & 0.5 & & & 0.55 & 0.55 & 5.5 & & & & \\
\hline \multirow[t]{2}{*}{$\begin{array}{l}\text { Root-crops: } \\
\text { roots. }\end{array}$} & $\begin{array}{l}0.3 \\
1.1 \\
\end{array}$ & $\begin{array}{l}0.5 \\
1.4 \\
\end{array}$ & $\begin{array}{l}0.12 \\
3.6 \\
\end{array}$ & & 4.4 & $\begin{array}{l}0.1 \\
2.5 \\
\end{array}$ & t & $\begin{array}{r}5 . \\
26 . \\
\end{array}$ & 4. & 23. & $\begin{array}{l}0.8 \\
8.0 \\
\end{array}$ \\
\hline & 0.6 & 1.0 & 0.67 & & 3.9 & 0.33 & & 11. & 12. & 85. & 1.0 \\
\hline \multirow[t]{2}{*}{$\begin{array}{l}\text { tops-crops } \\
\text { tops. }\end{array}$} & $\begin{array}{l}1.1 \\
3.0\end{array}$ & $\begin{array}{l}0.8 \\
2.0\end{array}$ & 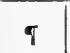 & & $\begin{array}{l}0.5 \\
1.4\end{array}$ & $\begin{array}{l}0.3 \\
10 .\end{array}$ & 8. & $\begin{array}{l}12 . \\
38 .\end{array}$ & 9. & $\begin{array}{r}21 . \\
129 .\end{array}$ & $\begin{array}{l}3 . \\
10 .\end{array}$ \\
\hline & 1.7 & 1.5 & & & 0.6 & & & 26. & 25. & 60. & 6. \\
\hline \multirow[t]{2}{*}{ Şalt. } & $\begin{array}{r}1.4 \\
10.6 \\
\end{array}$ & & $\begin{array}{l}0 \\
\text { tr. }\end{array}$ & & & $\begin{array}{l}0.5 \\
3.7 \\
\end{array}$ & & & & & \\
\hline & 6.0 & & & & & 1.9 & & & & & \\
\hline \multirow[t]{2}{*}{$\begin{array}{l}\text { Saltpetre } \\
\text { (Chili). }\end{array}$} & & & $\begin{array}{l}571 . \\
620 .\end{array}$ & & & & & & & & \\
\hline & 10. & & 596. & & & 8.0 & 170 & & & & \\
\hline
\end{tabular}

* Sugar.-t Present. - T Possibly present. 
TABLE X.-[Continued.

\begin{tabular}{|c|c|c|c|c|c|c|c|c|c|c|c|}
\hline & $\begin{array}{l}\dot{0} \\
\mathbb{E}^{-1}\end{array}$ & 퐁려 & $\begin{array}{l}0 \\
0 \\
1: 4\end{array}$ & 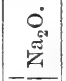 & 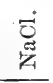 & $\dot{m}$ & $\dot{\mathscr{Z}}$ & 题 & 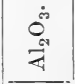 & $\begin{array}{c}\dot{\infty} \\
0^{\infty} \\
\dot{1}\end{array}$ & 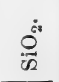 \\
\hline \multirow[t]{2}{*}{ Soils. } & & $\begin{array}{l}920 . \\
990 .\end{array}$ & $\begin{array}{l}\text { tr. } \\
28\end{array}$ & $\begin{array}{c}\operatorname{tr} \\
20.7\end{array}$ & & $\begin{array}{l}0.0023 \\
0.102\end{array}$ & tr. & $\begin{aligned} \operatorname{tr} . \\
14.0\end{aligned}$ & $\begin{array}{c}8 \\
140 .\end{array}$ & 15. & + \\
\hline & & 950. & 4.0 & 2.0 & & 0.0485 & 5.0 & 3.0 & 50. & 30. & \\
\hline \multirow[t]{2}{*}{ Sugar-beet. } & $\begin{array}{l}800 . \\
900 .\end{array}$ & $\begin{array}{l}3 . \\
6 .\end{array}$ & $\begin{array}{r}2.5 \\
3.5 \\
\end{array}$ & $\begin{array}{l}0.15 \\
0.3\end{array}$ & $\begin{array}{l}0.4 \\
0.9 \\
\end{array}$ & \multirow[t]{2}{*}{ ฯ } & $\begin{array}{l}0.4 \\
0.7\end{array}$ & $\begin{array}{l}0.16 \\
0.21\end{array}$ & & $\begin{array}{l}0.1 \\
0.2\end{array}$ & \\
\hline & 815. & 5. & 3.0 & 0.2 & 0.7 & & 0.5 & 0.2 & & 0.12 & 0.1 \\
\hline \multirow[t]{2}{*}{$\begin{array}{l}\text { (2) } \\
\text { Superphos- } \\
\text { phate. }\end{array}$} & $\begin{array}{r}94 . \\
223 . \\
\end{array}$ & $\begin{array}{l}576 . \\
728 . \\
\end{array}$ & \multirow[t]{2}{*}{ T } & \multirow[t]{2}{*}{9} & & & 159. & $\begin{array}{c}0 \\
22 .\end{array}$ & & $\begin{array}{l}0 \\
3.0\end{array}$ & \\
\hline & 155. & 665. & & & & & 230. & 1.0 & & & \\
\hline \multirow[t]{2}{*}{$\begin{array}{l}\text { Urine. } \\
\text { Herbivora. }\end{array}$} & $\begin{array}{l}860 . \\
925\end{array}$ & $\begin{array}{l}17 . \\
47 .\end{array}$ & $\begin{array}{l}6.0 \\
20 .\end{array}$ & $\begin{array}{l}2.0 \\
5.0\end{array}$ & \multirow[t]{2}{*}{$\dagger$} & & $\begin{array}{l}0.31 \\
0.16 \\
\end{array}$ & & & & \\
\hline & $8 \%$ & 30. & 13. & 3.0 & & & 4.2 & & & & \\
\hline \multirow{2}{*}{$\begin{array}{l}\text { Urine. } \\
\text { Man. }\end{array}$} & $\begin{array}{l}934 . \\
970 . \\
\end{array}$ & $\begin{array}{l}10.3 \\
14.5 \\
\end{array}$ & $\begin{array}{l}1.7 \\
5.0\end{array}$ & $\begin{array}{l}1.0 \\
3.0\end{array}$ & $\begin{array}{l}3.6 \\
8.0\end{array}$ & $\mid \begin{array}{l}0 \\
0.9\end{array}$ & $\mid \begin{array}{l}0 \\
0.33\end{array}$ & 0.23 & & & \\
\hline & 948. & 13.5 & 2.5 & 2.0 & 6.0 & & 0.26 & 0.2 & & & \\
\hline \multirow[t]{2}{*}{ Water, rain. } & & & tr. & $\begin{array}{l}0 \\
\text { ti. }\end{array}$ & & $\begin{array}{l}9.0001 \\
9.001 \\
\end{array}$ & \multirow[t]{2}{*}{$0^{0} \operatorname{tr}}$. & \multirow[t]{2}{*}{${ }^{0}$ tr. } & & \multirow[t]{2}{*}{ tr. } & ${ }^{3} \mathrm{tr}$. \\
\hline & & & & & & .0 .0014 & & & & & \\
\hline \multirow[t]{2}{*}{$\begin{array}{l}(5) \\
\text { Water, river. }\end{array}$} & & & $\mid \begin{array}{l}0 \\
0.013 \\
\end{array}$ & $\begin{array}{l}0 \\
0.024 \\
\end{array}$ & & $\begin{array}{l}0.00009 \\
0.005 \\
\end{array}$ & {$\left[\begin{array}{l}0.007 \\
0.1\end{array}\right.$} & $\begin{array}{l}0.002 \\
0.032\end{array}$ & 0.007 & 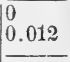 & $\begin{array}{l}0.001 \\
0.013\end{array}$ \\
\hline & & & & & & 0.001 & 0.061 & 0.01 & & 0.006 & \\
\hline Water, spring. & & . & $\begin{array}{l}0 \\
0.41 \\
\end{array}$ & $\begin{array}{l}0 \\
0.58 \\
\end{array}$ & & 0.0006 & $\left|\begin{array}{l}0.002 \\
0.23\end{array}\right|$ & $\mid \begin{array}{l}0 \\
0.104\end{array}$ & 0.0128 & 0.0045 & 0 \\
\hline & & & & & & & $|\overline{0.02}|$ & & & & \\
\hline
\end{tabular}

+ Present.- - Possibly present.-(1) Mn, traces to 17 ; average 0.S. SiO and insoluble silicates $240-930$; average $7 r_{0}--(2) \mathrm{Fe}_{2} \mathrm{O}_{3}$, usually traces. Sand and insoluble silicates $29-178$; average 48 . Soluble $\mathrm{P}_{2} \mathrm{O}_{5}$ in older and foreign phosphates, 120; in recent American, 33. Chlorine, usually 0.-(3) Hippuric acid, 1.8-60. Urea, 18-70; average 28.-(4) Urea, 23-33; averace 29. Uric acid, 0.5-1.1: average 1.-(5) $\mathrm{Mn} .0-0.003 .-(6) \mathrm{Al}_{2} \mathrm{O}_{3}, \mathrm{NH}_{3}, \mathrm{Fe}_{2} \mathrm{O}_{3}, \mathrm{P}_{2} \mathrm{O}_{5}$, and $\mathrm{N}_{2} \mathrm{O}_{5}$ usually $0 . \mathrm{MgO}, \mathrm{K}_{2} \mathrm{O}, \mathrm{Na}_{2} \mathrm{O}, \mathrm{SO}_{3}, \mathrm{CO}_{2}$, and $\mathrm{Cl}$, rarely 0 . Organic matter $0-0.07$; average 0.03 . 
TABLES.

TABLE X.-[Continued.

\begin{tabular}{|c|c|c|c|c|c|c|c|c|c|c|c|}
\hline & $\dot{0}$ & $\begin{array}{l}0^{\dot{0}} \\
\hat{R}^{-1}\end{array}$ & $\begin{array}{l}0 \\
0 \\
Z^{\circ}\end{array}$ & $\delta^{\dot{\theta}}$ & $\dot{\pi}$ & $\dot{0}$ & 学 & 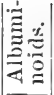 & 量 & 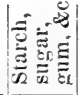 & ت્ટ \\
\hline \multirow[t]{2}{*}{ Soils. } & $\begin{array}{r}0.07 \\
11.0\end{array}$ & $\begin{array}{l}0.001 \\
5.00\end{array}$ & $\begin{array}{l}0.001 \\
0.12\end{array}$ & $\begin{array}{c}0 \\
220\end{array}$ & & $\begin{array}{l}0 \\
14 .\end{array}$ & 0.5 & & & & \\
\hline & 1.5 & 1.0 & 0.03 & 5. & & 0.3 & 2. & & & & \\
\hline \multirow[t]{2}{*}{ Sugrar-beet. } & $\begin{array}{l}0.18 \\
0.28\end{array}$ & $\begin{array}{l}0.37 \\
1.0\end{array}$ & $\begin{array}{l}0.3 \\
1.7\end{array}$ & & \multirow[t]{2}{*}{ t } & \multirow[t]{2}{*}{$\dagger$} & \multirow[t]{2}{*}{$\dagger$} & $\begin{array}{r}\mathbf{6} . \\
28 .\end{array}$ & $\begin{array}{l}10 . \\
34 .\end{array}$ & $\begin{array}{r}66 . \\
138\end{array}$ & 6. \\
\hline & 0.2 & 0.7 & 1.0 & 0.1 & & & & 8. & 13. & 100. & 8. \\
\hline \multirow[t]{2}{*}{ Superphosphate. } & 121. & $\begin{array}{l}126 . \\
233 .\end{array}$ & & & & $\begin{array}{c}0 \\
59 . \\
\end{array}$ & $\begin{array}{l}3.9 \\
27 .\end{array}$ & & & & \\
\hline & 210. & 170. & & & & & 20. & & & & \\
\hline \multirow[t]{2}{*}{$\begin{array}{l}\text { Urine. } \\
\text { Herbivora. }\end{array}$} & $\begin{array}{l}0 \\
1.6\end{array}$ & & & $\begin{array}{l}8.7 \\
14.0\end{array}$ & & $\mid \begin{array}{l}0 \\
3.3\end{array}$ & $\mid \begin{array}{c}4.4 \\
26 .\end{array}$ & & & & \\
\hline & & & & 10.8 & & & 15. & & & & \\
\hline \multirow[t]{2}{*}{$\begin{array}{l}\text { Urine. } \\
\text { Man. }\end{array}$} & $\begin{array}{l}0.4 \\
3.7\end{array}$ & $\begin{array}{l}1.7 \\
3.0\end{array}$ & & & & 2.0 & $\begin{array}{r}7 . \\
18 .\end{array}$ & & & & \\
\hline & 1.5 & 2.0 & & & & 3.6. & $\overline{14.5}$ & & & & \\
\hline \multirow[t]{2}{*}{ Water, rain. } & ${ }^{0}$ tr. & 0 & $\begin{array}{l}0.0001 \\
0.006\end{array}$ & & & & & & & & \\
\hline & & & $|0.0005|$ & & & & & & & & \\
\hline \multirow[t]{2}{*}{ Water, river. } & $\begin{array}{l}0.002 \\
0.079\end{array}$ & & $\begin{array}{l}0.001 \\
0.01\end{array}$ & $\left\{\begin{array}{l}0.0017 \\
0.08\end{array}\right.$ & & $\begin{array}{l}0 \\
0.089 . \\
\end{array}$ & & & & & \\
\hline & 0.022 & & & 0.046 & & 0.01 & & & & & \\
\hline \multirow[t]{2}{*}{ Water, spring. } & $\begin{array}{l}0 \\
0.5\end{array}$ & $\left|\begin{array}{l}0 \\
0.006\end{array}\right|$ & 0.67 & | & & $\begin{array}{l}0 \\
0.560\end{array}$ & & & & & \\
\hline & & & & 0.2 & & • & & & & & \\
\hline
\end{tabular}

* Sugar.-t Present. 


\section{INDEX.}

Acctic acid, as reagent, 8-estimation, 101-in vinegar, 268-occurrence of, 145-reactions.....101

Acetometer ....................2.

Acids, free, in wine............. 280

Albumen, 117-in milk...........263

Albuminoids, see protein compounds.

Alcohol as reagent, 10-estimation, 126-in wine................2\%9

Alcoholometer...................24

Alkalies, elimination by milk of lime, 157-by oxalic acid, 15sestimation as chlorides, $53,15 \%$ -as sulphates, 53-in gypsum, 238-in limestone, 209-in marl, 207 -in wine................283

Alumina, hydrated, in soil.........1S6 Aluminium, elimination of, $15 \%$-estimation of, 66 -reactions...... 65

Ammonia, estimation of by distillation with sodic hydrate and titration, 57-by distillation and Nessler's solution, 58-platinic chloride, 55 -Schlössing's process, 56 -in beets, 260 -in fodder, aqueous extract of, 254 -in guano, 232-in manure of the farm-yard, 214-in soil, 183-in superphosphate, 205-in urine, 219-in water...............272

Ammonia, reactions of........... 54

Ammonic acetate as reagent, carbonate chloride, fluoride, 10hydrate molybdate, nitrate, oxalate, sulphate, sulphide, 11tartrate ................. 12

Ammonio-ferrous sulphate, as reagent.....................12

Ammonium, see ammonia.

Analyses, calculation of.......... 49

Analysis, qualitative, course of for acids, 130-for bases, 136-table for.......................144
Analysis, quantitative, schemes for, 161-special methods for separation in .................... 146

Animal substances, ash of........248 Aqua regia, as reagent........... 8 Argentic nitrate as reagent, 12standard solution of.......... 95

Arsenic, occurrence of, 145-reactions..................... ${ }_{6}$

Artichokes...................202

Ash analysis, preparation of ash for, 241-statoment of results...247 Ash, climination of carbon and carbonic acid in................150

Ash of animal substances, 248--of bone-black, 230-of bone-meal, 228-of coal, 243-of flour, 262 of fodder, aqueous extract, 253 - of green fodder, 251-of fuel, 249-of guano, 232-of manure of the farm-yard, 213, 216-of milk, 263 - of peat, 243 - of plants, 241-of seeds, 262-of superphosphate, 235, 236-of urine, 218,219 -of wine, 278 - of wool.....................2

Ash of plants, carbonic acid, chlorine, 243-coal, sand and silica, 243

Ash of plants, Reichhardt's method of preparing, for estimation of sulphur and chlorine.........246

Ash rich in carbonates, 243-rich in silica ....................244

Ash, sulphur in ...............246

Ashes of fuel, carbonic acid, chlorine in, complete analysis of, potassa in..................249

Baker guano.................. 234 Baric acetate as reagent, chloride hydrate, nitrate.............. 13 Barium, occurrence of, 145-reactions................... 59 Bark, tanner's, tannic acid, water in, 270 Beets (and turnips), ammonia in, 
258-ash of, 258-crude cellulose in, fat, $258-n i t r i c$ acid 260 -nitrogen, pectose, 258-starch 260

-sugar, 25S-water...........257

Bunc-ash... ..................281

Bone-black, ash of, 230-calcic hydrate in, carbonic acid, chlorine, nitrogen, phosphoric acid, etc., water.................230

Bone-meal, ash of, 228, 229-fat in, fineness of division, gelatine in, 229-nitrogen, phosphoric acid, water.....................298

Bunsen's method of filtration..... 33

Butter (and cheese), casein in, fat, 267 -salt, 26s-water.........267

Butter in milk, estimation of, 264 , 266--by Vogrel's optical milktest ... .................. $\approx 65$

Calcic chloricle as reagent, hydrate, fluoride, sulphate........... 14

Calcic hydrate in bone-black....... 230

Calcium, elimination of, 157-estimation of as carbonate by ignition of oxalate, 60 -as lime by ignition of oxalate, $61-a \mathrm{~s}$ oxalate by titration of oxalic acid, 61-as oxalate in presence of phosphoric acid, 62-as sulphate by conversion of oxalate into sulphate, 62 - reactions, $60-$ separation from magnesium.... 64

Calculation of analyses......... 42

Carbon eliminated from residue left after incineration, 150-in urine.223

Csrbonic acid, estimation of, 79by Fresenius's apparatus, $81-$ in ash left in the determination of volatile matter, 150-in ash of plants, 213, 244-in ashes of fuel, 219-in bone-black, 230in gypsum, 23s--in manurc of the farm-yard, 213, 215-in marl, 206-in soils, $1 \% 3$-in urine, 218 -reactions of, 79 -separation from chlorine............. $\$ 3$

Casein, 11s-in butter and cheese, 267 -in milk...........263, 266

Cellulose, 108 - in excrements of animals, 223-in fodder, 252,256 -in seeds, etc., 262-in roots, $25 s-$ reactions.................
Cement, hydraulic, analysis and testing of...................211

Cheese, (see also butter)..........267

Chili saltpetre, adulterations detected, 210-complete analysis of, 239-nitric acid in, 210-potash, soda, water in. . ........... 239

Chlorine, estimation of by gravimetric process, 94-by volumetric process, 95-in ash of fuel, 249 -in ash of plants, 243,244 -in bone-black, 230 - in farm-yard manure, 215-in organic combination, 152-in the plant, $245-$ in soil, 186--in urine, 220 -reactions of, 94-separation from carbonic acid.............. \$3

Citric acid, as reagent, S-occurrence of, 145-reactions........103

Clark's method of determining hardness of water............274

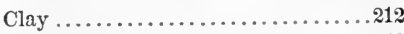

Coal (carbon) in ash of plants.....243

Coal ashes... .................250

Cobaltic nitrate as reagent....... 15

Cochineal as reagent... . ....... 15

Copper, occurrence, 145-reactions. 73 Coprolites, complete analysis of-

phosphoric acid in..........231

Cupric acetate as reagent, sulphate, 15

Curcuma-paper ................ 15

Cyanogen, occurrence, 146 - reactions .................... 97

Desiccator, the............... 40

Desiccation of substances.........147

Division of solutions in quantita-

tive analysis............. 40

Dragendorff's process for estimat-

ing starch..................111

Dung of animals...............223

Ether, as reagent.............. 15

Evaporation, 27-of solutions containing excess of ammonic salts, when the residue is to be ignited......................... 2s

Excrements, solid..............223

Fat, 125 -in beets, 25s-in bonemeal, 229-in butter, $26 \%$ - in flour, 262-in foldler, 252-in milk, 261 -in sceds...........262

Fehling's solution...............113 Ferric chloride as reagent, $15-$ ni- 
trate, oxide

Ferric oxide, climination, 153-estimation, $6 \%$-hyclrated, with aluminic hydrate in soil, 186and other substances in farmyard manure, 216-reactions, 66 -separation from phosphoric acid......................153

Ferrocyanogen, occurrence, 146reactions................. 9s

Ferrous chloride as reagent, 16sulphide.................. 10

Ferrous oxide in soil, estimation, 187 -reactions...............66 60

Fertilizers, 213--commercial, tariff of prices for valuation of. . . . . 226

Fiber, see cellulose.

Fibrine.....................118

Filters, incineration of, 3S-washing of with dilute acid......... 31

Filtration, 31-by Bunsen's process, 33 -by the wash-bottle arrangement................... 37

Fleck's method of determining hardness of water...........2\%6

Flour, (sce also seeds)............262

Fluorine, reactions............. 9?

Fodder, aqueous extract of, estimation, 253-ammonia in, 254-ash of, 253 -gum, nitric acid in, 255 --nitrogen, 251 -sugar......... . 25.

Fodder, dried, 251-ash, 251-cellulose in, fat, protein compounds, 253 -starch, 257-water........ 251

Fodder, green, ash of, water in, preparation of sample for analysis...................... 251

Gelatine in bone-meal............229

Glucose, estimation, reactions......113

Graduated instruments, testing and use of.................. 40

Guano, ammoniacal (Peruvian), ash of, and ammonia in, 232-complete analysis of, 233--marks of a good article, 293-nitrogen in, 232-oxalic acid, 233-phosphoric acid, etc., 232-solubility in water, 233-uric acid in, 233water in................ 232

Guano, phosphatic (Baker, etc.)... .231 Gum, estimation of, 112-in fodder, aqueous extract of, 255 - in winc. . ...............2\%9

Gypsum, alkalies in, and carbonic acid, 233-complete analysis of. 23\%-solubility in acid, water in......................237

IIeat, absorbent power of soil for, and conducting power, 197-retaining power................198

IIippuic acid, estimation, reactions, separation from uric, 106 -in urine................221 IIops, statement of analysis of ash of.......................219

IImus in marl, $208-$ in soil........183 IIyclric disodic phosphate as reagent ................... 21

IIydriodic acid, reactions of. ... . . . 98 Hydrochloric acid as reagent, S-estimation, see chlorine - reactions................... 94

Hydrocyanic acid.............. 97 Hydroferrocyanic acid........... 9S IIydrofluoric acid......... . . . . 99 Hydrogen as reagent, 16-in urinc, 223 Hydrosulphuric acid as reagent, 8estimation, sec sulphur-reactions .................... 98

Ifygroscopic moisture, estimation..147 Ignition of precintates, 38-of residues containing excess of ammonic salts................ 28

Incinerution of filters, 38-to determine organic matter..........149

Indigo solution as reagent........ 16 Iodine as reagent, 16-occurrence, 146-reactions.............. 98

Iron (see also ferric oxide), estimation by precipitation, .67-by volumetric process with potassic permanganate, $6 \%$-by volumetric process with sodic hyposulphite, $\% 0$ - reactions, 66 separation from alumina and phosphoric acid..............153

Iron turnings as reagent, 16-wire.. 16 Lactic acid, estimation, 105-occurrence, 115 -reactions..........104

Lactometer .................24

Lacto-protein in milk...........266

Lactose, $11 \%$-in milk... ........266

Lead, occurrence, 146-reactions... $\% 2$

Lcad-paper as reagent........... 16 
Levigation................... 26

Levulose......................115

Lime, burned.................209

Lime in marl, 206-in water, 2\%3-reactions and estimation, sec calcium....................

Limestone, 209-alkalies in, 209value for mortar lime, 210 -for hydraulic cement..............211

Litmus-paper, blue and red....... 16 Magnesia (calcined) as reagent, 17 -magnesia mixture.......... 17

Magnesium, elimination from mixture of metals, etc., 15i-estimation as pyrophosphate, 63reactions, 62-separation from calcium as pyrophosphate, $61-$ by sulphuric acid............ 65

Malic acid, estimation, 104-in wine, 2S:--occurrence, 145-re-

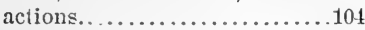

Malt, as reagent................ 17

Manganese, climination from mixture of substances, 156-estimation, 71-occurrence, 146-reactions................... 11

Manganic binoxide as reagent.... 17

Manures, commercial, general considerations, 224-nitrogen in, 225-phosphoric acid, 221-potassa, 225-statement of analysis, illustrated, 225 -tariff of prices for valuation of.........226

Manure of the farm-yard, 213-ammonia in, 214-aqueous extract of, 214-ash, carbonic acid, 213 -insoluble part, 214, 216-nitrogen, organic matter, 213-statement of analysis, illustrated, 217-sulphur, sulphuric acid in, 214-water................213

Marl, alkalies in, 207-carbonic acid, 206-humus, 208-lime and magnesia, 20\%-nitrogen, 208phosphoric acid, 207-silt analysis of, 205 -water............206

Marl, burned..................20s

Mieal (see also seeds).............262

Measurement of solutions. ....... 40

Mercuric nitrate as reagent, 1\%standard solution of..........122

Mercurous nitrate as reagent... . . 17
Milk, albumen in, ash, casein, $\approx 68-$ fat, 261, 265-lacto-protein, etc., 266-protein compounds, 263sugar (lactose) 266-Vogel's optical test, 265 -water.......... 263

Milk of lime as reagent.......... 17 Nessler's solution as reagent, 55estimation of ammonia with... 5S

Nitric acicl as reagent, S-estimation of by fusion of nitrate with silica, 92-by insolubility of ammonic nitrate in alcohol, 93by Schlüssing's process, 89 -in bects 260 - in Chili saltpetre, 210-in farm-yard manure, 215in fodder aqueous extract, $255-$ in soil...................... 185

Nitric acid, reactions............ 88

Nitrogen in beets, 258 - in boneblack, 230 -in bone-meal, 228in commercial manures, $225-$ in fodcler, 252, 254-in guano, 232 - in manure of the farmyard, $213,215,216$-in marl, 20sin soil, 173-in superphosphate, 235 -in urine...............219

Nitro-hydrochloric acid, see aqua recria.

Nitrous acid in water............2 27

Organic matter, estimation by ignition in muffle, 149-ignition in platinum dish, 149-by titration with potassic permanganate, 151-in manure of the farm-yard, 213, 215-in soil, 183-in urine, 218 -in water...............272

Oxalic acid as reagent, 9-estimation by conversion into carbonic acid, 101-by titration with potassic permanganate, 100 -in guano, 233-reactions of, 99standard solution of.......... 50 Oxygen, preparation of.......... 17 Pea, as fodder plant, statement of analysis of.................257 Peat ashes.....................250 Pectose in beets................25s Peruvian guano.................232 Phosphate, see superphosphate...

Phosphatic guano...............284 Phosphoric acid, 83-climination by ammonic molybdatce, 85,157 -by 
ferric chloride, sodic acctate, magnesia mixture, and citric acid, 159-by metallic tin, 155in presence of large excess of ferric oxide, 160-when it alone is to be estimated, 159-estimation as magnesic pyrophosphate 84 - by volumetric process, S6-in bone-black, 230 -in bonemeal, 228-in commercial manures, 224 -in coprolites, $231-$ in guano, 232-in marl, 207 -in phosphorite, 231-in superphosphate, insoluble, 236-soluble, 235-in urine...............222

Phosphoric acid, reactions of...... 83 Phosphoritc, complete analysis of, 231-phosphoric acid in.......2231

Phosphorus salt, as reagent...... 1s

Piknometer.................. 23

Plant ash, sce ash of plants... ....

Plant, chlorine in, 245, 216-sulphuric acid (ready formed), 245 - total sulphur.............245, 246

Platinum crucibles, carc of....... 40

Platinic chloride, as reagent....... 18

Plumbic acetate, as reagent, binoxide, oxide.................. is

Potash compounds, commercial....239

Potassic acetate as reagent, 1S-bisulphate, chromate, chlorate, dichromate, ferricyanide, ferrocyanide, hyclrate, iodide, permanganate, 19-and sodic carbonate, and sodic tartrate, sulphocyanate...............

Potassium, elimination from mixture of metals by milk of lime, 157 - by oxalic acid, 158 - by platinic cliloride, 159 -from silicates, r6-estimation as chloride, 45 - as potassic platinic chloride, 46-sulphate, 46-by titration with standard acid, 47 -in ashes of fuel, 249-in Chili saltpetre, 239 - in commercial manures, 235 -in water.........272

Potassium, reactions, 44-separation from sodium by indirect determination as chloricle, 53as sulphate, $53-$ by platinic chloride................... 5
Potassium and sodium, conversion of mixed sulphates into chlorides..................... 53

Potatoes, dry substance in, soluble in water, protein compounds in, 261-starch, 262-water.........261

Precipitation................. 29

Precipitates, ignition of, with filter, 3S-after separation from filter, 38 -transferring of to filter, 30 washing of, 32 -weighing of.... 38

Protein compounds, estimation of, 118-in fodder, 252-in milli, 263 -in potatoes, 261 -in seeds, 262 -in wine, 2 \%s-reactions of....117 Qualitative analysis, course of.....130 Quantitative analysis, schemes of...161 Quartz powdered, as reagent...... 20 Residues, ignition and weighing of, 38 Results of analyses, calculation of.. 42 Rocks, and products of their weathering....................205

Saccharose, estimation, 116-reactions......................115

Saccharometer .................24

Salt, complete analysis of, 238--estimation of in butter and cheese..268 Saltpetre, Chili, see Chili saltpetre. Sand in ash of plants, 243-in soils, 182-separation of from silica.. 75

Schlössing's process for estimating ammonia, 56-nitric acid....... 89

Seeds, ash, etc., dry substance soluble in water, in starch, water...262

Silica and sand in ashes..........243

Silicates, fusion of with sodic and potassic carbonate, 76 - solution of, 74-treatment of with ammonic fluoride, 77 -with hydrofluoric acid .................. 77

Silicic acid, estimations and reactions, 74 -separation of from coal and from sand............ 75

Silt analysis of marl, 205-of soils, Dietrich's method, 172-Nöbel's method ....................169

Silver refuse, to work over........ 12

Skin, powder of. as reagent...... 118

Soda-lime as reagent............ 20

Soda, standard solution of........ 50

Sodic acetate as reagent, 20 -sodic and ammonic phosphate, 20-bi- 
sulphite, carbonate, hyposulphite phosphate, nitrate....... 21 Sodium, elimination of from silicates, 76 -climination with milk of lime, $15 \%$ - with oxalic acid, $15 \mathrm{~S}$-estimation of as chloride, or as sulphate, 52-by indirect processes, 53-in Chili saltpetre, 239

Sodium, reactions, 51-separation from potassium by indirect method, as chloride or as sulphate, 53 -by platinic chloride......... 52

Sodium, sulphate of converted into chloride................. 53

Soil, absolute weight of, 19S-absorptive power of for salts, 1SSadhesive power of . .........200

Soil analysis, experiments to be combined with, 200 - general considerations in regard to, 165 -preparation of sample for....166

Soil analysis, chemical part, preparation of solutions for, 1r4with carbonated water, 1\%with cold hydrochloric acid, $1 \% 4$ -with hot hydrochloric acid, 179-with hydrofluoric acid, 181 -with phosphoric acid, 182with sulphuric acid...........180

Soil analysis, mechanical part, 16Ssilt process by Dictrich's method, 172-by Nübel's metlıod, 169

Soil analysis, physical part, in relation to heat-absorbing power, 19\%-to heat-conducting power, 19\%-to heat-retaining power, 198 -consistency, 199--power of absorbing water-vapor, $192-$ of retaining liquicl water, 193-of retaining water-vapor, 192-rate of evaporation of water from, 194 - readiness with which water moves downward in, 197 -readiness with which water moves upward, 196-readiness with which water percolates through,196-volume when completely saturated with water, 199 -porosity, 199-specific gravity, apparent and real, 198-tenacity,199

Soil analysis, statement of results illustrated................188
Soil, estimation of ammonia in, $18 S$ -of carbonic acid, 173-chlorine, 186-ferrous oxide, 15\%hydrated alumina and ferric oxide, 1S6-humus, 1s3-nitrogen, total in, 173-nitric acid, 1S5-organic matter, 183-sand, by phosphoric acid, 182-sulphur, 186 -water ................. $1 \% 3$

Solution ................. 25

Solutions, division and measurement of .................. 40

Solutions staudard, preparations of, $48,55,67,70,86,95,100,113,122$, $151 ; 266 \ldots \ldots \ldots \ldots \ldots \ldots . . . \ldots 274$

Solutions, estimation of solid matter in by simple evaporation on water-bath, 14s-after mixturc with gypsum, 149-by eraporation in vaccuo on hot sand, 148 -to save ammonia that may be given off.................148

Specific gravity of liquids, with the areometer,23-with the piknometer or specific-gravity bottle, $23-$ of soil apparent and real, 19Sof solids by specific gravity of liquid of the same density, $25-$ if soluble in water, 25-by volume of water displaced, 24-by weight of water displaced in piknometer, 2t-of urinc, $21 \%$ of wine, 278 - of wool .........2\%0

Starch, 109-estimation by conversion into sugar by malt, 109-by sulphuric acid, 110 - Dragendorft's process, 111 -in beets, 260 -in fodder, 25\%-in potatoes, 262-in seeds, 262-reactions of,109

Starch paper................. 21

Sugar (see also saccharose, glucose, etc.) estimation in beets, $25 \mathrm{~S}-$ in fodder, aqueous extract, 255 -milk. 266, 26\%-in wine......2\%9

Sulphur, estimation in organic combination, 152-in manure of the farm-yard, 214-in plant, total, 245-in soil, 286 -in urine, 223reactions................ 9s

Sulphuric acid as reagent, 9-elimination of, 157-estimation, 78in gypsum, 237-in manure of 
the farm-yard, 214-in plant, 245 -in urine, 223-in vinegar, 268 -in wine, 283-reactions of, is — standard solution of.......... 48

Superphosphates, ammonia in 235 ash, 235-complete analysis of, 236-nitrogen in, 235-phosphoric acid, insoluble, 236 -soluble, 235 -water.............................

Tables ...........................

Tamner's bark.................. จั0

Tannic acid, as reagent, 10-estimation, 107-in bark, 2\%0-in winc, 280 -occurrence, 145-reactions.102

Tin, as reagent, 21 - use to eliminate phosphoric acid............155

Turmeric as reagent............. 21

Uranic acetate as reagent, 21-standard solution of ............... is

Urea as reagent, 22-estimation, 12: -in urine, 221 -reactions.......122

Uric acid, estimation, 105-in guano, 233-in urine, 221 -reactions, 105 -separation from hippuric.....106

Urine, ammonia in, 219-ash of, 218 , 219 -carbon in, 223-carbonic acid, 218 - chlorine, 220-dry substance in solution, 218-hippuric acid, 221-hydrogen, 223-nitrogen, 219-phosphoric acid, 222sulphur and sulphuric acid, 228 -urea, 220-uric acid, 221specific gravity of ...........21\%

Valuation of manures.............226

Vinegar, acetic acid in, 268- frec sulphuric acid ..............268

Vogel's optical milk test...........265

Washing bottle.................. ร3

Water distilled as reagent......... 22

Water, hygroscopic, estimation of by simple desiccation on the water-bath, $14 \gamma$ - estimation when ammonia is present, 147- estimation by simple ignition, 147-estimation of in bark, 270 -in beets, 257-in bone-black, 230-bone-meal, 228-butter and cheese, $26 \%$-Chili saltpetre,239folder, 251 -green parts of plants, 241-gypsum, 237-guano, 232marl, 206-milk, 263-potatocs, 261-roots, 211-salt, 238-seeds, 262-soil, 173-superphosphate, $231-$ wool .................. $2{ }^{2} 0$

Water, estimation of ammonia in, $2 \% 2$-of dry substance in solution in, 271-of hardness, Clark's method,271-hardness byFleck's method, 276 - of lime in, 273 -of nitric acid, $2 \% 2$-of nitrous acid, 2\%3-organic matter, 272 - the same by titration with potassic permanganate, 151-potassa in..272

Water, expulsion of from solutions, sec evaporation-relation of to soil in liquid form, 195-as rapor..................... 192

Wine, alcohol in, 2\%9-alkalies in, 2S3-ash of, 275-average composition of, 2S3-dry substance in solution, 27 - free acids in, 2S0-gum and sugar, 2:9-malic acid, 282-protein compounds, 2\%8-specific gravity of, 278sugar, 279-sulphuric acid free, 283-tannic acid, 2S0 - tartaric acid.......................282

Wolff's process for converting starch into sugar..................111

Wool, estimation of ash of, 2\%0-of effect of washing at the factory, $2 \% 0$-water in, $2 \% 0$-preparation of sample for examination.....269

Zinc as reagent, 22-occurrence, 146-reactions.............. 72 


\section{ADDENDA}

FROM PERIODICALS RECEIVED WHILE THE FOREGOING MATTER WAS IN PRESS.

Bunsen's filtration process; page 33. R. S. Dale (Chem. Neus, Eng., Ed. 20, 108) states, that more rapid filtration can be obtained by substituting platinum-wire gauze, for the foil in the funnel, without any more danger of tearing the paper; and the gatuze funnel can be fitted in the glass one with sufficient accuracy, by means of a cone of wood turned to the proper angle. Undoubtedly, this gamze fumnel can be advantageously used in cases where the pressure on the liquid in the filter is much less than an atmosphere, as when the rarefaction of the air in the filtering flask is effected by means of the flow of water from one bottle to another.

Standard acid and alkat.ine solutions; page 48. Dr. Fleischer (Chem. News; Am. Repr., 5, 83) gives some good reasons for preferring a standard hydrochloric acid, instead of sulphuric; it forms soluble salts with all the alkaline earths, is readily obtained pure, is estimable with great aceuracy by a standard solution of argentic nitrate as well as by an alkali, and its constancy is unimpeachable. The standard of the acid can be determined by means of a weighed amount of pure calcic carbonate, that has been slightly heated, or by the standard argeutic solution.

For a standard alkaline solution, ammonia has many advantages over soda; it is more easily obtained pure, and has so slight a tendency to absorb carbonic acid from the air, that no special provision need be made against it.

As some neutral ammonic salts have a slight acid reaction when the solution is hot, the liquid to be tested should be cold. A solution containing half an equivalent of ammonia in the litre, is recommended.

Both of these standard solutions should be kept in a cool place, free from dust. If the ammonic solution is exposed to hot summer we:ther, the bottle containing it should be placed in eold water that is renewed every day; by exposure to a temperature above $25^{\circ} \mathrm{C}$., the standard of the solution will be very slightly altered.

Estimation of iron by the perifanganate process; page 67. M. Moyaux (Revne Universelle des Mines, etc., Chem. News, Am. Repr., 5, 179) states, that the use of ammonio-ferrous sulphate to determine the stand- 
ard of the permanganic solution is unsafe, for the reason that the composition of the salt is not constant, and that, consequently, metallic iron or oxalic acid must be used. Fresenius also, gires the preference to the use of metallic iron as the most accurate, although perhaps less convenient, method; he gives the following directions for executing the process. Weigh out about $0.2 \mathrm{grm}$. of the finest piano-forte wire, free from rust, and add to it in the long-necked flask (p.68) 20 c.c. of dilute sulphuric acid, and as much water, and proceed with the solution in the current of carbonic acid, and the subsequent titration, as directed in the case of the use of the ammonio-ferrous sulphate. Instead of $\frac{F}{7}$,

in the proportion on page 69 , substitute $\mathrm{F} \times 0.997$; this product is taken as the weight of pure iron in the weight $\mathrm{F}$ of iron used, since the purest wire contains about $\left.0.3{ }^{\circ}\right|_{0}$ of impurities.

In the text (pp. 69, 154) the preference is gipen to a sulphuric-acid solution of the ferrous salt for titration rather than a solution in hydrochloric acid. In an appendix to his Quantitative Anulyse, Fresenius states, that the titration of a bydrochloric-acid solution is unreliable unless conducted as follows. Make the volume of the solution up to a quarter of a litre, add 50 c.c. of this solution to a considerable quantity of water acidified with sulphuric acid, titrate this mixture with permanganate, add to it 50 c.e. more of the ferrous solution, titrate again, and so on with a thisd and fourth portion of the same solution; finally use the last two results, the mean of which multiplied by five will give the amount of permanganic solution that should be required for the whole amount of the ferrous solution.

The PRecipitate of aMmonio-Magnesic PHosphate, in the ESTIMATION OF MAGNesicin, PAgE 64, AXd OF PHOSPHORIC ACID, PAgE 87.

As the results of experiments by Kubel and by Kiesel (Fres. Zeitschrift $8, p p .125,164)$, it appears that the solubility of this precipitate in the ficuid in which the precipitation takes place, in the presence of considerable ammonic chloride and a not too great excess of magnesic sulphate, is very nearly compensated for by the minute quantity of basic magnesic sulphate, or of magnesia, that is precipitated at the same time; hence the correction for the imperfect insolubility of the precipitated phosphate seems to be unnecessary.

Orgaxic matter in water, page 272. R. Angus Smith, who is a strong and earnest champion for the permangauate process, in the examination of water with respect to the presence of hurtful organic matter, uses a stronger solution than Kubel (see page 151). He adds 2 grms. of the salt to a litre of water, and gives the following directions for the titration:

To not less than a litre of the water add a drop of this permanganate solution; stir the liquid well, and wait until the color disappears, and proceed in this manner as long as the color disappears quickly, say in a minute or two; generally, considerable permanency of color is obtained 
in 10-15 minutes. Then add 3 grms. of sulphuric acid to the liquid and proceed to add more permanganate in the same manner as before.

According to Dr. Smith, the oxygen of the permanganate used before adding the acid, was taken up by products of putrefaction in solution in the water, such as sulphuretted hydrogen, and that required after the adidion of the acid, was consumed by ensily oxidizable organic (animal) matter; all matters that thus act speedily on the permanganate are the most harmful in a sanitary point of view.

According to this writer and to W. A. Miller also, the results obtained can be expressed more aceurately, by giving instead of the number of cubic centimetres of permanganie solution used, the amount of availitble oxygen therein- of which each cubic centimetre contains 0.005 grm.

Dr. Smith estimates the nitrous acid in the water roughly, by diluting a measired quantity of it until iodized starch paper (paper dipped in a solution of potassic iodide containing a little starch) is no longer colored blue by it, even after a contact of several minutes; this diluted solution then contains about one part of nitrous acid in 100,000 of water, and upon this basis the proportion in the water before dilution ean be estimated. (Chem. News dm. Repr. 5.141, Eus. Etl. 20.113). 


\section{VALUABLE AND BEAUTIFUL WORK.}

\section{H A R R I S' \\ Insects \\ Injurious to Vegetation. \\ BY THE LATE

\author{
THADDEUS WILLIAM HARRIS, M.D.
}

A New Edition, enlarged and improved, with additions from the author's manuscripts and original notes.

Illustrated by engravings drawn from nature under the supervision of

\section{PROFHSSOR AGASSIZ.}

Edited by CHARLES L. FLINT,

Secretary of the Massachusetts State Board of Agriculture.

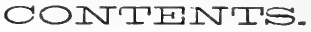

CHAPTER I.

INTRODUCTION. - Insects Defined-Brain and Nerves-Air-Pipes and Breath. ing-Holes-Heart and Blood-Metamorphoses or TransformationsClassification; Orders and Groups.

\section{CHAPTER II.}

COLEOPTERA--Beetles-Scarabæians-Ground-Beetles-Tree-Beetles-Cockchafers-Flower, Stag, Spring, Timber, Capricorn, Leaf-mining, and Tortoise Beetles-Chrysomelians-Cantharides.

\section{CHAPTER III.}

ORTHOPTERA.-Earwigs - Cockroaches - - Soothsayers - Walking-sticks or Spectres-Mole, Field, Climbing, and Wingless Crickets-GrasshoppersKatydid-Locusts.

\section{CHAPTER IV.}

HEMIPTERA.-Bugs_Squash-Bug-Clinch-Bug-Plant Bugs-Earvest FliesTree-Hoppers-Vine-Hoppers-Plant-Lice-American Blight-Bark-Lice.

\section{CHAPTER $V$.}

LEPIDOPTERA.-Caterpillars - Butterflies - Skippers - Hawk-Moths-AEgerians or Boring Caterpillars-Moths-Cut-Worms-Span-Worms-LeafRollers-Fruit, Bee, Corn, Clothes, and Feather-Winged Moths.

\section{CHAPTER VI.}

HYMENOPTERA.-Stingers and Piercers--Saw-Flies and Slugs--Elm, Fir and Vine Saw-Fly - Rose-Bush and Pear-Tree Slugs-Horn-Tailed Wood-Wasps-Gall-Flies-Barley Insect and Joint Worm.

\section{CHAPTER VII.}

DIPTERA.- Gnats and Flies-Maggots and their Transformations-Gail Gnats-Hessian, Wheat, and Radish Flies-Two-Winged Gall-Flies, and Fruit-Flies.

APPENDIX.-The Army Worm.

Published in two beautiful editions; one plain, with steel engravings, $8 \mathrm{vo}$. oxtra cloth, \$4; the other in extra cloth, beveled boards, red edges, engras. Ings colored with great accuracy, $\$ 6$.

Sent post-paid on receipt of price.

ORANGE JUDD \& CO..

24.5 Broadway New-York City 





